SERVIÇO DE PÓS-GRADUAÇÃO DO ICMC-USP

Data de Depósito:

Assinatura :

\title{
Consultas por Similaridade Complexas em Gerenciadores Relacionais ${ }^{1}$
}

\author{
Adriano Siqueira Arantes \\ Orientador: Prof. Dr. Caetano Traina Júnior
}

Tese apresentada ao ICMC-USP, como parte dos requisitos para a obtenção do título de Doutor em Ciências de Computação e Matemática Computacional.

USP - São Carlos

Fevereiro/2005

${ }^{1}$ Este trabalho foi desenvolvido com o apoio financeiro da FAPESP (Fundação de Amparo à Pesquisa do Estado de São Paulo). 
Aluno: Adriano Siqueira Arantes

\section{A Comissão Julgadora:}

Prof. Dr. Caetano Traina Junior

Prof. Dr. Luis Gustavo Nonato

Prof. Dr. Alberto Henrique Frade Laender

Profa. Dra. Marta Lima de Queiros Mattoso

Prof. Dr. Mauro Biajiz
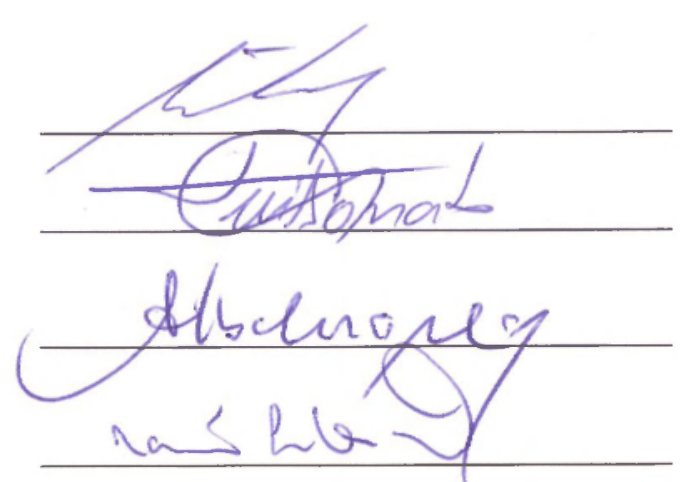

MamoBity 
À princesa Cássila e à princesinha Ana Carolina. Aos meus pais Adalberto e Eliete. En memória do minha avó Aua Rita. 
"Deus ć forte o Deus ć grande. Quando Ele quer, não tem quem não queira." Ayrton Senna 


\section{Agradecimentos}

A meu Pai, cu agradeço por estar sempre a mou lado. por me fazer parecer forte, por me fazer perseverar mesmo em momentos de extrema desesperança, e por jamais doixar do mostrar o meu caminho. Ó Pai, obrigado do fundo de meu coração.

A meu orientador, Prof. Dr. Caetano Traina Júnior, agradeço a oportunidade, o apoio, a confiança e a orientação concedidas a minha pessoa, tornando possível a realização destc trabalho. Obrigado também por me fazer entender melhor o significado da palaver perseverança.

À Profa. Dra. Agma Juci Machado Traina pelo conhecimento e ajuda oferecidos nestes anos de trabalho no Grupo de Base de Dados o Imagens (GBDI).

A Varcos Rodrignes Vicira agradeço pela disposição o colaboração nos trabalhos desenvolvidos juntos e também pelo apoio à realização dos cxperimentos durante este projeto doutorado. Obrigado pela amizade e confiança, principalmente no momentos difíceis.

Aos membros do GBDI, obrigado pola colaboracano, amizale e pacioncia que tiveran conigo durante este doutorado. Um agradecimento especial an cuiabano e "impressor" Josiel M. de Figueiredo.

Aos Professores Mauro Biajiz e Marina T. P. Vieira por fazerem despertar em mimo interesse pela área de Bance de Dados.

A meus tios e tias, padrinho e madrinha, irmão, irmã o demais familiares. Muito obrigado pelo carinho e amor dedicados a minha pessoa.

A meus anigos que torceram por mim mesmo não estando tão perto: ao grande? Toshiba; ao pequeno Gnomo; aos compadres Leucir, Baiano, Aluísio, Mosquito; a Rubem Paulo e família; à pilota Alessandra; ao irmão gêmeo Maurício: ao Jovi, Okawa, Fernandão o Andró, Vocês sempre estarão con minlia nemória.

A todas as pessoas que, direta ou indiretamente, contribuíram para que cu chegasse até aqui.

A HAPESP. pelo apoio financeiro. 


\section{RESUMO}

Em domínios de dados complexos (tais como, dados multimídia, sequiencias genònicas, cntre outros), a similaridade entre elementos surge naturalmente como a maneira mais adequada para consultar esses dados. Existem, basicarnente, dois tipos de consulta por similaridade: por abrangência o aos k-vizinhos mais próximos. Com o aumento no volume de dados complexos armazenado em Sistemas de Gerenciamento de Bases de Dados (SGBD), também chamados neste trabalho de gerenciadores, torna-se necessário prover suporte a esses tipos de darlos. Lim modo de dar suporte a tipos de dados complexos nos gerenciadores atuais é incluir consultas por similaridade em seu processador de consultas, e consegiientemente, na álgebra relacional. Este fato leva à produção de manciras para expressar tais consultas na linguagem do gerenciador como predicados em operações de seleção. Como uma conseqüência, os principais tipos de consultas por similaridade podem ser compostos om expresseres mais complexas por meio de conjunçöes a disjunçöes booleanas entre eles, isto é, consultas por similaridade complexas. Entretanto, para que um gerenciador processe consultas por similaridade complexas eficientemente. é necessário dar suporte as ctapas de olimizagão e exccução na arquitetura do processamento de consultas. Embora diversos trabalhos envolvan o desenvolvimento de algoritmos para responder a uma simples o especílica consulta por similarilade, não há un algoritmo gevérico apto a manipular eficientemente consultas por similaridade complexas. Além disso, a otimização de consultas por similaridade é um aspecto ainda pouco explorado na literatura. Esta tese propore un métorlo estruturado de como analisar consultas por similaridade complexas. Esse método é utilizado para estender a álgebra rolacional por meio de regras algébricas e determinar um pequeno conjunto de algoritmos que podem ser utilizados para responder a qualquer consulta por similaridade complexa. O método proposto também permite formalizar regras para estimar a seletividade dessas consultas auxiliando na previsão de custo. Para validar os conceitos apresentades, experimentos säe realizados com conjuntos do dados reais e sintéticos destacando os resultados obtidos. As regras algébricas, os algoritmos e as métricas para se estimar a seletividade podem ser utilizados por um gerenciador relacional na etapa de otimização, para derivar planos de execução eficientes para consultas por similaridade complexas. Portanto, os aspectos abordados nesta tese contribuem para permitir o uso prático de consultas por similaridade em gerenciadores relacionais.

ARANTES. A. S. Consultas por Similaridade Complexas em Gerenciadores Relacionais, São Carlos, 2005. 127 p. Tesc de Doutorado - Instituto de Ciências Matemáticas e de Computação - ICMC, USP. 


\section{ABSTRACT}

The similarity among elements emerges naturally as the most adequate to ask about complex data (such as, multimedia and genomic secuences annong others). There are two basic similarity queries: Range Query and $k$-Nearest Neighbor Query. The increasing volume of complex clata stored in Databasc Management Systems (DBMS), makes it necessary to provide support for these data types. One way to support complex data types in current DBMS is to include similarity queries in its query processor, and consequently; in the relational algebra. This fact leads to produce ways to express such queries in the DBMS language as predicates in select operations. As a consequence, the two basic similarity queries can be combined in more complex expressions involving boolean conjunctions and disjunctions among them, i.e., complex similarity queries. However, for complex similarity queries to be processed efficiently in a DBMS, it is necessary to provide support in the optimization and runtime layers of the query processing. There are many works involving the development of algorithms to answer specific and simple similarily query whereas there is not a generic algorithm efficiently able to handle complex similarity queries. Furthermore, the similarity query optimization is a topic not frecuently explored in the literature. This work establishes a structured method on low to anlalyze complex similarity queries. This method is used to extend the relational algebra through algebraic rules and to determine a small set of algorithms that can be used to answer any complex similarity query. In addition, the proposed method makes it possible to formalize rules for solectivity estimation of these pueries thus assisting cost estimation. To validate the concepts presented. experiments are being performed on real and synthetic data sets that highlight meaningful results. The algebraic rules. algorithms and metrics to stimate the selertivity can be cmployed in the optimization process of a DBMS in order to derive efficient complex similarity query execution plans. Therefore, this work deals with essential points that mable the practical use of similarity cueries in Relational Dataladse Management Systems. 


\section{Lista de Figuras}

1.1 Arquitetura descrevendo as ctapas do processamento de consultas om um gerenciador relacional. Esta arquitetura é dividida em : Compilador.

Otimizador e Executor. . . . . . . . . . . . . . . . j

1.2 Pontos abordados nesta tese considerando as etapas do processamento de consultas em um gerenciador relacional - Arquitetura. . . . . . . . . . 8

2.1 Árvore de consulta abstrata gerada a partir da consulta expressa em SQL do Exemplo 2.1. . . . . . . . . . . . . . . . . . . 13

2.2 Plano de consulta inicial produzido a partir da árvore de consulta abstrata do Excmplo 2.1. . . . . . . . . . . . . . . . . . . 14

2.3 Plano de consulta inicial expresso na forma de árvore para a consulta SQL do Exemplo 2.2. . . . . . . . . . . . . . . . . . . . . . 21

2.4 Plano de consulta alternativo movendo seleçôes para baixo na árvore de consulta. . . . . . . . . . . . . . . . . 21

2.j Distribuição de valores do atributo idade da relação Artista considerando a distribuição uniforme (DU) e a distribuição não uniforme (DNU). . . . 26

2.6 Distribuição dos dados para o atributo idade da relação Artista usando histogramas Equi-Widh e Equi-Depth. . . . . . . . . . . 27

3.1 Representação dos pontes siluades à rlistanncia $r$ a partir do objeto $s_{q}$ : considerando as diferentes métricas da família $L_{p}$ e exemplos de consultas por abrangência utilizando essas métricas. . . . . . . . . . . 35

3.2 Excmplo de consultas por similaridade utilizando a função de distância $L_{2} . \quad 37$

3.3 Exemplo do uso da propriedade de desigualdade triangular no descarte (poda) de objetos. . . . . . . . . . . . . . . . 38

3.4 Consultas $R q$ e suas seletividades considerando dados uniformemente distribuídos e dados agrupados. . . . . . . . . . . . . . . . . . 42

3.5 Conjuntos $M, N$, e $P$ compostos por dados pontuais distribuídos ao longo

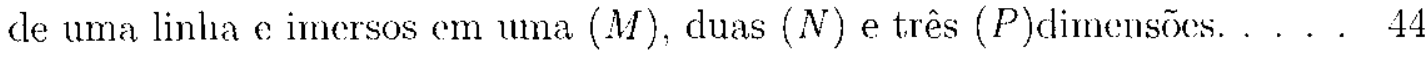

3.6 Distance plot do conjunto de dados MGCounty, mostrando sua Dimensão de Correlaça Fractal $\mathcal{D} \approx 1.81 \ldots \ldots \ldots \ldots$. . . . . . . . . 5 5

4.1 Regiões formadas polos nin-termos $m_{0:}^{p} m_{1}^{p}$ e $m_{r}^{p}$ em um espaço bidimensional com a mótrica Euclidiana. 
4.2 Regiōes formadas pela expressão na forma norrmal disjuntiva $p_{1} \vee\left(\neg p_{2} \wedge p_{3}\right) \vee$ $\left(\neg p_{5} \wedge p_{6}\right) \vee\left(\neg p_{4} \wedge p_{7}\right) \vee\left(\neg p_{8} \wedge p_{10}\right) \vee\left(\neg p_{9} \wedge p_{11}\right) \vee \neg p_{12}$, considerando predicardos range e a função de distância Euclidiana em um espaço bidimensional. . . . 57

$4.3 \mathrm{O}$ min-termo $m_{a}^{p q}$ em um espaço bi-dimensional corn a métrica Euclidiana pertencente a uma expressäo SCMP an DNF com pelo menos dois mintermos onde a Propriedade 12 pode ser aplicada. . . . . . . . . . . . 62

4.4 Casos possiveis entre os valores limites dos predicados range o k-nearest, dada um conjunção entre eles usando a métrica Euclidiana em um espaço bi-dimensional e o operador $\theta={ }^{\prime} \leq \ldots \ldots \ldots \ldots \ldots$. . . . . . 64

4.5 As três possibilidades que o min-termo $m_{a}^{p / q}$ pode assumir em uma expressão SCMP em DNF sendo ilustradas por regiōes em um espaço métrico bidimensional com função de distância Euclidiana. . . . . . . . . . . 60

4.6 Cassos possíveis entro os valores limites dos predicados range ou $k$-nearest, dada um disjunçăo entre eles usando a métrica Fuclidiana cm um espaço bi-dimensional e o operador $\theta={ }^{\prime}{ }^{\prime} \ldots \ldots \ldots \ldots \ldots$

5.1 Como usar o distance plot de um conjunto de dados para estimar o número

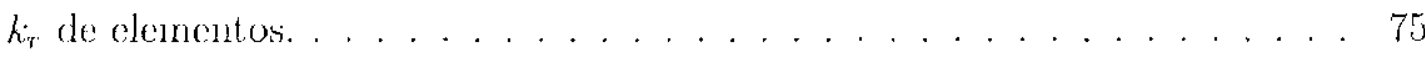

5.2 Possibilidades de estimativas de seletividade para un min-termo SCMP em DNF. . . . . . . . . . . . . . . . . . . . 82

6.1 Distribuição dos conjuntos de dados utilizados nos experimentos no espaço métrico. . . . . . . . . . . . . . . . . . 88

6.2 Avaliarino da consultan $\operatorname{SCSP} \sigma_{\left(k_{c} N N\left(s_{q}\right)\right)} S \wedge \sigma_{\left(\neg k_{i} N N\left(s_{q}\right)\right)} S$ para os conjuntos Cidades, MetricHisto e MGCounty . . . . . . . . . . . . . 92

6.3 Avaliação da consulta SCSP $\sigma_{\left(k_{e} N N\left(s_{q}\right)\right)} S \wedge \sigma_{\left(\neg k_{2} N N\left(s_{q}\right)\right)} S$ para os conjuntos Moedas, Sintético6D e Palavras. . . . . . . . . . . . . . . 93

6.4 Avaliação da consulta SCSP $\sigma_{\left(R q\left(s_{q}, r_{e}\right)\right.} S \wedge \sigma_{\left(\neg R q\left(s_{q}, r_{i}\right)\right.} S$ para os conjuntos Cidades, MetricHisto e MGCounty. . . . . . . . . . . . . 94

6.5 Avaliaf̧ão da consulta SCSP $\sigma_{\left(R q\left(s_{q}, r_{c}\right)\right)} S \wedge \sigma_{\left(\neg R q\left(s_{q}, r_{2}\right)\right)} S$ para os conjunitos

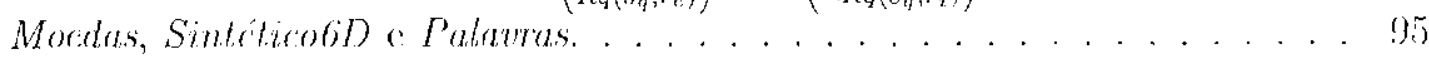

6.6 Comparação entre os algoritmos Range() e RingRange() com $r=r_{e}$ para o conjunto Cidades. . . . . . . . . . . . . . . . . 9.

6.7 Avaliação da consulta $\operatorname{SCMP} \sigma_{\left(R q\left(s_{q}, r\right)\right)} S \wedge \sigma_{\left(k N N\left(s_{q}\right)\right)} S\left(\theta={ }^{\prime} \leq\right.$ ') para os conjuntos Cidades, MetricHisto e MGCounty. . . . . . . . . . 97

6.8 Avaliação da consulta SCMP $\sigma_{\left(R_{q}\left(s_{q}, r\right)\right)} S \wedge \sigma_{\left(k N N\left(s_{q}\right)\right)} S(\theta=' \leq)$ para os conjuntos Moedas, Sintético60 o Palavras. . . . . . . . . . . . 98

6.9 Avaliação da consulta SCMP $\sigma_{\left(k_{q}\left(s_{q}, r\right)\right.} S \vee \sigma_{\left(k N N\left(s_{q}\right)\right)} S\left(\theta={ }^{\prime} \leq\right)$ para os conjuntos Cidades, MetricHisto e MGCounty. . . . . . . . . . . . . 99

6.10 Avaliação da consulta SCMP $\sigma_{\left(R q\left(s_{q}, r\right)\right)} S \vee \sigma_{\left(k_{N N\left(s_{q}\right)}\right)} S\left(\theta={ }^{\prime} \leq\right)$ para os conjuntos Mocdas, Sintético6D e Palavras. . . . . . . . . . . . . . 100

6.11 Variações dios valores de $k$ para expressões SCMP em DNF e CNF para o conjunto MGCounty. . . . . . . . . . . . . . . . . . . . . 101

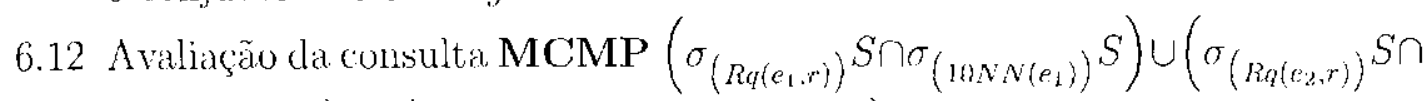
$\left.\sigma_{\left(1 \cap N N\left(i_{2}\right)\right)} S\right) \cup\left(\sigma_{\left(\operatorname{sig(r_{3},r)}\right)} S \cap \sigma_{\left(10 N N\left(e_{3}\right)\right)} S\right)$ equivalente à consulta $\mathrm{Q5}$ da Seção 1.3 para os conjuntos Cidadcs, Mctric Histo o MGCounty. . . . . . 102 
6.13 Avaliação da consulta MCMP $\left(\sigma_{\left(k_{q\left(e_{1}, r\right)}\right)} S \cap \sigma_{\left(1 n N N\left(e_{1}\right)\right.} S\right) \cup\left(\sigma_{\left(k q\left(e_{2}, r\right)\right.} S \cap\right.$ $\left.\sigma_{\left(10 N N\left(e_{2}\right)\right)} S\right) \cup\left(\sigma_{\left(R q\left(r_{3}, r\right)\right)} S \cap \sigma_{\left({\text {roNN }\left(e_{3}\right)}_{3}\right)} S\right)$ equivalente à consulta Q5 da Seção 1.3 para os conjumtos Moedas, Sintético61 e Palavras. . . . . . . . 103

6.14 Avaliação da consultia MCMP $\left.\left(\sigma_{\left(R q\left(e_{1}, r\right)\right.} S \cap \sigma_{\left(10 N N\left(e_{1}\right)\right.}\right) S\right) \cup\left(\sigma_{\left(R q\left(e_{2}, r\right)\right.} S \cap\right.$ $\left.\sigma_{\left(10 N N\left(e_{2}\right)\right)} S\right) \cup\left(\sigma_{\left(R, q\left(e_{3}, r\right)\right)} S \cap \sigma_{\left(10 N N\left(e_{3}\right)\right)} S\right)$ equivalente à consulta Q5 da Seção 1.3 onde são comparados a execução da consulta MCMP complet a com apenias urn mintermo prara o conjunto de dades Metric Histo. . . . . 104

6.15 Escalabilidade do algoritmo $k$ AndRange() utilizando tanto uma lista sequiencial (SeqScan) quanto a estrutura de indexação Slim-tree sobre o conjunto Sintético 300 . . . . . . . . . . . . . . . . . 106

6.16 Escalabilidade do algoritmo kOr Range() utilizando tanto una lista seqüencial (SeqScan) quanto a estrutura de indexação Slim-tree sobre o conjunto Sintéticos0D. . . . . . . . . . . . . . . . 107

6.17 Avaliação das fórmulas de estimativa de soletividade usando o modelo baseado na teoria de fractais. Gráficos comparando a cardinalidade estimada, usando as fórmulas propostas com um erro de $30 \%$ e a cardinalidade real. . 108

6.18 Avaliaçāo das fómulas de estimativa de seletividade usando o modelo baseado na teoria de frartais. Gráficos comparanclo a carclinaliclade estimada, usando as fórmulas propostas e a cardinalidade real, considerando o desvio padrăo. . . . . . . . . . . . . . . . . . . 109

A.1 Estrutura lógica dos nós índice (inderNode) e folha (leafNode) da Stim-trec. 129

A.2 Excmplo da estrutura lógica de uma Stim-tree contendo 7 cadeias de ca-

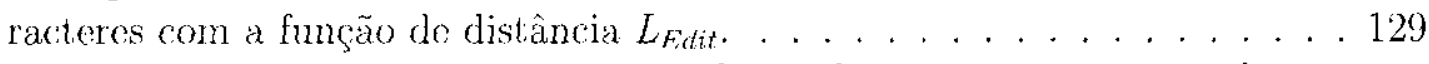

A.3 Representaçăo de uma Slim-lrece contendo 17 objotos e sua correspondente netrutura lógica. . . . . . . . . . . . . . . . . . . . 131

A.4 Exemplificação do mecanismo de quebra de nós segundo a política $M S T$ (Minimal Spanning Tree) em un conjunto de objetos. . . . . . . . . 132

A.5 Exemplo da aplicação do algoritmo Stim-Downo en três nós folha. . . . . 1333 


\section{Lista de Tabelas}

4.1 Consultas por sinilaridade o suds variacoes, sens respectivos predicarlos o algoritmos básicos utilizados para implententá-las. . . . . . . . . . . . . . . 49

4.2 Primeipais símbolos usados em expressoes por similaridade complexas. . . . 50

4.3 Os algoritmos desenvolvidos e as expressóes em que cada un deles é utilizado. 71

5.1 Principais símbolos utilizados noste capítulo. . . . . . . . . . . . . . . 74

5.2 As fómmulas de estimativa de seletividade desenvolvidas o as expressoes $\mathrm{cm}$ que cada um delas ć utilizada. . . . . . . . . . . . . . . . 85

6.1 Descrição dos conjuntos de dados reais o sintéticos utilizados nos experiincntos. . . . . . . . . . . . . . . . . . 87

6.2 Algoritmos normativos propostos e a respectiva composição dos algoritmos básicos para responder a consultas por similariolade complexas. . . . . . . . 91 
Siglas

\begin{tabular}{|c|c|}
\hline CIRCF & Content-based Image Retrieval Core Engine. \\
\hline $\mathrm{C} \times \mathrm{F}$ & Conjunctive Normal Form - Forma Normal Conjuntiva. \\
\hline DBM-tree & Density-Bused Metric: Iree. \\
\hline DCF & Dimensão de Correlação Fractal. \\
\hline DNF & Disjunctine Normal Form - Forma Normal Disjuntiva. \\
\hline DNU & Distribuição Não Uniforme. \\
\hline $\mathrm{DU}$ & Distribuição Uniforme. \\
\hline$k N N$ & $\begin{array}{l}k \text {-Nearest Neighbors Query-Consulta por similaridade cujo tipo é aos } \\
k \text {-Vizinhos Mais Próximos. }\end{array}$ \\
\hline $\mathrm{M} \Lambda \mathrm{M}$ & Método de Acesso Métrien. \\
\hline $\mathrm{MCMP}$ & $\begin{array}{l}\text { Multiple Centers/Mulliple Predicate types - Múltiplos Centros/Tipos } \\
\text { de Predicados Diferentes. }\end{array}$ \\
\hline $\mathrm{MST}$ & Minimal Spanning Tree - Árvore de Caminho Mínimo. \\
\hline MVP-tree & Multi-Vantage Point tree. \\
\hline ()Id & Objret Identification - código do identificanerano do objetos. \\
\hline$R q$ & Range Query - Consulta por similaridade cujo tipo é por Abrangência. \\
\hline SCMP & $\begin{array}{l}\text { Single Center/Multiple Predicate types - Mesmo Centro/Tipos de Pre- } \\
\text { dicados Diferentes. }\end{array}$ \\
\hline SCSP & $\begin{array}{l}\text { Single Center/Single Predicate - Mesmo Centro/Mesmo Tipo de Pre- } \\
\text { dicado. }\end{array}$ \\
\hline SGBD & Sistema de Gerencianento de Bases de Dardos. \\
\hline SQL & Structured Query Language. \\
\hline$S Q L / M M$ & S(LL Multmedia Spatinal Standard. \\
\hline
\end{tabular}




\section{Tabela de Símbolos}

\begin{tabular}{|c|c|}
\hline $\mathbb{S}$ & Conjunto de todos os elementos válidos no domínio de objetos. \\
\hline$S$ & Conjunto do dados oncle as consultas säo feitas. $S \subseteq \mathbb{S}$ \\
\hline$\nu$ & Número total de objetos de $u$ conjunto de dados $S$. \\
\hline$d\left(s_{i}, s_{j}\right)$ & $\begin{array}{l}\text { Função de distância métrica ou função de dissimilaridade. } \\
d: \mathbb{S} \times \mathbb{S} \rightarrow \mathbb{R}^{+}, s_{i}, s_{i} \in \mathbb{S}\end{array}$ \\
\hline$s_{q}$ & $\begin{array}{l}\text { (objeto de referência, objeto de busca on objeto centro da consulta. } \\
s_{q} \in \mathbb{S}\end{array}$ \\
\hline$r$ & Raio de uma consulta por abrangência. $r \geq 0$ \\
\hline$k$ & $\begin{array}{l}\text { Número de objetus que se deseja recuperar en uma consulta aos } k \text { - } \\
\text { viminhos mais proximes. } k>1\end{array}$ \\
\hline $\operatorname{Rq}\left(s_{q}, r\right)$ & Predicado do uma consulta por abrangência - predicado range. \\
\hline$k N N\left(s_{q}\right)$ & $\begin{array}{l}\text { Predicado de um consulta aos } k \text {-vizinlos mais próximos - predicarlo } \\
k \text {-nearest. }\end{array}$ \\
\hline$p_{i}, \quad q_{i}$ & $\begin{array}{l}\text { Predicado do tipo } p \text {, onde } p \text { representa apenas predicados range ou } \\
k \text {-nearest e } q \text { representa o outro tipo do predicado. }\end{array}$ \\
\hline$u_{i}, \quad v_{i}$ & $\begin{array}{l}\text { Valor limite do predicado } p_{i} \text {. Se } p_{i}=R q\left(s_{q}, r\right) \Rightarrow u_{i}=r, \operatorname{senão} u_{i}=k \text {, } \\
\text { e } v_{i} \text { ć o valor do outro tipo de predicado. }\end{array}$ \\
\hline$m_{i}^{p}, m_{i}^{q}$ & 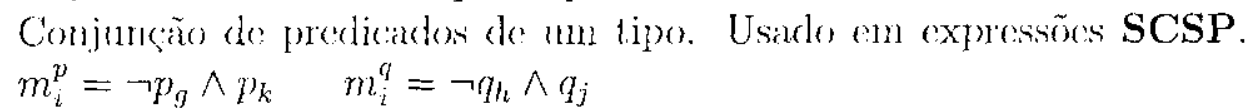 \\
\hline$m_{i}^{p q}$ & $\begin{array}{l}\text { Conjunção envolvendos os predicados range o k-nearest. Usidlo em } \\
\text { expressóes SCMP. } \quad m_{i}^{p q}=m_{i}^{p} \wedge m_{i}^{y}\end{array}$ \\
\hline$m_{i}^{p}$ & $\begin{array}{l}\text { Conjunção de predicados no objeto de referencia } c \text {. Usado em expres- } \\
\text { sóes MCMP. }\end{array}$ \\
\hline$m_{1}^{p}$ & $\begin{array}{l}\text { O min-termo consistindo de } u m \text { único predicado não complementado. } \\
m_{1}^{p}=p_{i}\end{array}$ \\
\hline$m_{0}^{\prime \prime}$ & $\begin{array}{l}\text { O min-termo consistindo de um ínies predicado complementado. } \\
m_{0}^{p}=\neg p_{j}\end{array}$ \\
\hline $\mathcal{D}$ & Dimensão de Correlação Fractal ou distance exponent. \\
\hline$R$ & Diâmetro do conjunto do dados $S$. \\
\hline$P C(r)$ & Número de pares do elementos dentro de uma distancia $r$. \\
\hline & $\begin{array}{l}\text { Número estimado de oljectos a ser retornado por uma consulta por } \\
\text { abrangência de raio } r \text {. }\end{array}$ \\
\hline
\end{tabular}




\section{Sumário}

Lista de Tabelas

Siglas

Tabela de Símbolos

1 Introdução 1

1.1 Consideragões Iniciais . . . . . . . . . . . . . . . . . . 1

1.2 Definição do Problema . . . . . . . . . . . . . . . . . 4

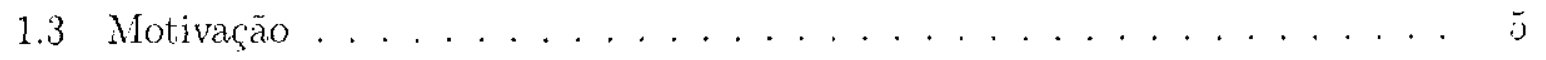

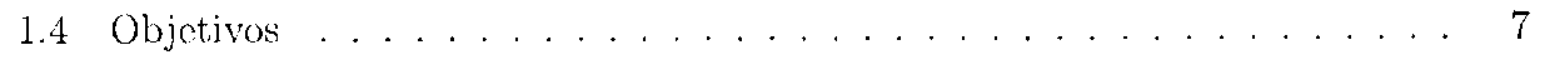

1.5 Principais Contribuiçōes . . . . . . . . . . . . . . . . . . . 9

1.6 Organização do Trabahtho . . . . . . . . . . . . . . . . . . 10

2 Processamento de Consultas 11

2.1 Introduciano . . . . . . . . . . . . . . . . 11

2.2 Etapas do Processamento de Consultas . . . . . . . . . . . . 12

2.2 .1 Compilador . . . . . . . . . . . . . . . . 12

2.2 .2 Otimizador . . . . . . . . . . . . . . . . . . . 13

2.2 .3 Executor . . . . . . . . . . . . . . . . . . . 15

2.3 Leis Algébricas . . . . . . . . . . . . . . . . . 16

2.3 .1 Leis envolvendo Seleção . . . . . . . . . . . . . . 18

2.4 Formas Normais. . . . . . . . . . . . . . . . . . . . . . 22

2.5 Estimando o Tamanho do Resultado . . . . . . . . . . . . . 23

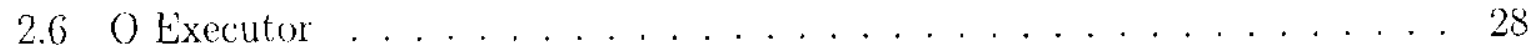

2.6.1 Classificacáo dos Algoritmos . . . . . . . . . . . . 29

2.6 .2 Materializaçāo x Pipelining . . . . . . . . . . . . . 29

2.7 Conclusão . . . . . . . . . . . . . . . . . . . . . . . . 30 
3 Consultas por Similaridade 32

3.1 Introdução . . . . . . . . . . . . . . . . . . . . . 32

3.2 Espaço Métrico . . . . . . . . . . . . . . . . . . . . . . . . . . 33

3.2 .1 Espaço Vetorial . . . . . . . . . . . . . . . . . . . . 34

3.3 Consultas por Similaridade . . . . . . . . . . . . . . 35

3.4 Algoritmos para Consultas por Similaridade . . . . . . . . . . 38

3.5 Estimativa do Seletividade para Consultas por Similaridade . . . . . . . . 41

3.5 .1 Dinensão de Correlação Fractal . . . . . . . . . . . . . . 43

3.6 Conchusão . . . . . . . . . . . . . . . . . . . 46

4 Regras Algébricas e Algoritmos $\quad 47$

4.1 Introdução . . . . . . . . . . . . . . . . . . . 47

4.2 Variaçoes dos Tipos de Predicados Básicos . . . . . . . . . . . 48

4.3 Consultas por Similaridade Complexas com Mesmo Centro . . . . . . . . 50

4.3 .1 Expressons SCSP . . . . . . . . . . . . . . . . . 50

4.3 .2 Expressões SCMP . . . . . . . . . . . . . . . . . . . 59

4.4 Consultas por Similaridade Complexas com Wúltiplos Contros . . . . . 67

4.5 Conclusão .......................... 70

$\begin{array}{lll}5 & \text { Estimativa de Seletividade } & 72\end{array}$

5.1 Introducăo . . . . . . . . . . . . . . . . . . . . 72

5.2 Estimando o Número de Objetos Usando Fractais . . . . . . . . . . . . . . 73

5.3 Seletividade para Consultas por Similaridade . . . . . . . . . 76

5.3 .1 Seletividade para Expressoes SCSP . . . . . . . . . . . . . . 76

5.3 .2 Seletividade para Expressoes SCMP . . . . . . . . . . . . . 79

5.3 .3 Soletividade para Expressios MCMP . . . . . . . . . . 83

5.4 Conchus̃o . . . . . . . . . . . . . . . . . . 84

6 Experimentos $\quad 86$

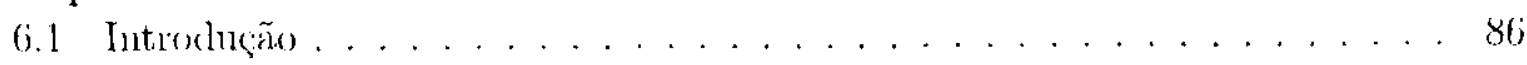

6.2 Materiais e Mótodos . . . . . . . . . . . . . . . . . . 87

6.3 Resultados e Discussão . . . . . . . . . . . . . . . . . . . . . 90 90

6.3.1 Algoritmos para Expressões SCSP . . . . . . . . . . . . . . . . . . . . . 92

6.3.2 Algoritunos para Expressocs SCMP . . . . . . . . . . . . . . 96

6.3 .3 Algeritmos para Expressoes MCMP . . . . . . . . . . . . . . 101

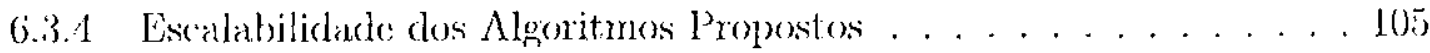

6.3 .5 Fómulas de Lstimativa de Seletividade Propostas . . . . . . . . . 105

6.4 Conclusão . . . . . . . . . . . . . . . . . . . 111

7 Conclusão 113

7.1 Consideracos Finais . . . . . . . . . . . . . . . . . 113

7.2 Principais Contribuiçoes . . . . . . . . . . . . . 115

7.3 Proposta para Trabalhos Futuros . . . . . . . . . . . . 117

$\begin{array}{ll}\text { Referências Bibliográficas } & 118\end{array}$

A O MAM Slim-trce 128

A.1 Organização da Slim-tret . . . . . . . . . . . . . . . 128

A.2 Construindo uma Slim-trec . . . . . . . . . . . . . . 129)

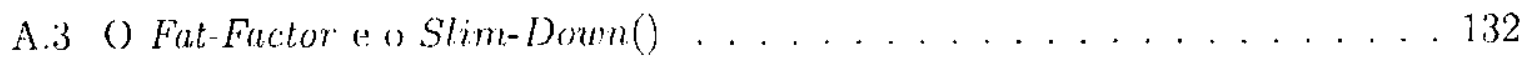


B Desigualdade Triangular 


\subsection{Considerações Iniciais}

volume de darlus amozenado e manipulako om Sistemas de Gerenciamento de Bases de Dados (SGBD), também chamados neste trabalho simplesmente de gerenciadores. ven crescendo muito nos últimos anos. Fsise crescimento, alén de ocomer quantitativanente, tem larga parcola qualitativa, pois novos tipos de dados mais complexos que os dados convencionais (numeres e textos curtos) estão sendo incorporados aos gerenciadores. Esses novos tipos de dados, hamados de dados complexos, incluem: dados multimidia (imagens, víkeo áudio, texto longo), infornacoes geo-referenciadas, sequêencias temporais, daelos de tolemetria, dados do "mgenbaria o

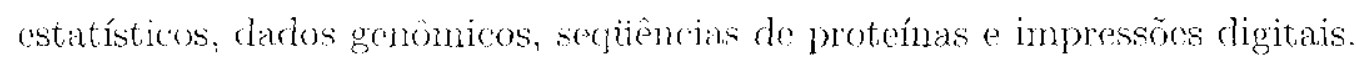

Os gerenciadores foran inicialmente resenvolvidos para manipular dados convencionais, aproveitando a relação de ordem total entre os elementos desses dominios do dados. Lim dominio de dados tem relaça de ordem total quando é possivel comparar qualloner

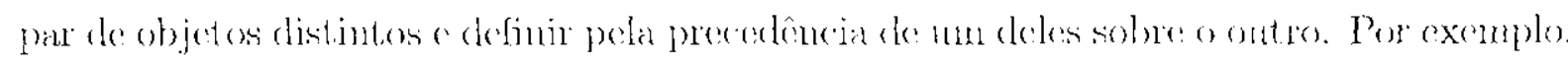
a relaça de ordom numórica em dominios muméricos, ou a relacão de ordem lexicográfica crn domínios de cadeias curtas de caracteres são relacones de ordem total. Os gerenciadores tradicionais ou convencionais, tais como os gerenciadores relacionais, usam

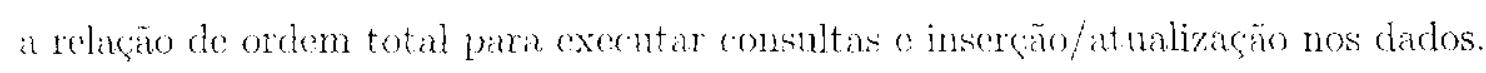

Nesses genenciadones, as consultas mais usuais sobre os dados sido as que convolvem intervalo (faixa de valor(s), por excmplo, "olster as pessons com idade entre 15 e 30

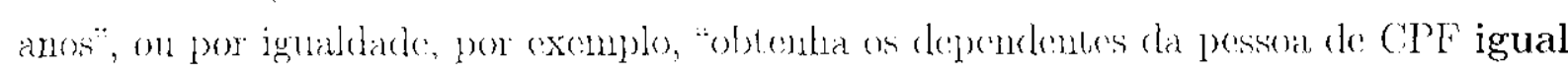
a 999.999.999-99". Os SGBDs tradicionds uban estruturas de indexação para agilizar a resposta para una delcminada consulta. Existem várias estruturas de indexacão para 
dados convencionais. Entre as mais importantes estaio os índices simples (densos on espar-

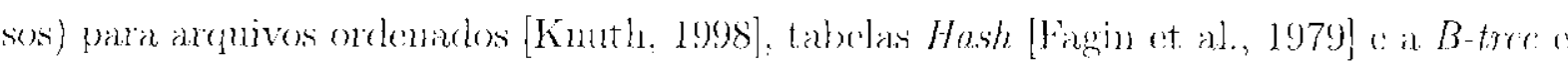
suas rariantes [Comer, 1979]. Note-se que, mesmo quando uma (onsulta chvolvo apenas comparação por igualdade, as estruturas de indexacão empregadas para agilizar a busca dependem das rolaçoes de ordem entre os dados.

Domínios de dados complexos geralmente não definem a relação de orden total necessária para que consult as por intervalo possam ser realizadas. Além disso, consultas por igualdade têm aplicarăo restrita, uma vo que a existencia de dois clementos cxatamente

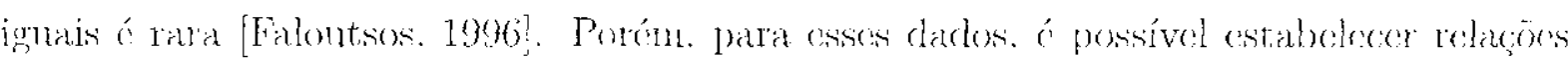
de similaridade cutre pares do objet os, permitindo a realizaça a de consultas por si-

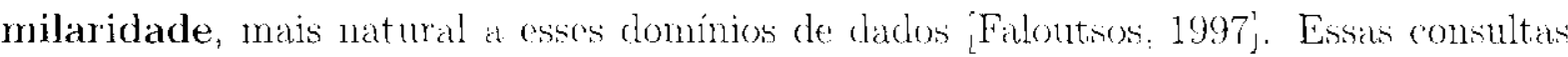
retoman os objotos do conjunto de dados cune atencham a cortos critérios de similaridade. em raçã̃o a um objeto de referência, tanbém chanado de objeto central ou centro rlat consulta

Para aplicar consultas por similaridade sobre um domínio do darlos, uma função

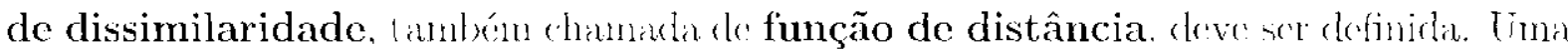
funçño de distancin $d\left(s_{1}, s_{2}\right) \rightarrow \mathbb{R}^{+}$compara dois elementos $s_{1}$ e $s_{2}$ e retoma um valor positivo que expressa a "distâncja" entre os dois clementos. Istó b, quanto menor for a distància, mais próximos ou mais similares cstão/säo os clenentos. Una função de distáncia que atenda ì propriedacles de simetria, não-negatividade "desigualdade triangular í channala de função de distância métrica ou simplesincute métrica CChávez et al., 2(101!

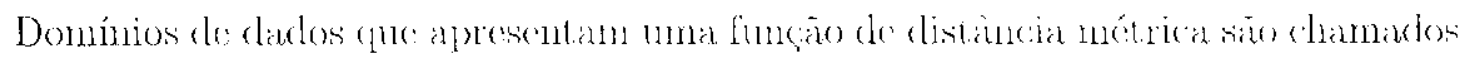
domínios métricos ou espaços métricos os çuais são adecquados para se aplicar comsultas por similaridade. Existem basicanente dois tipos de consultas por similaridade que pordem ser expressas usando os predicados por similaridade correspondentes': consulta por abrangência ${ }^{2}$ (Runge $Q u e r y-R q$ ) c consulta aos k-vizinhos mais próximos

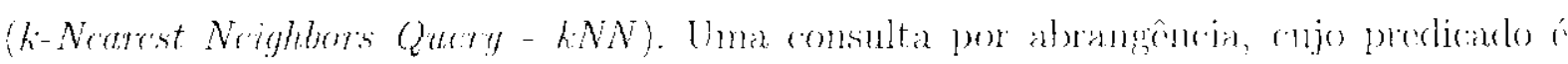
Rq $\left(s_{q}, r\right)$ : recebe cono parimetros um elemento do domínio de dados (objeto central da consulta) o um grau de similaridade $r$ o obtém todos os elementos da base de dados que difcrem do centro da consulta no máximo a similaridade indicadla. Lin oxemplo de consulta por abrangencia em uma base de dados do estrelas ci: "screcionce as estrelas que estão

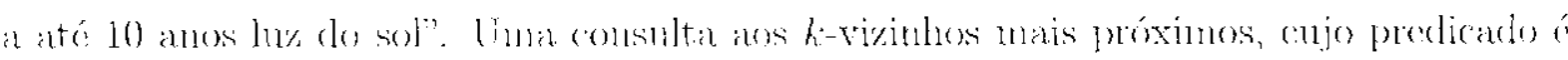
kNN $\left(s_{q}\right)$. recebe como parâmetros um semento do domínio de dados e uma quant idarle $k$. obtendo a quantidade $k$ especificarla de elementos do domínio de dados que estejam mais próximos ao centro da consulta. Une exemplo de consulta ans h-vizinhos mais próximos nsantlo a mesma base de daxlos si "selecione as 5 cstrelas mais próximas do sol".

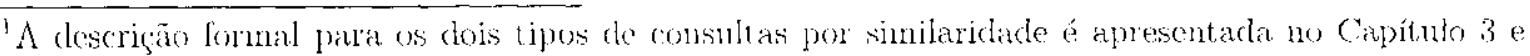
suas variacòes são doscritas no Catpílulo 4.

2O tonno em inglés Range Query á utilizado tanto palla constitas por abrangencia guanto para consultas por intervalo. No entanto, esta teso faz distinçäo ont re esses dojis tormus por se tratarem de consultas molvenko propricklackes distintas. 
As cstruturas de indexação para dados convencionais não săo adequadas para indo-

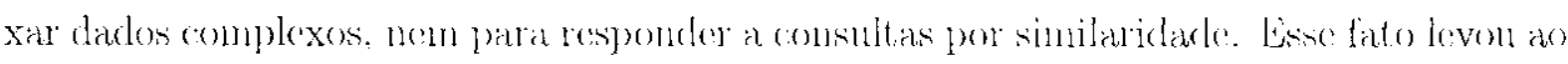

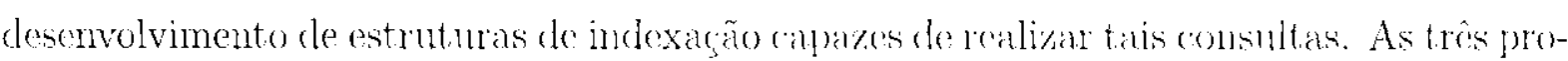
priedades ritaklas anteriomente para in funçào de distâne ia métrica do possibilitam a construção de estruturas de indexação baseadas em árvore, chamadas de Métodos de Acesso Métrico (MAMs). MAMs sẫo fundanentais para agilizar busceas en grandes conjuntos de

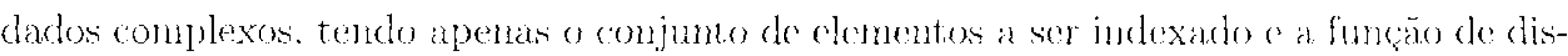

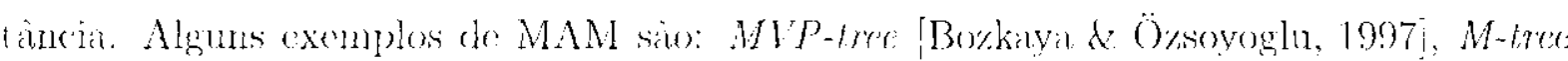
[Ciacein et al., 1997], Slim-tree [Thaina Jr, ft al., 2002] e DBM-tree IVicira et al., 2004] os quais podem methorar emito o desempenho de consultats por similaridade.

Consultas por similaridade tèm siek consideradas por algnus antores [Beyer et al., 1999] [Natsev et al, 1999) TYoshitaka \& Ichikawa, 19999 como oporacóos

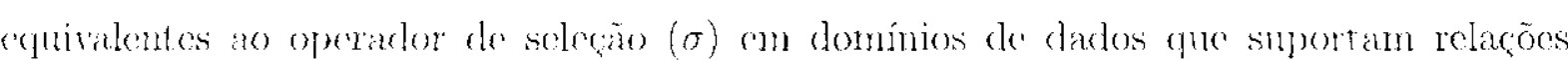

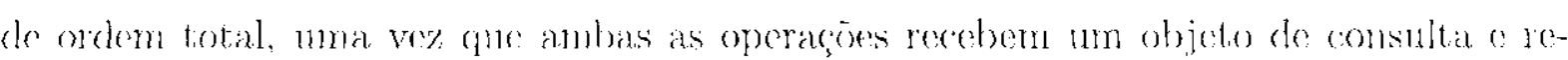

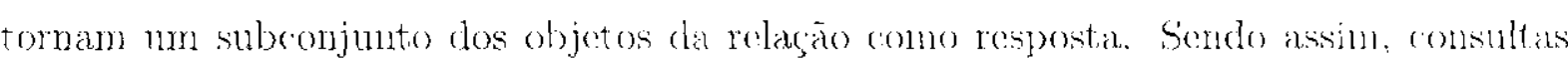

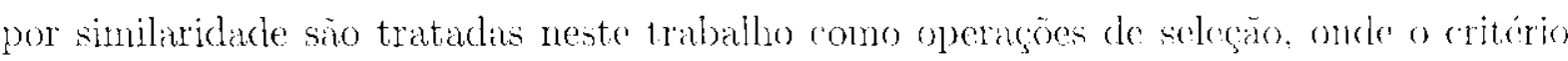
de scleçăo (predicado) wijliza a similaridade de dados om domínios métriess.

Para responder eficientenente anos operadores de selecão por similaridade, algoritmos e ostruturas de indexação tom sido intonsamente estudados a já poderiam ser utilizados com eficiència em ferramentas reais de consulla a clacks complexos. Eutre-

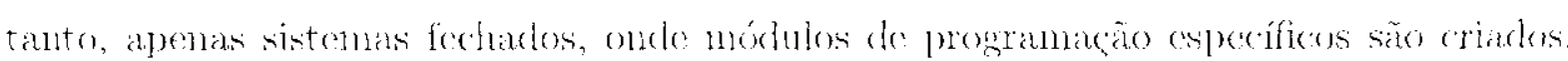
têm sido constrúdos respondendo a consultas predefindas [Flickner d alli, 1995]. IJn passo importante a ser darbó ce permitir que consultas por similaridade possam ser incorpo-

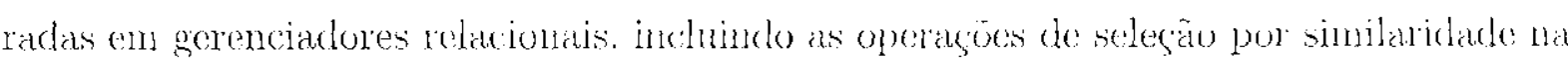

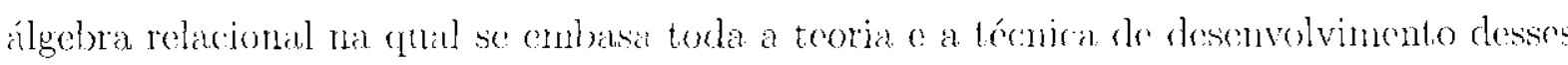
gerenciadores.

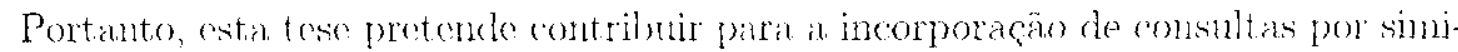
laridade em gerenciadores relacionais. Algumas consideraçoes iniciais parn o bon entendimento ao longo do texto sa a apresentadas a seguir. O temo consulta é usarlo para expressar momodo de como se pretende recuperar os chates na linguagem do gerencia-

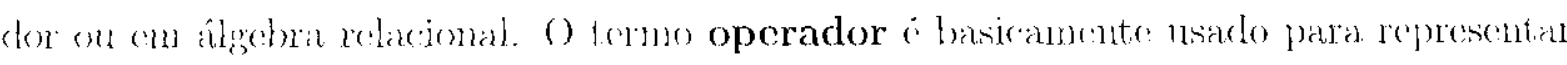
um processo (fuc á parte de uma expressano de consulta. geralmente em álgebra relacional. () trmo predicado comesponde an (riterio especificado en 1 moperador como, por

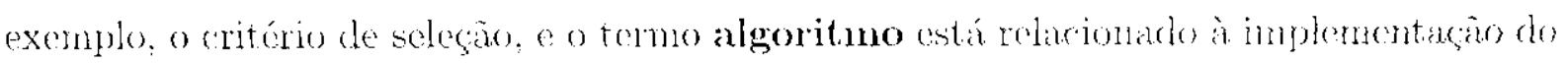
operador.

Um esclarecimento importante a sor feito é que, ano longo desta trese, os exemplos de conjuntos de dados complexos presentes em clase torlas as figuras aprescrutam objetos

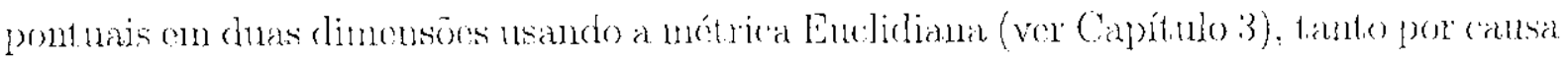
da facilidade de representá-los grafiranente: quanto pelo late desso romínio de dados ser

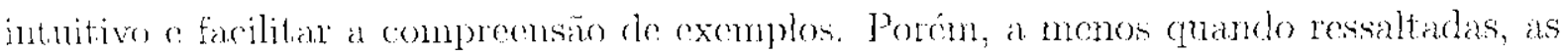


explicaçốs c exemplos poderăo ser generalizados para quaisquer dimensós e quaisquer tipos de dartos romplexess.

\subsection{Definição do Problema}

A maioria dos trabalhos solore consultas por similaridade ronsidera cada consulta como uma operaçáo isolada t: não como parte de uma expressão mais complexa envolvendo mais de um predicado por sinilaridade. Além disso, os algoritmos existentes para respon:-

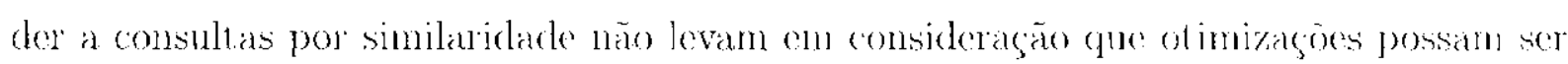
realizadas devido à combinaf̧äo entre os predicados por similaridark. Esses algoritmos não otimizaros para responder apenas a una consulta específica. Portanto, a execução de consultas envolvendo mais de um predicado por similaridade por meio de conjunçóes o disjungoes entre cles. isto é consultas por similaridade complexas, tende a sor

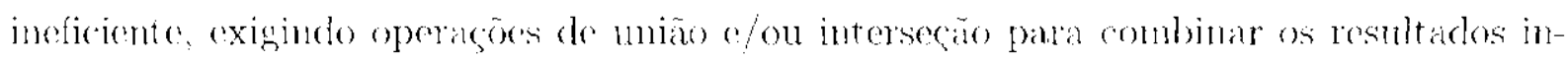
termediários obtidos de cada predicado por similaridade.

Im gernciador com suporte a dados complexos precisa responder a consultas por similaridade complexas eficientemente. Una procedimento natural para dar suporte a esses tipos de dados en gerenciadores relacionais á incluir consultas por similaridade na álgebra relacional. Isso implica con fornecer maneiras para processar eficientemente consiltas por similaridade em cada uma das etapas do processamento de consult as de un gerenciador relacional, que estáo ilustradas na Figura 1.1 e são detalladlas no Capút ulo 2. sendo elas: Compilador. Otimizador a Executor.

Portanto. o gerenciador relacional deveria prover manciras de: interpretar consultas por similaridade expressas como predicados na clátsula "where" do comando "select" na linguagem de consulta cstruturada (Structured Query Language - SQL); traduzir as

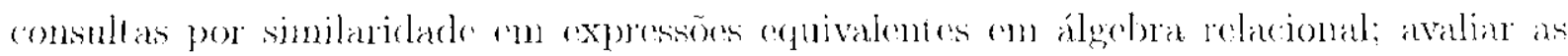
possibilidades do otimizaça considerando regras algébricas, estimativa de seletividade e cle custo: e, executar busens cur consultas por similaridade complexas por moio de algoritmos específicus.

Como una consegüencia, consultas por similaridade poderian ser ulilizadas juntamente com outros predicados já existentes na álgebra relacional, tais como a busca cexata

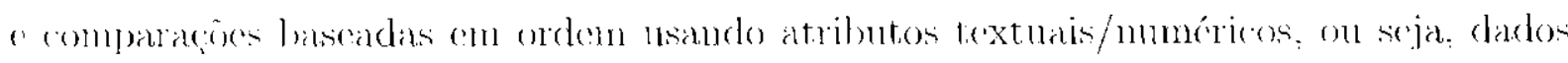
convencionais. Alóm disso, comparaçóes entre dois ou mais predicados por sinilaridade

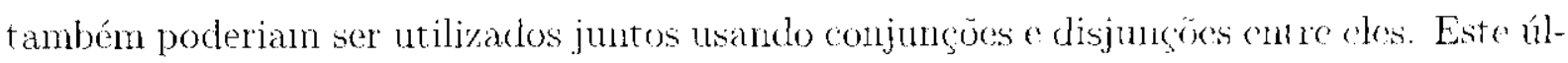
timo aspecto. denominado de consultas por sinilaridade complexas, é o assunto abordado nesta tese.

Consultas por similaridade complexas apresentam dois problemas principais que

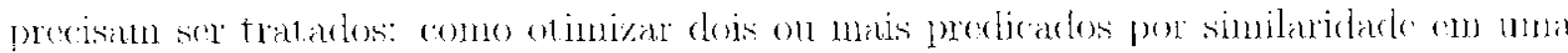
mesmar consulta: e como consultas por similaridade conplexas frecliontemente ntilizadas

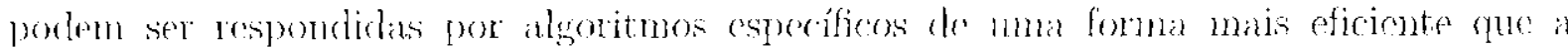




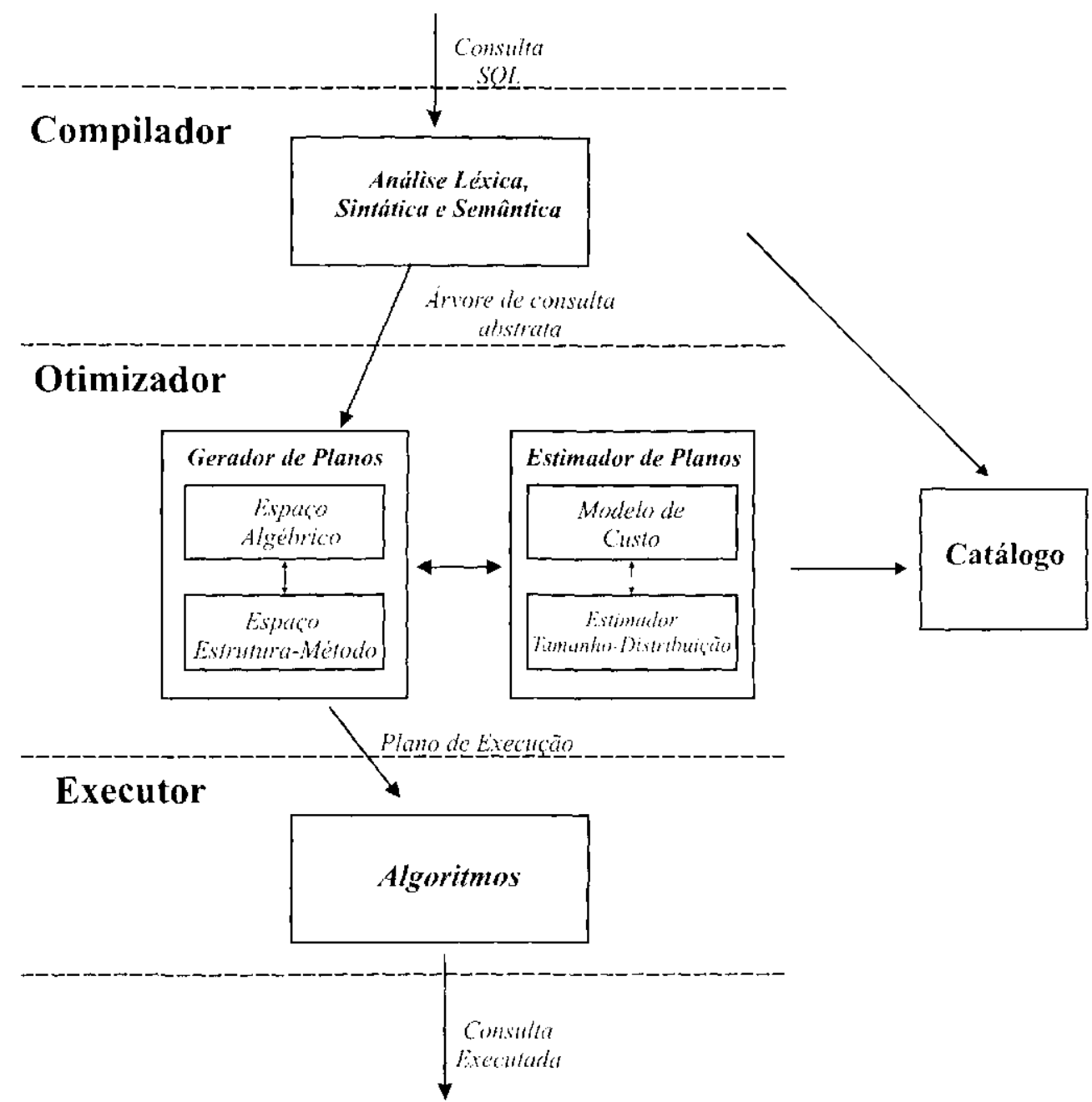

Figura 1.1: Arfuitetura clescrevendo as etapas do processamento de consultas en un gerenciador relacional. Est arquitetura é clividida em : Compilador. Otimizador e Executor. Arquitetura adaptada do [lommidis, 1996]: 'Carria-Nolina et al., 2000\}? ¿Ramakrishnan \& Gohrke, 20033].

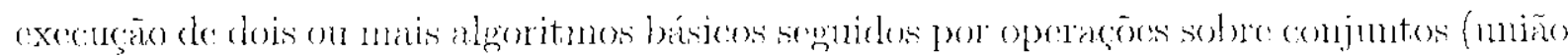
c/ou interseçno).

\subsection{Motivação}

$A$ composiga de mais de un predicado por similariado toma-se freqüntenente neressária cm sistenuas reais. Algums exemplos de consultas por similaridade complexas são descritas a seguir, onde os operadores de mião (U), interseçăo (n) e negação ( $)$

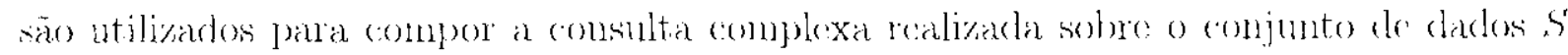
correspondente.

Q1) Lin sistemas de informa(ä) geográfica (SIG): "Enconte os 10 restentuntes muis próximos do local onde estamos (le:), desde que elés cstegnan a no máximo 1 quilometro."

$\sigma_{(10 N N(t e))} S \cap \sigma_{(\operatorname{Riq}(t): 1 k m))} S$ 
Q2) Frn sistemas de pesquisas genônicas: "Sclectone pelo menos gol) seqüencias de

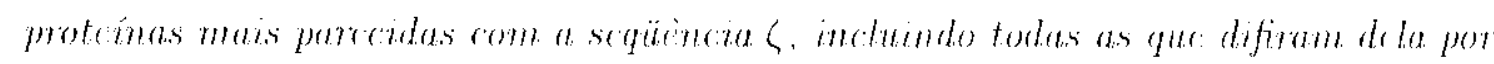
até 10 códons.."

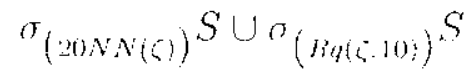

Q3) Em un processador de textos: "Quando uma palaura for digitada errada ("pe'),

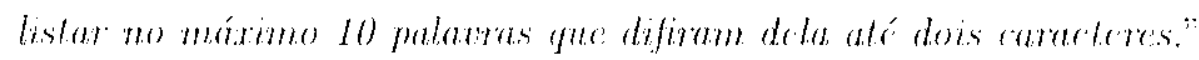

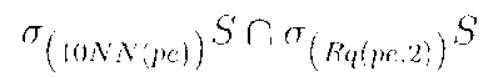

Q4) Em um sistema imobiliário: "Mostre as 10 casas dispontwets mais próximas de meu trabalho ('mt') desde que olas estcjam a no máximo 13 quilometros dele. mas que também estejam a no máximo 15 quilômetros de trabalho de minha esposa ('te.)."

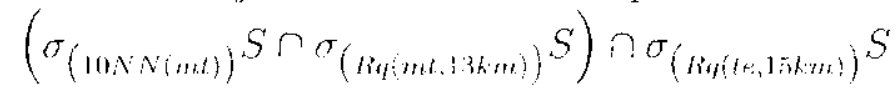

Q5) En sistemas de informaçăo para medicina: "Mostre os cames de Raio X' de qualque" paciente que están cutre os 10 mats similares de cada um desses 3 arames $e_{1}, e_{2} 6$ e. de meu paciente atual, mas que nào difiram deles mais que 5."

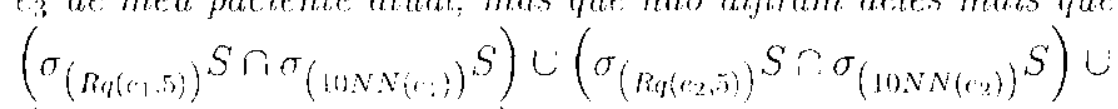

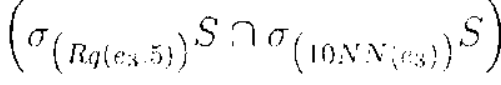

Q6) Em SIG: "Encontre as cidadrs que distam cntre 400100 quilometros da cidade 'sp"."

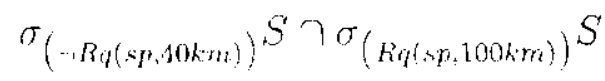

Apesar da necessidade de compor operadores por similaridade en sistemas reais. como mostram os exemplos acima, na maioria dos trabalhos os algoritmos por simila-

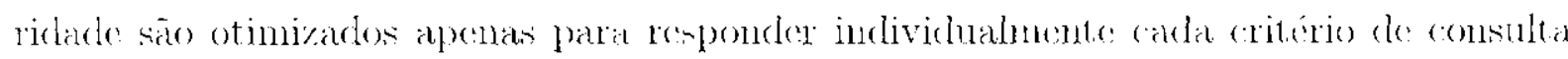
por similariclade. Alóm clisso, não há no padrão SQL sintaxe para expressial critérios do soleçăo bascados con similaridade. Entretanto, existem diversas propostas para isco. incluindo o suporto específico na proposta de extensão para dados espaciais - SQL/MM (SQL Multimedia Spatial Standard) INelton \& Eiscnberg, 2001. 13249-3:2001, 2001!

Existem também alguns sistemas já disponíveis que implementanu a interpretaçáa de comandos para consulats por similaridade, tais como o sistema CIRCE (Contentbesed Image Retrienal Core Engine) (Araujo et al, 2002, que visa a estender a SQL para responder a consult as por similaridade sobre conjuntos de imagens. Lm todos os casus. múltiplos critérios deven sor expressos em comandos separados (atravio do sub-selct) que poden ser combinados através de operaçocs sobre conjuntos (união e interseção).

Senclo assim, as consultas por similaridade complexas pordem ser respondidas por algoritmos básicos de consulta por abrangência e aos k-vizinhos mais próximos seguidos

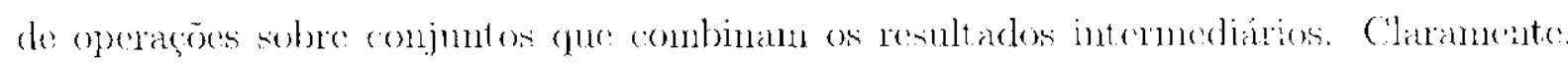
esta abordagem năo oferece o melhor desempenho considerando, por exemplo, tempo do

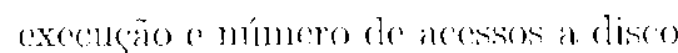


Consultas por similaridade complexas poderiam ser mais eficientemente respon-

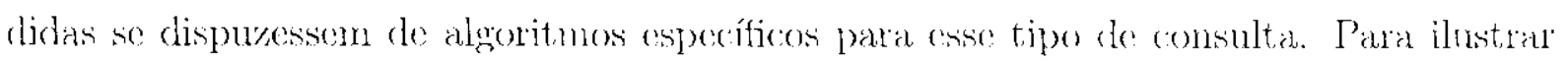
isso, considere a consulta Q6. Essa consulta por similaridade complexa poderia ser realizada por um alyoritmo específico praticamente com o mesmo tempo da execucano da consulta $\sigma_{(R q(s, 100))} S$, an passo que a inexistència desse algoritmo leva à cxecugáa de duas operaços de consulta por abrangencia e mais uma operaça de intersegäo ent re conjuntos.

Portanto, una abordagem mais eficiente seria construir operadores mais gerais, on scja: operadores compostos pan consult as por similaridado complexas que seriam parametrizados pelo otimizador de consultas do gerenciador usando algoritmos especificos. Nesse caso, um pequeno conjunto de algoritmos deveriam ser constrúklos para que eles purlessem responder a qualquer consulta por similatidade complexa, empregando o Otimizador de. consultas para parametrizálos por meio de planos de consulta eficientes.

\subsection{Objetivos}

Este trabalho explora como os tipos de consultas por similariclake mais comuns, por abran gènela e aus k-vizinhos mais próximos, poetem ser utilizados em expressöes complexas envolvendo mais de un predicado por similaridade por meio de conjungoes e disjuncóns. O objotivo ó definir urn conjunto de operacônes compostas que sejam melhor implementadas por algoritmos específicos. Essas operaçoes, juntamente com a descriçäo algébrica de slats

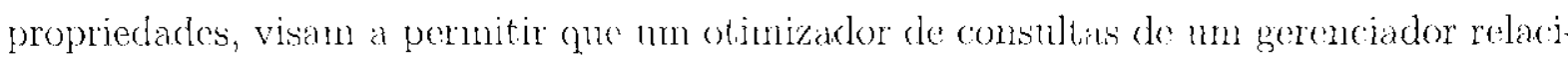
onal gere planos altenativos o possilsilite a escolha de um plano de consulta fifiente para.

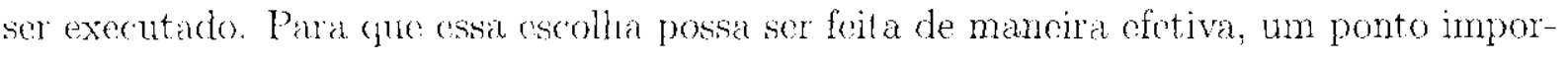
tante é adotar um modelo de seletividade para consultas por similaridade complexas, e a

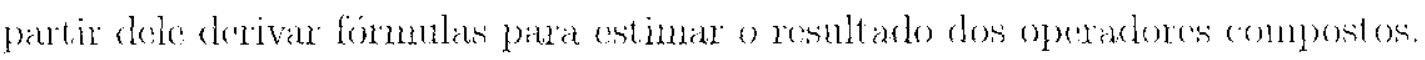

Esta tese protenderesponder as seguintes questocs:

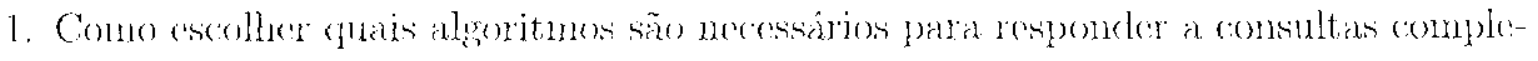
xas, envolvendo conjuncoues en disjunçoes de predicados por similaridade?

2. Quais regras sân necessúnias para guiar o processo de otimizaçäo de consultas lia geraçao de estratégias alternativas do execução para consultas por similaridade?

3. Como representar uma consult a on una forma normal, adequarla a ser submetida aos algoritmos de busca por similaridade?

4. Qual modelo de seletividade poderia ser adotado para consultas por similaridade complexas?

5. Quais fómulass sáo necessárias para estimar a quantidade de objelos a ser recuperada pelos opreradores compostosit? 


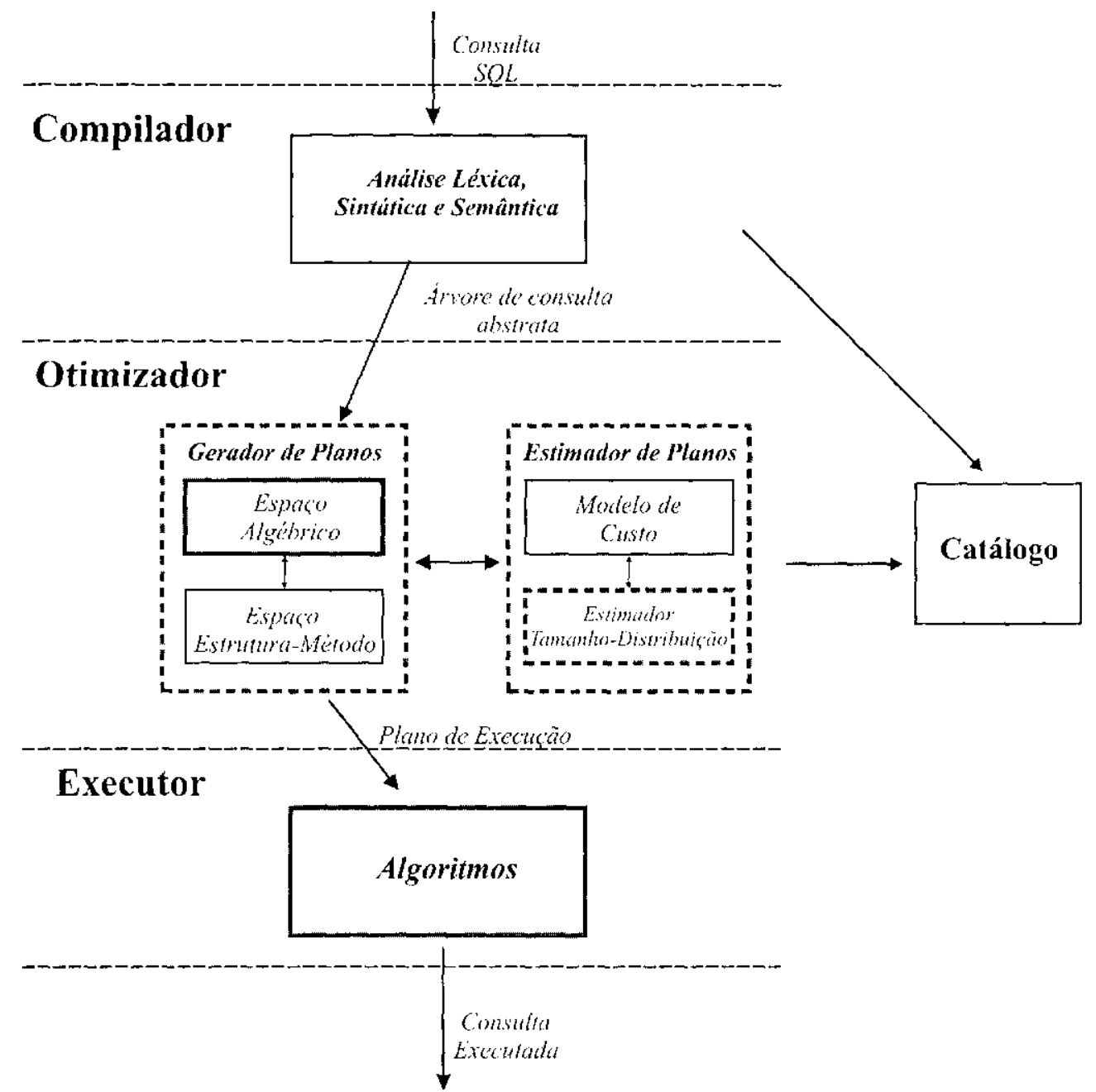

Figura 1.2: Pontos abordidos nesta tese considerando as elapas do processamento de consultas om um gerenciador relacional - Arquitetura. Alguns módulos do Otimizador co Executor, os quais est ĩo destacados na figura por linha comtínua mais grossa (representando um ponto totalmente abordado) e tracejada (representado un ponto parcialnente abordado), săo o foco deste trabalho.

Portanto, a nucta ó fornecer regras algébricas para direcionar o otimizador de consultas de um gerenciador relacional a processar consultas por similarirlande complexas, possibilitando-o escolher planos de consulta eficientes que possann ser exerutados por um ('onjunto de poucos algoritmos de busca jor similaridade. Além disso, o modelo de scleti-

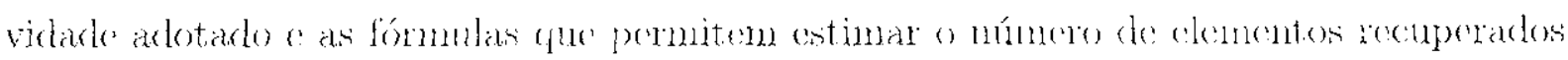
pelos algoritmos visam a auxiliar o processo de otinizasgo de consultas por similaridade complexas. A Figura 1.2 destaca na arguitedura do processador de consultas de unn gerenciador relacional os módulos que são abordados por csta tese. Entre as etapas do processamento de consultas apresentadas na figura, este trabalho se concentra no Executor : nos módulus Espaço Algébrico "Estimador Tamanho-Distribuição dı Otimizador do consultas.

As soluçocs apresentadas para os assumos tratakdos nesta tese consideram cule as consultas por similaridade estádo enu espacos métricos, ou seja, existem apenas os elomentos 
de um conjuntos de chados e a função de distância métrica ${ }^{3}$ usadla para obter a similaridade custre elest

\subsection{Principais Contribuições}

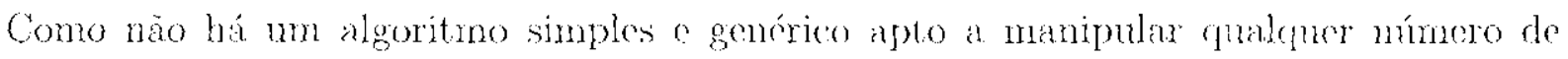
predicados cm una consult a por similaridade complexa, este trabatho contribui estendenclo a álgebra relaxional o determinando um comjunto de algoritmos que podem ser combinados para responder a qualquer consulta por similaridade complexa. A extensino

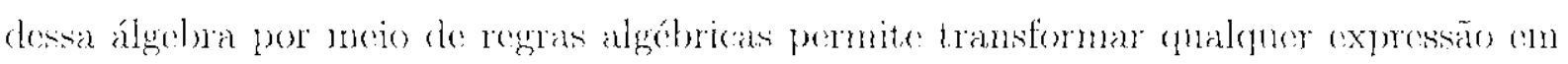
uma forma adecpuadia para ser submetida aos algoritmos descnvolvjos. Essas regras e algoritmos também levan en consideração que otimizacoues possam ser realizadas por un gerenciador relacional para derivar bons planos de execuça do consultaks.

Além disso, a escolha de un modelo de seletividade o a formalizingio de um conjunto de regras para estinitr a quantidade de objotos a ser recuperada pelos operadores

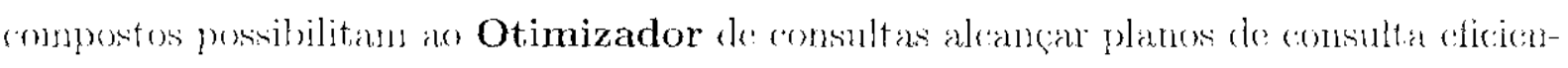
tes, constituindo assimn uma outra contribuiçăo deste trabalho.

Para validar os conceitos apresentados aqui, foran realizades diversos experinent-

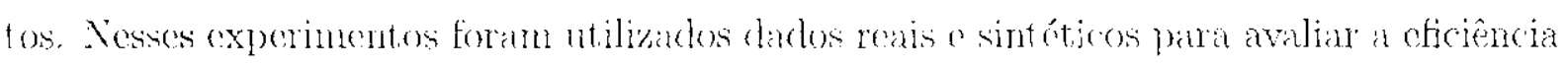
dos algorituos desenvolvidos e as fómulas de estimativas de scletividade propostas para consultas por similaridade complexas usando o modelo de seletividade adotado. Os al. goritmos desenvolvidos e os algoritmos para responder consultas Re a hN chamados de algoritmos básicos, cstão implementabos en una lista sceqüencial e na estrutura de:

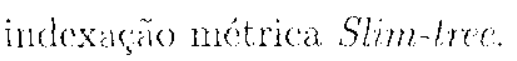

A ahordagem propesta mesta 1ese, não apenas possibilita dar o suporte necessírio a consult as por similaridade complexas em gerenciadores relacionais, nas tamben fornece um modo eficiente para exceutá-las, obtemelo vantagem das técnicns de otimizaläa gue um processaddor de consultas baseado en similaridade possa fazer.

Portanto, do mancira resmmira, as principais contribucicoes desta tese são:

- a definição de regras algébricas seguindo a álgobra rolarionil para combultas por similaridate:

- a claboracão de algoritmos para responder a consultas por similaricliade complexas;

- a formalizacio do estimativas de seletividade para consultas por similaridade romplexas segunclo o modelo de seletividade adotiado.

${ }_{3}^{3}$ Espaços mét ricos siño formahmento apresentatos no Capítulo 3 


\subsection{Organização do Trabalho}

Esta trese de doutorado apresenta a seguinte organizarãa:

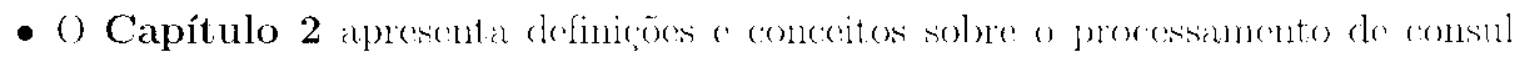
tas con gerenciadores relacionais, sendo discutidess em mais detalhes as 3 principais ctapas desse processamento;

- O Capítulo 3 formaliza os dois tipos mais comme de combultas por similaridade consulta por alnrangência e aos k-vizinhos mais próximos. Em scguida, săo apresentadas as definiçôes de espaço métrico e algumas funçoes de distancia métricas. Além disso, são discutidos alyuns aspectos relacionaclos a estimativan de seletividade para (ssas consultas e os algoritmos para implementátas;

- O Capítulo 4 apresenta as regras algébricas seguindo a álgebra relacional para (onsultas por similaridade complexas o um pequeno conjunto de algoritmos apto a respondê-las:

- () Capítulo 5 define fómulas para estimativa de seletividade em consultas por similaridado complexas:

- O Capítulo 6 apresenta os resultados experimentais obtidos para: os algoritmos apresentados no Capítulo 4 comparando-os com os algoritmos básicos já existentes: cas estimativas de seletividade propestats no Capítulo ij.

- O Capítulo 7 encerra esta tese de doutorado, apresentando as consideraçöes finais, as principais contrilunçoes e as propostas para trabalhos futuros

Esta tese possui ainda 2 apêndices que trazem informaçoes complementares para auxiliar no entendimento deste trabalho:

- O Apêndice A apresenta o Mérolo de Acesso Métrico Shim-tret, usado na realização dess experimentos do Capítulo G.

- Por fim, o Apendice B ilustra o uso da desigualdade triangular no descarto (poda) de objetus e subírvores on árvores métricas. 


\section{Processamento de Consultas}

\subsection{Introdução}

manoira uswal de representar operagoes para se armazenar o recuperar dados em Sistemas de Gerenciamento de Bases de Dados (SGBDs). on simplesmente gerenciador, é por meio de una linguagem. Linguagens de baixo nível em SCBBDs legados [Taylor \& Frank, 1976 ] obrigavam o usudrio a cscolleer a estratégia para processar uma consulta no SGBD. Isto significava ao llsuário exprestar. não aponas quais inlomagoes ele desejava, mas tanbem como isso deveria ser executade. Portanto, para uma deteminada consulta, o núário precisava decidir quais operaçoes do baixo nível serian necessárias para obter o resultado desejado e também em que ordem das deviam sel exocutadas. Por possuir mma representação semântica mais baixa, essas linguagens podem ser dassificadas como linguagens de baixo nível. onde ma "otimização" deveria sce levila pelo próprio deslário.

As linglatgens dos gerenciadores relacionais possuem un nível semântico mais alto.

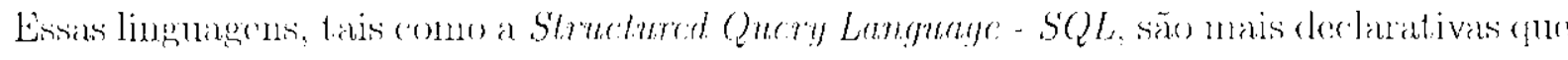
slas predecessoras, pois nelas o usuário declara o que ele quer, e o gerenciador decido como isso pode ser realizado. A característica decharativa de uma linguagem de alto nivel obriga ao próprio sistema (gerenciador) procurar maneiras para obter mm melhor desempenho. Portanto, a otimizacăo de consultas ("automática") ćassunto fundamental

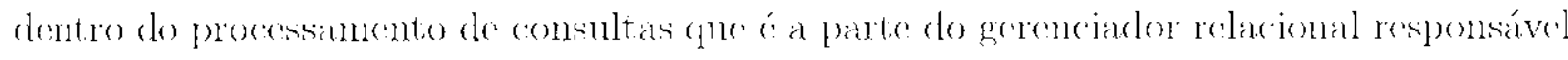
por avaliar como uma detorminada comsulta. expressa em SQL, deve ser executada.

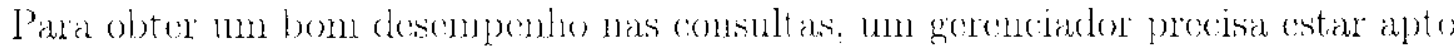
a produrir, antomaticamente, alternativas de execução para uma determinada consulta o escolher a de melhor deserrpenho motro clas. Para efue isso possia ser feito de maneira 
efetiva, o gerenciador utiliza várias inlormaçoos armazenadas em tabelas especiais (metadados), chmadas do catálogo do sistema (ver Figura 1.1), as (quais säo nsadas paral escolher o melhor modo de executar uma consulita.

Comsultas são geralmente compostas por vários operadores (e esses operadores podem ser combinados, permitindo haver diversas maneiras para exceutar cada consulta. ()

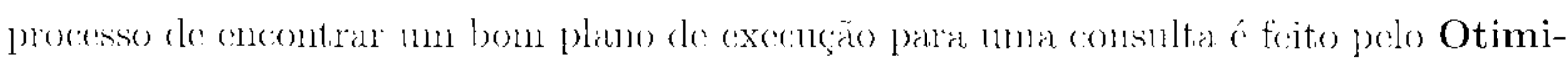
zador de consultas do gerenciador (Figtra 1.1). De maneira bem simples, o otimizador de consultans gera vários planos alternativos em relação ao plano de execuçäo inicial considerando: conhecimento sobre us dados obtidos do catálogo do sistema: propricdades algébricas de cada operador (Seção 2.3); estintalivas de tamanho do resultado de cada operador, usando estimativas de seletividade sobte atributos (Secrão 2.5); cstimativas de custo de execução dos operadores; o os algoritmos presentes no Executor (Secãa 2.6). Após avaliar c decidir qual plano de uma determinada consulta possui o melhor desempenho (menor custo compulacional), ele ó passado ao Executor quo utiliza os algoritmos, já previamente escollidos pelo Otimizador, para responder à consulta.

Portanto, a arcpuitetura (lo processamento de comsultas ke um gerenciador. para responder a uma consulta expressa inicialmente em SQL, porle ser dividida em basicat mente très etapas (camadas) que estáo ilustradlas ua Figura 1.1, sendo elas: Compilador,

Otimizador e Executor. Essas etapas são analisaldas na seçăo scguninte.

\subsection{Etapas do Processamento de Consultas}

A esscencia do que um processador de consultas precisa fazer é um consenso entre os pesquisadores, porén us detalhes de cada camada e os módulos da arquitetura do procensamento de consultas naño são. Por isso, a arquitetura apresentada nesta tese para as

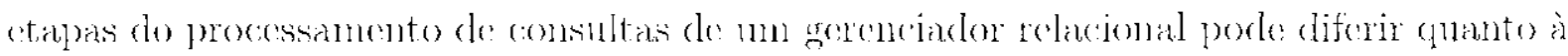
nomenclatura dos módulos e sobre a divisão das camadas, niaks mantém a funcionalidade geral do processo. Note-se que o processador de consultas de um gerenciador poderia ser constrúclo bascedo na aucuitotura apresentada da Figura 1.1, porén em sistemas reais os módulos internos nem sempre têm limites bem definiclos.

Este trabalho considera que há três camadas divididas em módulos internos a a princira das três camadas pela qual passa uma consulta éo Compilador.

\subsubsection{Compilador}

Para que uma consulta expressa inicialmente en $\mathrm{SQl}$ seja considerada válida, o Compilador precisa fazor sua análise léxica, sintática o semantitica. $\Lambda$ análise léxica verifica us tokens (palavras-chave) da linglagem SQL. $\Lambda$ análise sintática usa os tokens gerados no

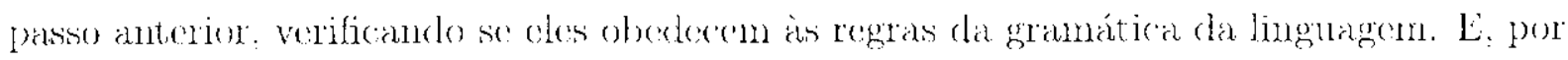
fim, a análise semantica envolve: verificar as relaçôs usadas - cucla rolaçăo mencionada na clánsula FROM deve ser uma relacăo on visä́n no esquena: verificar e definir os alributos 


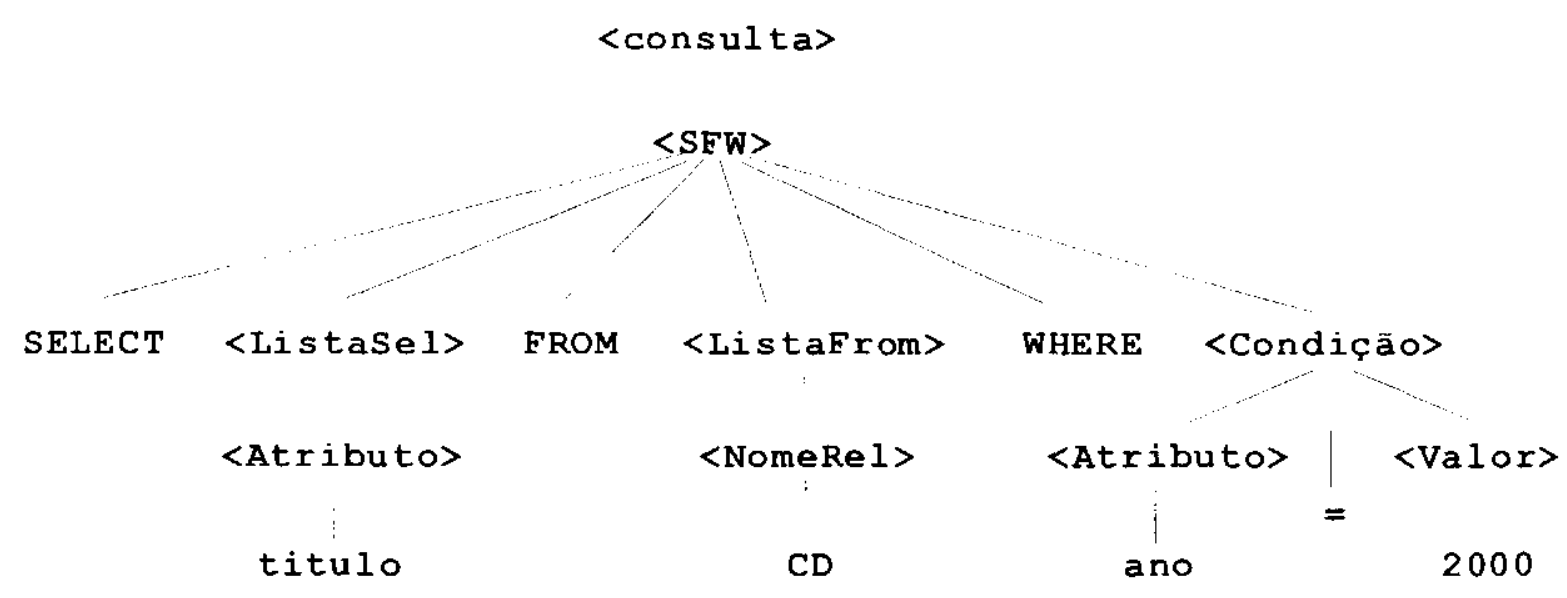

Figura 2.1: Árvore de consulta abstrata gerada a partir da consulta expressa em SQL do Lxemplo 2.1.

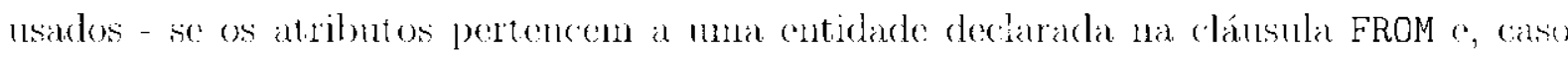
pertençam, definir de qual entidade cles săo; e fazer a verificañono de tipos.

Após o Compilador passar por ésirts análises com exito, a consulta é considerada válida e, como saída, é gerada a árvore de consulta abstrata. Esssár árvore sorrá utilizarla como entrada na fase de otimização para que seja gerada uma expressio canonica em álgebra relacional. geralmente expressa em árvore. representando o plano cle consulta inicial ainda sem sofrer as devidas otimizacónes. () exemplo a seguir ilustra o processo.

Exemplo 2.1 Considere o escuema relacional

$$
\begin{aligned}
& \text { Artista }=\{\text { codigo, nome, estilo, idade }\} \\
& C D=\text { numero, titulo, gravadora, ano, codart }\}
\end{aligned}
$$

onde codart é chave cstrangeira de CD, referindo-se à relagino Artista, a a consulta expressa $\mathrm{cm} \mathrm{SQl}_{\text {a a seguir. }}$

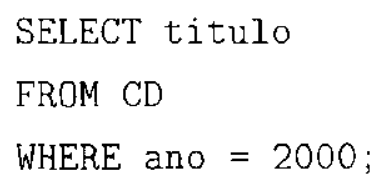

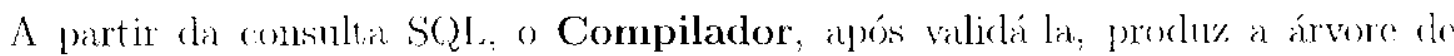
consult a ałstrata representada na. Figura $2.1^{1}$, passando-a à camada scguinte, ou seja, ao Otimizador.

\subsubsection{Otimizador}

O) Otimizador é a camada do processarlor de consultas yue examina as alternativas a

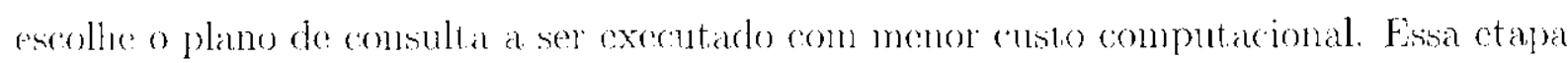

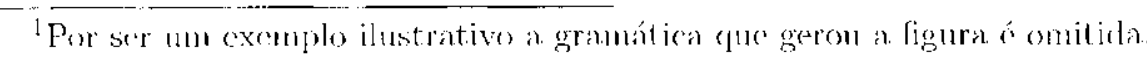




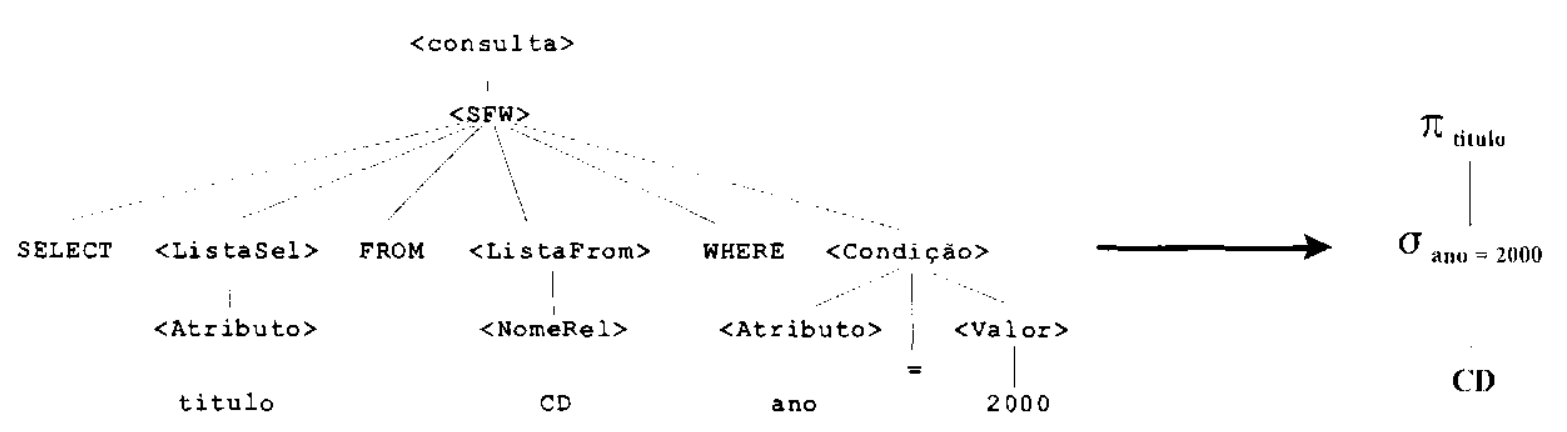

Higura 2.2: Plano de comsulta inicial produziclo a partir da árvore de consulta abstrata do Excmplo 2.1.

pode ser subdividida em: Gerador de Planos e Estimador de Planos.

() móxulu Gerador de Planos inicialmonte transforma a árvore de comsulta abstratia. produzida na etapa anterior (Compilador), (m 1 m plano do consultin inicial, ane 6́ mar representaçäo algébrica da consulta geralmente na forma do árvore. Os nós bolha

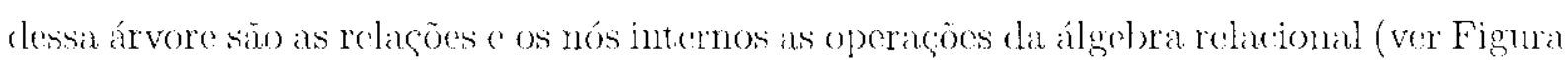
2.2).

Dado o plano de consulta inicial, o Gerador de Planos produz vários planos

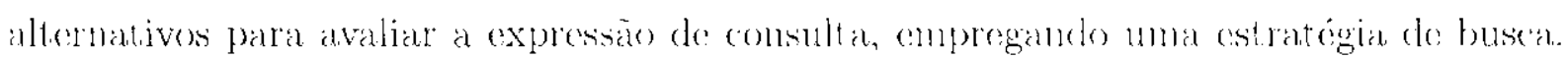
Esisc estratégia explora o espaco de plinos de acesso determinados pelo Espaço Algébrico e Espaço Estrutura-Método, considomado um subconjuntos de todos os planos possiveis, pois o número de planos possíveis pode ser muto grande.

\section{Espaço Algébrico}

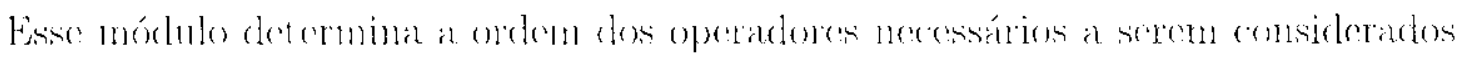
pelo Gerador de Planos para executar una consulta possibilitando a geracäo de planos do consulta equivalentes para cada operador segundo a álgebra rolacional. Fan uma ce-

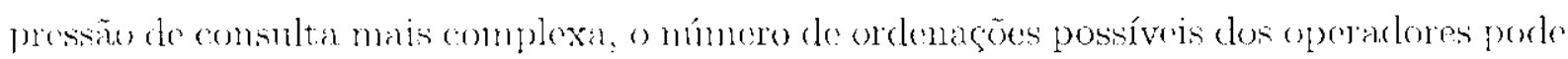
ser enorme. Para redurir o tamanho do espaco cue a estratégia de busca deve explorar,

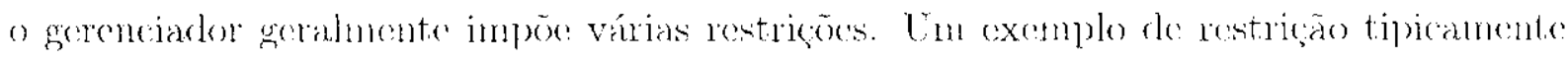
usida pelo gerenciador é muncra gerar produtos cartesianos desnecessírios.

\section{Espaço Estrutura-Método}

Esse módulo cletermina as escolhas do implementação cue existenn para a execuçär de carda operador expecificado pelo Espaço Algébrico. Essas escolhas estäo rolaciomadas,

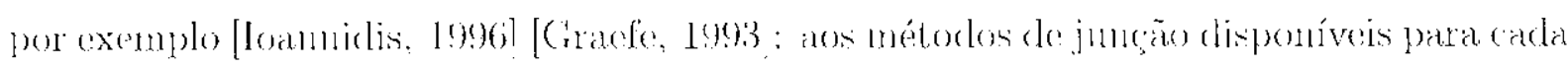
junçào - junção de loop aninhado, merge e hash: se/crando duplicatus são clininadas e as características de implementação deteminadas pelo gerenciador; os índices disponíveis partat acessar caclia relação, entre untros.

Dado um plano do consulta an árvore pelo Espaço Algébrico, esse módulo pro- 
duz todes os plauos de acesso correspondentes os quais especificam at implementaçäo de

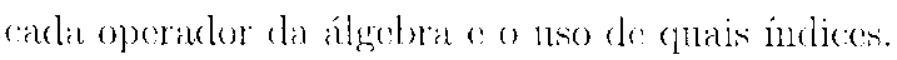

Dessá mancira, ó planos altcrnativos gerados são comparados polo Gerador de Planos baseados nas estimativas de seus c'nstos obtidas do módulo Estimador de Planos, sondo escolhido para ser excutado aquele que obteve o menor custo computacional.

() Estimador de Planos usa as informacócs obtidas do catáloge de sistema, com () oljetivo do fornecer suporte aus móxhlus Modelo de Custo o Estimador TamanhoDistribuição para a avaliação de un determinado plano (vor Figura 1.1).

\section{Modelo de Custo}

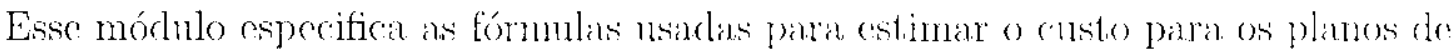
acesso que são passados pelo Gerador de Planos. Para cada método de junção diferente. estrutura de indice diferente existente, o $\mathrm{cm}$ geral para cada tipo distinto do operador cneontrado no plano de acesso, conforme descrito pelo Espaço Estrutura-Método, há

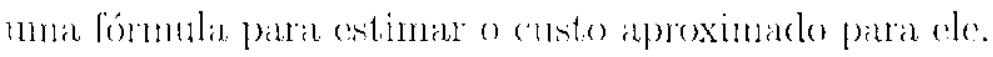

\section{Fstimador Tamanlo-Distribuição}

Esse módulo estima os tamanhos de resultades intermediários de caula operador no

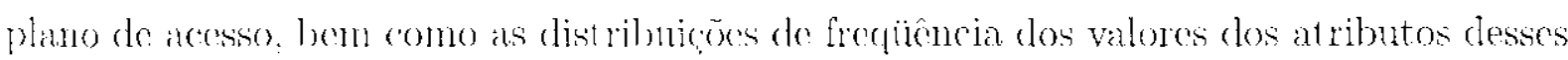
resultarlos. Essas estimativas são usadas pelo mórlulo Modelo de Custo.

Várias técnicas tên sido propostas na literatura para estimar o ta-

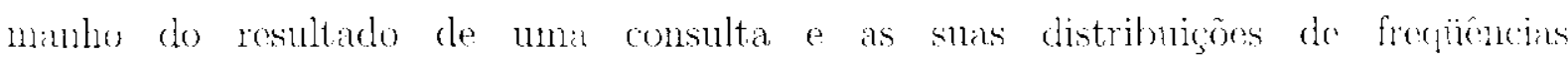
[Sclinger ot al., 1979), [Mannino et al., 19886] como, por exemplo, usando amostragem dos dados [Lipton \& Nanght,on. 19901)]. Entretanto, na maioria dos gerenciadores relacionais comerciais suas estinativas hão baseadas em histogramas [Ioanniclis, 2003]. O 11 so de histogramas en estimativas ó discutick em majores detalhes na Seçäo 2.5 .

\subsubsection{Executor}

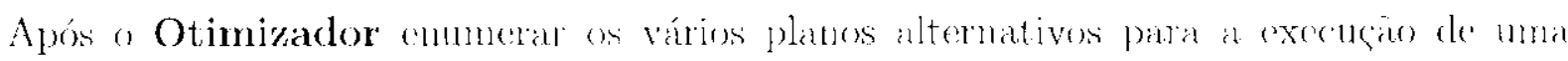
consulta, estimande o custo (le (adia plinno (escolhendo (nntre eles o de mais baixo custo computacional, o plano de execurián é enviado ao Executor.

Esssa camada contén as várias inplementaçoes dos algorit.nos de cada operador

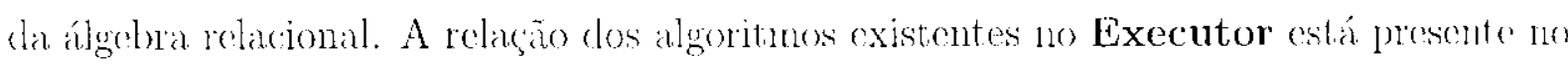
módulo Espaço Estrutura-Método, permitindo a essé móxdulo gerar os vários planos de acesso para uma determinada consulth. Portanto, quando o plano de excengão para mina

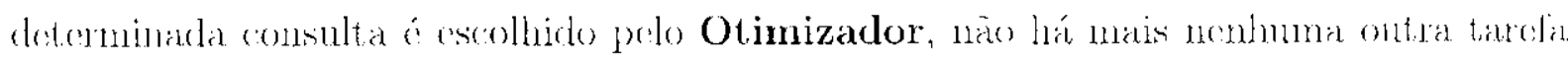
a ser feita pelo Executor, além de executar o plano ciscolhido, produrindo a resposta fara a consulta inic ialmente expressa om SQL. Os algoritnos presentes no Executor são 
discutidos om mais detalhes na Seçăo 2.6 .

Ifá uma extensa bibliografia relacionada a contexto de processamento re comsultals em gerenciadores relacionais. Levantamentos sobre execuçäo o otimizacão de comsultass são oncontrados nos trabalhos de 'Graefe, 1993] o [Jarke \& Korh, 1984] respectivamente. Uma visăo geral sobre otimização de consultas SQL en gerenciadores relacionais pode screncontrada en [Chandhuri, 1998?. Este capítulo considera principalmente os asjectos levantados por csses trahalhos.

Portanto, devido à extennão deste assunto, as seçöes seguintes se restringem a discutir apenas os tópicos de processamento do consultas que são abordados por esta tese, como por exemplo, leis algébricas utilizadas pelo unódulo Espaço Algébrico do obimizarlor de comsultas apresentindo as seguir.

\subsection{Leis Algébricas}

As leis algébricas são utilizadas para transformar um plano de comsulta inicial en planos altemativos cepuivalente's nsando o módulo Espaço Algébrico do Otimizador. As lois algébricas mis comms utilizadas para simplificar expressóes säo as leis (propricdades on postulados) oriundas da álgebra Boolenun [Jarke \& Koch. 1981]. [Garcia-M Lolina ct al., 2000].

Lima álgebra Booleana $B=:[A, \wedge, \vee, \neg, O, I]$ é um conjunto $A$ com duas operacoes binárias $(\wedge . \vee)$, dois limites universais $(O, I)$ o uma operação mária $(-)$ tal que para todo $x, y, z \in A$, os seguintes postulados (axionas) são atendidos [Birkhoff \& Bartee, 1970?:

B) Comutativa:
(a) $x \wedge y-y \wedge x$
(b) $x \vee y=y \vee x$

$B \cdot 2$ Associativa:
(a) $(x \wedge y) \wedge z: x \wedge(y \wedge z)$
(b) $(x \vee y) \vee z=x \vee(y \vee z)$

$B_{3}$ Distributiva:

(a) $x \wedge(y \vee z)=(x \wedge y) \vee(x \wedge z)$
(b) $x \vee(y \wedge z)=(x \vee y) \wedge(x \vee z)$

$B_{\uparrow}$ Identidade/Limites Universais
(a) $x \wedge I=x$
$x \wedge O=0$
(b) $x \vee O=x$
$x \vee I=I$

$B_{i}$ Complemento:

(a) $x \wedge \neg x=()$

(b) $x \vee \neg x=I$ 


\section{$B_{6}$ Absorção:}

$$
\begin{aligned}
& \text { (a) } x \wedge(x \vee y)=x \\
& \text { (b) } x \vee(x \wedge y)=x
\end{aligned}
$$

Um sistema algébrico constitui uma álgebra Booleana se, e somente se cle tem clois

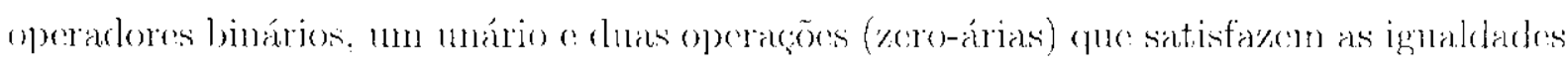
especificadas nos postulados $B_{1}$ a $B_{6}{ }^{2}{ }^{2}$ Birkhoff \& Bartec, 1970].

Um exemplo de álgebra Booleana é o conjunto potência de qualquer inteiro positivo $n$, ou seja todos os subconjuntos do conjunto $n=\{1, \ldots, n\}$. Assinn, dacto o conjunto potência de $n P(n), B^{n \prime}=[P(n), \cap, \cup,-, \emptyset, n]$ constitui una álgebra Bosleana, onde $\wedge$. $\vee c \neg$ são, respectivamente, o conjunto intersesão, união e complemento, com $O$ como o comjunto vario $\emptyset$ e com $I=n$.

Portanto, dado que un conjunto satisfaz os postulados apresentados sobre dois operadores binários, um unário e dois zero-ários cle juntamente com sous operadores formam uma álgebra Booleana sem importar se scus elementos representam conjuntos, proposi̧̧öes lógicas: ou descriçöes matemáticas de hardware cletrônico [Birkhoff \& Bartee, 1970), [Lipschutz, 1964]. Desde que conjuntos e proposições são exemplos clássicos do álgebra I3ooleana muitos textos denotam as operagoes da álgebra Booleana por $\vee \in \wedge$ ou por $\rfloor$ o r. Fiste traballo também segue a mesma equivalencia de representação.

A álgehra relacional ó uma coleção de operadores sobre relaçócs, e desde que relaçoes säo conjuntos, é possível aplicar us operadores de conjuntos sobre das Codd, 1970). Assinn, a álgebra relaxional o dividida cm chats classes [Jarke \& Koch 1984: operadores sobre conjuntos tradicionais, tais como, produto cartesiano, uniăo, interseçäo e diferenca; e operadores da álgebra relacional especiaie, tais como, projeção, junção, divisão e seleção.

Entre as keis da álgchra Booleana, as mais utilizadas para simplificar expressões da álgebra relacional sào [Jarko \& Koch. 1984, Garcia-Molina ot al., 2000]: a connutatival o a associativil. A lei Comutativa para um operaclor significa que, independente da ordem

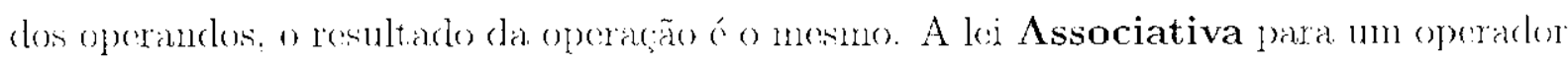
informa que é possível agrupar sens operandos aos pares pela esquerda ou pela direita obtchdo o mesmo resultado. Se um operador ć associativo e conutativo qualquer número do operandos ligados por ele pode ser agrupado e ordenado da maneira cono se descija.

Vários operadores da álgebra rolacional são comutativos e associativos, tais como [Garcia-11olina et al., 2000]: o produto cartesiano, a junçăo, a uniào, a interseção o a

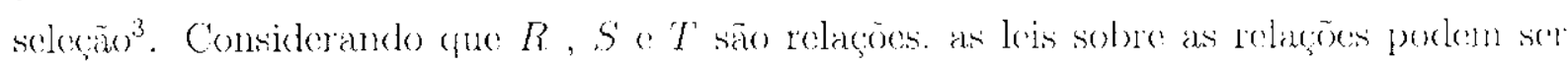
exemplificadas conformo a seguir:

${ }^{2}$ Existem de\% postulados on axionas subre a álgobra Booleana [Birkhoff \&. Barteee, 1970]. Entretanto, apenas seis pustulados são apresentades nesta tesc uma vez que os outros quatro sào conseciüencias deles.

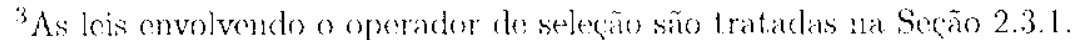


1) Produto Cartesiano: $R \times S=S \times R$ :

$$
(R \times S) \times T=R \times(S \times T) \text { : }
$$

2) Junção: $R \bowtie S=S \bowtie R$;

$(h \bowtie S) \bowtie T-R \bowtie(S \bowtie T) ;$

3) União: $R \cup S \quad S \in R$

$(R \cup S) \cup T=R \cup(S(T)$

4) Interseção: $\left.R \cap S^{\prime} \cdots S ? l\right\}$ :

$$
(R \cap S) \cap T=R \cap(S \cap T) \text { : }
$$

Como o objetivo desta tese 6 incorporar consultas por sinilaridade complexas

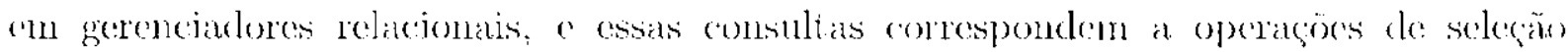

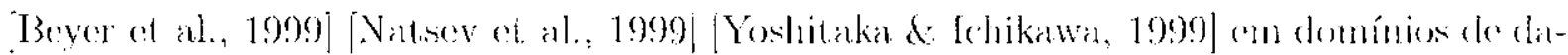
dos complexos. apenas as leis envolvendo o operador de seleça da álgebra ralacional são discutidas.

\subsubsection{Leis envolvendo Seleção}

Seleçoes sào operaçoes importantes para a otimizaça de consultas, nuna vez que olan

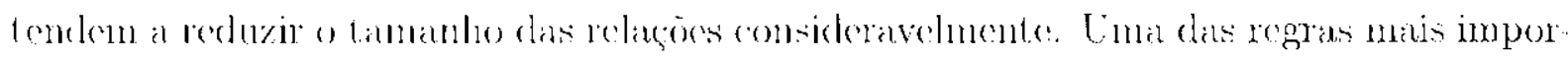

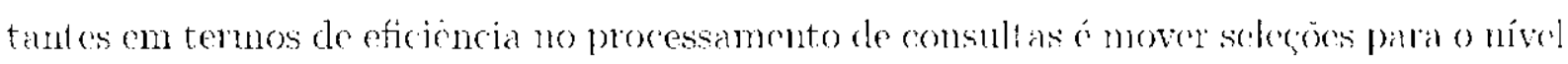
matis baixo possível na árvore de consulta Wong \& Youssefi. 1976). Os otimizadores do

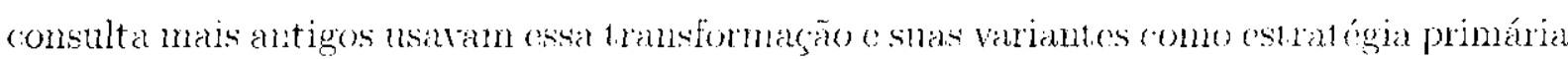
bara seleciontr bons planos cle comsulta [Solinger et al. 1979]. No ontanto, mulas veres

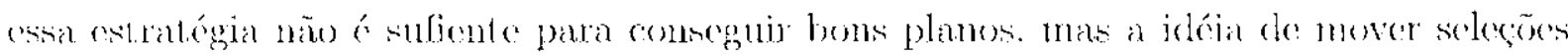
para baixo na arvore ainda é uma das principadis ferramentas utilizadas pelo otinizador de comsulta.

Conherendo as lais algébricas, as quais estro presentes no módulo Espaço Al-

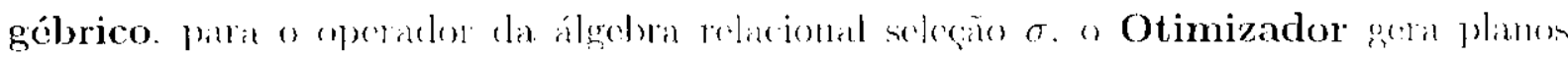

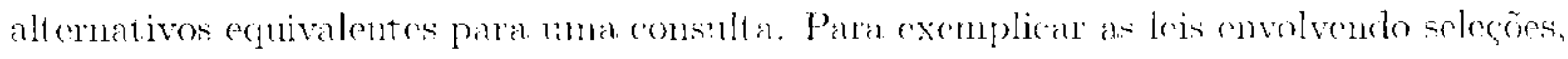

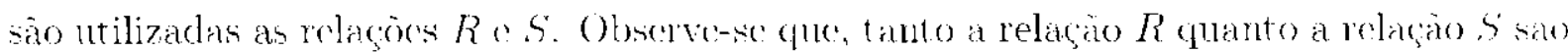

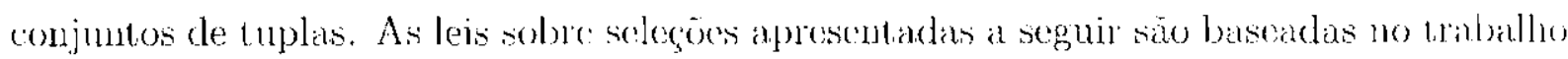
de: Gearcia-Molina et al., 2000).

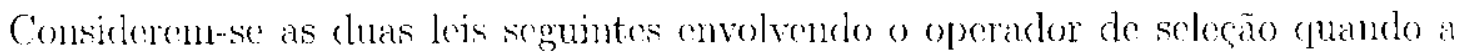

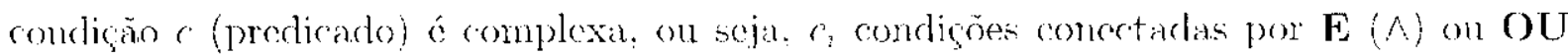
(V): 


$$
\begin{aligned}
& \sigma_{c_{1} \wedge r_{2}}(R)=\sigma_{c_{1}}\left(\sigma_{c_{2}}(R)\right)=\sigma_{c_{1}}(R) \cap \sigma_{c_{2}}(R) ; \\
& \sigma_{c \vee c_{2}}(R)=\sigma_{c_{1}}(R) \cup \sigma_{c_{2}}(R) .
\end{aligned}
$$

Desmembrando a condiçâ complexa o cho suas partes constituintes tom-se quo uma parte, chvolvendo monos atributos que a condição inteira, pode ser movida para um local adeculado no plano de consulta, tomando-o mais eficiente

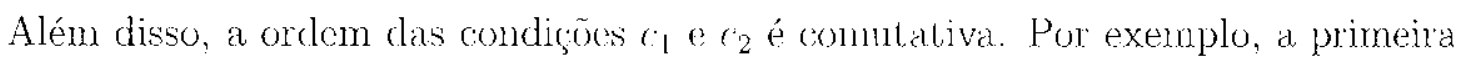
loi (Lei 2.1) poderia tere a condição a aplicada a pós c. como:

$$
\sigma_{c_{1} \wedge c_{2}}(R)=\sigma_{c_{1}}\left(\sigma_{c_{2}}(R)\right) \cdots \sigma_{c_{2}}\left(\sigma_{c_{1}}(R)\right)
$$

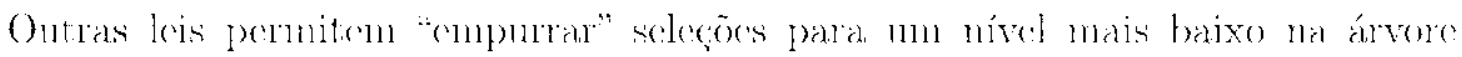
os quais envolvem operadores binários, tais como: produto cartesiano, junçäo, união e interseção. Éssas leis associam a seleçäo para cada un dos argumentos ou näo, onde o argumento corresponde ì relação ( $R$ ou $S$ ). Por exemplo:

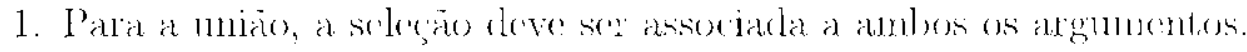

$$
\left.\sigma_{t}(R\lrcorner S\right)-\sigma_{r:}(R) \cup \sigma_{c}(S)
$$

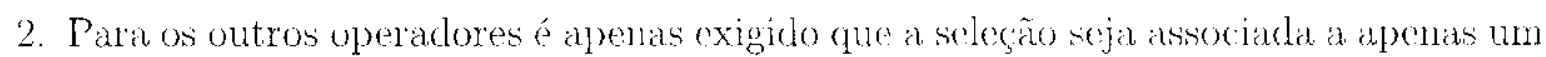
argune-nto. Para junçóces e produto cartesiann, por exemplo, pode năo fazer senticlo

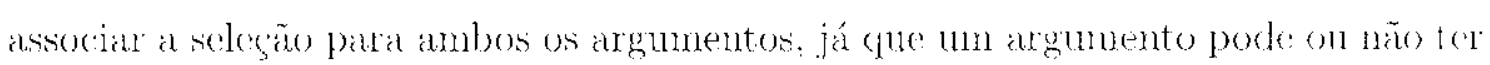
os atributos que a seleçào exige.

Exemplificands o item 2 para os operadores produto cartesiano, junçüo o intersecão. Se a seleção $6 \sigma_{t}$, cutão ó possível associar a seleção para a relação que possui todos os atributos mencionados en e Considere-se que apenas a relaçäo $R$ possui todos os atributos mencionados on a Assim, tem-se flue:

$$
\begin{aligned}
& \sigma_{c}(R \times S)=\sigma_{c}(R) \times S ; \\
& \sigma_{c}(R \bowtie S)=\sigma_{c}(R) \bowtie S ; \\
& \sigma_{r}(R \cap S)=\sigma_{c}(R) \cap S .
\end{aligned}
$$

Se c tem apenas atributos do $S$, então pode-se escrever:

$$
\begin{aligned}
& \sigma_{c}(R \times S)=R \times \sigma_{c}(S) \\
& \sigma_{c}(R \ltimes S)=R \rtimes \sigma_{c}(S) \\
& \sigma_{r}(R \cap S)=R \cap \sigma_{c}(S) .
\end{aligned}
$$


E, se e possui atributos de $R$ e $S$, onde a condição som temenas atributos de $R$ $\therefore c_{2}$ tem apemas atrilutes de $S, c e=c_{1} \cup c_{2}$, ent a $(s)$ :

$$
\begin{aligned}
& \sigma_{c}(R \times S)=\sigma_{c_{1}}(R) \times \sigma_{c_{2}}(S) ; \\
& \sigma_{c}(R \bowtie S)=\sigma_{c_{1}}(R) \bowtie \sigma_{c_{2}}(S) ; \\
& \sigma_{c}(R \frown S)=\sigma_{c_{1}}(R) \cap \sigma_{c_{2}}(S) .
\end{aligned}
$$

Empregando as leis algébricas para selecão, numesentadias até aqui, o Otimizador poderia gerar vários planos de consulta cquivalentes ao plano de consulta inicial. Em gacral há muitos planos de consulta diferentes em álgebra relacional e. conseciucentemonte, muitas árvores de consulta que podem ser equivalentes, isto f. comespondem à mesma consulta. O Otimizador, por meio do módulo Espaço Algébrico, posstri as

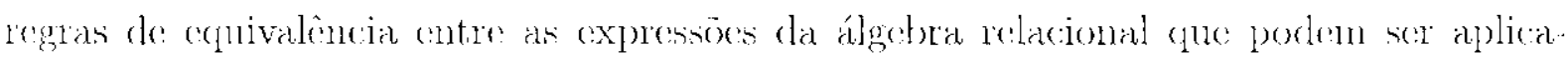
das à árvore de consulta inicial. Para aplicar essas regras de equivalencia e rescrever o plano de consulta inicial em planos cquivalentes, o Otimizador usa algumas heurísticas (leis). Há várias heurísticas que tendem a melhorar os planos de consulta. As seguintes: convolvendo o operator de seleção, são as mais conumente utilizadas em otimiza-

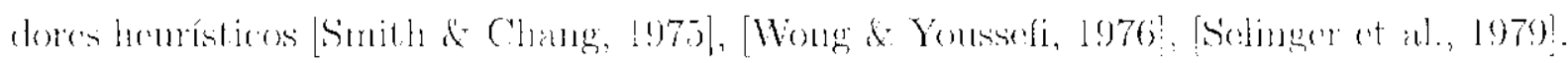
[Garcia-Molina et al., 20(0)]:

- Seleçoes poden ser movidas para níveis inferiores (baixo) na árvore de expressócs o máximo possível. Se a condição de seleção é o $\mathrm{E}(\Lambda)$ de várias condiçócs, então é possível dividir a condição e mover cada uma para baixo la árvoro separadamente.

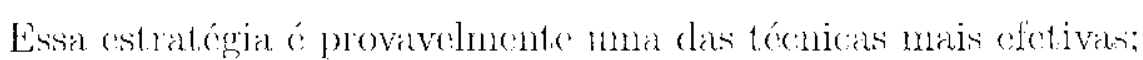

- Certas selecóes podem ser combinadas com um produto cartesiano para transfomar o par de operaçoos con uma junçăo, que geralmente é mais eficiente que as duas operaçoes executadas separadanente.

Para ilustrar cono essas leis poolem ser usadas para molhorar um plano de consulta inicial considere-se o exemplo as seguri

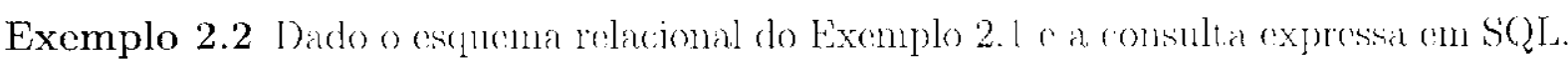
SELECT nome, titulo

FROM Artista, CD

WHERE ano $=2000$ and estilo = 'clássico' and codigo = codart;

Um plano de consult a inicial expresso na forma de árvore poderia ser o apresentado na Figura 2.3.

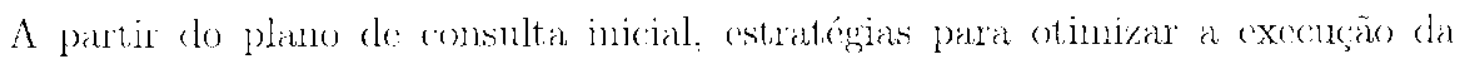
consulta usando leis algébricas para selegão poden ser aplicadas, gerando un plano de consulta alternativo. Considerando o Excmplo 2.2, a figura 2.4 ilustra um plano do 


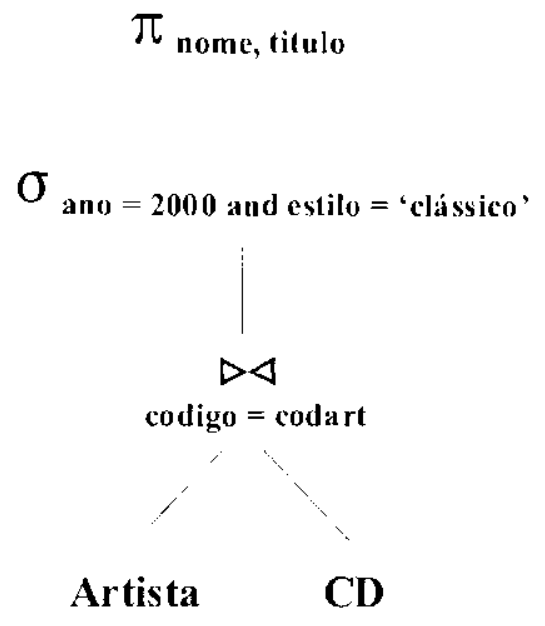

Figura 2.3: Plano de consulta inicial expresso na forma de árvore para a consulta SQL do Exemplo 2.2

consultid alteruativo ao plano inicial, o cual usou a heurístiea de mover seleçón para baixo no plano de consulta inicial an árvore.

(a)

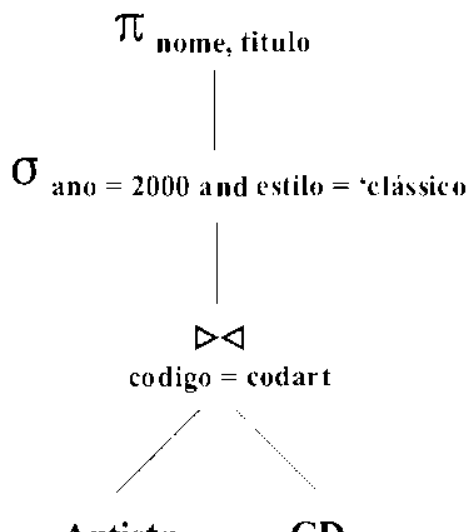

(b)

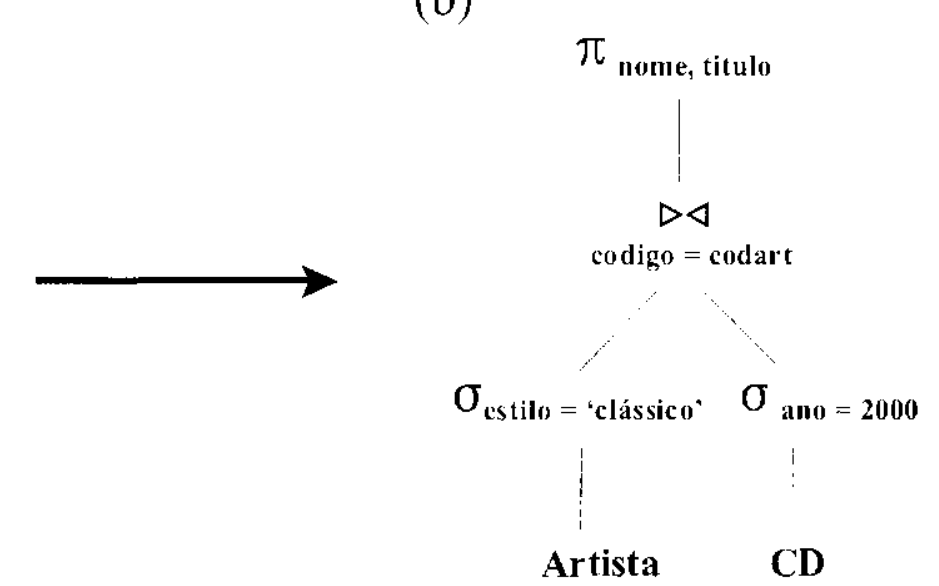

Figura 2.4: Plano de consulta alternativo movendo selecós para baixo na árvore de consulta. (a) plano ste consulta inicial; (b) plano de consultia aldomativo cmpurmando seleçoos para um nível inferior na árvore de consulta.

Para gerar o plano de consulta alternativo da Figura 2.4, o Otimizador utiliza a

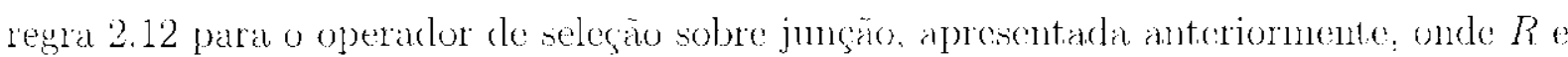

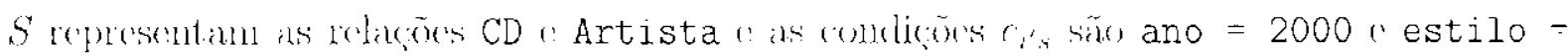
'clássico'.

Aplicando regras como as utilizadas nesse plano cle consulta alternativo, o Otimizador tenta cncontrar planos do consulta com menor custo computacional.

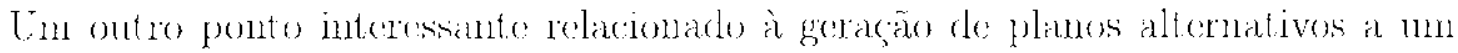

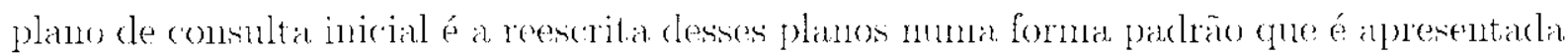
na secano sconinte. 


\subsection{Formas Normais}

Xo Exemplo 2.1, ilustrado pela Fignra 2.2. tem-se a condleäo de seleçäo (predicado) na forma alr op valor $(R)$, onde atr é un atributo da relaça $R$, por excmplo, valor corresponde a um valor válido dentro do domínio de valores possíveis para o atributo atr como. por exemplo. o domúnio de $R$, e op é un operador de comparaçáo válido no domínio do atributo envolvido como, por exemplo, on operadores $<\leq,>, \geq:=0 \neq$.

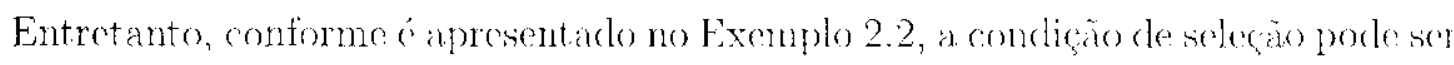
mais complexa. Na verdade, na maioria dos casos a condição de seleção é mais complexa, correspondendo a uma combinação Booleana, isto é, una cxpressão nsando os conectivos lógicos $\wedge$ e $\vee$ de min-termos. Esses min-termos tên a forma alt op conslante ou atr op atr.

Para processar mua opcraça de seleçào con uma condiçäo de seleção complexa. ć preciso expressar a condição na Forma Normal Disjuntiva (DNF) ou na Forma Normal Conjuntiva (CNF) para que cla possa ser exceutada [Jarke d Koch, 1984]. A

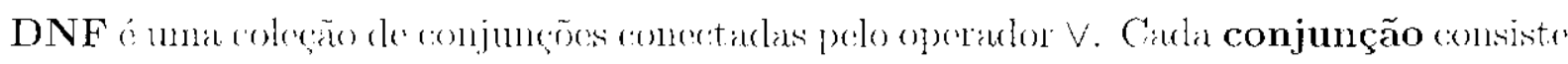
de unn ou mais min-termos complementados $(\neg)$ ou não e conectados pelo operalor $A$. A CNF é represcontada de mancina análoga à DNF. Assim, a CNF é uma coleção de disjuncoes conectadus pelo operador $\wedge$. Cada disjungāo consiste de um on mais min-

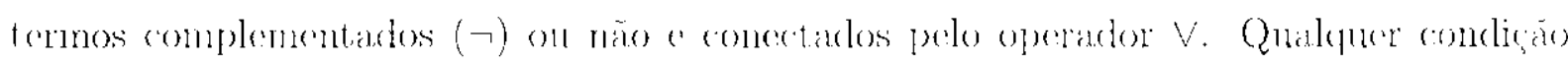

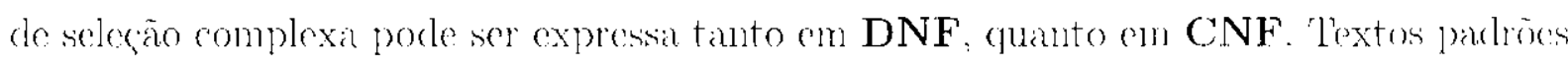
de lógica matemática. como por exemplo [Lipschutz, 1964] e [Birkhoff \& Bartec, 1970], travern maiores detalles sobre o assunto.

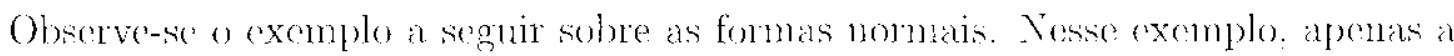
DNF é rutilizada a título de ilustracaio.

Exemplo 2.3 Considere-se a seguinte consulta expressa em SQL o o escuema relacional (to) Exemplo 2.1

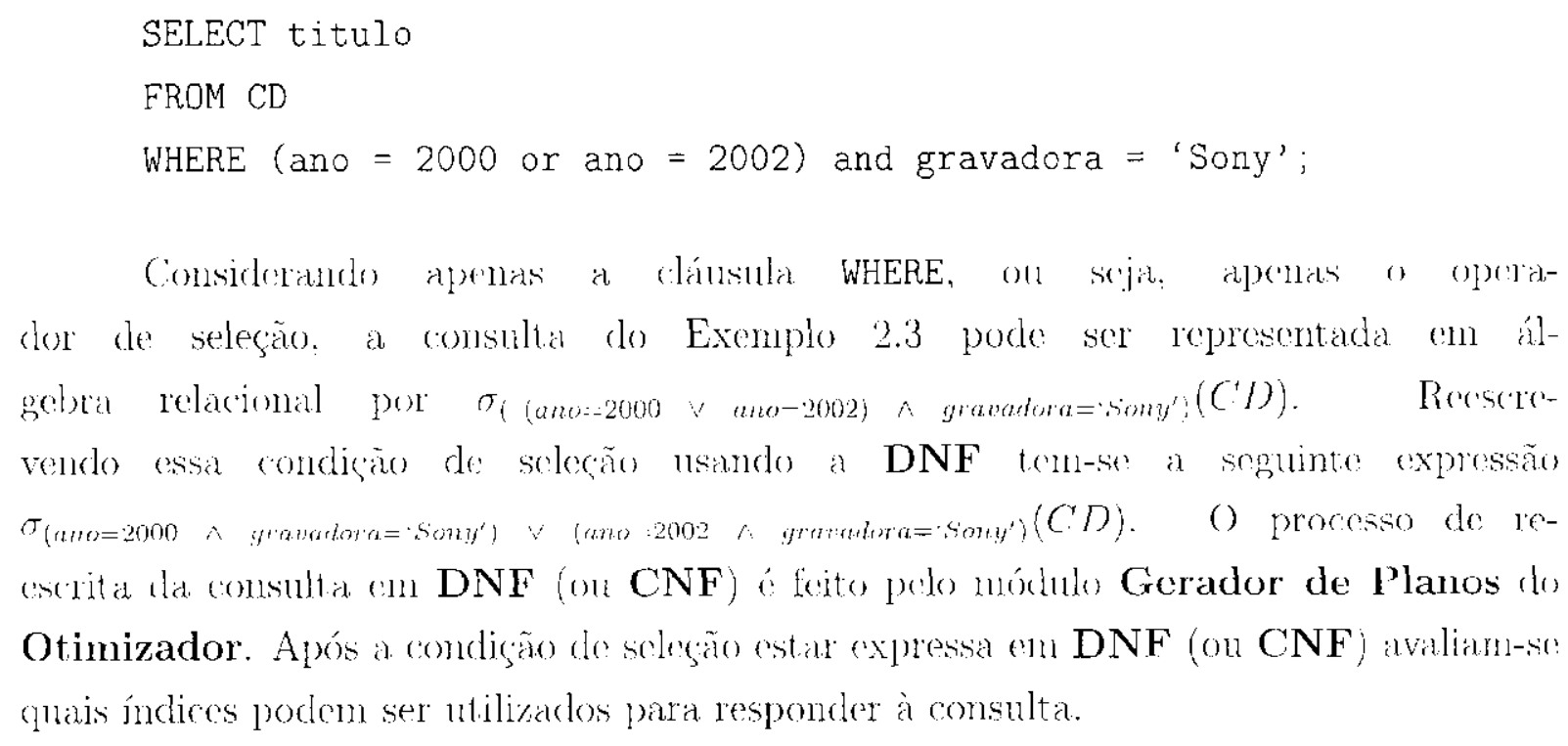


Muitos trabalhos na literatura tratan de otimizaçoes de consulta cnvolvendo ex-

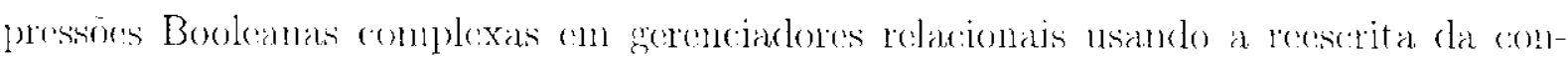

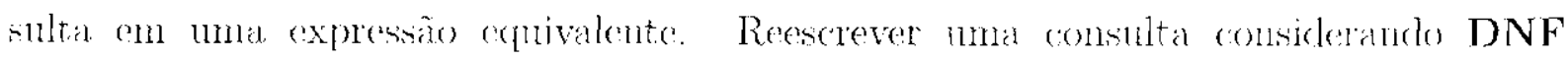
Chuct \& Delobel, 1992] [Dayal, 1987] ou CNF [Selinger et al., 1979] usanto un indice por expressão é uma técnica bem conherida. Os trabalhos de [Mohan et al. 19900] e [Leslie et al. 1995] exploran núltiplos índices por expressä́o. Em Lésie et al.

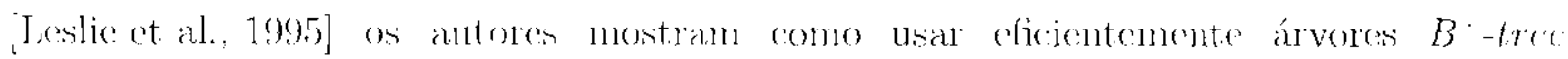
[Kunth, 19988] (quando alguns campos da chave não estâo presentes na consulta. Esso é um dos poucos trabalhos a explorar a otimização de disjunçäo (OU) entre os prediicados, dado cue a maioria se concentra em otimizar conjunçós (E) devido à sta maior restritiviclade

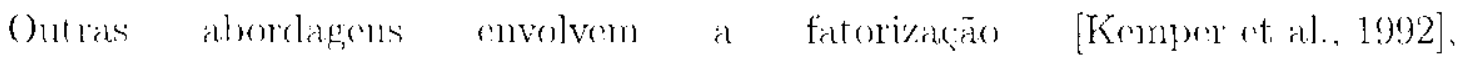
[Chaudhuri et al.. 2003] e otimizan predicados definidos pelo usuário considerando seletividade e custo para expressooes com vírios Es [Ifellerstein \& Stonebraker, 1993]. [Chandhuri \& Shim. 1999], [Srheufele \& Mocrkotte 1998] \& com virios OUs [Komper et al., 1994.: Chaudhuri \& Grawano, 1996]. As téchicas propostas pela abordagen de (Chaudhuri \& Cravano, 1996 tentam reduzir o custo total do avaliar a expressão determinando uma ordem para avaliar os predicados definidos pelo usuário, levande en consideracano a seletividade dos predicados o estimando os sene custos.

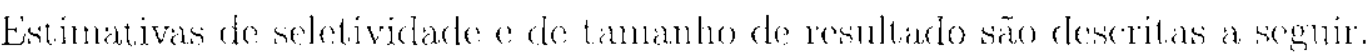

\subsection{Estimando o Tamanho do Resultado}

() Estimador de Planos raleula o custo para cada plano de comsulta produrido pelo Gerador de Planos. Tendo conhecinento desses custos, o Otimizador compara-os o escolhe o de melhor descmpenho (monor custo computacional) para sor cxecutado. Estimar o custo de execucia total de um plano de consulta envolve, de mancira garal, us

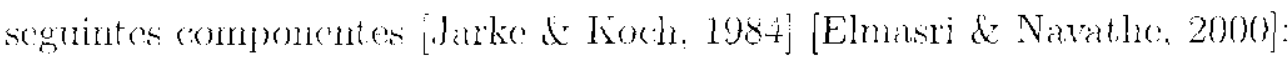

- Custo de acesso a memória secundária: é a custo de buscar, ler e escrever blocos de bados na momória secundálian, principalnente no disco rígido:

- Custo de ammacnanento: é o custo de armazenar clados intermediários que sano gerados pela estratógia de exerucão da comsulta;

- Custo de compulaçao: Co chlsto de realizar operacoes (2m menória sobre os dados duranto a execucăo da consulta;

- Custo de acesso à memória principal é o custo relacionado ao número de bloros do

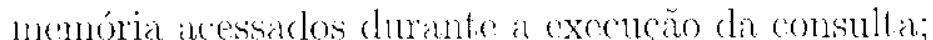

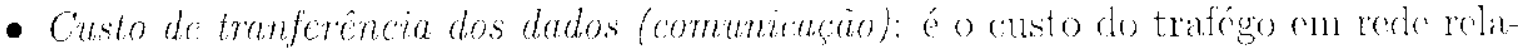

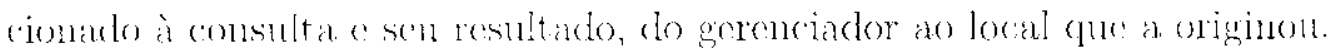


Avaliar o (ansto de todos esses componentes por neio de uma função que distribui

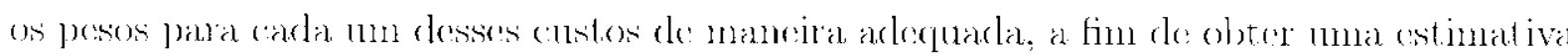
de custo realística, ó uma tarefa rifícil. Por isso, por questexs de simplicidude, na maioria dos casos ${ }^{4}$ (banco de dados centralizados) os gerenciadores consideran apenas o fator número de acessos a disco, pois considera-se que csse fator influencia todos os outros custos.

Portanto, estimar o custo de um plano de consulta significa basicamente avalian

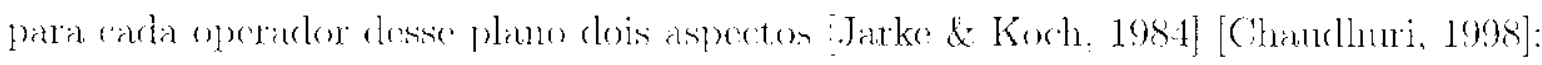

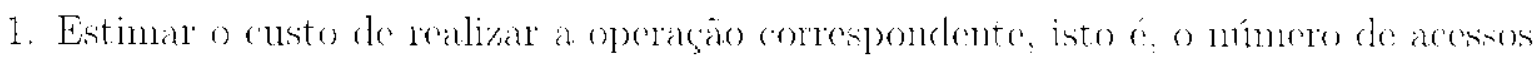
a disco em memória secundária:

2. Estimar o tamanho do resultado para cada operador; on seja, o mumero de l.uplat resultante após uma operaciào.

O número de acessos a disco para un plano de consulta se sulustancialmente afetarlo se relaçoes temporárias são ou não criadas para amazenar o resultado cle cada operador cm disco (ver Sogna 2.6.2). Alóm disso, o número de tuplas retornado por cada opcrader afetada dirctamento a estimativa do plano total, já que este resultarlo é usado como entrada polo operador seguinte no plano de consiltar.

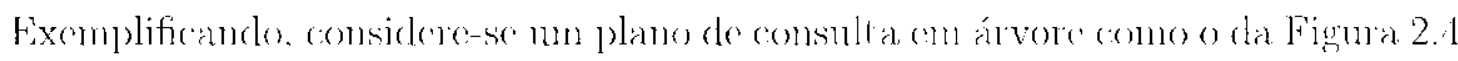
do Exemplo 2.2. Para cada nó dessa árvore, os dois pontos acina citados são avaliados.

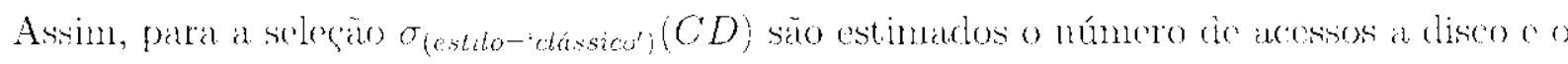

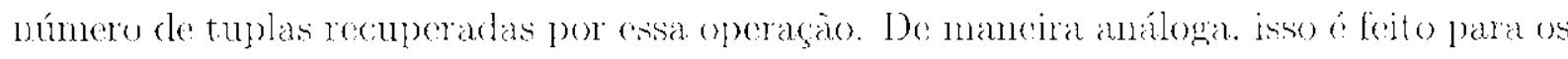
demais operadores da árvore de consulta. Assim, estimar o número de tuplas resultante

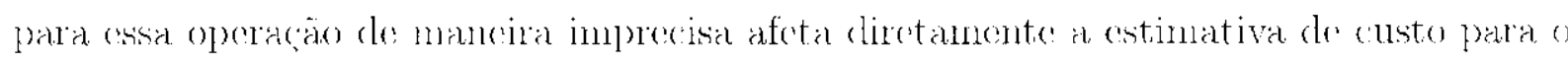
operador de junçäo e sucessivamente para os operadores nos niveis acima da árvore de consulta.

Para obter boas estimativas do tamanho cle resultado e custo dos operadores, as gerenciadores utilizan informaçoes mantidas no catálogo do sistema que são acessadas prolo Otimizador. Alguns exemplos dessas informaços usalas para estintar o custo do

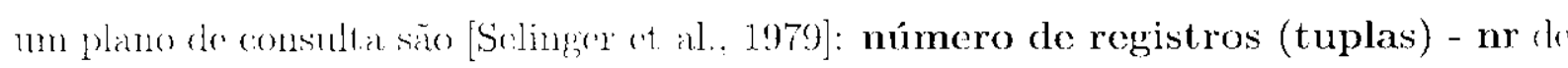
uma relação; tamanho médio do registro - tr de uma relaçào; número de blocos de disco - nb necessários para armazenar una relagino, informacōes sobre os métodos de acesso disponíveis para cada operador, bem como informacoes especificas sobre cada un deles (numero de níveis de un f́ndice por exemplo).

Além disson, outras informacoés relacionalas diretamente com a estimativa do tat

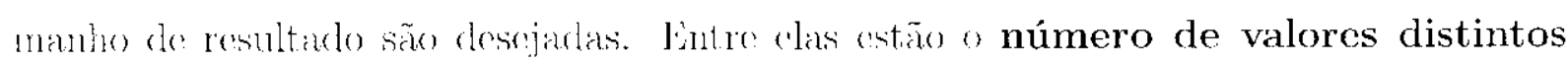
- nvd de unn atributo e a sua seletividade - sel. A scletividade para un atributo

\footnotetext{
${ }^{4}$ Banco de clados distribuídes, onde vários locais podem estar mulvides no processanento de consulta ¿ um exemplo típico om que mais de um fator deve sete considerado pelo gerenciador. Nesse caso, o custo de commincayaso entre os locais para executar a consult a $\dot{x}$ até mais importante que o custo de acesso it menuórià seccunclárial.
} 
pode ser definida como a fração de registros que satisfaz una condiçăo de igualdade sobre

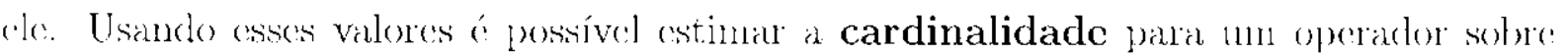
um atributo, on seja, o núnero de tuplas retornados por cle considerando o atributo em cunestão. Para o opcrador de seleção tem-se então a cardinalidade de seleção - es cun é o númoro médio de tuplas que satisfaz a condição de igualdade para o operador seleçano sobre un cleterminado atributo. Assim, a carclinalidarle de selecaño sobre unn atributo pode ner expressa por $\mathrm{a}=\mathrm{sed} \times m$.

Para un atributo não chave a seletividade pode ser estimada como sel $=\frac{1}{n u l}$. Já para um atributo chave, $n v d=n r, s e l=\frac{1}{n n}$ e $c s=1$ [Selinger ct al., 1979]. Essa definiçäo

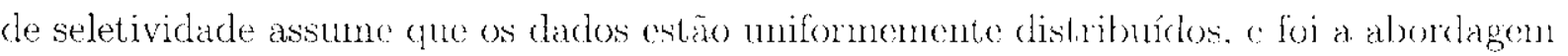
usialia en gerenciaktores mexcionatis mais antigos [Solinger ot al., 1979].

Note que como a seletividade é expressa por meio de una condição de igualdade sobre um atributo, o valor um está frefiüntenente presente no numerador das definições encontradas na litcratura. Isso ocorre porque entre os valores distintos de um atributo é

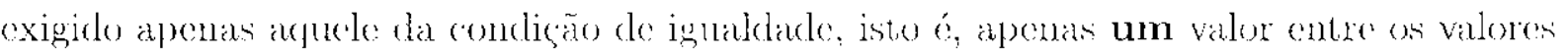

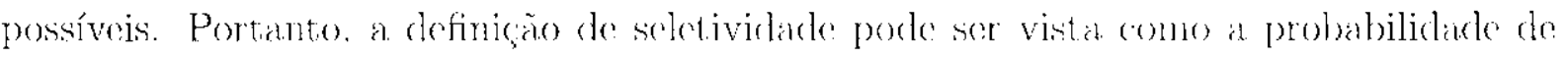
encontrar o valor do atributo descjado entre os valores possíveis. Assim, uma definiçăo mais geral de seletividade é

$$
s c l=\frac{n c p}{n c d}
$$

onde nup representa o mímero de valores possiveis de serem encontrados dada un condi-

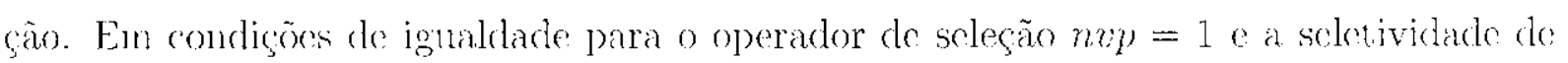
1111 atributó é sel $-\frac{1}{\text { mut }}$.

O Exemplo 2.4 ilustra os conceitos sobre estimativa de tamanlo de resultado in(duincle seletividade de atributos.

Exemplo 2.4 Assuma-se (pue algunas das informagoes manticlas no catálogo do gerenciador para as relaçoes Artista e CD säo apresentadas na tabela a segnir " yue se deseja. saber a cardinalielado de seleçăo para es atributos ano da relacão CD c estilo da rolação Artista do Exemplo 2.2.

\begin{tabular}{|c|c|}
\hline Artista & CD \\
\hline $111($ Artista $)-90$ & $\operatorname{mr}(\mathrm{CD})=360$ \\
\hline $\operatorname{mvd}(\cos t i l o)=10$ & $\operatorname{nvd}(\operatorname{ano})=20$ \\
\hline $\bmod (\operatorname{codig} 0)-90$ & $\operatorname{nvd}($ codiart $)=90$ \\
\hline nevd(icladle $)-15$ & avd (gravadora) $=5$ \\
\hline
\end{tabular}

A seletividade do atributo ano da rolagéa CD para o operador de seleção é $\operatorname{sel}(a n o)=\frac{1}{n t^{\prime}(a n o)}=\frac{1}{2 n} \cdot A$ cardinalidade de seleção comresponde a $\operatorname{cs}($ ano $)=$ sel $($ ano $) \times$

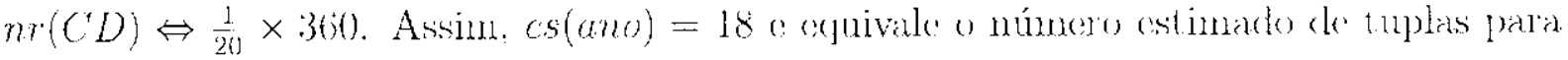

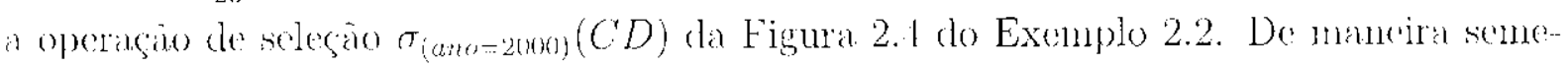

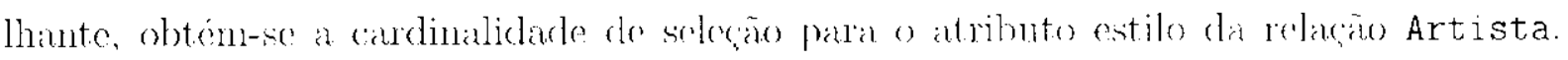




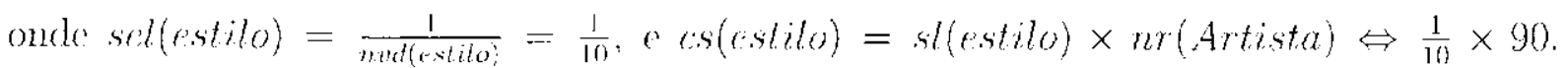

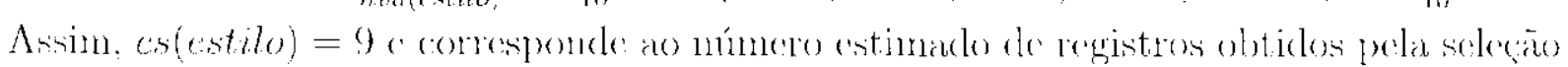

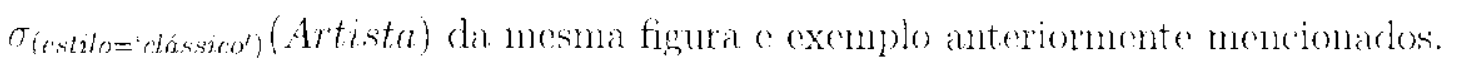

Os resultardes obtidos para a soletividade dos atributos c suas respect ivas cardinalidades para o operador de seleça do Exemplo 2.4 consideram que a distribuigão dos dados seja uniforme [Solinger et al. 1979?. Portanto, descle que os valores do atributo estejam

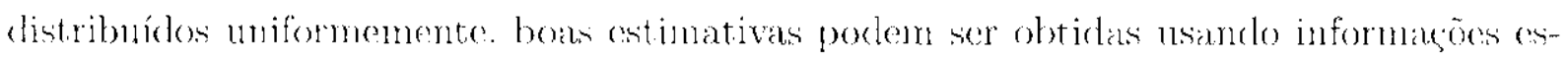
tatísticas simples solme os dados. como por excmplo, armazenando os valores mínimor máximo de um atrilunto gue é usado para obter o número de valores distintos. Porém, os valoros de um dotemonindo atributo podem possuir onl ras distribuiçoes, diferente da distribuiçäo uniforme, o que toma essa estinativa näo muito adequada nesses casos. A Figura 2.5 ilustra un exemplo de distribucão uniforme (DU) e nãa uniforme (DNU) para o atributo idade da relagăo Artista. A DU aproxima a real distribuicãa para o atributo que é representada na DNU.

(a) $D U$

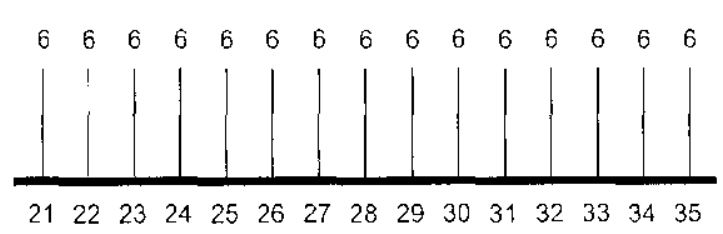

(b) $D N U$

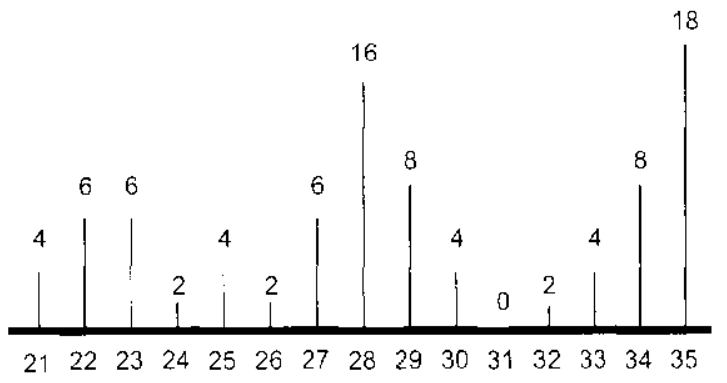

Figura 2.5: Distribuicão de valores do atributo iddade cla relação Artista. O valor mínimo para esse atributo é 21 e o máximo 35. (a) Distribuição uniforme (DU); (b) distribuição não uriforme (DNU)

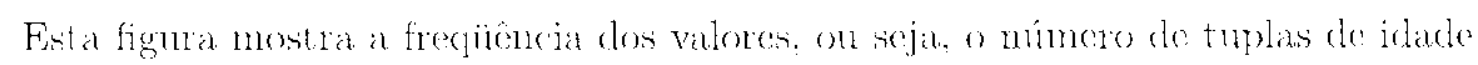
na relaçu Artista para carla valor possível desse atributo. O valor mínimo do atributo idade é 21 e o valor máximo é 35. Fntăo, tem-se que a relação Artista possui para a idado igual a 21 quatro tuplas, considerando a DXU, escis tuplas para a DU, conforme mostra a Figura 2.5. Como a ditribuição do itcm (a) da Figura 2.5 é uniforme, a frequînucia para o at rilututo idacle é a mesma para todos os valores desce atributo.

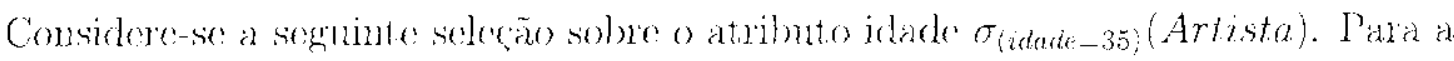
DNU (Figura 2.5 item (b) ). é possívol verificar que o tamanlo de resultado ten dezoito tuplats $(\cos ($ idade $)=18)$. Pormém, usindo a DU, o qual aproxima a real clistribuição dos dados, o tamanho de resultado estimado ó es (idade) $=\frac{1}{15} \times 90=6$ tuplas. Claramentes a estimativa usando a distribuiçăo uniforme dos dados con alguns casos é bastante imprecisa.

$$
\text { (os histogramas [Iommidis. 20033], [Muralikrishma de 1) wit.t, 1988]: }
$$

[Shapiro \& Connell, 1984 foran deenvolvidos visendo a obter uma maior precisio

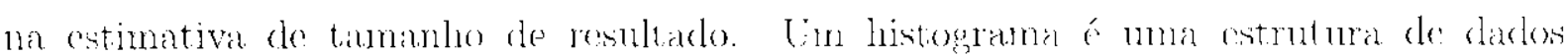


mantida pelo gerenciador para aproximar a distribuiçäo dos dados. Ele é formado particionando o dominio de um atributo em buckets (intervales de valores) a assimminde uma distribugăo uniforme dentro de cada bucket, isto é, todos os valores do atribute dentro de um buckel têm a mesma frequiência. Observe-se que a distribuicão uniformo dos dados pode ser considerada como un histograma de un único buckict. conforme nostra a Figura 2,5 (a). Lisar listogramas com un numero maior de buchetes pode levar

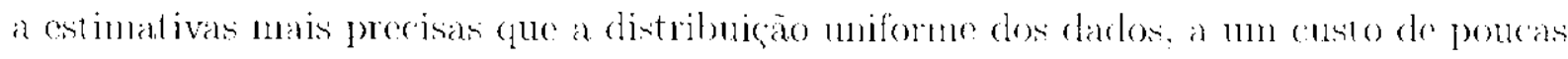
centenas de bytes por histograma. A questão é como dividir o domínio de valores de unn atributo formando buckets. Duas bern conlecidas estratégias săo os histogramas Equi-Width o Equi-Deplh, que estäo ilustrados na Figura 2.6.

(a) Equi-Width

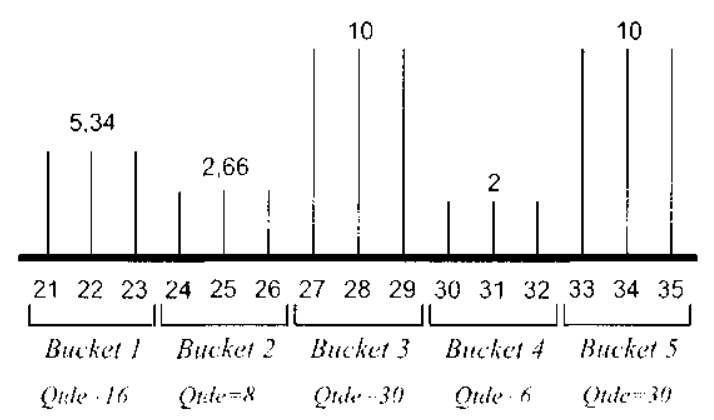

(b) Equi-Depth

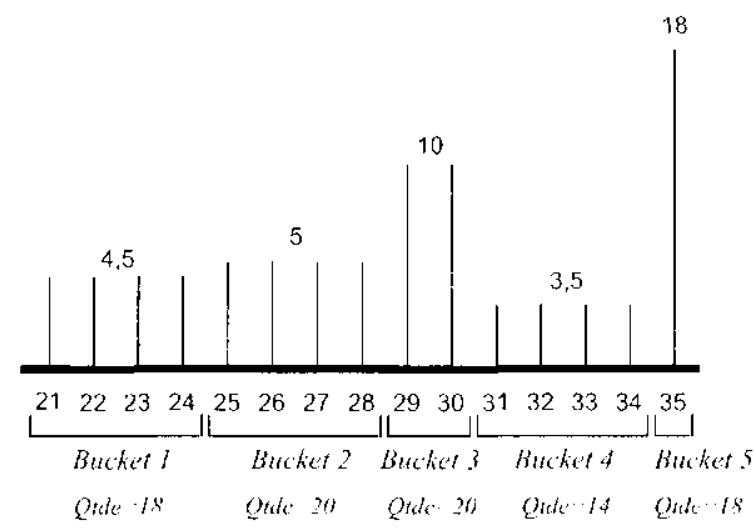

Figura 2.6: Distribuição dos dados para o atributo idade da relaça Artista usandelo histogranlas: (a) Equi-Width o (b) Equi-Depth

Un histograma Equi. Width jMuralikrishna \& 1)ewitt, 1988: divide o donnínio de valores de um atributo em intervalos de igual tamanho. A Figura 2.6 (a) mostra um histograma Equi-Width para o atriluto idlado da relagão Artista levando em consideraşäo a DNU da Figura 2.5 (b). Observe-se que o clomínio de valores dense atributo foi dividido em cinco partes (buckets) de igual tamanho, com calda parte tendo tres valores distintos de idade. () valor constante dentro de cada bucket é obtido somando as freciicencias e dividindo pelo número de valores distintos dentro de cada parte. Assim. para a

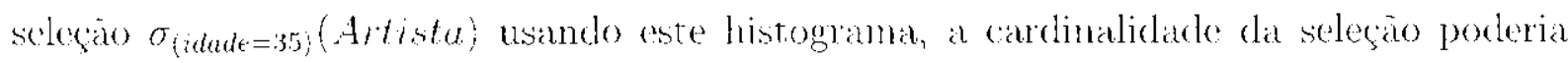

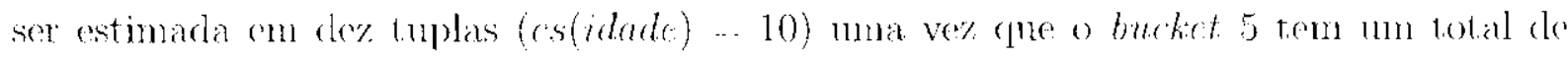
trinta tuplas con tres valores clistintos para idarle. Portanto, a cardinaliclade é obtida por $c($ idade $)=$ sel (idade $) \times n r($ tucket 5$) \Leftrightarrow \frac{1}{3} \times 30=10$ que representa um valor mais próxino à real distribuição do atributo quando comparado con a clistribuiçấo uniforme des dardes.

Lma outra possibilidade ó dividir o domínio de valores de um atributo em intervalos de tal mancira que o número de tuplas dentro de cada bucket seja ignal on o mais próximo

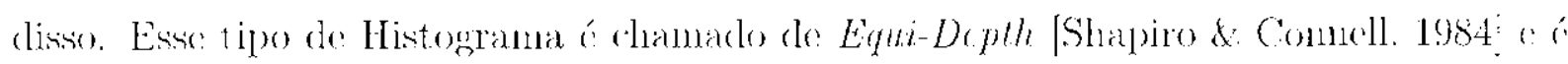

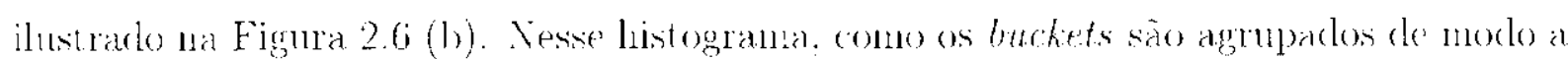

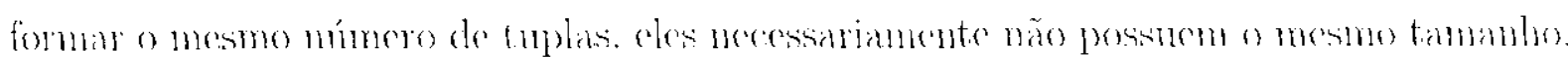


() valor constante dentro de cada bucket ć obtido da mesmat maneira que em histogramas

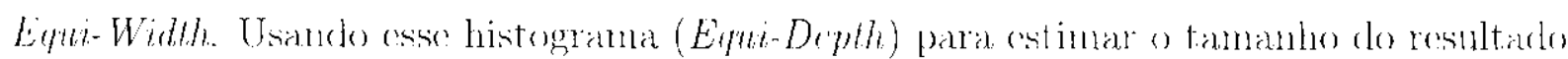
para a selecão $\sigma_{(i d a d f-35)}($ Artista), chega-se ao bucket 5 . Esse bucket contém apenas valores para a idado 35, cue corresponde à resposta exata para seleçäo, on seja, dezoito tuplins $(r s=18)$.

Histogramas Equi-Depth produzem melhores estimativas que histogramas Equi-

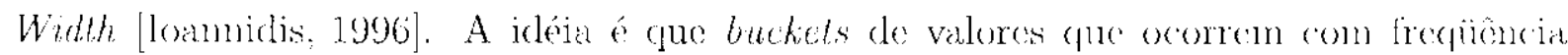
possulem um 'tamanho' monor om histogranas Equi-Depth: e como a distribuiçăo dos valores ć uniformo dentro de mu bucket. isso leva a molhores aproximações para valores frequientes [Ramakrishnan \& Gohrke, 2003?

Além de histogranas. ténicas baseadas em amostragem [Lipton \& Nanghton, 1990b], Lipton d Nanghton, 1990a], [11aras ot al. 1990)],

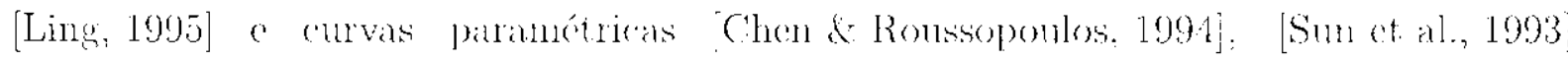

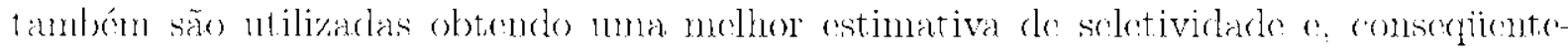
mente, estimativas de tamanho de resultado mais precisas para os dados. A combinação dessus técricas para gerar histogramas mais precisos está presente nos trabalhos de [Poosala et al., 1996] o [König \& Woikum, 1999:. Porm, a maioria dos gerenciadores relacionais atualmente usam histogramas Equi-Depth para a distribuicão dos valores de atributos [Lamiclis, 20033): [Ramakrishan \& Gehrke. 2003].

\section{$2.6 \quad$ O Executor}

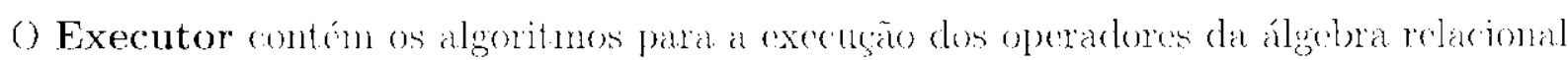

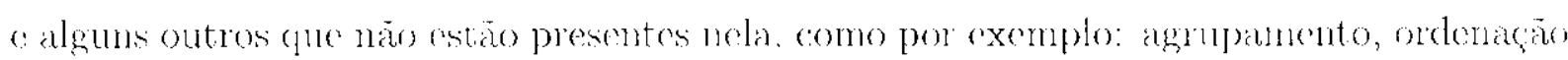
e eliminaçấo de duplicatas. Quando o Otimizador faz a enumeração de um plano de consulta, ele leva en consideração apenas os algoritmos que estão implementados nessa camada (Executor) do gerenciador. As cstimativas de custo säo feitas comsiderando as funcoes de custo pertinentes a cada $n$ mos algoritmos relacionados a um operador [loaniclis, 1996:

Esses algoritmos diferem con sua cstrat tógia básica, onde examinar, misturar, classificar o indexar poden ser consideradas as abordagens mais importantes. Outra diferença entre esses algoritmos está na suposição de memória principal disponivel para screm exe-

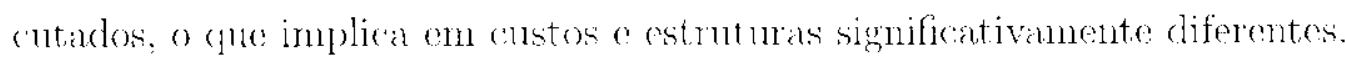

O objet ivo aqui não é apresentar ou descrever un deteminado algonitmo cesperífico que pode ser utilizado por $u \mathrm{~m}$ gerenciador, nem discutir as suas estruturas, mas sim

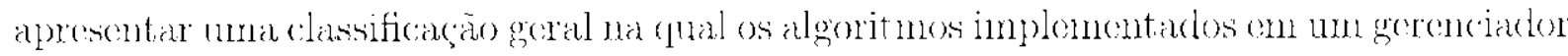
se encuadran, bem como a mancira como us resultados (tuplas) desses algoritmos podem ser passados de un operiador paria outro. 


\subsubsection{Classificação dos Algoritmos}

$\Lambda$ escolha de tom algoritmo para cadia operador, que é foita pelo módulo Espaço Estrutura-Método, é un dos passos essenciais do processo de otimização de um plano de consulta. Enbora muitos algoritmos para operadores tenham sido propostos, geralnente no Executor de $110 \mathrm{n}$ gerenciador são encontradas tres classes de algoritmos [Cracte, 19933] [Garcia-Molina ot al., 2000] [Antoshenkov \& Ziauddin, 1996:

1. Algoritmos bascrados on classificacão;

2. Nlgoritmos bascados em hash;

3. Algoritmos bascarles en indiecs.

Alóm disso. é possível dividir os algoritmos para os operadores em três gralls do

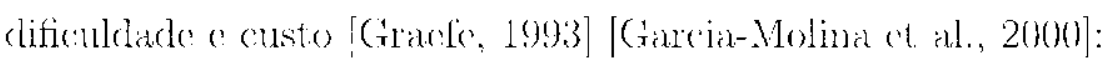

- Alguns algoritmos chvolvem a leitura clos dados apenas una vez. Essess sion os algoritmos de uma passagem. Em geral eles funcionam apenas quando pelo menos um dos argumentos da operação so cncaixa na memória principal embora liaja exceçòs, como para seleção e projeção;

- Alguns algoritmos sãa mais adequados para grandes volume de dados que não cabom na memória principal disponível. Fiscres algoritmos são classificados como algoritmos do duas passagens. Eles säo caracterizados por lereme os dartus do disco ma primeira ve\%, processín-los do alguma forma, gravarem todos ou parte deles no disco.e depois fazerem uma segunda leitura para processamento adicional durante a segunda passagem polos dados;

- Alguns algoritnos funcionane sem considexar un linite de lamanho para os dados.

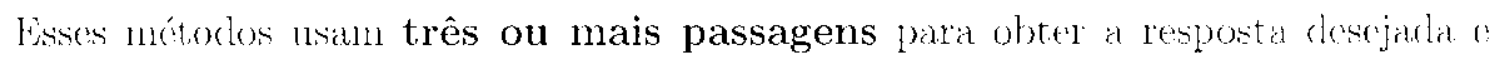
podene ser considerados como gemeralizagöes dos algoritmos de duas passagens.

Portanto dado um determinado operador, o módulo Espaço Estrutura-Método

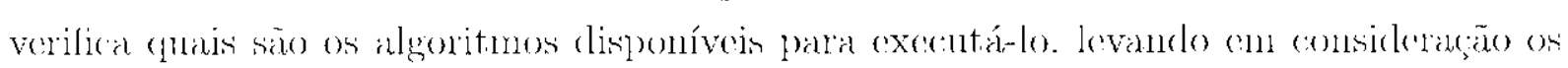
dois aspectos apresentindos nesta seção o enumerando essas possibilickades pala serem avaliadas pelo módulo Estimador de Planos. Esse módulo também considera a mancira como o resultado é passado de um operador para o outro, por materialização ou pripelming.

\subsubsection{Materialização x Pipelining}

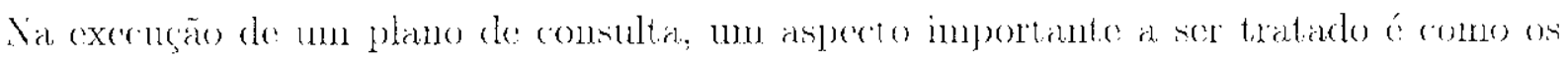
resultados dos operadores sáo passialos para op próxino operador. Esse aspecto influencia dirctanuente o colsto de 1 mo operador a ser cstimado pelo Otimizador. Assim, a maneira 
como os resultados da soleção $\sigma_{(\text {urno:20no) }}(C D)$ da Figura 2.4 sấo passados para o ope-

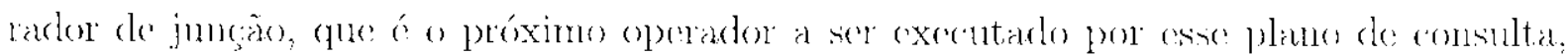

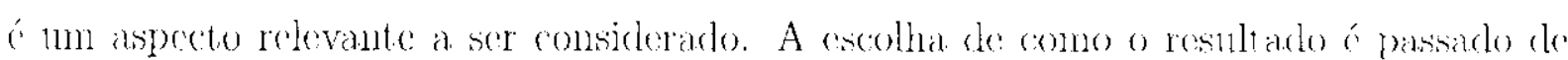
urn operador para outro a feita pelo Espaço Estrutura-Método do Otimizador ficando como funçăo do Executor apenas realizá-lo. Basicamente, existem 2 estratégias Jarke \& Koch, 1984]: matcrializay̆üo e pipelining.

Na materialização, o plano de consulta ó executado ordenando as operaçoes de forma apropriada o armazenando o resultado de cada operação en clisco, atcí que esse resultado seja exigido por outra operação. A ordenaçăo ć feita para cue uma operaçăo

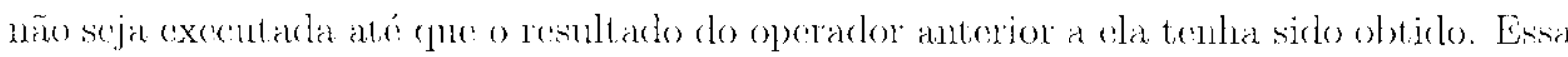
cslratégia é chamada de materializangäo, pois cala resultado proveniente de un operador na árvore de consulta ć armazenado ("matcrializade") em disco.

Na abordagem pipelining o plano de consulta é executado podendo possuir várias operaços con exerugão ao mesno lempo. As tuplas produridas por uma operação são

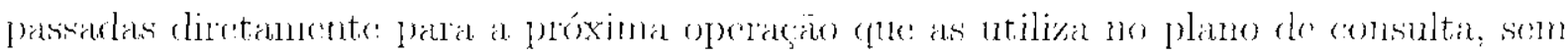
armazenar o resultaclo proveniente do operactor em disco.

A abordagem pipelining ó, em geral, mais eficicute que a nuaterialização, pois cconomiza acessos à memória sccundária já que uão escreve os resultados de $11 \mathrm{~m}$ operador em

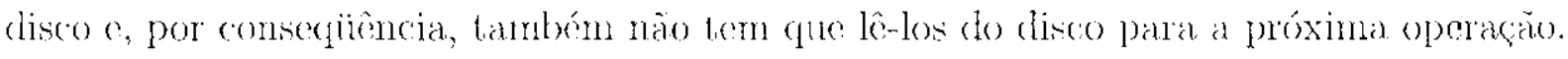
Fortanto, (aso scja possível a unn operactor ter sen resultado passade ao próxino operador por meio de pipelining, o seu custo de execução ó reduzido, bem como o custo tolal ch plano de consulta em questão.

\subsection{Conclusão}

Torla consulta expressa em SQL passa obrigatoriamente por um procenso antomátier de processamento que é feito pelo gerenciador con etapas. As etapas do processamento de consultas podem ser divididas basicamente em: Compilador, Otimizador e Executor.

A icléia é que, dada ma determinada consulta, existam diversas manciras do gerenciador processá-la. produzindo a mesma resposta. Essas maneiras devem gerar o mesmo resultado final mas varian en custo computacional, especialmente quanto an tempo necessário para executá-las. O gerenciador então examina as alternativas possíveis estimando o custo de cada uma delas o escolhe a que necessita da menor cuantidade de tempo para ser executada. Esse processo autonálico de escolha é feito pela ctapa Otimizador do processatnento do consultas, usando informaços sobre os dados, operadores e algoritmos.

Para fazer sua tarefa de maneira cfetiva, isto ć, cmumerar vírios planos altenativos equivalentes para se executar uma consulta e escolher entre des o molhor, o Otimizador

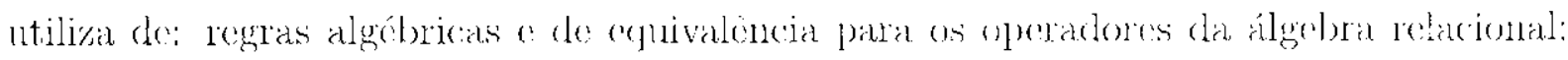
algoritmos presentes no Executor para cada operador: estimativas de custo cle cala opesrador considerando as implementagenes presentes no Executor; estimativas de soletividade 
o dr tamanho de resultado necessárias para se estimar o chisto de cada operador.

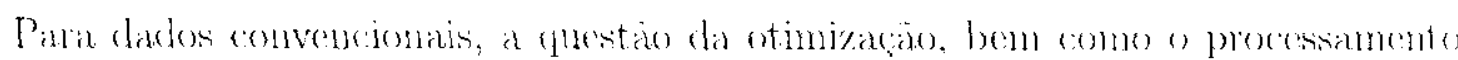
de consultas como $u m$ todo, está ben sedimentado apesar de haver alguns tópiers cue

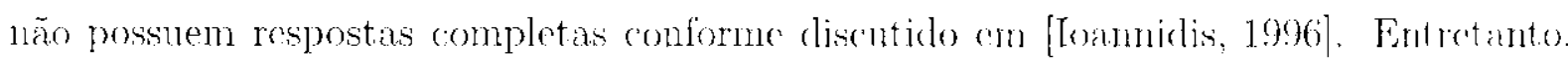
dar suporte a dados complexos nesses gerenciadores exige o desenvolvinnonto de maneiras para que esses dados possam ser consultados e armazenados do mesmo morlo que os dados

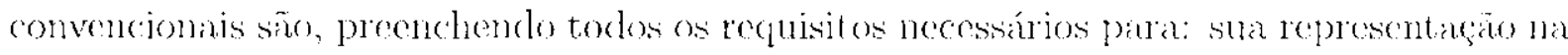

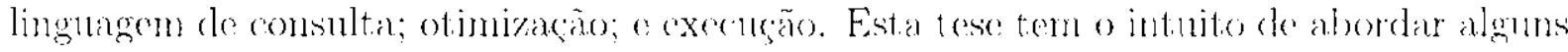
deses requisitos para permitir que consultas por similaridade possam ser utilizadas en gerenciadores relacionais. 
Capítulo

3

Consultas por Similaridade

\subsection{Introdução}

\& Sisteman do Gerencianmento de Bases de Dardon (SGBDs) tradiciomais realizan buscas sobre dados convencionais (números e texlos curtos) por meio de relaçoes de igualdade e de ordem existentes nesses dados. Entretanto, qulando se utilizam SGBDs para armazenar dados complexos como por exemplo dados nulti-

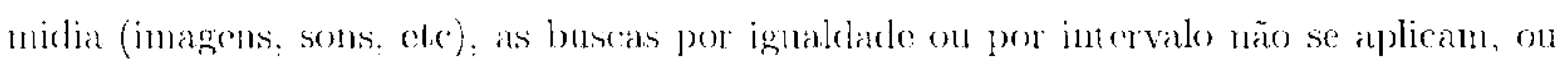
simplesmente tôm ponca utilidade. Exanes de tomografia' são um bom exemplo disso. Dificilmente a tomografia do córobro de um paciente céclentica à cle ontro paciente on até

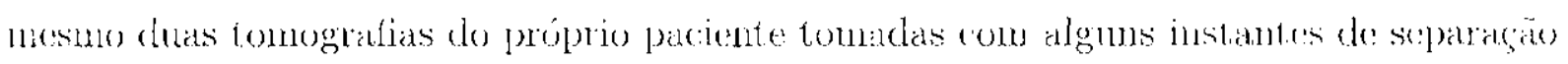

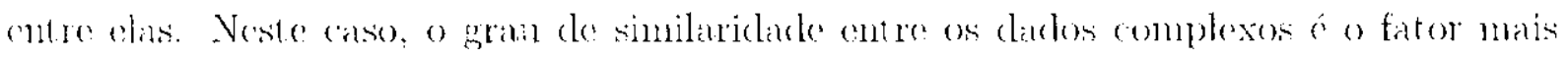
importante flatoulsos, 1997 .

() tipe do busca denominado consulta por similaridade consiste em proculure can um conjunto por objotos que, segundo algun critério de similaridake, scjan mais "parecidos" on maje "dist intos" com/de un determinarlo oljeto. Emo outras palavras, consultats por similasidade comparam todos os ob jetos do comjunto (om un objeto chcolhido, selecionaudo a ponas os elementos que atendam a mn corto critório do simuilaridacle. Por exemplo.

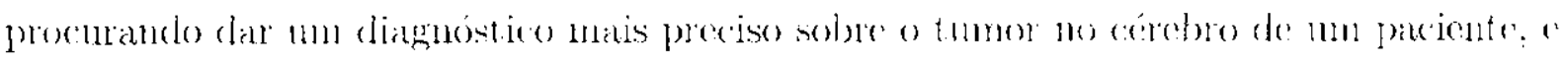
alé nesmo tentando encontrar subsílios para decidir como encaminhar o tratanonto, nun módico estaria interessado em concontrar as tomografias de creboro gue apresentom un

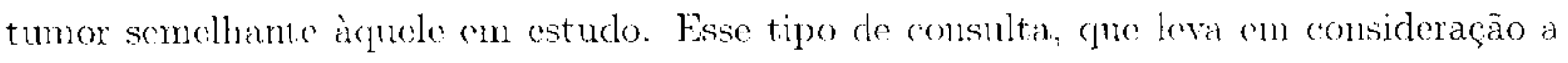
informaçăo inerente ao objeto cle refercincia ć chamado de Consulta Baseada em Con-

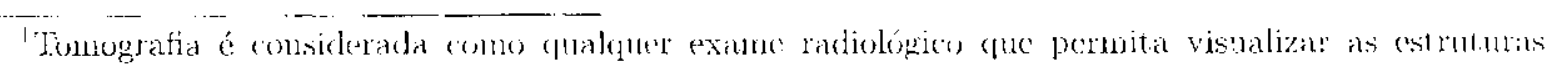

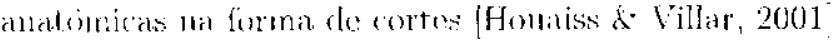


teúdo (Content-Based Query). Ou seja, a consulta 6 feita a partir dos dados contidos no

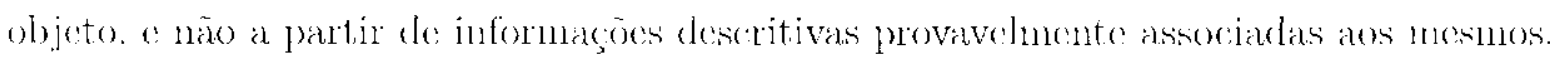

Para se determinar a similaridade entre os objetos, eles podem ser comparados diretamente on a partir do vetores de características (cor. forma e textura por exemplo) extraídos dos mesmos. Nos dois casos, uma função de distanncia d() é definida para calcular o grau de similaridade, retomando un valor numérico que quantifica o quăo sinilares dois objetos säo. Por definigão, esses valores são sempre maiores ou iguais a zero, tendo valores próximos de zero para objetos muito similares (zero para objetos ignais) e valores maiores para objotos menos sinulares. Essa função é chanada de função de dissimilaridade on de função de distância e deve sempre scr definicla por un espexialista no domínio em

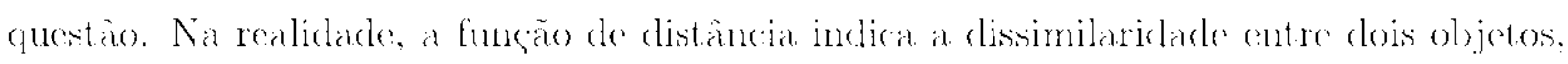
e convém colocar clue a similaridadé medida pelo sen inverso. Para simplificar a compreensão do texto, muitas ve\%es os autores estabelecem que a função do distância indica a similaridade, já que esta ó facilmente obtida pela dissimilaridade.

Existen vírius tipos de consult as por similaridade, sendo a consulta por abrangincia a a consulta anos h-vizinhos mais próximos as mais commes (Serăo 3.3). Para estimar a quantidarde de objetos a serem recuperados pelas consultas mais comuns, algumas estimativas de seletividade têm sido propostas na literatura (Seção 3.5). Além disso. no pesquisadores possuem grande interesse na chaboraçio de algoritmos de busca para exe-

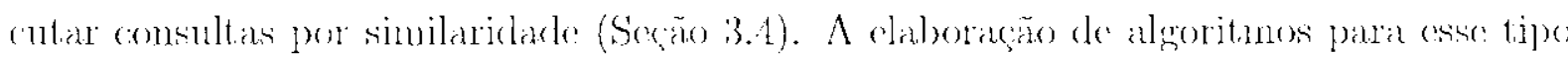
de consulla exige a existencia de leis algébricas para reger o comportamento dos objetos 10 domínio o mana função de distancia. A definição dessas leis gera espaços ondo as con!sultas por similaridade podem ser applicadas. Fespacos métrices e vetoriais säu cletallados a seguir.

\subsection{Espaço Métrico}

Inicialmente ó apresentada a notaçăo a ser utilizada gue for bascaula nos traballoos de [Burkhard \& Foller, 1973j: [Chacria of al., 1997] e [Cháves et al., 2001]

Seja $\mathbb{S}$ um domínio de objetos. O subcomjunto finito $S \subseteq \mathbb{S}$ representa o conjunto de objetos no qual as consultas säo efetuadas. $\Lambda$ funçäo $d()$ :

$$
d: \mathbb{S} \times \mathbb{S} ; \mathbb{R}^{+}
$$

corresponde à medida de "distância". também chamada do "similaridade", centre doin ob)jetos. Isso significa que fuanto menor a distunncia entre dois objetos. mais próxirnos on scmelhantes (sinilares) eles são. So uma funcão de distancia possuir as seguintes propriedacles:

1. Simetria: $d\left(s_{1}, s_{2}\right)=d\left(s_{2}, s_{1}\right)$

2. Nāo negatividade: $0<d\left(s_{1}, s_{2}\right)<x s_{0} s_{1} \neq s_{2} \circ d\left(s_{1}, s_{:}\right)=0$ 
3. Desigualdade triangular: $d\left(s_{1}, s_{2}\right) \leq d\left(s_{1}, s_{3}\right)+d\left(s_{3}, s_{2}\right)$

onde $\left\{s_{1}, s_{2}, s_{3}\right\} \in \mathbb{S}$, o espaço $\mathbb{M}$ definido pelo par $\langle\mathbb{S}$, do $>$ c chamado de Espaço Métrico e a função de distancia ó chamada Função de Distância Métrica, ou simplesmente Métrica. Note-se que nenhuma informaçâo geonétrica, como num domínio

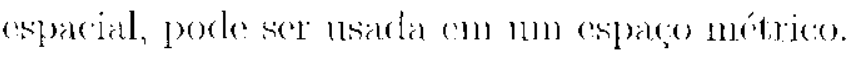

As funcous mót ricas mais ulilizadas säen as métricas de Minkowski - $\left(L_{p}\right)$ [Wilson \& . Martine\% 1997] (detallarlas na Seço 3.2.1). utilizadas en domínios multidirnensionais, e de Levenshtein - $\left(L_{\text {Edit }}\right)$ !Levenshtein, 1966, utilizadla para o cálculo de similaridade entre cadeias de caracicres. A métrica $L_{L^{\prime} d u}\left(s_{1}, s_{2}\right)$ retorna o numoro mínimo

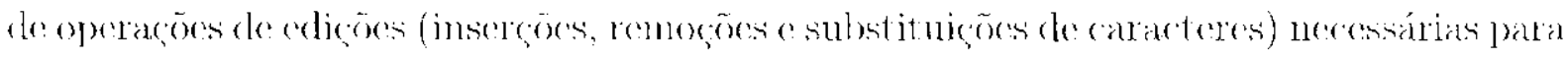
transformar a carleia de caracteres $s_{1}$ na cadeia $s_{2}$.

As propriedades dos espaços métricos, principalmente a designaldade triangular, permitem a elaboração de técnicas de indexaçäo capazes de responder a consultas por similaridade de modo cficiente. (ver Secão 3.3).

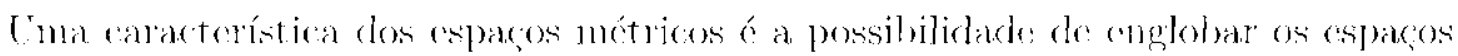
vetoriajs, bem cono espaços adimensionais (conjuntos de imagens, palavras, sons ou dados genômicos), desde que haja una métrica adequada. Un espaço é adimensional quando o

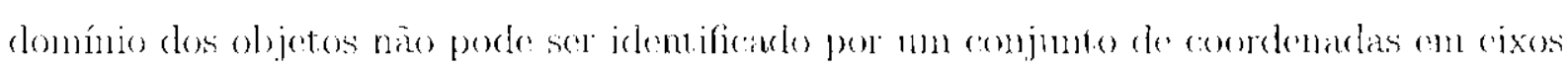
ortogonais numa dincusino finita.

\subsubsection{Espaço Vetorial}

Se os objetos do dominio $\mathbb{S}$ correspondem a vetores de valores numéricos então o espaçó chanado Espaço Vetorial com Dimensão Finita, ou simplesmente Espaço Vetorial.

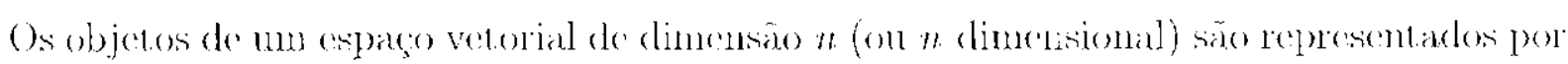

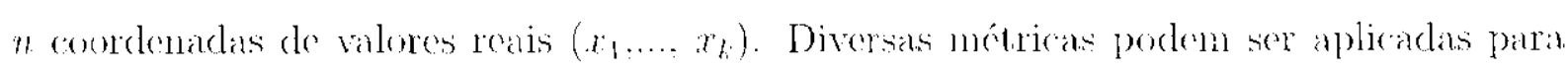
comparar os objeton do $\mathbb{S}$ sendo as mais conhecidas as da família $L_{p}$ (ou Minkowski). definidas por:

$$
L_{p}\left(\left(x_{1}, \ldots, x_{k}\right) \cdot\left(y_{1}, \ldots, y_{k}\right)\right)=\left(\sum_{i=1}^{k} x_{i}-y_{i} \eta^{p}\right)^{1 / p}
$$

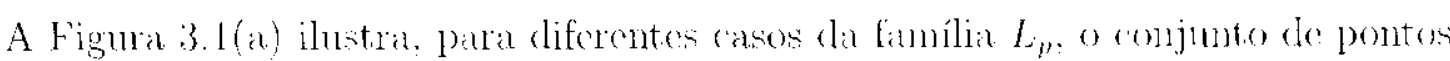

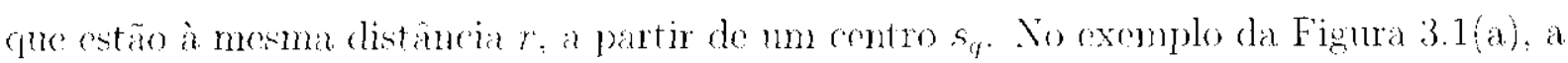

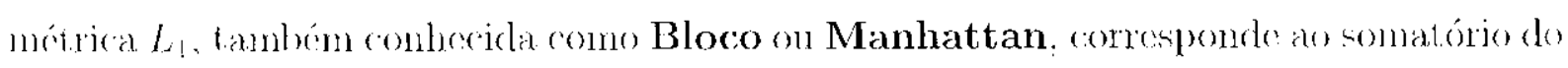
módulo das diferenças entre as coordenadas. Nesse caso, o conjunto de pontos de mosma distancia $r$ forma um losango con os dianmetros paratelos ans cixos das coordenadias. A métrica $L_{2}$, mais conhecicla como distancia Euclidiana, corresponde à funçäo usual para distancia entre vetores. O conjunto de pontos de mesma distancia ao centro sa para

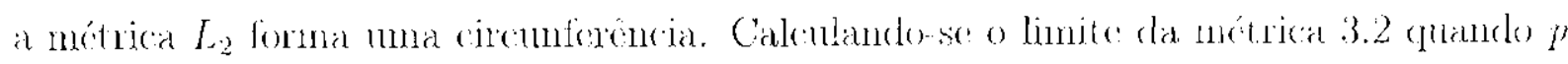
tende ao infinito, obtém-se a métrica $L_{\infty}$. também conhecicla cono Chebychev, dada pela Éguacão 3.3. na qual o conjunto de pontos com mesma distância formam um quadrado 
(a)

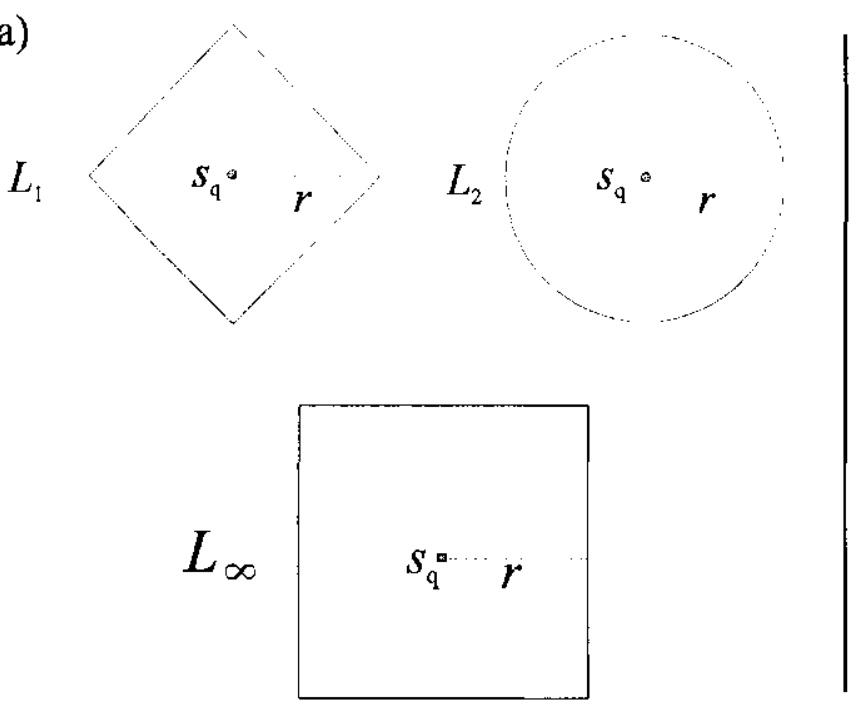

(b)

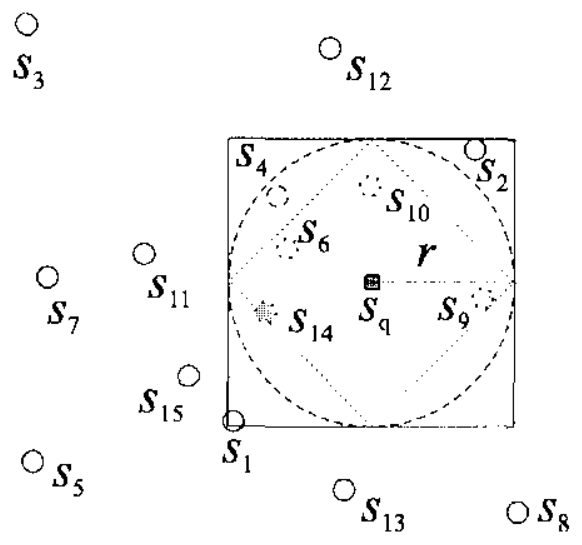

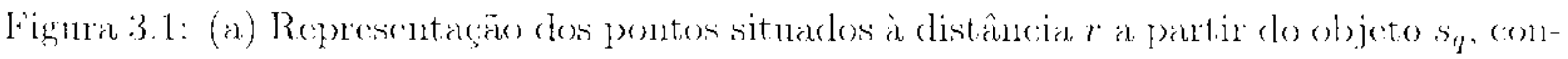
siderando as diferentes métricas da família $L_{p}$. (b) Exomplos de consultas por abrangencia

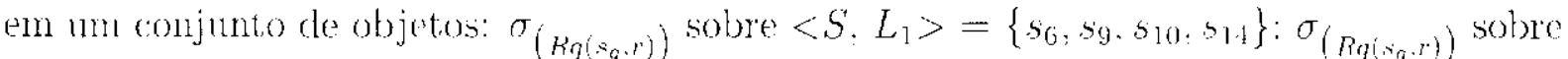

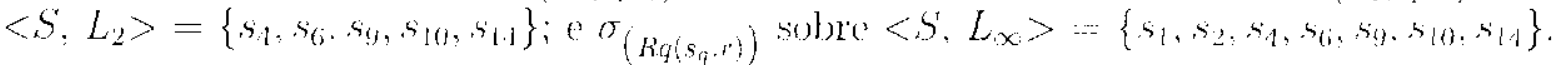

com os lados paralelos aos eixos das coordenadas.

$$
L_{\infty}\left(\left(x_{1}, \ldots, x_{k}\right),\left(y_{i}, \ldots, y_{k}\right)\right)=\max _{i \rightarrow 1}^{k}\left|x_{i}-y_{i}\right|
$$

A Figura 3.1(b) representa um conjunto de objetos $\left(s_{i}\right)$ : um objeto de consulta $s_{q}$, o raio de consulta $r$ e três métricas $L_{1}, L_{2}$ e $L_{\infty}$ para uma consulta que deseja obtcr quais sào os objetos a una distanncia $\leq r$ do objeto de referência $s_{q}$. () conjunto de objotos $\left\{s_{66}, s_{9}, s_{10}, s_{14}\right\}$ contide no losango de consult a da Figura 3.1(b) faz parte do conjunto

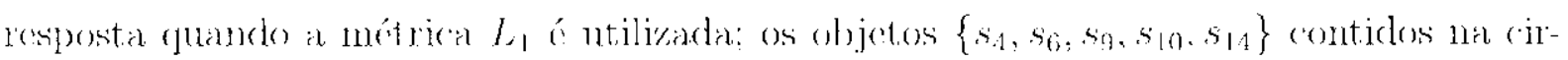
cunferencia de consulta da Figura 3.1(b) fazem parte do conjunto resposta consideranclo a métrica $L_{2} ; c$, os objetos $\left\{s_{1}, s_{2}, s_{4}, s_{b}, s_{9}, s_{10}, s_{1.1}\right\}$ contidos no quadrado de consulta da

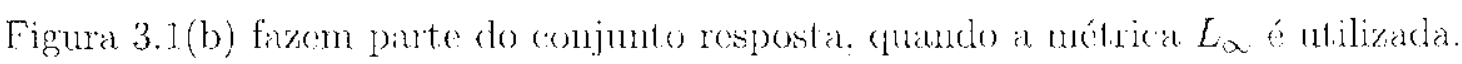

As tres métricas citadas anteriormente foram escollidas por serem muito utilizarlas erm consultas por similaridade.

\subsection{Consultas por Similaridade}

Considere-se um conjunto de objetos $S=\left\{s_{1}, s_{2}, s_{3}, \ldots, s_{n}\right\}$ pertencentes a un domínio $\mathbb{S}$ (c una métrica $d($ ). Os tipos mais comuns de consultas por similaridade são:

1. Consulta por Abrangência (Range Query - Rq): wma consulta por abrangência

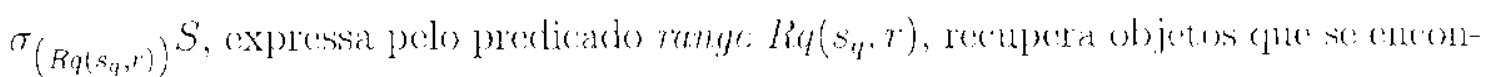

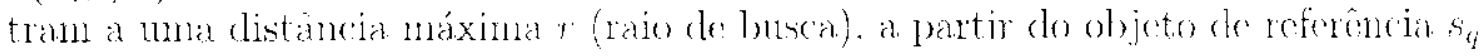

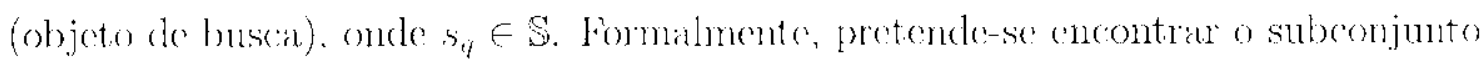


$A \subseteq S$ que atenda:

$$
R q\left(s_{q}, r\right)=A=\left\{a r \in S, d\left(s_{q}, a\right) \leq r\right\}
$$

$\Lambda$ Figura 3.2 (a) ilustra um excmplo de uma consulta por abrangencia com a funf̧ăo de distância Euclidiana $L_{2}$. Os objetos contidos na circunferéncia (cor cinza) pertenceni an suberoujunto $A$.

En exemple de consulta $R q$ seria: "Selecione as protrinas que difiram da proteńna $\zeta$ por até 5 bases purínicas", no qual $s_{q}$ é a proteína $\zeta$ o universo $\mathbb{S}$ co o conjunto de proteínas, o subconjunto $S \subseteq \mathbb{S}$ ć una base de dados contendo as proténats conhecidas, o raio de busca $r=5$ bases purínicas e a métrica $d() \equiv L_{\text {Edit }}$. Essa

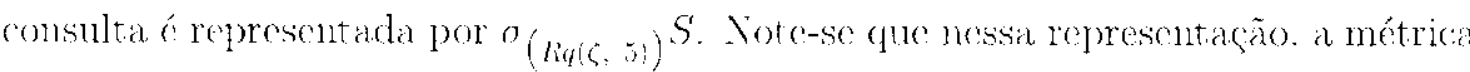
utilizada não estŕ explícita. Isso ocorro porque se considera o conjunto do dados Samostrado no domínio do espaço métrico onde a métrica está definida. Assim. a

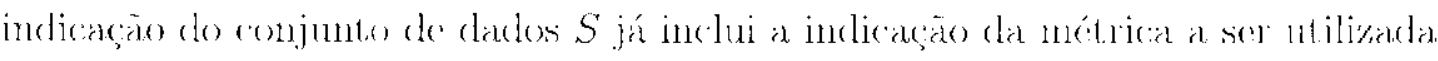

2. Consulta aos k-Vizinhos Mais Próximos (k-Neurest Neighbor ( $u \in t y-k N N)$ una consulta ans $k$-vizinluss mais próxinos: $\sigma_{\left(k_{N N}\left(s_{n}\right)\right.} S$, expressa pelo predicado $k$-nearest $h N N\left(s_{q}\right)$, recupera os $k$ objotos mais proximos a objoto de reforencia

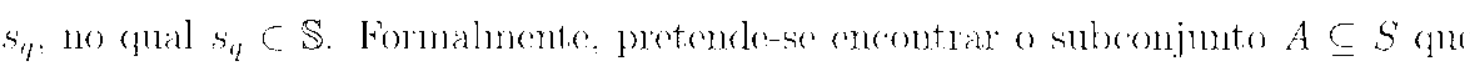
atenda a:

$$
k N N\left(s_{q}\right)=A=\left\{a\left|a \in S, \forall s_{i} \in S-A, d\left(s_{q}: a\right) \leq d\left(s_{q}, s_{i}\right),\right| A \mid \cdots k\right\}
$$

A Figura 3.2 (b) ilustra um exemplo de uma consulta aos k-vizinhos mais próximos

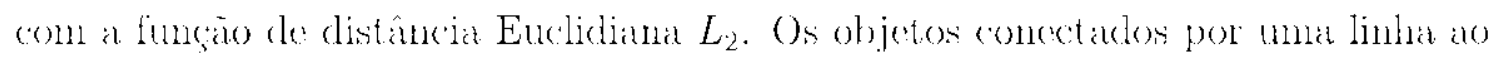
(s) jete de consultia pertencem ano conjunto respestia.

Lsando as mesmas definiçoes para proteínas, un exemplo de consulta kNN seria "Selecione as 3 proteinas mais semelhantes à proteína $\zeta$ ", onde $k=3$. Esse exemplo é representado por $\sigma_{(3 N N(\zeta)} S$.

Vale observar que en caso do empate, nuito conmum quando o domínio de $d($ )

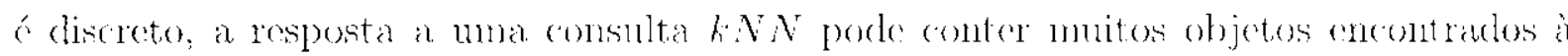
distancia máxima. Essa possibilidade leva a duas variantes para una consulta $k N N$. A

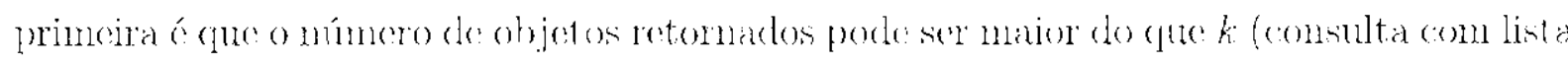
de empate) [Arantes et al., 20031)] e a segunda retornia qualquer combinação dos $k_{i}$ objetos cmpatados ì distância máxina (consulta sem lista rle empate) [Arantes et al., 2004]. () presente trabalho considera que empates con consultas hNN são quebrados de mock arbitrário, isto é, consultas sem lista de empate, como a maioria dos trabalhos encontrados nia literatulua.

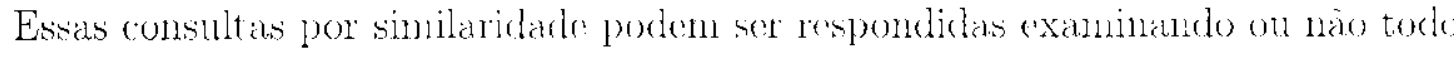

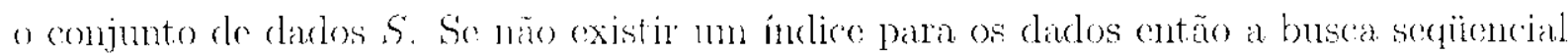


(a)

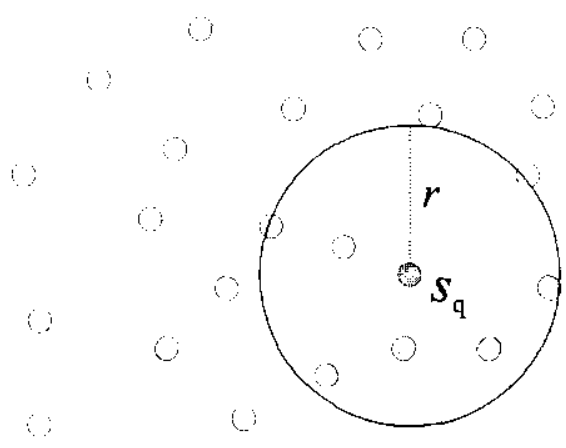

(b)

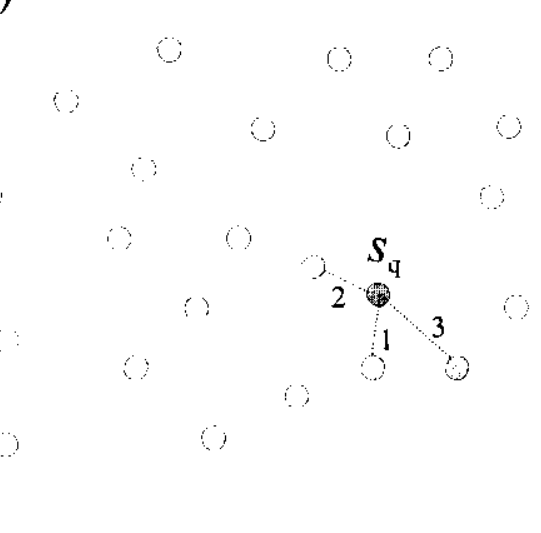

Figura 3.2: Exemple de consultas por similaridande utilizando a funçäo de distancia $L_{2}$. () objete sif é o objetor de busca encuarto os objetos cinza constituem os objetos do conjunto resposta. $A$. (a) Ihustra uma consult a por abrungencia - $\left.\sigma_{\left(\operatorname{Rq}\left(\alpha_{q}, r\right)\right.}\right)^{S^{\prime}}$ o (b) ilustra uma consultad aos $k$-vizinhos mais próximoss - $\left.\sigma_{\left(3 N N\left(w_{q}\right)\right.}\right)^{S}$.

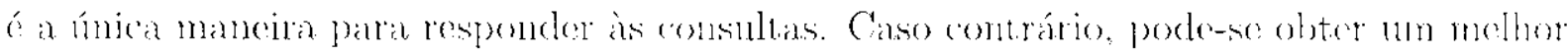

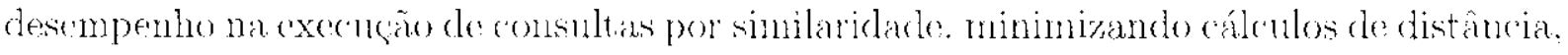
acessos a disco e termpo totat de processanento. Nesso caso, o índice usa as propriedades inerentes we denínio do deades para melhomar o tempo de resposta destas consultas.

Para dados enn espackos métricus, semelo chamados de dados em domínios métricos, indices porlem ser constrúclos por mero de Métodos de Acesso Métricos (MAMs). MAMs hierárquicos isto ć, compostos de nó raiz. nó intermediários e nós fothas são chamaklos de árvores métricas. A idéla geral da maioria dos .MAMs consiste em

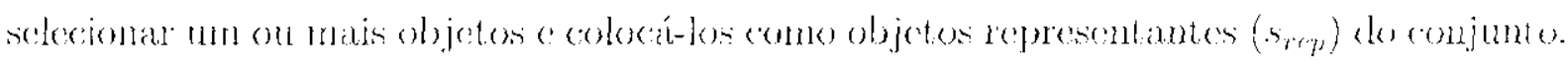

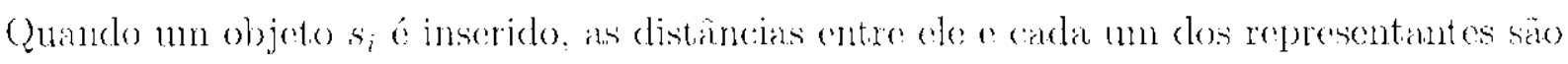
calculardas e armazenadas junto com sens dados (maiores detalhes no Apondice $\Lambda$ ).

Como as distancias entre todus os objetos armazenados e cada $110 \mathrm{n}$ des objetos representantes säo conheridas, a propriedade de desigualdade triangulat pode ser usada

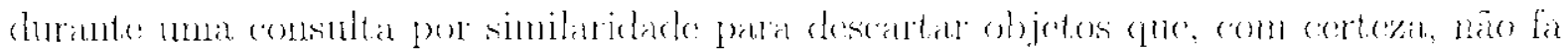

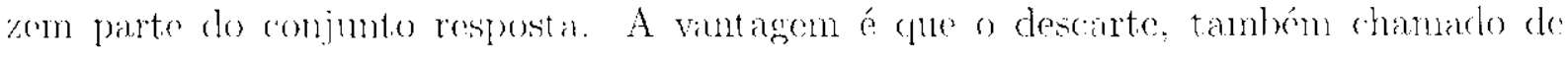
poda, pode ser feito sem a necessidade de calcular as distancias entre os objetos armazenados e o objeto de consulta. Dessa mancirat: a culanticlade de cálculos de distanncia

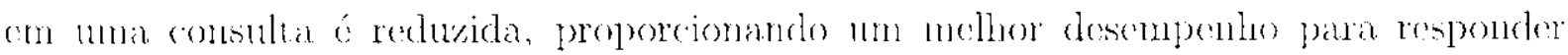

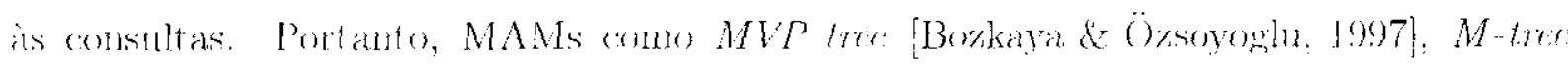
[Ciaccia et al., 1997], Slim-tree [Trana Jr. et al., 2000b)' DBM-tree [Vieira et al., 2004] podem melhorar o desempenho de consultas por similaridade sobre dados ("omplexos om ordens de mannitude.

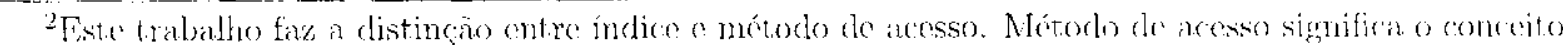

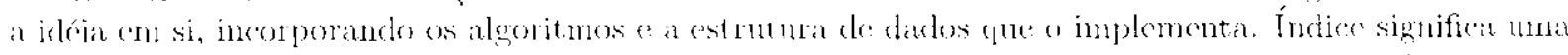

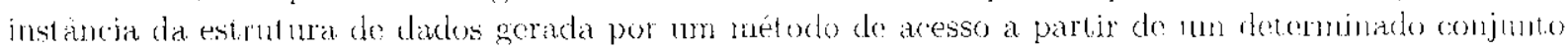
do dindes de ont ratal. 


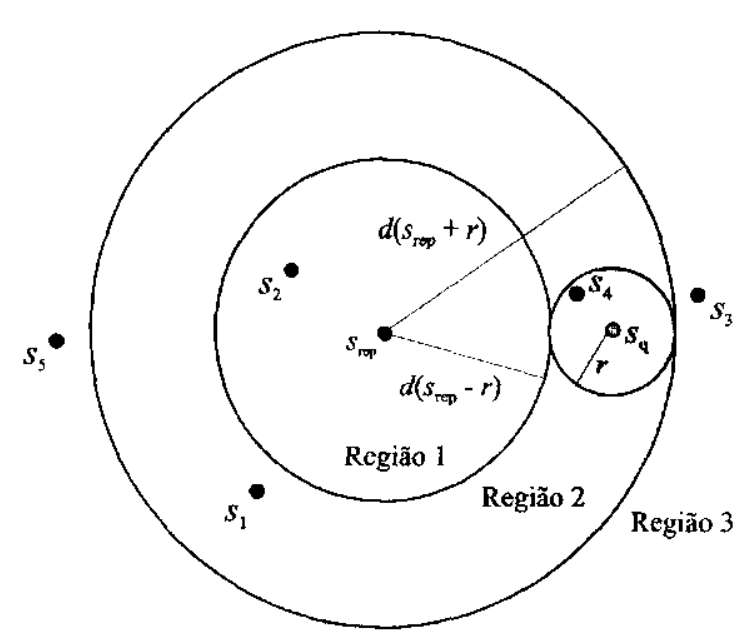

Figura 3.3: Através da propriedado de designaldade triangular é possivel descartar cualquer objeto que esteja na regiäo 1 on 3 , sem mesmo calcular a distância entre os objetos contidos nestas región o o objeto de referéncia da consulta. Já us objetos que estiverem na regiäro 2 não podem ser descartarlos apenas com o uso da desigualdade triangular.

O descarte por desigualdade triangular é feito da scguinte mancira: dados o espaço

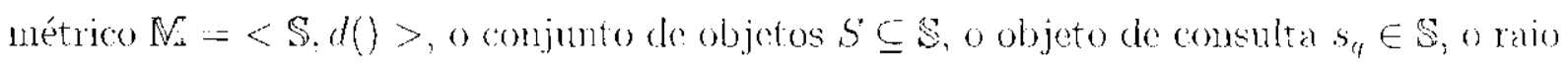
de consulta $r$ e um objeto representante $s_{r e p} \in S$, am objeto $s_{i} \in S$ perderá ser descartado

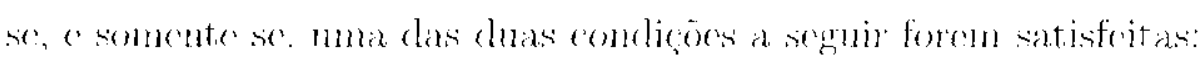

$$
\begin{aligned}
& d\left(s_{r, p}, s_{i}\right)<d\left(s_{r(p)}, s_{q}\right)-r \\
& d\left(s_{r, p}, s_{i}\right)>d\left(s_{r, p p}, s_{q}\right)+r
\end{aligned}
$$

Note-se que $d\left(s_{r(p)}, s_{i}\right)$ foi previamente obtida e armazenada com $s_{i}$ na estrutura de indexaçăo. Na Figura 3.3, a regiāo 1 equivale à condição 3.6 e a rogião 3 à condição 3.7. Qualquer objeto que estiver na regiño 1 ou 3 pode ser descartado através da propriedade de desigualdakte triangular, sem calcular sua distancia com o objeto da consulta. Já na

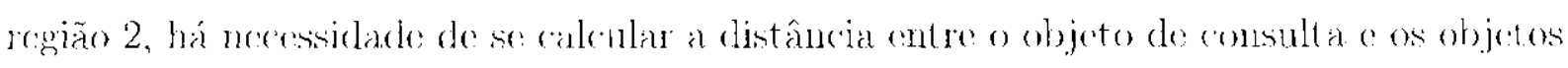
pertencentes à regiào.

Nesta figura, os objetos $\left\{s_{1}, s_{2}, s_{3}, s_{4}, s_{5}\right\}$ pertencem ao ronjunto $S$. Os objetos $\left\{s_{2}, s_{3} . s_{5}\right\}$ poden ser descartados sem nenhum cálenlo de distancia adicional; o objelo s não pode ser descartado, mas não faz parte do conjunto resposta: e $s_{4}$ não pode ser descartado e faz parte do conjunto resposta. A prova do descarte utilizando a designaldade

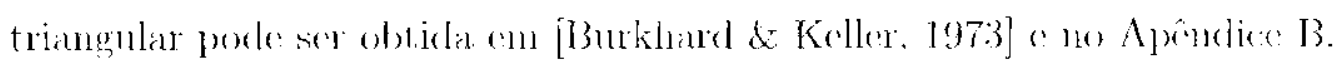

\subsection{Algoritmos para Consultas por Similaridade}

Iniciadmente comsidere-se a descriga de algoritmos para consultas por sinilaridado sem ntilizar uma cotrutura do indexaño especifica. Algoritmos para responder a consultas por abrangéncia tom un: raio limitante conlacedo durante todo o procesco de busca. Assim, 
um algoritmo para consultas $R q$, chamado do Range $\left(s_{q}, r\right)$, calcula a distancia do objeto

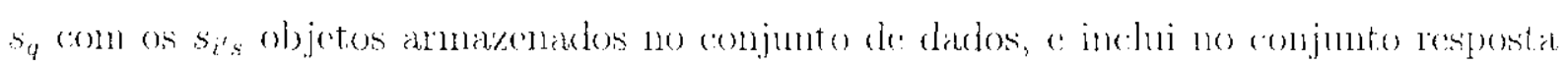
rodos atqueles que estän a inma distancia menor ou igual a $r$.

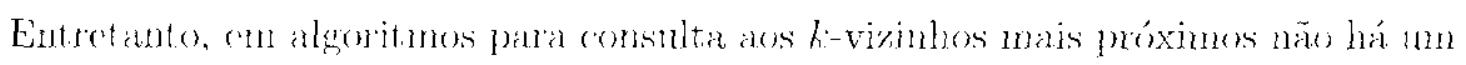
raio limitante conhecido desde o inicio da busca. Portanto, um algoritmo para consultas $h N N$, chamado de $N$ earest $\left(s_{q}, h\right)$, utiliza um raio dinânico o qual inicia con un valor representanclo a maior distancia possível entere os elementes do conjunto de dades $S$ on simplesmente infinito $(x)$. O algoritmo é exerutado calculando-se a distancia do objeto

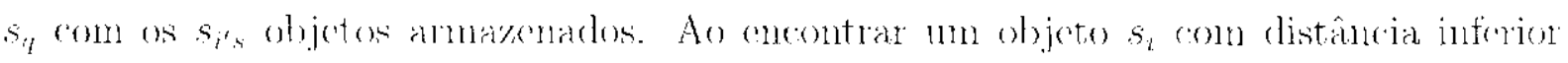
ao raio dinâmico, ele é inserido na resposta. A partir de he elomentos na responta, o raio dinannico vai sendo ajustado. recebendo o valor do k-cimene elenento (o mais distante (encontrado até o momento). Qundo nm objeto s; com distâneia inferior ao raio dinâmico ¿́ encontraclo após haver $h$ elementos na resposta. esse objeto é inserido, o objeto mais

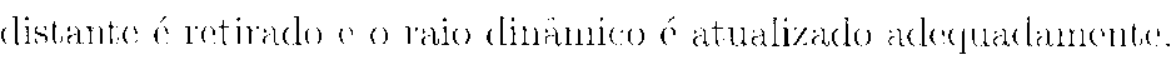

Algoritmos para responder a comsultas por similaridiale utilizando estruturan de:

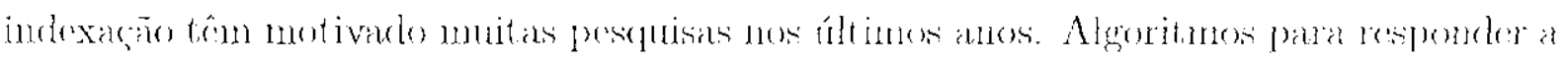
consultas por abrungincia são implementados usando o raio limitante $r$, conhecido desde o início da busca. Asim, una estrutura de indexação em árvore é percorrida da raíz até as suas folhas conciderando: o raio linitante e as proprieclades inerentes da estrutura de indexaçăo e do domninio de dados para limitar o processo do buscar. Em árvoren unétricas

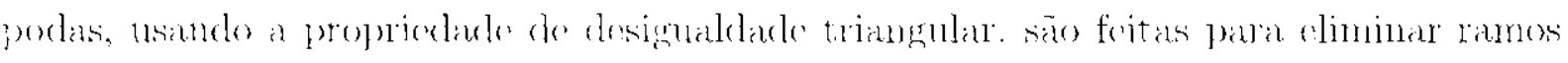
(subárvores) durante uma busca. Portanto, una subádvore é percorrida apenas quanclo

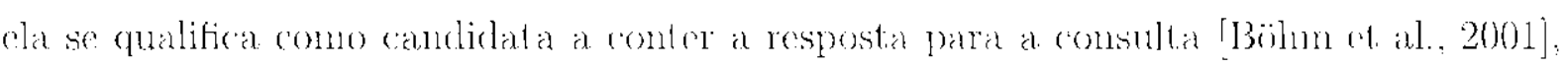

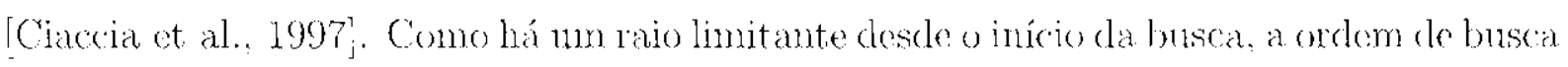
das subárvores nầ é importante om un algoritno Ronge $\left(s_{q}, r\right)$, pois cla nä́o influencia o desmpernluo desse algoritıno.

Como o raio do k-ésimo elemento não é comlecino andecipamente para a consultat

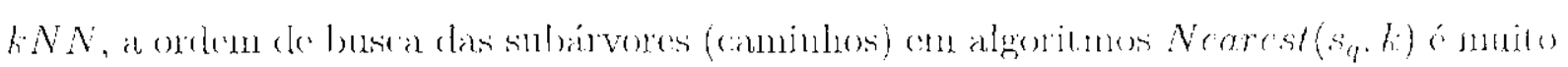
importante. Isso orome porque o raio de um algoritmo Nearesto é clinarnico, sendo progressivamente reduzido à modida que objetos nais próximos são encontrados durante. o processo de travessia da árvore. Conseqüentemente caminbes que encontram objetos mais proximos primeine proporcionam descartal mais subarvores dumbere o processo do

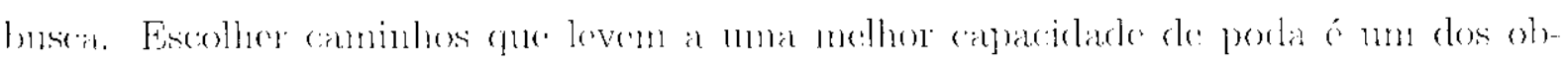
jetivos mais perseguidos no desemvolvimento de novos algoritmos para consultas $h N N$ [Traina Jr. et al., 2002]. Para isso, os algoritmos Nearest) usam listas de priorielade (lo-

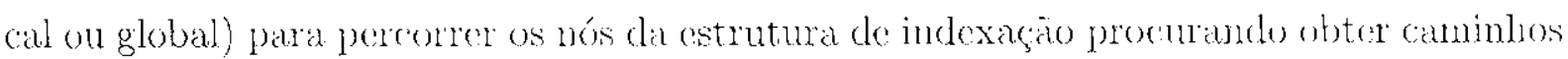
que laven primeiro aos objetos mais próximos [Hjaltason \& Samet, 2003]. Os algoritmos

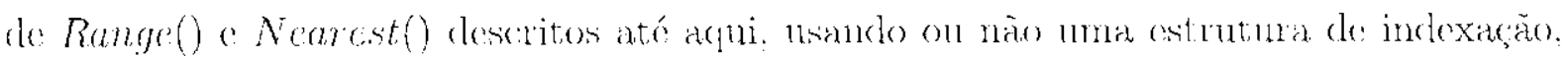
são chamados neste trabalho de algoritmos básicos para as consultas por similaridade".

${ }^{3}$ Alommas variacoes das consultas por similaridade mais comuns sao apresematas ma berao t.:. Lima

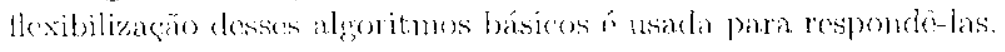


Portanto, devido às caractcrísticas das consult as por similaridade mais comuns, o

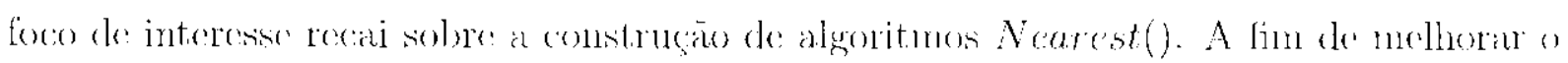
desempenho de consultas $k N N$, vários algoritmos tôm sido propostos por pescunisadoleres usando diferentes abordagens. Entre as abordagens cxistentes, a mais commun fo a branchand-bound. $\mathrm{Na}$ abordagem branch-and-bound a busca começa pela raiz da estrutura de inclexarăo, om cada passo são utilizadas heurísticas para se determina quais nós devem ser examinados e quais porlen ser descartades. As heurísticas comsiderano o domínio

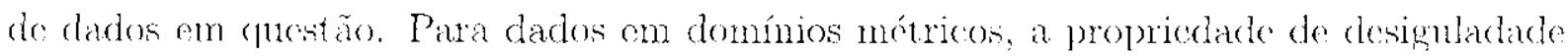
triangular é uma heurística utilizada. Alguns exemplos de trabalhos que proporm algoritmos para consultas kNN segundo esta abordagem, são: [Roussopoulus et i1., 1995: [Benetis et al., 2002], Stanoi ct al., 2000], [Arantes et al., 200331];

A alowdagen que se bascia no uso de algoritmos incrementais para consultas kNN é encontrada nos trabalhos de [Hjaltason \& Samet, 1999], [Park \& Kim. 2003] e [H jaltason \& Samet, 2003]. Esses algoritmos procuram calcular de maneira eficiente os $(k+1)$ vizinhos mais próximos, dado que os $k$ vizimhos já foran calculados. Para isso.

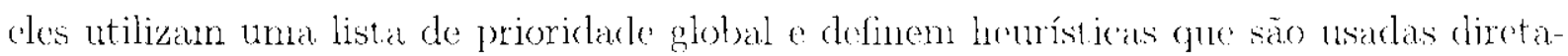

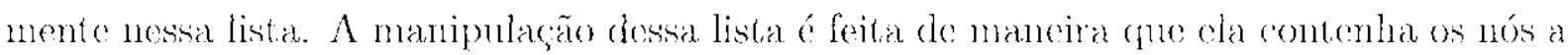
serem percorridos e também a resposta para a consulta (objetos). As heurísticas definidas garantem que us $k$ objetos mais próximos estão sempre no início da lista, e para obter o

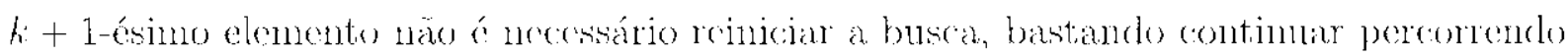
a lista de prioridade a pratir do parseso anterior. onde nesse caso, foi obtido o k-ésimo

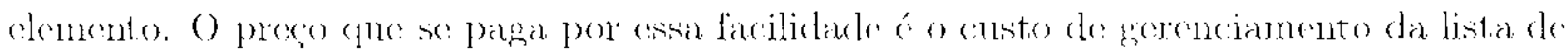
prioridade que pode ser muito (levaldo, degenerando assim o desempenho dessa técnica.

Outros algoritmos para responder a consultas kNN são os algoritunes malli-step propostos en [Korn et al., 1996], [Seidl \& Kriegel, 1998] \& o algoritmo paralelo proposto em 'Berchtold et al., 1997'. 'Todes os algoritmos citados até acpui consideram apenas um rúco predicado por similaridade.

Consultas por similaridade cxccutadas simultaneanente são propostas na literatura nos trabalhos de [Böhn et al., 2000], [Braummiüler et al., 2000] fornecendo mu maior polencial para otinizagão clo gue apenas mua única consulta por similaridarle. Lm parti-

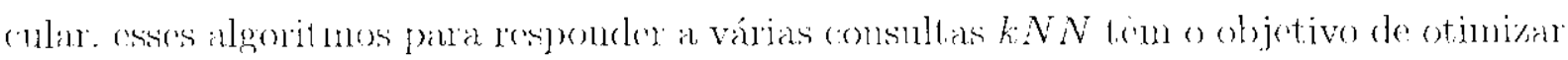
o desempenho de aplicaçós intrnsivas de mineracăo de dados reduzindo tempo a acessos a disco. Entretanto, apesar de várias consultas $6 N N$ seren executadas sinultaneanente. exsces trabalhos näu consideran combinar as consultas por similariclade por mocio de conjunçoss o disjuncóes entre os predicados.

Algoritmos para consultas por similaridade complexas compostas, por mais de um predicado, são destacadas nos trabalhos de [Chaudhuri \& Gravano. 1996], [Fagin, 1996],

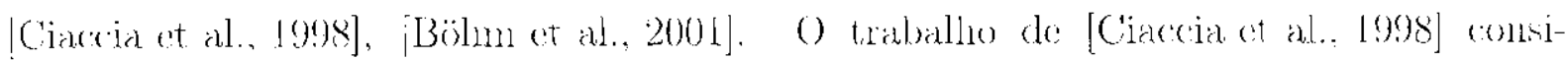
dera apenas una unica caracteristica para avaliar a consulta envolvendo o dark com-

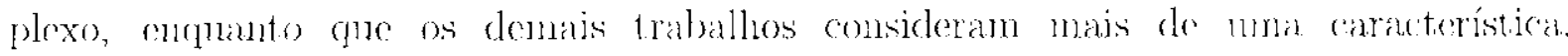


[Chaudhuri \& Gravano, 1996] e [Fagin, 1996] consideram que os dados complexos pos-

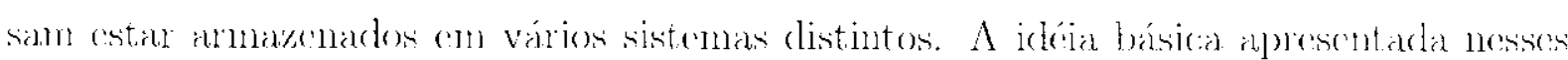
trabalhos ó cue a avaliagâo dos prodicados por similaridade cla consulta náo pode sor ralizada independentenente clesde que a consulta depende dos valores combinados de cada predicado cm sistemas distintos. Já em [Böhn et al. 2001] e [Ciaccia et al. 1998] os antores propoem nsar estruturas do inclexaça com o oljetivo do acolerar as respos-

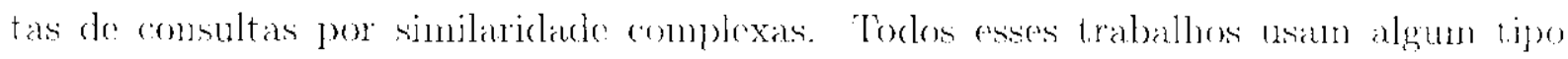
de função de pontuação para avaliar os pontos obtidos pelos objetos em cada predicado por similaridade. Fsssa avaliação determina a pertinência de um objoto à resposta da consulta por similaridade complexa envolvendo mais de um predicado. Segundo os au-

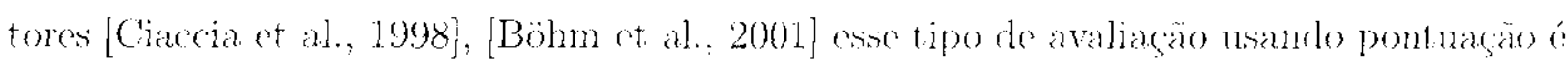
o mais adoqualo para aplicacóos mult inídia especifícas, tais como, a realimentação por relevancia (relenance feedback) [Porkaew et al., 1999].

Algoritmos para executar consult as por similaridade complexas entre os predicados range e k-nearest usando os operadores Boolcanos $\mathrm{E}(\Lambda)$ o OU (V) foram recentemente propostos em [Arantes et al., 20031)], [Arantes et al., 2004]. Esses algoritmos consideram uma úmica característica para avaliar a consulta por similariclate complexa o um mesmo objeto cle referência. Um aspecto importante levantado por esses traballos ć que regras algébricas scguindo a álgobra relacional podem ser aplicadas ans predicados por similariclicle possibilitando-lhes screm otimizados. Portanto, a idéla ć usar cesas regras algébricas para da suporte à incorporagão do consult as por similariclade complexas no Otimizador de consultas de um gerenciador relacional.

Além de algoritmos de busca, estimativas de seletividade tambóm tem sido pro-

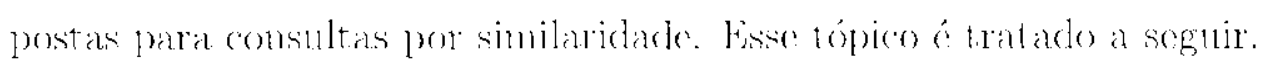

\subsection{Estimativa de Seletividade para Consultas por Si- milaridade}

Um objetivo importante para so estimar a seletividade de un detcrminado atribulo (predicads) ó conseguir predizer cuantas tuplas (objotos) portem ser retornadas por cose predicarto, on seja, a sua cardinalidade. Estiman a cardinalidade para cadla predicado de nuna (onsultia auxilia o Otimizador a determinar o custo computiacional de texlad a comsult a antes de executá-la. Existindo opçóes diferentes para executar uma determinada consulta e sabendo anteciparlanncinte quais serão os recursos utilizados por cla, o objetivo é esco-

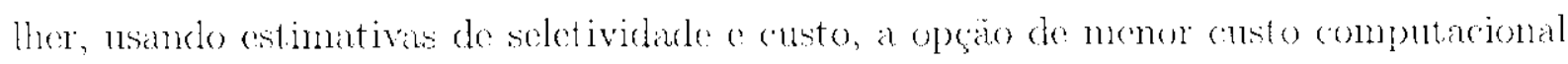
(ver Capítulo 2).

Consikerando estimativas de seletividade para consultas por similaridade, o focr

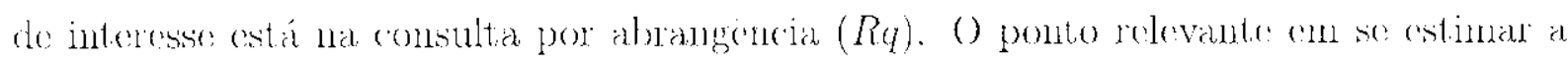

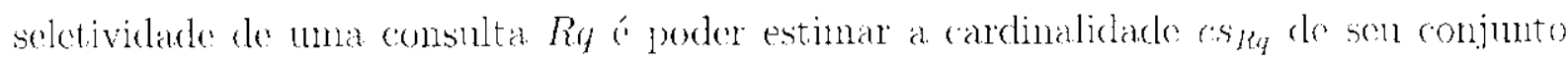
resposta, pois, dependendo clo valor do raio r da consulta. o conjunto cs ra pode conter ale 


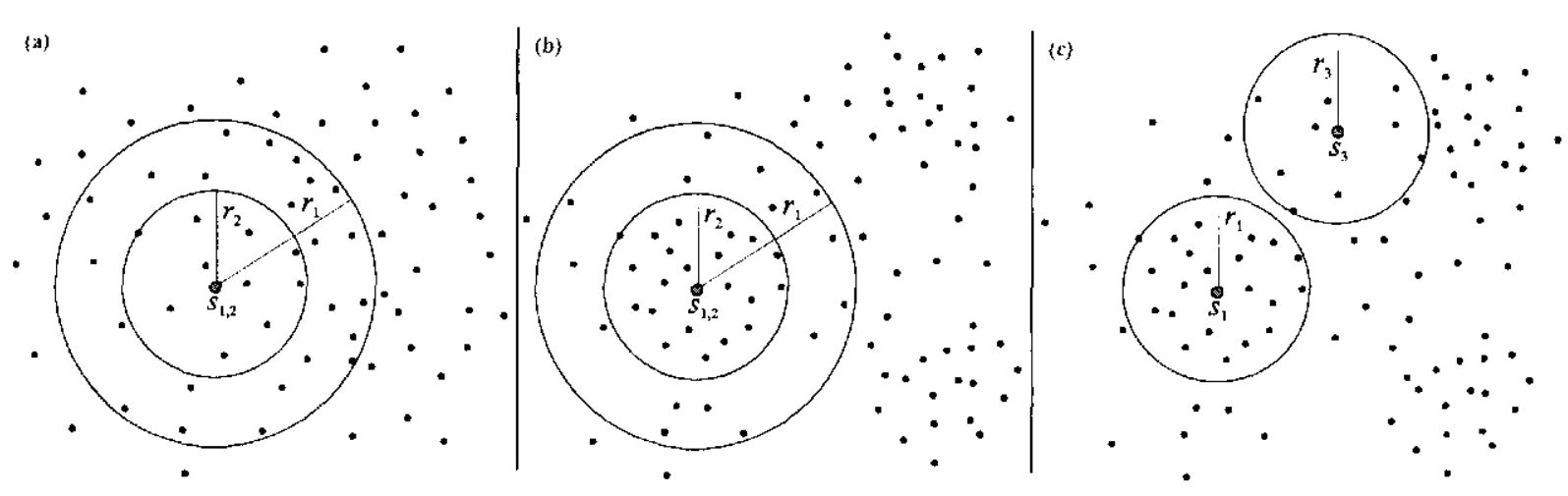

Figura 3.4: Consultas $R_{q}$ e suas seletividades: (a) dados uniformemente distribuídos c as

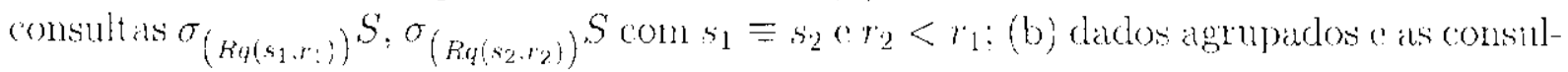

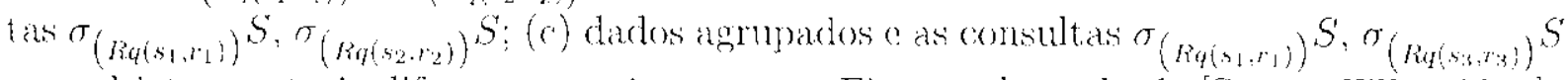
com objetos centrais cliferentes e raios $r_{1}=r_{3}$. Figura adaptada de [Santos Filho, 200:3].

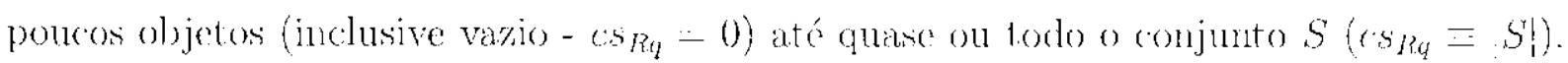
Portanto, láx casos en que a buscin seqüencial pode ter lun custo computacional menor que uma estrutura de indexação. Tin exemplo disso seria quando o raio de busca é relativamente grande; o que ocorre, em geral, quando o numero de objetos retornados supera $10 \%$ do total de objetos de un conjunto de dados.

Alguns fatores influencian estimativas de seletividade para consultas por si-

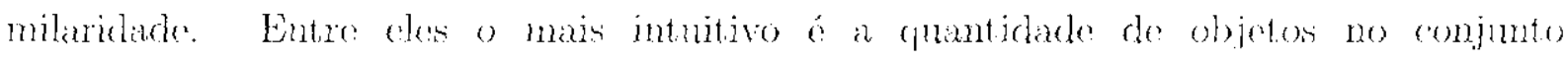

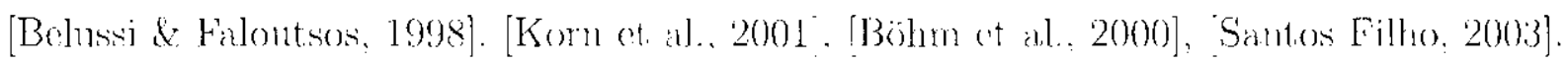

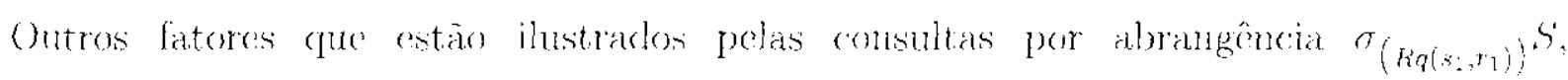

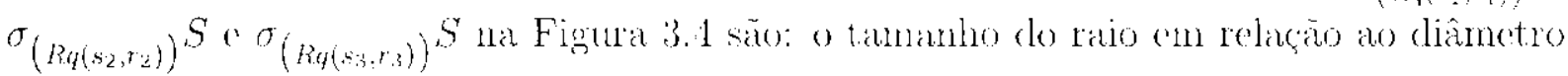
ro conjunto, que corresponde à maior distanncia rentre todos os pares possíveis de objetos

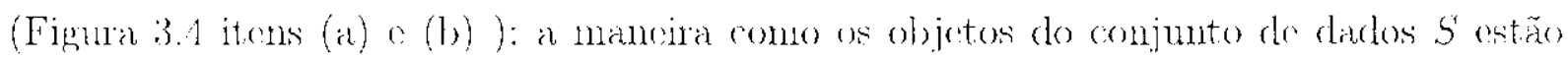
distribúdos no espago (Figura 3.4 itons (a) o (b) ); e por fim a posição do objeto de busca

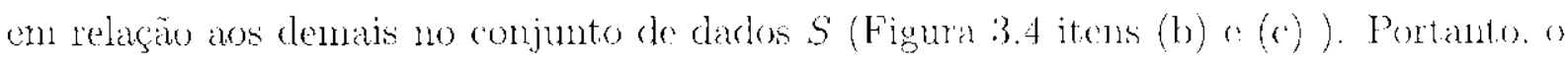
problema que surge é como morlelar a distribução dos objetes, on seja, como considerar a distribuicão desses oljetos 10 o espaço (métrico ou vetorial) para obter uma boa estimativa de soletividade, rlada una determinada consultat.

Consiclerando o espaço velorial, vários trabalkos sobre estimativa de seletivi-

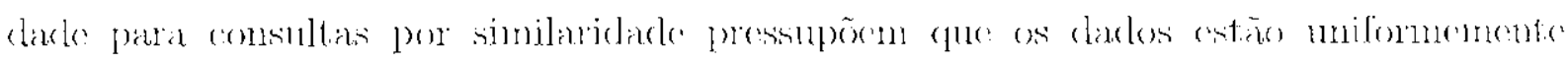
distribuílos no espaco [Faloutsos nt al., 1987]. [Aref \& Samet, 1991]. [Weber et a.., 1998]. [Aggriwal ot al, 2001]. [Böhn et al. 2001]. Segundo [Korn ot a1.. 2001] essat abordagem é freqüentemente utilizada pela sua facilidade de análise. Parn exse caso, a estimativa de seletividade é facihmente obtida em função do numero de objotos no conjunto o do

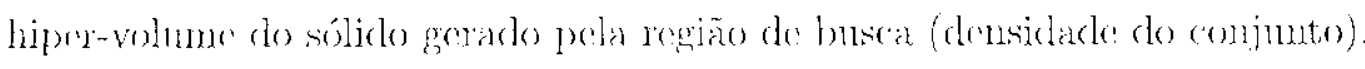

Entretanto, alguns trabalhos encontrados na literatura contestam o fato de os

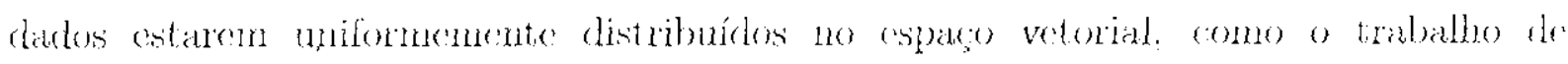

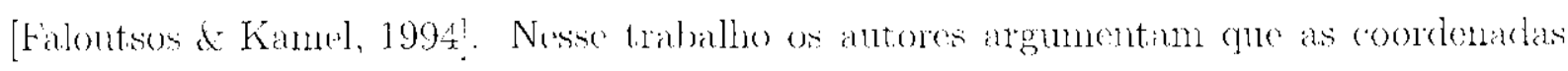
(dimensouen) dos vetores on conjuntos de dados reais tenden a estar correlacionadas entre 
si, tornando a distribuição não uniforme. Como alternativa, propöem aplicar a teoria

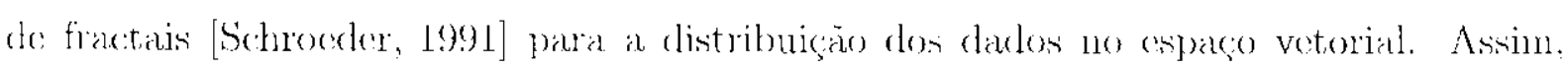
os autores assumem que a distribuição dos dados pessue un comportamento fractal, ou scja. uma distribuição fractal dos dados. A partir dos resultados apresentados em [Faloutsos \& Kamel, 1994], Belussi e Faloutsos desenvolveram fórmulas de estimativa de seletividade para consultas em dados vetoriais [Belussi \& Falontsos, 1995), [Belussi \& Faloutsos, 1998] apresentando resultardes de testes que mostran a precisào cle suas equacơoes. Fin conscyiuencia disso, trabalhos mais recentes, como os de ¿Böhm et al., 2000], [Korn et al., 2001], começaram a analisar os conjuntos do dados reais, assumindo cue os dades cstão distribuidos no espaço votorial de maneira náo uniforme, insurelo a teoria de fractiais.

O trabalho proposto em [Traina Jr. et al., 2000al, para espaços métricos, também segue a tendência desses trabalhos desenvolvidos para o espaço vetorial mas usando a

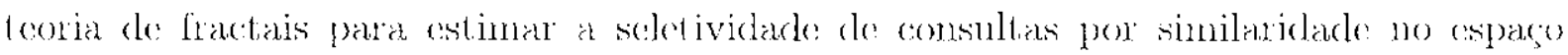
métrico, onde essa distribuiçăo se caracteriya pela Dimensão Intrínsica ou Dimensão de Correlação Fractal do conjunto.

\subsubsection{Dimensão de Correlação Fractal}

A dimensão intrínsica on Dimensão de Corrclação Fractal - DCF de um conjunto de dados é definida como o número mínino de variáveis livres necessárias para representar

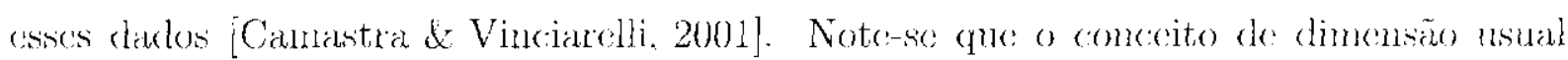
se refore à dimensão de imersão e corresponde ao número total de coordenadas que definem o espaço vetorial. Para cxemplificar a diferença entre dimensão de imersão o dimensão intrínsica, considere-se a Figura 3.5. Essa figura apresenta os conjuntos $M$, $N$ e $P$, compostos por clados pontuais alinhados, imersos em uma, duas e três dimensóes. Entretanto, usatr o valor très para caracterizar esses conjuntos transnite uma "idcia" muito matior de volume do que o realmente ocupado por eles. Assime considerando o conceito de dimensão intrínsica tem-se que os conjuntos $M, N$ e $P$ podem ser representados por apenas uma variável e, portanto, possuem dimensão íntrinsica um, independente de qual é a dimensão do espaco onde o conjunto de dados está inerso. Gencralizando. un conjunto

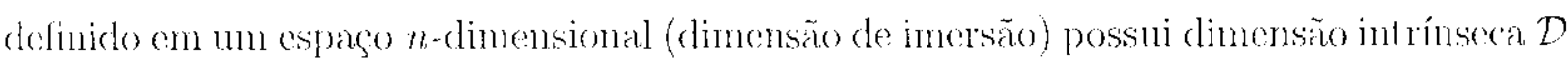
$(D \leq n)$ se os dados "cabem" inteiramente (podem ser totalmente imcrsos, representados) em um subespaço D-dimensional [Camastra \& Vinciarelli, 2001]. Assim. tom-se que a dimensà intrínseca dos conjuntos $M, N$ o $P$ da Figura 3.5 é um.

A distinção entre dimensão de imersão e climensão intrínseca tem sido muito utilizada no contexto de dados espaciais como um nodo de avaliar quanto a distribuiça do um conjunto diverge da distribuição uniforme [Korn et al., 2001], uma vez que conjuntos

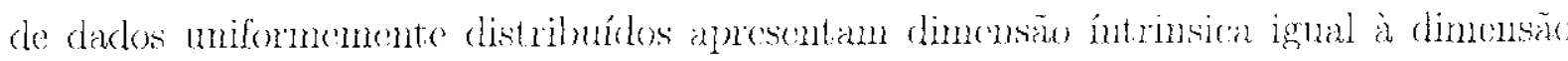
de inersão. A importanncia da dimensão intrínseca ó ainda maior no contexto dos espa-

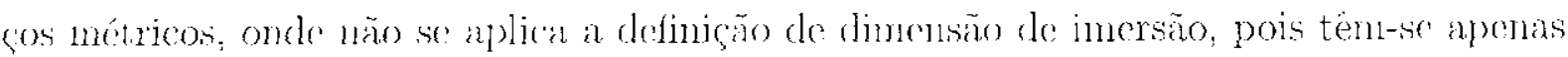




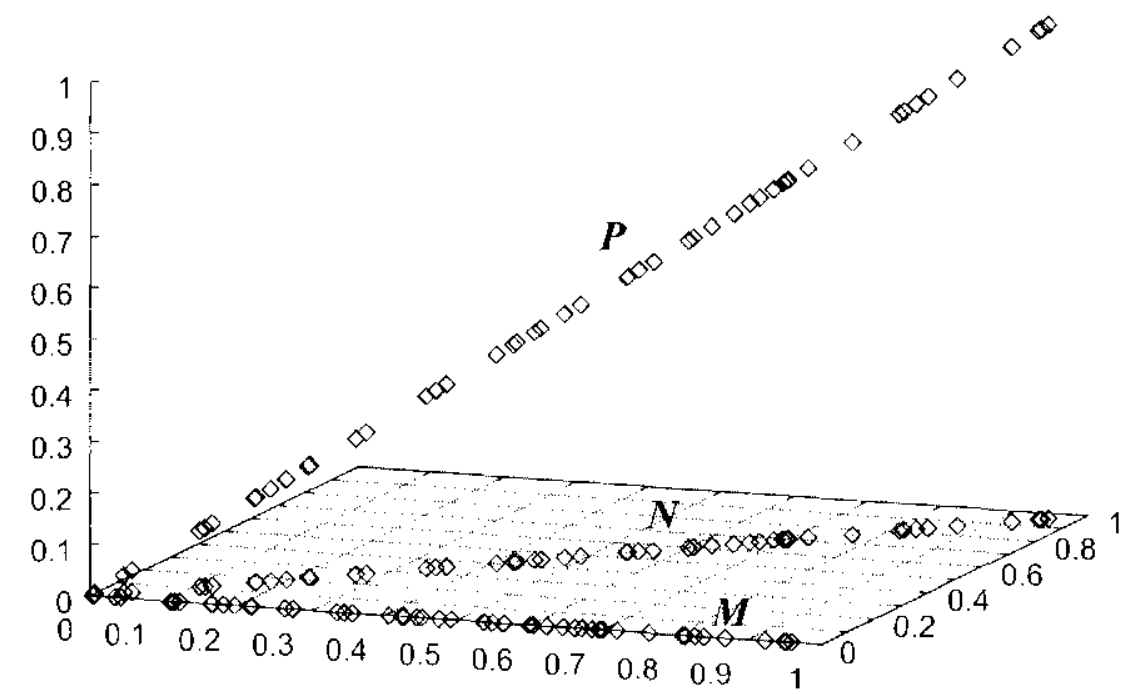

Figura 3.5: Conjuntos $M$. N e $P$ connpostos por dados pontuais distrilunídos an longo de uma linha e imersos om una $(M)$, duas $(N)$ e três $(P)$ dimensiós

objetos e distâncias.

Considerando espacos mótricos, a distribuciço de distanncias contre pares de elementos na maionia dos conjuntos de dados reais näo segue qualquer distribuiçäo estatística traclicional, tais como Gaussiana ou Poisson, porén cusa distribuição possui um conportamento fractal [Traina Jr. et al., 1999: [Traina Jr. et al., 2000a], [Faloutsos et al., 2000].

Para conjuntos de dados que possuem comportamento fractal, dado um conjunto de dados com $\nu$ elenentos e com função de distáncia métrica d $\left(s_{i}, s_{j}\right)$, o mímero médio $k_{r}$ cle vizinhos dentro de uma dada distancia $r$ é proporcional a $r$ elevado a $\mathcal{D}$. Assima a quantidade do pares do clementos dentro de una distancia $r$, isto é $P C(r)$, segue a lei de poténcia [Traina Jr. et al., 1999: [Traina Jr. et al, 2000ad, Arantes ot al., 2003al]:

$$
P C(r)=K_{p} \cdot r^{D}
$$

onde $K_{p}$ de a constante de proporcionalidade. e $D$ é a Dimensão de Correlaşan Fractal (DCF) do conjunto de dados.

Sompre que um conjunto de dados apresenta unna função de distância métrica entre pares de elementos: um gráfico descrevendo a distribuição de distâncias pode ser

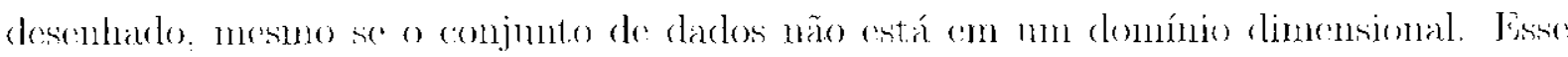
gráfico contendo o núnero de pares dentro de um raio $r$, quando tragado em escala log-log. é chamado distance plot [Traina Jr. et al., 1999!, e para a maioria dos conjuntos de clados reais resulta em uma linha quase reta para uma faixa significativa de distancials.

O ângulo formado pela linha tangente à distribuigano das distânclàs no distence

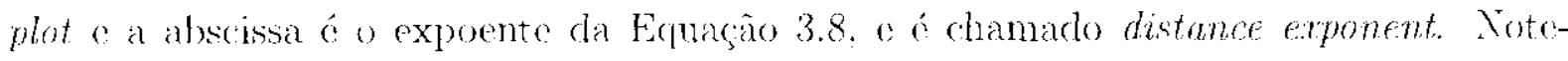
se que. $\mathcal{D}$ se aproxima muito da DCF de um conjunto de dados e, portanto, de slla

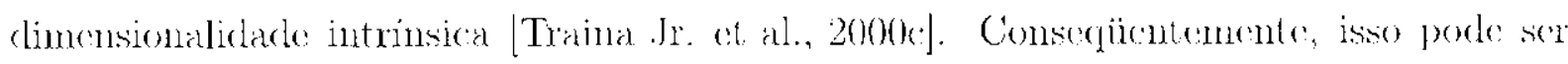
visto cono uma medida de como os elementos no conjunto de dados cstäo distribuídos. mesmo gue o conjunto de dados não tenlan propriceliale espacial. 


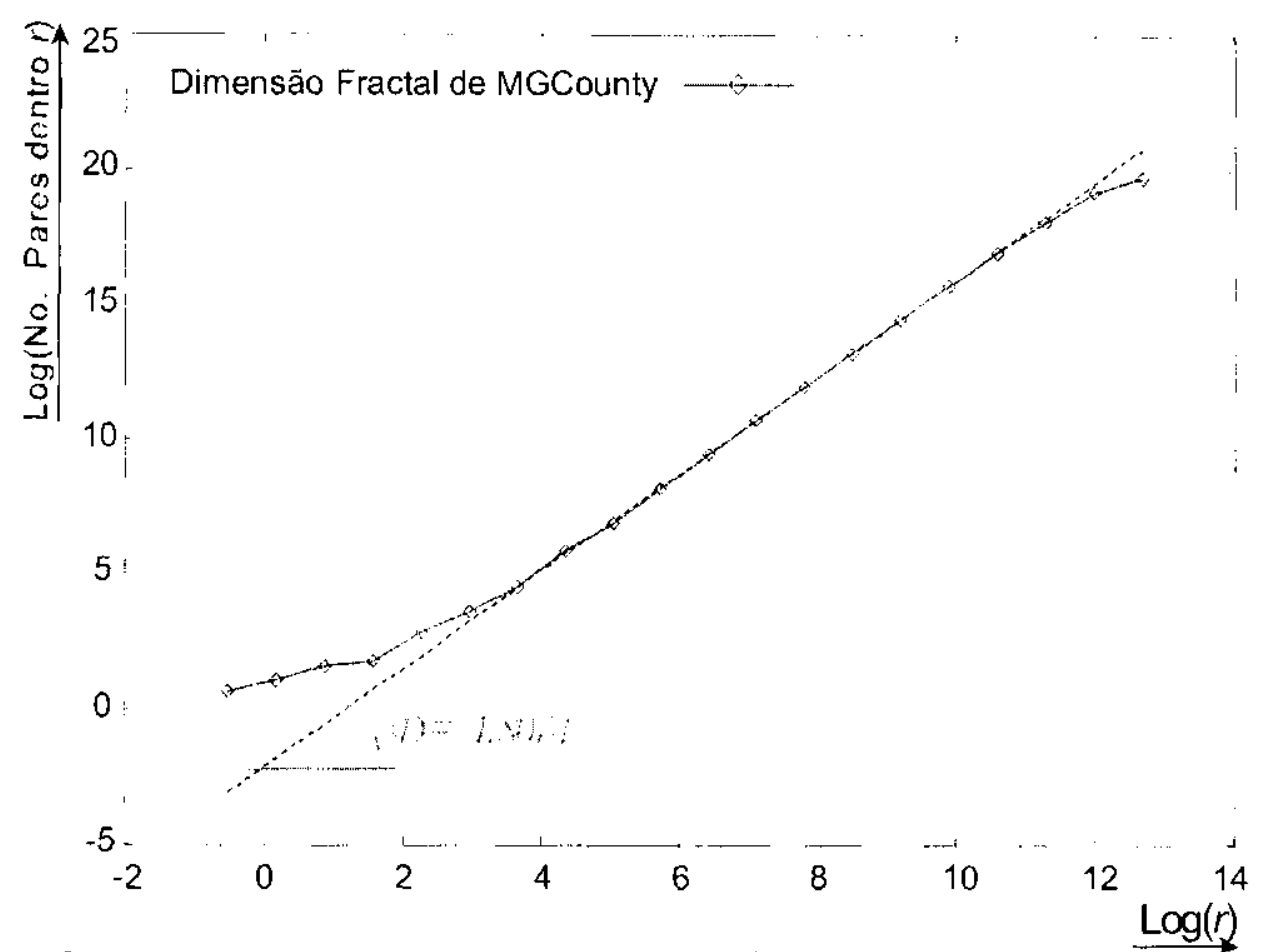

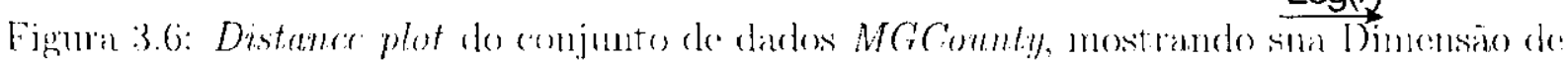
Comelaga Fractal $\mathcal{D} \approx 1.81$.

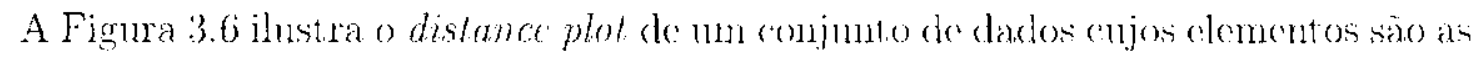
coordenadas geográficas das intersecgoes de mas e estradas do condedo de Monlgomery nos Estackes Uniclos (MGCounty - ver Capítulo 6). Observe-se que o gráfico é linear pata un ample intervalo de raios que corresponde às distancias típicas envolvidas 100 conjunto de dados. As regiones do raios muito prepuenos on muito grandes não apresentam essa caracteristica do linearidade. Essas regiones representam raios chjas distancias mujo raramente são desejadas por nma consulta por similaridade. Śndo assim. clas näo săo importantes para as consultas por similaridade que deven sor tipicamonte respondidas e: portanto. a hăo lincaridade porde ser desconsiderada.

Usaudo gráficos como esse, o distance exponent $\mathcal{D}$ de equalcuer conjunto de dados

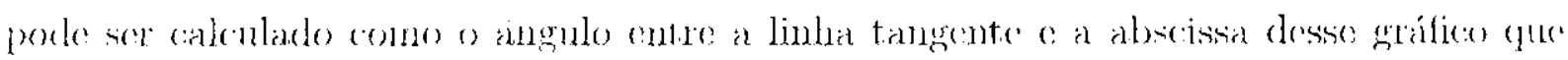
melhor se arlecpue a curva resultanute no distance plot. Portanto. consinderando a Figures 3.6. a equagio 3.8 pode ser cepressia como

$$
\log (\Gamma C(r))=\mathcal{D} \cdot \log (r)+K_{d}: K_{d l}-\log \left(K_{p}\right)
$$

O distanere enponent tem outras propriedades interessantes derivadas da Dimen-

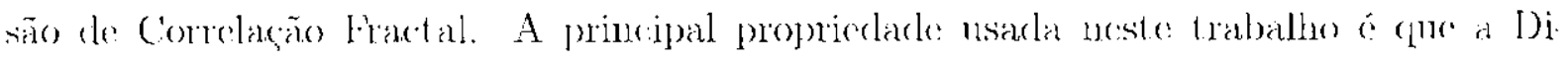
mensão do Correlagaio Fractal $\mathcal{D}$ ó invariante ao tamanho do conjunto do darlos, desde

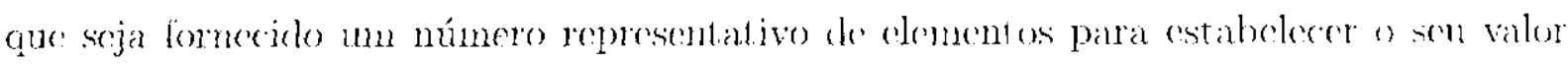
[Faloutsos et al., 2000]. Portanto, os angulos das linhas correspondentes aos conjuntos de dados obtidos do mesino domínio de dados são sempre os mosmos. Isto permite que,

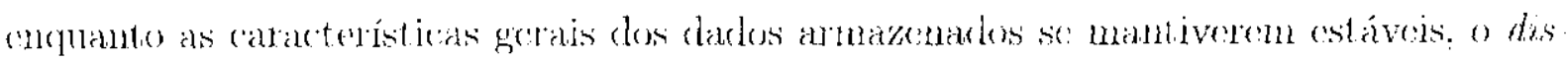

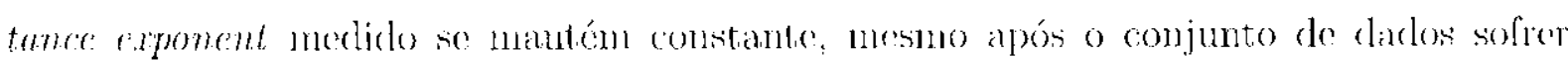

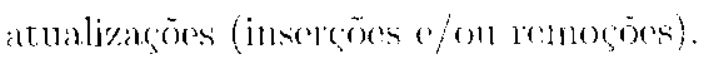




\subsection{Conclusão}

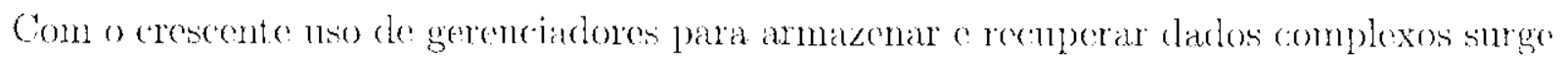
a nocosidade deles responderem a consultas basearlas no conteído dos dados por meio de similaridade. Entre os diversos tipos de consultas por similaridade as mais utilizadas sào as por abrangencia e aos k-vizinhos mais próximos.

Os espagos métricos constituem uma formularão matemáticapropriada para abordar consultas por similaridade, pois para cles estas são operaçoes naturais. Bascando-se apenas cm uma funça de distâneia métrica e em suas propriedacles é possível elaborar técnicas de indexação eficientes capazes de responder a essas comsultas. Porém. a clefiniçio

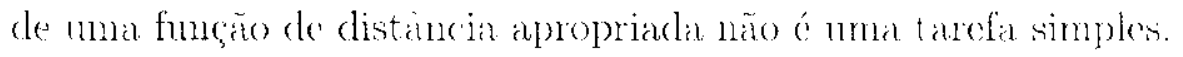

A sclotividade para comsultas por similaridade, bem como algoritmos para responder a essas consultas sino tópicos discutidos por vários trabalhos na literatura. Para. rstimativas de seletividade, o foco de atenção se detém en consultas por abrangênuia, onde modelar a distribuiço dos dados é o principal problema. Apesar de năo haver un

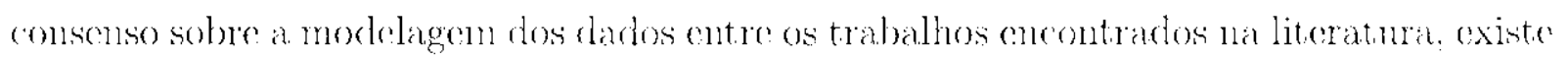

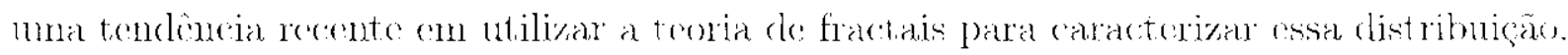

Algoritmos para responder a consultas por similaridade usam métodos de acesso, como por exemplo os MAMs, para melhorar o desempenho. Diversas aborelagens já foram propostas, principalmente para acclerar a resposticl a consultas anos h-vizinhos manis proximos. Entretanto, apesar da necessidade crescente do lidar com dados complexos em

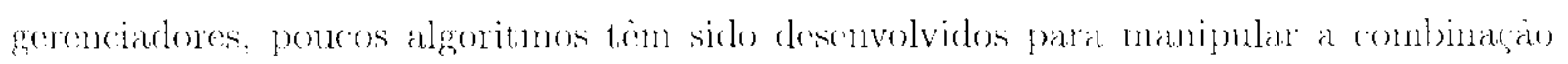

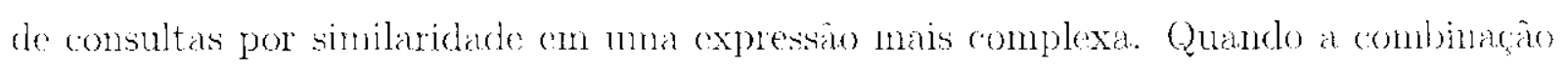
dos predicados por simbiaridade säo considerados, an maioria dos algonitmos resenvolvi-

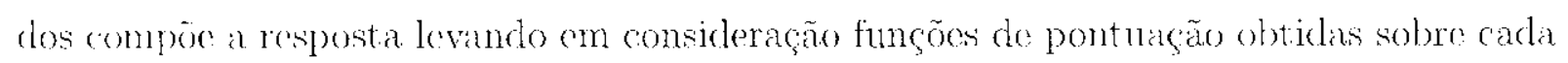
predicado e năo operaçós booloanas crutre eles.

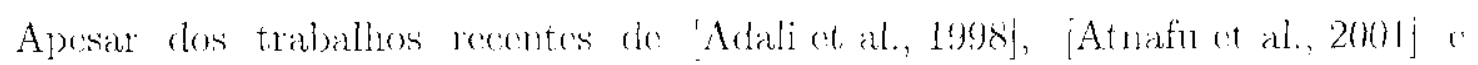

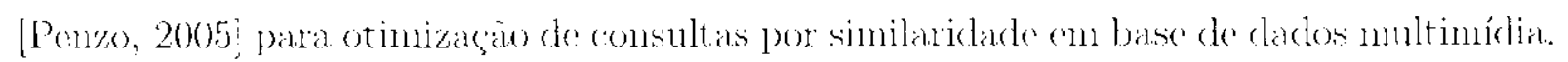
nenhum trabalho (onsidera otimizaços para os operadores de solncano por similaridade em expressões complexas usando operagöos Booleanas em CNF ou DNF. Operaçö́s booleanas entre predicados seguindo a álgebra relacional são operaçoes típicas de gerenciadores

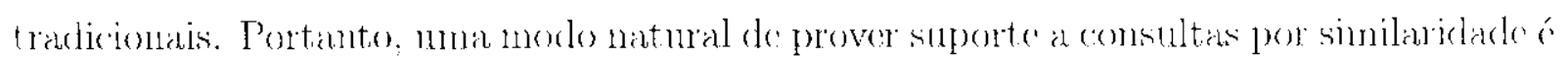
fornecer regras algébricas segundo essa álgebla e algoritmos de busca especificos para responder a uma consulta por similaridade complexa por meio de operadores Booleanos contro os predicados por similaridade. Esses aspectos estão entre os necossádos para incorpo-

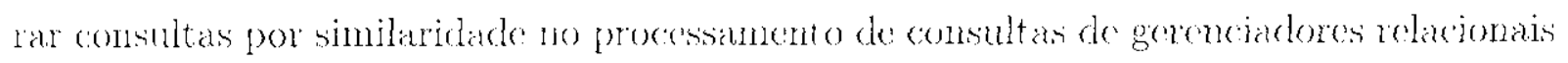
atuais segundo a estrutura já existente e säo apresentarlos no próxinuo capítulo. 


\section{Capítulo}

4

\section{Regras Algébricas e Algoritmos}

\subsection{Introdução}

$24 \begin{aligned} & \text { egras algébricas são do suma importancia para gerar planos alternativos para } \\ & \text { una determinada expressão do consulta. Com essas regras, o Otimizador de }\end{aligned}$ consulta inicial. Esses planos são avaliados pelo Otimizador levando en consideracão us algoritmos presentes no Executor para cucollore entre os planos a de menor custo computacional. O plano escolhido é (ntão passado para o Executor que se encarrega de executar al consultia.

Consultas por similaridane são as mais adequadas para manipular dados om domínios complexos. Un gerenciador relarional que de suporte a dades complexos deveria incorporar essas consultids segundo os padrós já existentes no processamento de consultas. A numeira natural para isso é fornecer suporte a consultas por similaridade na álgebra relacional que representa a base das operagoes nos gerenciadores atuais e mas linguagens do comsulta, tais como a $\mathrm{SQL}$.

Dentro do ambiente necessário para dar suporte a consultas por similaridade no processamento de comsultas do lum gerenciador relacional, cote capítulo apresenta regras algébricas a algoritmos para consultas por similaridade complexas compostas de dois ou mais predicados pon similaridade combinados pelos operadores Borlennos $\wedge(\mathbf{E}), \vee(\mathrm{OU})$ (? (Negação).

Para analisar as expressoes representando consultas por similaridade complexas

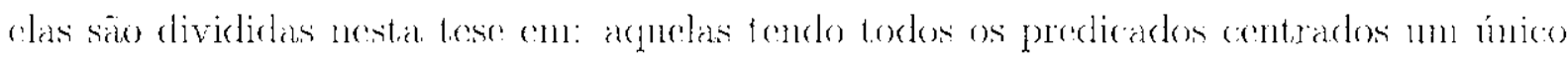

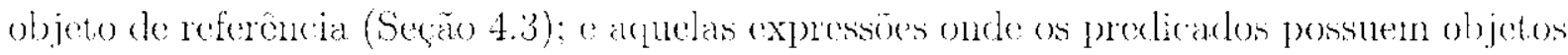
contrais diferentes, contros distintos on múltiplos contos (Seçäo 1.1). Expressoes onde 
cada predicado tem un ńnico centro sào subdivididas em: apenas un ínico tipo de

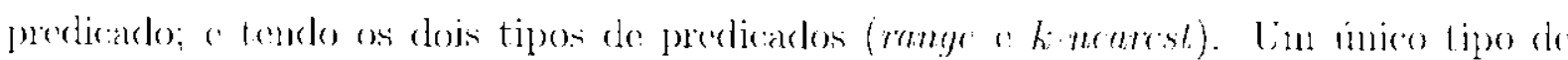
predicado significa apenas predicados do tipo range on k-ncanest, porlendo inchur fodat. as shas variaçoes (Seçu 1.2 ).

Portanto, uma expressão por similarjade complexa ć dividida em trés chsses: Mesmo Cintro/Mesmo Tipo de Prodicado (Single Center/Single Predicate - SCSP): Wesmo Centro/Tipos do Prediondos Diforenles (Single Center/Multiple Predicale types -

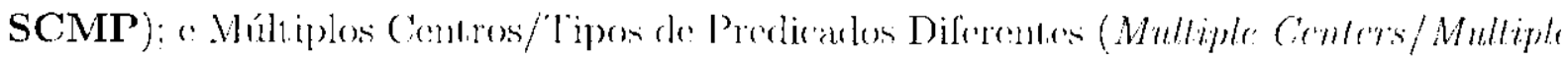
Predicate types - MCMP). Vale lembrar que essas expressóes são analisadas consideraselo que os predicados pertencem a un conjunto de dados $S \subseteq \mathbb{S}$ de mon expaco métrico

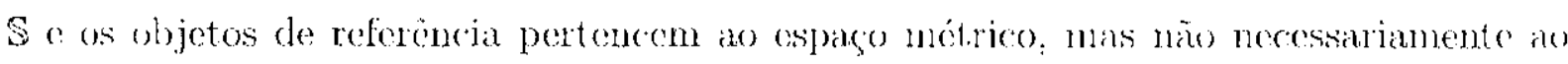
conjunto do dados ammazenado $\left(s_{q} \in \mathbb{S}\right)$. Fssa análise também considera que uma únjea

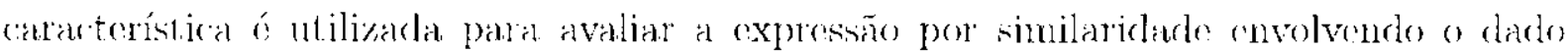
(comploxo.

Como un ponto de partida para que possan ser definidas maras algébricas e algoritmos para comsultas por similaridade complexas em gerenciadores relacionais, inici.

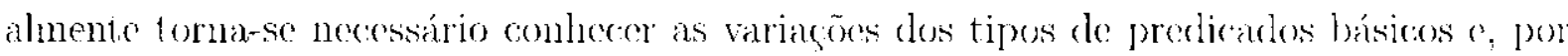
consecüiencja. os sous algoritmos correspondentes.

\subsection{Variações dos Tipos de Predicados Básicos}

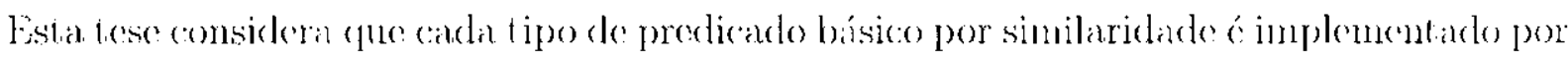
um algoritmo básico. porén flexível. visando a coblir o maior múmero de opecoes possiveis de consultas por similaridade. Assim. o predicado range $R q\left(s_{q} . r\right)$ é implementado pelo algoritmo Ronge $\left(0, s_{q}, r\right)$ ro prodicalo $k$-nearest $k N\left(s_{q}\right)$ e implementado pelo algoritmo $\left.\operatorname{Niarcst}(\theta), s_{q}, k\right)$

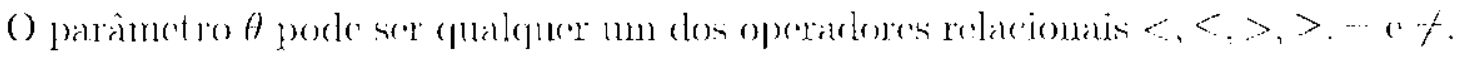
Esse parâmotro indica como a distância de cada elemento no conjunto de dados so compara com o vaio $r$ em relaça ao objeto de reforencia $s_{q}$ em predicados rangr. Para joredicados $k$ -

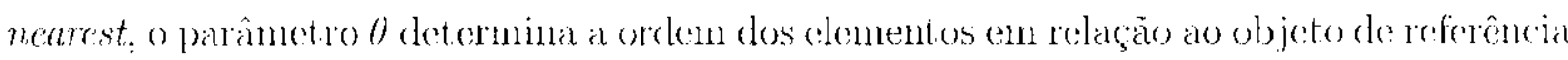
$\therefore$ para obter o mimero de clementos descejados nesso tipo de predicardo. Os predicardo

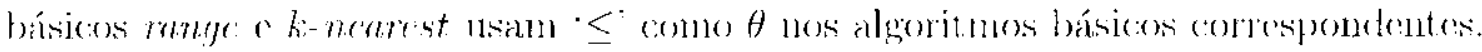

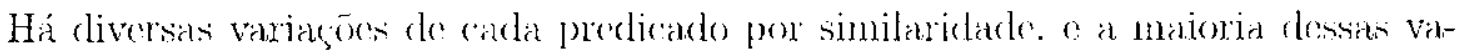
riaçoes podem ser implementadas usando os dois algoritmos básicos, paranetrikando-os para se adequarem ia comsulta desejaxla. As primeiras variaçoes dos predicados básicos säro os casos limites dos predicados range o k-nearest, respocidivancute, (fuande o raio é igual a zoro $(r=0)$ e o núnero de vizinhos é ignal a um $(k=1)$. O algoritmo Rango( $\left.\leq: s_{q}, 0\right)$

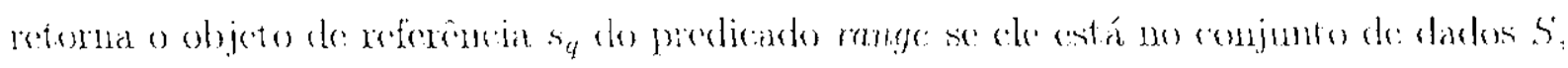

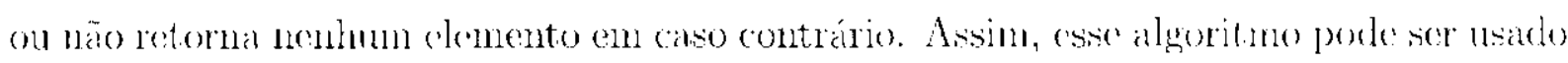
para responder a uma consulta Pontual (Point Query) om um prodicado Pqúsq). Já o 
algoritmo Nearest $\left(\leq \leq s_{q}, 1\right)$ retorna o elemento mais próximo do objeto de referencia $s_{q}$ para o predicarlon $N N\left(s_{q}\right)$.

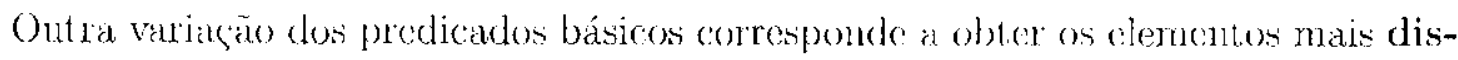
tantes an invés doe main proximes. Ansim, o predicalo reversed range $R q^{-1}\left(s_{4}\right.$.r) retorna

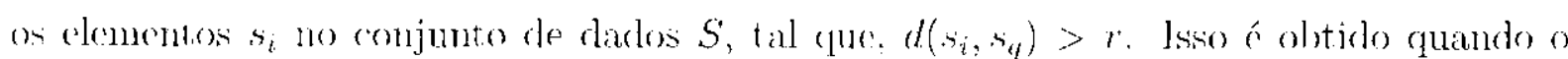
parânetro 0 no algorituno Range () 60 operador $>$. O predicado k-farthest $k F N\left(s_{q}\right)$ retorna os $k$ elementos mais distantes ao objeto de roferencial sq. Da mesma maneina que

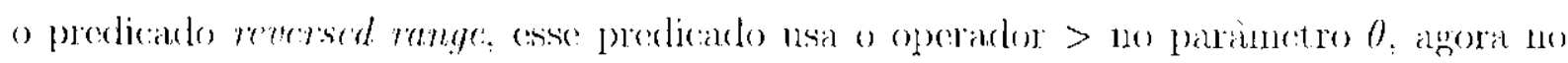

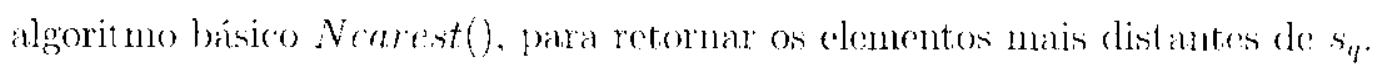

Além das variaçós apresentadas para os predicados básicos por similaridade ó

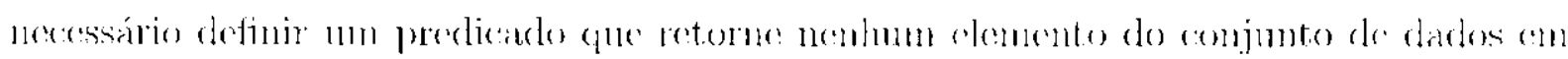

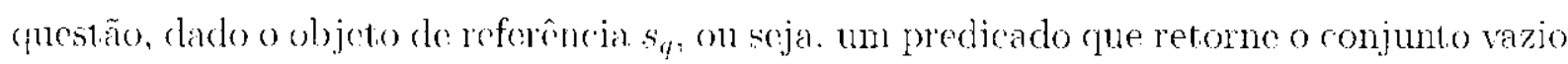
(0). Esse predicado é importante por ser utilizado nas regras algébricas apuresent adas nas

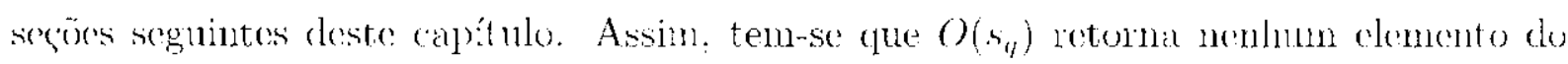

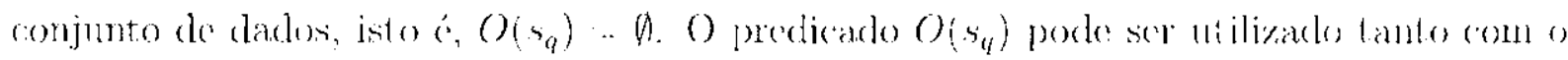

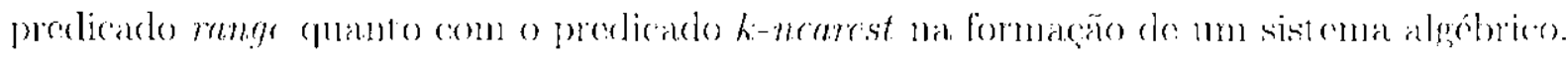

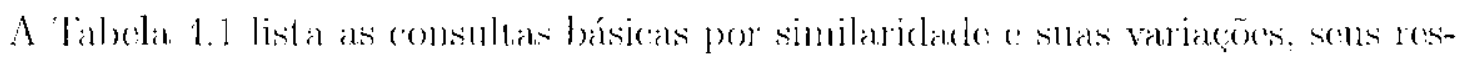
pectivos predicados. e como csses predicados säo implementados usando os algoritmos básicos. Nosta tose sĩo usados apenas os operadores $\leqslant 0\rangle$ como $\theta$ para os algoritmos básicos por similatriclarle. A Tabela 4.2, para facilitar a leitura deste capítulo, smmariza os principais símbolos usaclos; envolvento as expressōes complexas por sinilaridarle. Consul-

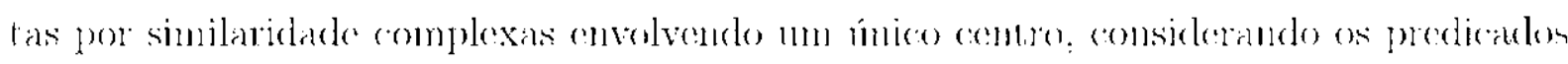
bísicos por similaridado e suas respectivas variaçoes são as primeiras expressoncs a serem atlalisiadats.

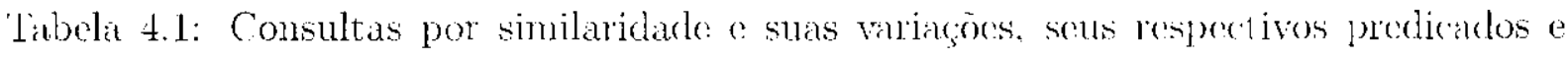

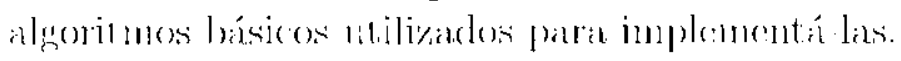

\begin{tabular}{|c|c|c|}
\hline Consultas & Predicados & ritmos \\
\hline por Abrangência (Range Query) & $R_{q}\left(s_{q}, r\right)$ & 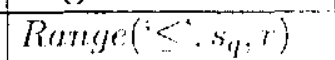 \\
\hline & $P\left(s_{q}\right)$ & Range $\left(<\leq: s_{4}: 0\right)$ \\
\hline sa (Reverst. & $R_{q} q^{-1}\left(s_{q}, r\right)$ & Rangre( $\left(>s_{q}, r\right)$ \\
\hline$r$ Query) & $k N N\left(s_{q}\right)$ & $\operatorname{cst}\left({ }^{\circ} \leq s_{q}, k\right)$ \\
\hline & $N N\left(s_{q}\right)$ & $f\left(\leq \leq s_{q}: 1\right)$ \\
\hline & $\angle F N\left(s_{q}\right)$ & $\left(>s_{q}, k\right)$ \\
\hline as & $\begin{array}{c}F N\left(s_{q}\right) \\
O\left(s_{q}\right)\end{array}$ & $s\left(1>s_{q} .1\right)$ \\
\hline
\end{tabular}


Tabela 4.2: Principais símbolos usados em expressós por similaridade complexas.

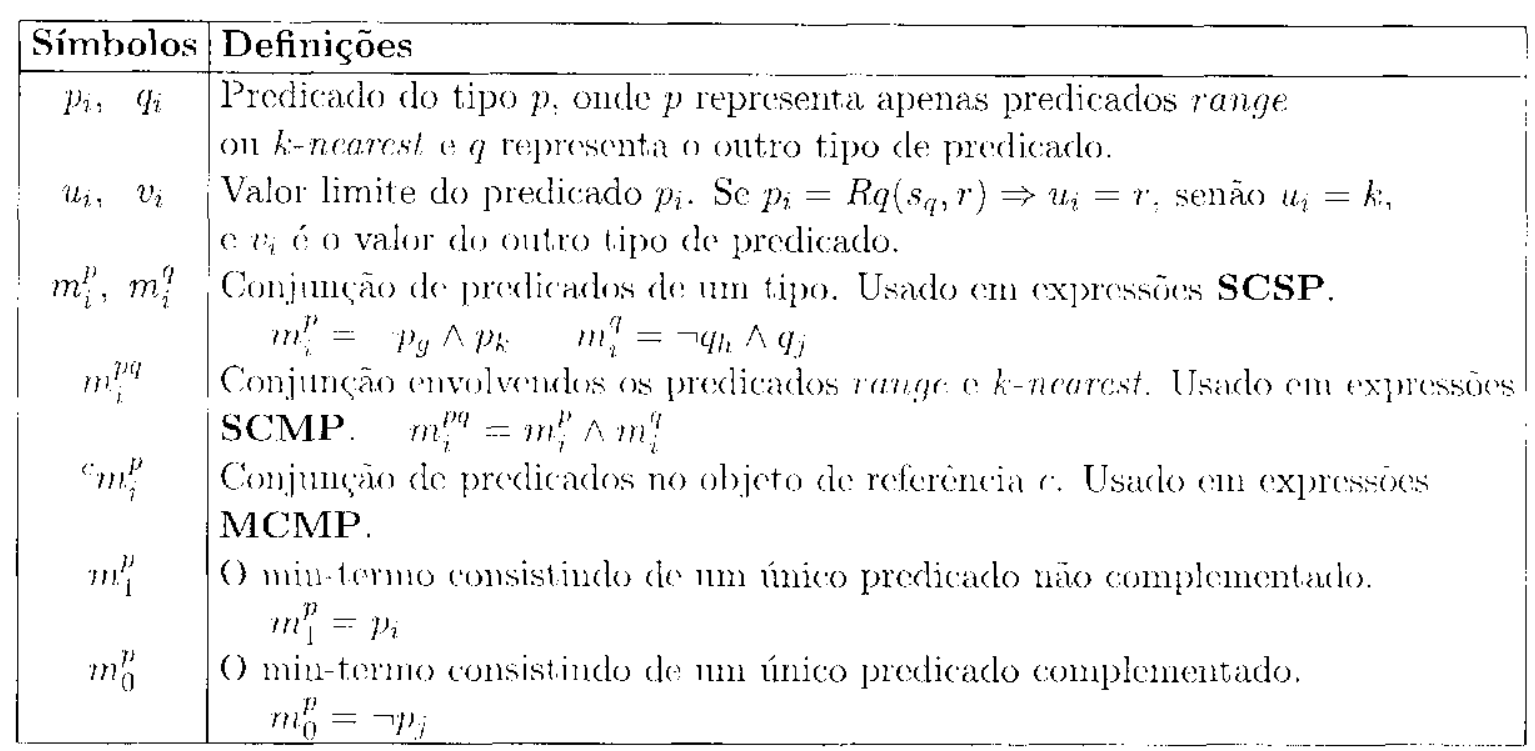

\subsection{Consultas por Similaridade Complexas com Mesmo Centro}

Consultas pol similaridade complexas com un único centro podem ser formadas apenas por predicados do tipo range e subs variagoes, aperas por predicandos do tipo k-neamest

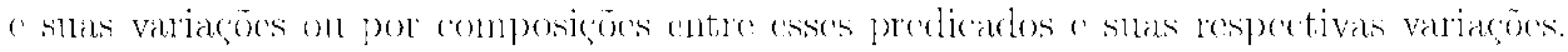
Inicialmente, considerem-se consultas por similaridade complexas envolvendo aryus predicados do tipo range ou k-nourest e suas respectivas variagors. Fssas consultas formam expressoos chanadas neste traballo do expressoes SCSP

\subsubsection{Expressões SCSP}

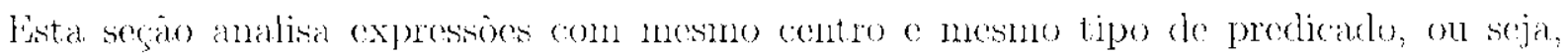
expressōes SCSP. A análise dessas expressöos iniciat-se considerando apenas un predicado básico por similaridado com o operador - Seja y a cardinalidade do conjunto do dados $S \subseteq \mathbb{S}$ : quer dizer, $\nu=|S|$. Assim, as duas propriedades seguintes podem ser definidas.

Propriedade 1: Complemento de Consulta por Abrangencia-O complemento do

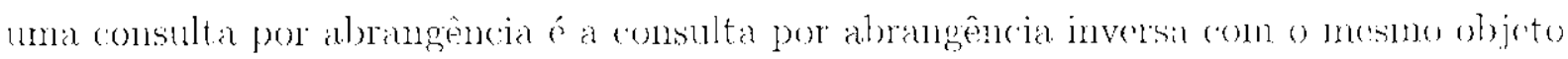
de referêrucia c: o mesmo raio de consulta, então tem-se:

$$
\sigma_{\left(-\operatorname{lig}\left(s_{q}, r\right)\right.} S \Leftrightarrow \sigma_{\left(H_{q}-{\left(s, s_{y}, r\right)}\right)} S
$$

\footnotetext{
1 o bono do texto. por simplicidado, os termos mane o k-nearest podem ser utilizados tamben par representar as variacoess de seus respectivos predicados. Isso f feito. geralmente, an frases onde o termo predicado está no plural. For exemplo, a frase "... us predicałos range...", se refere ao predicado básico range $h \eta(s, r)$, como também as suas variagöos
} 
Propriedade 2: Complemento de Consulla aos k-Vizinhos Mais Próxmos -

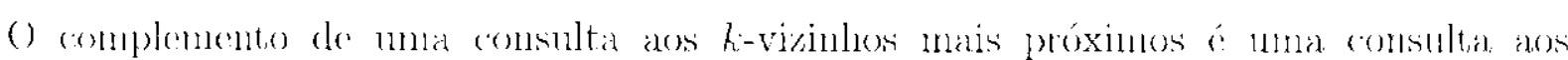
ki-vizinhos mais distantes com o mesmo objeto de referencia e o número de clementos desejados $\bar{k}$ ignal an número total de elementos $y$ no conjuuto de dados $S$ menos $k$. Então tem-se:

$$
\sigma_{(\neg N N N(s, n))} S \Leftrightarrow \sigma\left((1, h) F N\left(s_{1}\right)\right) S^{S}
$$

Conjunçoos e disjunçós de predicados range satisfazem as seguintes propriedades, onde min representa o mínimo entre dois valores e max o máxino cutro clois valores.

Propriedade 3: (Rq e $\left.R_{q}\right)$ com mesmo contro - A conjunção de dois predicados range ó equivalente a um único predicado range tendo o menor valor entre os raios dos

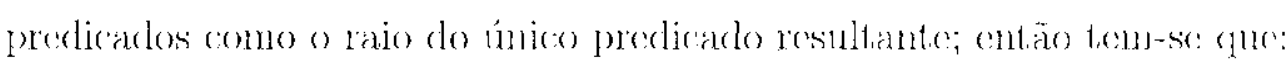

$$
\begin{aligned}
& \sigma_{\left(R_{q}\left(s_{q}, r_{2}\right)\right.} S \cap \sigma_{\left(h_{i\left(s_{q}, r_{2}\right)}\right)} S \Leftrightarrow \\
& \left.\sigma_{\left(\operatorname{lrq}\left(s_{q}, r\right), \wedge R q\left(s_{q}, r_{2}\right)\right.}\right) S \Leftrightarrow \\
& \sigma_{\left(R q l s_{q}, \min \left(v_{1}, r_{2}\right)\right\}} S
\end{aligned}
$$

Combinando com a Propriedlade 1 , a seguinte propriedate também ó dofinida:

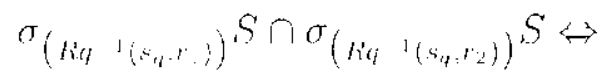

$$
\begin{aligned}
& \left.\sigma_{\left(k_{1} 1\left(s_{q}, r_{1}\right) \wedge R q^{-1}\left(s_{n}, r_{2}\right)\right.} S\right) \\
& \left.\left.\sigma_{(k q} \quad{ }^{\left(s_{q}, \max \left\{\left(r_{1}, r_{2}\right)\right.\right.}\right)\right\}
\end{aligned}
$$

Propriedade 4: $\left(R_{q}\right.$ ou $\left.R_{q}\right)$ com mesmo centro - A disjunçĩo do dois predicartos range é expluvalente a um único predicado range, tendo o maior valor entre os raios dos predicalos como o raio do único predicado resultante. Assinn tem-se:

$$
\begin{aligned}
& \sigma_{\left(R, q\left(s_{1}, r_{1}\right)\right.} S^{S \cup \sigma}{ }_{\left(R q\left(s_{q}, r_{2}\right)\right.} S \leftrightarrow
\end{aligned}
$$

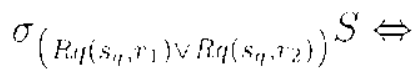

$$
\begin{aligned}
& \sigma_{\left(R q\left(s_{1}, m, n n x\left(r_{1}, r_{2}\right)\right)\right.} S
\end{aligned}
$$

e combinande com Propriedade 1, resultar em:

$$
\begin{aligned}
& \sigma_{\left(R q^{-1}\left(s_{q}, r_{2}\right)\right.} S \cup \sigma_{\left(R_{q}-1_{\left(s_{q}, r_{2}\right)}\right)} S \Leftrightarrow \\
& \sigma_{\left(R q^{-1}\left(s_{i}, r_{1}\right) \vee R q^{-1}\left(s_{t}, r_{2}\right)\right)} S \Leftrightarrow \\
& \left.\sigma_{(k i q-1}\left(s_{4}, m i m\left(r_{1}, r_{2}\right)\right)\right)^{S}
\end{aligned}
$$


Considerando essas propriedades, é possível mostrar que os predicados range

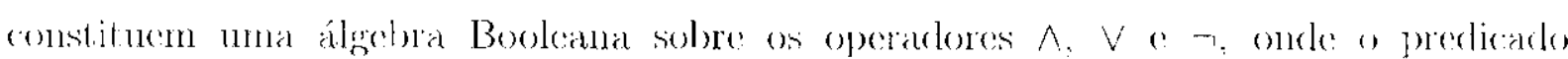
range com raio infinito é o clemento identidlade sobre o operador $\wedge$, a o predicado $O\left(s_{q}\right)$ é o elemento identidade sobre o operador $V$. Portanto, o conjunto de predicados range com mesmo objeto de referència $P_{R q}$ constitui uma álgebra Booleana $B^{R q}=\left[P_{R q} \wedge, \vee, \quad, O\left(s_{q}\right), R q\left(s_{q}, \infty\right)\right.$. sobre os operartores $\wedge, \vee$ \& $\neg$, c as seguintes mopriedades se mantem.

Comutatividade sobre $\wedge$ :

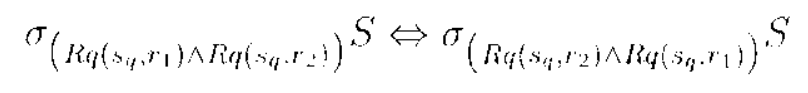

Comutatividade sobre $\mathrm{V}$ :

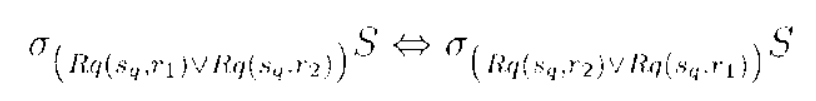

Associatividade sobre $\wedge$

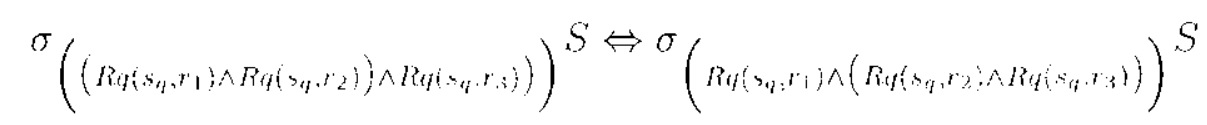

Associatividade sobre $v$ :

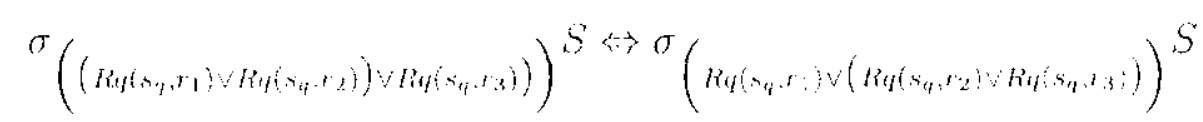

Distributividade de $\wedge$ sobre $\vee$ :

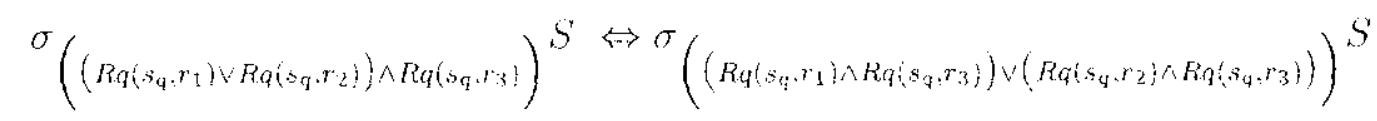

Distributividade $k \cdot \vee \operatorname{sol} r) \wedge$ :

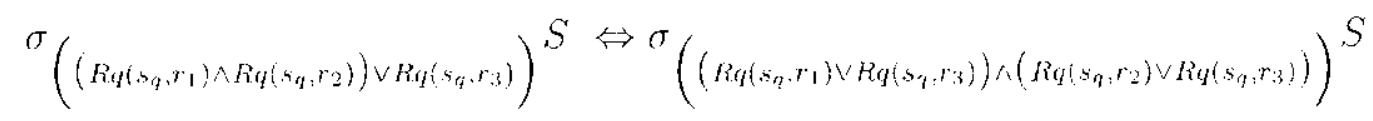

Identidade sobre $\wedge$ :

$$
\sigma_{\left(\operatorname{Rq}\left(\varsigma_{1}, r_{1}\right) \wedge \operatorname{Rq}\left(w_{1}, \infty\right)\right)} S \Leftrightarrow \sigma_{\left(\operatorname{R}\left(\omega_{1}, r_{1}\right)\right)} S
$$

Identidade subre $\vee$ :

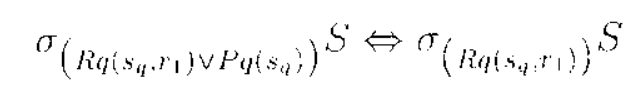

Complemento sobre $\wedge$ :

$$
\sigma_{\left(R q\left(s_{q}, r_{1}\right)\right.} S \wedge \sigma_{\left(-R_{q}\left(s_{q}, r_{1}\right)\right.} S \Leftrightarrow \sigma_{\left(\sigma_{\left(s_{q}\right)}\right)} S
$$


Complemento sobre $\vee$ :

$$
\left.\sigma_{\left(R q\left(s_{q}, r_{2}\right)\right.}\right) S^{\prime} \vee \sigma_{\left(\neg R q\left(s_{q}, r_{1}\right)\right.} S \Leftrightarrow \sigma_{\left(R q\left(s_{q}, \infty\right)\right.} S
$$

Absorção sobre $\wedge$ :

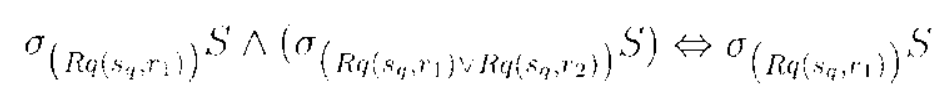

Absorçāo sobre $V$ :

$$
\left.\sigma_{\left(R q\left(s_{q}, r_{:}\right)\right.}\right) S \vee\left(\sigma_{\left(R q\left(s_{q}, r_{1}\right) \wedge R q\left(s_{q}, r_{2}\right)\right)} S\right) \Leftrightarrow \sigma_{\left(R q\left(s_{q}, r:\right)\right.} S
$$

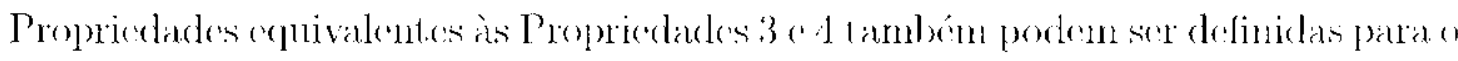
predicado k-nearest. Portanto, conjuncóos o disjunçón de predicados k-nearest obedecem às propriedades a seguir.

Propriedade 5: (KNN e kNN) com mesmo centro - A conjungăo do dois

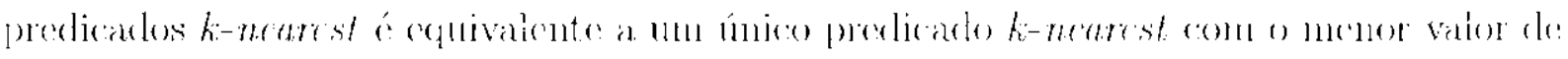
k. entre adueles exigidos pelos dois predicados. Assim, tem-se:

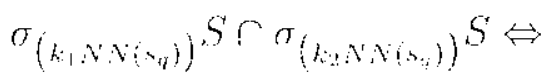

$$
\begin{aligned}
& \sigma_{\left(k_{1} N N_{\left.i s_{q}\right) \wedge\left(k_{2} N N\left(s_{q}\right)\right.}\right)} S \Leftrightarrow \\
& \left.\sigma_{\left(\min \left(k_{1} k_{2}\right) N N\left(s_{1}\right)\right.}\right)^{S}
\end{aligned}
$$

Tal propriedade, combinando con a Propriedade 2 , resulta en

$$
\begin{aligned}
& \left.\sigma_{\left(\left(\neg k_{2} N N_{N}\left(s_{q}\right)\right.\right.} S \cap \sigma_{\left(\neg k_{2} N N\left(s_{q}\right)\right.}\right) S \Leftrightarrow \\
& \sigma_{\left.\left(\nu-k_{1}\right) F N\left(s_{q}\right) \wedge(\nu-k 2) F N\left(s_{q}\right)\right)} S \Leftrightarrow \\
& \left.\sigma_{\left(1, \max \left(k_{1} k_{3}\right) N_{\left(w_{i}\right.}\right)}\right)^{S}
\end{aligned}
$$

Propriedade 6: (kNN ou kNN) rom mesmo centro - A disjunçán de dois predicados $k$-nearest é equivalente a um ínico predicado ki-neavest com o maior valor do $k$ entre aqueles exigidos pelos dois predicarlos. Entäo tem-se:

$$
\begin{aligned}
& \left.\sigma_{\left(\left(k: N N\left(s_{q}\right)\right.\right.} S\right\lrcorner \sigma_{\left(k_{2} \times N\left(N_{q}\right)\right.} S \Leftrightarrow \\
& \sigma_{\left(h_{1} N N_{\left(\sigma_{q}\right)}\right) \cup\left(k_{2} N N q_{s_{1}}\right)} S \Leftrightarrow \\
& \sigma_{\left(\operatorname{man}\left(k_{1}, k_{2}\right) N N_{(n)}\right)} S
\end{aligned}
$$


Combinando com a Propricdarle 2, tem-se

$$
\begin{gathered}
\sigma_{\left(\left(\neg k_{1} N N\left(s_{q}\right)\right)\right.} S \cup \sigma_{\left(\neg k_{2} N N\left(s_{q}\right)\right)} S \Leftrightarrow \\
\left.\left.\sigma_{\left(\left(1, k_{1}\right) F N\left(s_{q}\right) \cup(\nu\right.} k_{2}\right) F N\left(s_{q}\right)\right) \\
\sigma_{\left(1, \ldots \min \left(k_{1}, k_{2}\right) N_{N} N\left(s_{q}\right)\right)} S \Leftrightarrow
\end{gathered}
$$

Da mesma maneira que os predicados range, os predicados k-nearest tanubém constituem uma álgebra Booleana sobre os operadores $\wedge, \vee$ e ᄀ. Portanto, considerando o

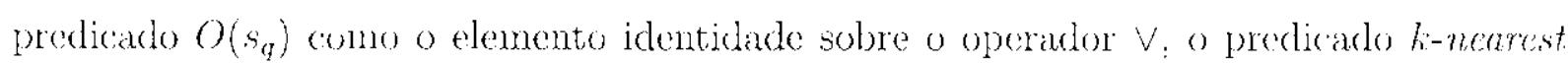
com $\nu$ elementos $\nu N N\left(s_{y}\right)$ come o elemento identidiade sobre o operactor $\wedge$. junto de predicarios ki-nearest sobre un mesmo objoto do reforencia $P_{k N N}$, lem-se que $B^{k N N}=\left[P_{k N N}, \wedge . \vee-\neg . O\left(s_{q}\right), \nu N N\left(s_{q}\right)\right]$ constitui uma álgebra Booleanda sobre os operadores $\wedge, \vee$ e $\neg$, e as propriedades $B_{1}$ a $B_{6}$ definidas na Seção 2.3 e apresentadas nesta segão para predicarlos range taubbém se mantêm para predicados k-nearest.

Dado que o conjunto de predicados range o o conjunto de k-neurest definem, cada um deles, uma álgebra Booleana sobre os operadores $\wedge, \vee$ e - ; qualquer expressão SCSP podo ser ropresentada ou na forma normal disjuntiva. on na forma nomal conjuntiva (DNF ou CNF respectivanente). Tinto a DNF quanto a CNF compartilham propri-

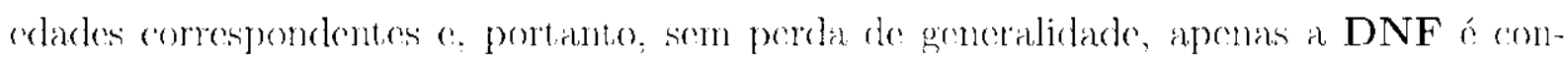
siderada nas discussóses seguintes deste capítulo. Uma DNF comsiste de uma disjungão de min-termos conjuntivos, onde cada min-termo conjuntivo é a conjunçăo dee una va-

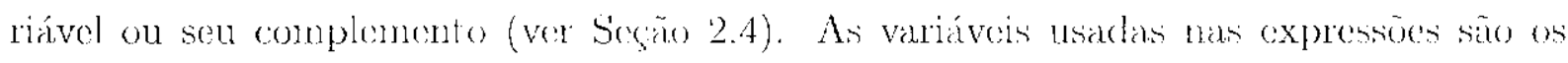
predicados básicos por sinilaridade. Portanto, qualquer expressão SCSP scmpre pode ser representada $\mathrm{cm}$ DNF.

Para simplificar a notação para expressões $\mathbf{S C S P}^{2}$, considere-se $p_{i}, i=1 \ldots n$ como o predicado por similaridade básico do tipo $p$, onde pé ou o predicado runge on o predicado

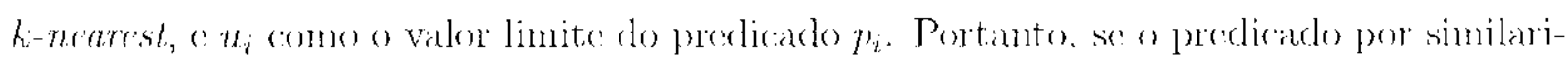
dade básico é range, então $u_{i}$ é o raio $r_{i}$ do predicado $p_{i}=h q_{(}\left(s_{q} . r_{i}\right)$. Caso contrário, $u_{i}$ é o núnero de vizinhos $k_{i}$ do predicado $k$-nearest $p_{i}=k_{i} N N\left(s_{q}\right)$. Considerc-se lambém que una conjunção de predicados do lipo pé expressa por $m_{a}^{p}$. Portanto, qualquer expressão SCSP de predicados do tipo $p$, cinvolvendo os operadores Booleanos $\wedge, \vee$ e $\neg$ sempre podo ser expressa em DNF como $E=\left(\neg p_{1} \wedge \ldots \neg p_{i} \wedge \ldots p_{j} \wedge \ldots p_{k}\right) \vee\left(\neg p_{x} \wedge \ldots p_{y}\right) \vee \ldots=$ $m_{u}^{p} \vee m_{i}^{p} \vee \ldots$ Observe que se $p_{i}$ representa o predicado range $p_{i}=R q\left(s_{q}, r_{i}\right)$ entäo $\neg p_{i}=R q^{-1}\left(s_{q}, r_{i}\right)$, o se $p_{i}$ representa o predicado k-nearest $p_{i}=k_{i} N N\left(s_{q}\right)$ entao $\neg p_{i}=\left(\nu-k_{i}\right) F^{\prime} N\left(s_{q}\right)$.

Considerando os predicalos básicos SCSP como variáveis de uma expressão em

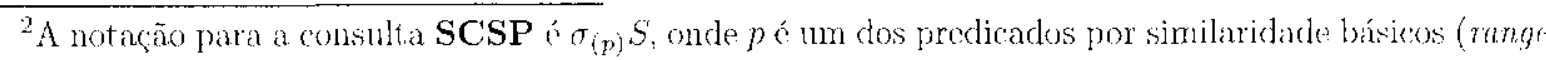
ou k-ncarest). Porém, por questoes de sinplicidade, tanto o operador de selegáo $\sigma$ quanto o conjunto do

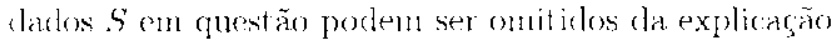


DNF, as Propriedades 3 (para predicados range) o 5 (para predicados k-nearest) permi-

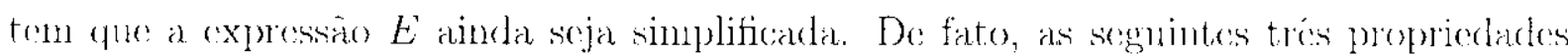
so aplicam a mintetermos conjuntivos o podem ser domonstradas usando as propricedades anteriores. Aqui essas propriedades são ilustradas referindo-se à Figura 4.1, que mostra

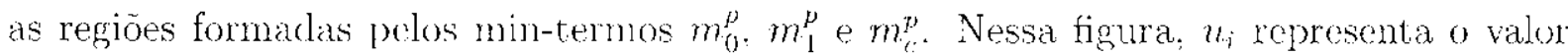
linite para os predicados minge ou k-nearest.

(a)

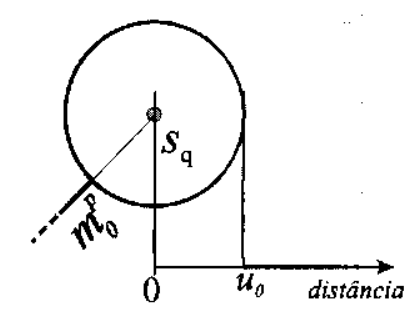

(b)

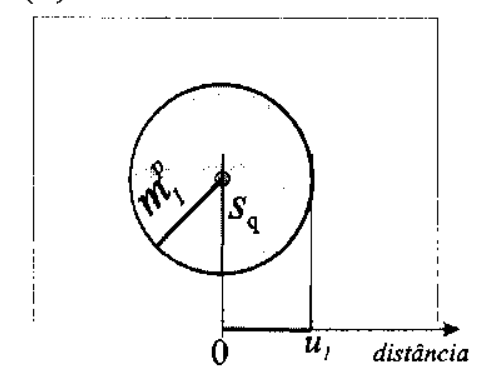

(c)

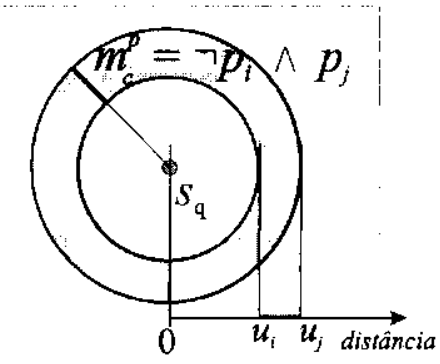

Figura 4.1: Regiões formadas polos nin-termos $m_{0}^{p}, m_{1}^{p}$ e $m_{c}^{p} \mathrm{em}$ um cspaço bidlimensional com a métrica Euclidiana. (a) o min-termo $m_{0}^{p}$ - um único predicado básico complementado; (b) o min-termo m.1 - um único predicado básico não complementakle; (c) o min-termo $m_{c}^{p}$ formando uma região $\mathrm{cm}$ ancl - dois predicados básicos, um complementarlo e ou ontro năos.

Propriedade 7: Dois predicados básicos por min-termo - Todo nin-termo do uma expressão SCSP (m DNF é connposto de no máximo dois predicados bésicos, um complementado o outro não complementialo:

$$
\sigma_{\left(\left(p_{1} \wedge \ldots p_{g}\right) \wedge\left(\neg m_{n} \wedge \ldots \neg p_{k}\right)\right)} S \Leftrightarrow \sigma_{\left(p_{i} \wedge \neg p_{j}\right)} S
$$

onde $u_{i}=\min \left(u_{1}, \ldots u_{g}\right)$ e $u_{j}=\max \left(u_{h}, \ldots u_{h}\right)$. Os min-termos que tem apenas um

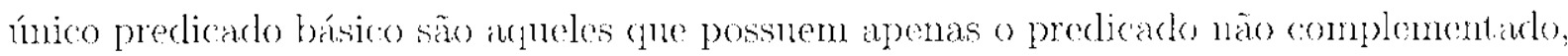
representado por $m_{1}^{p}$, ou o predicado complementado, representado por $m m_{0}^{p}$. Os mintormos $m_{0}^{\mu}$ e mil săo mostrados respectivanente nos itens (a) e (b) dar Figura 4.1.

Propriedacle 8: Montetmos como Anéris - Fun todo mintermo com doin predicados básicos, o valor limite do predicado complenentado deve ser menor on igual ao predicado não complementado, definindo uma região em forma de ancl, caso contrário o min-termo pode ser clininado da expressão DNF. Isto é:

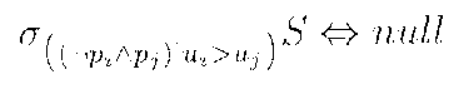

Na Figura 4.1(c) tem-so o min-terno $m_{c}^{p}=\neg p_{i} \wedge p_{j}$ que define uma regiầ não nula devido ans linnites de seus predicados $u_{i} \leq u_{j}$. Em uma situação oposta, ou seja, se $u_{i}>u_{j}$, as regiōes definidas pelos predicados $p_{j}$ e $p_{i}$ náa estariann se interceptando e, portanto, o min-termo formado por esses predicados nunca recuperaria qualquer clemento do conjunto de dados. Expressous su DNF, combinado os min-termos $m_{0}^{p}, m_{1}^{p}$ o $m_{c}^{p}$ : levam a expresiós complexas, conforme ilustrado na Figura 4.2. Essa figura é útil para anxiliar a contender a proprieclade seguinte. 
Propriedade 9: Sobreposiçao de Min-lermos - Min-termos com valores limites que se sobrepóm podem ser simplificados conforme apresentade a seguir:

$$
\begin{aligned}
& \sigma_{\left(\left(\neg p_{q} \wedge p_{j}\right) \cup\left(-p_{k} \wedge p_{2}\right) u_{3} \leq u_{i} \leq u_{i} \leq u_{j}\right)} S \Leftrightarrow \sigma_{\left(\neg p_{q} \wedge p_{j}\right)} S \\
& \sigma_{\left(\left(\neg p_{g} \wedge p_{i}\right)\left(\neg p_{h} \wedge p_{j}\right) i_{w_{g}}<u_{h} \leq u_{i} \leq u_{j}\right)} S \Leftrightarrow \sigma_{\left(\neg p_{g} \wedge p_{j}\right)} S
\end{aligned}
$$

A sobreposição pode ser total ou parcial. Na Figura 1.2, o min-t,crmo $m_{c}^{p}=\neg p_{1} \wedge p_{7}$ sobrepõe completamente o min-termo $m_{b}^{p}=\neg p_{5} \wedge p_{6}$. Assim, apenas o min-termo $m_{r}^{p}$ precisis ser mantido na expressão. Da mesma mancira, o nnin-termo $m_{d}^{p}=\neg p_{9} \wedge p_{1}$

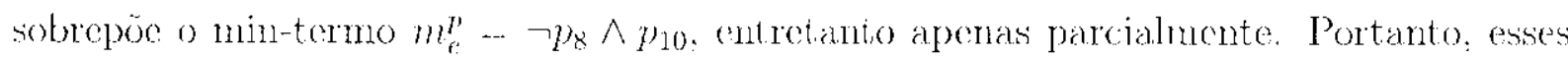

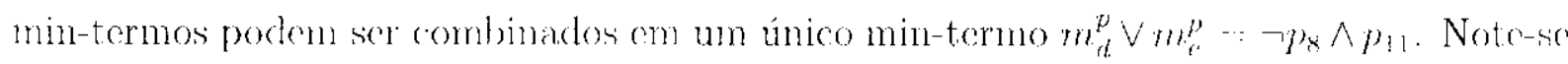
(uu é fossível verificar sobreposições para min-termos com apenas um predicado. Nesso caso, deve-se considerar que o predicado ausente ć $p_{\infty} \operatorname{com} u_{\infty}=\propto$ para o min-terno $m_{0}^{p}$. e $p_{0}$ com $u_{0}=0$ para o mintermo $m_{1}^{p}$. Usando a Propriedade 9, a expressáo em DNF $p_{1} \vee\left(\neg p_{2} \wedge p_{3}\right) \vee\left(\neg p_{5} \wedge p_{6}\right) \vee\left(\neg p_{4} \wedge p_{7}\right) \vee\left(\neg p_{8} \wedge p_{10}\right) \vee\left(\neg p_{9} \wedge p_{11}\right) \vee \neg p_{12}$ mostrada lla Figura 4.2 pode ser simplificadla para $p_{1} \vee\left(\neg p_{2} \wedge p_{3}\right) \vee\left(\neg p_{1} \wedge p_{\tau}\right) \vee\left(\neg p_{\phi} \wedge p_{11}\right) \vee \neg p_{12}$.

\section{Algoritmos para Executar Expressões SCSP}

Expressöes com mesmo centro e mesmo tipo de predicado (SCSP) m DNF năo

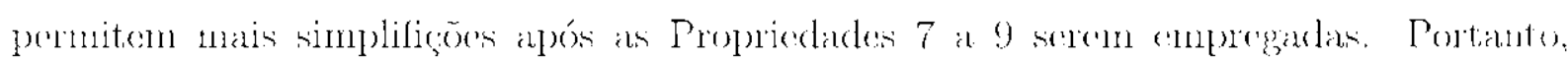
um SGBD capaz cle responder a consultas por similaridade deve possuir um conjunto de operadores para executar tais expressoes. Há duas abordagens que podenu ser criadas: uma combinação de algoritmos executando um min-termo por vez; um algoritmo específico capar de exerntar a expressio completa de mana só vez.

A primeira abordagem pode utilizar os algoritmos já exist cutes Runge $\left(0, s_{q}, r_{q}\right)$ o Neurest $\left(\theta, s_{\eta}, k\right)$, para os predicados range e k-nearest, respectivamente, para executar os min-termos $m_{1}^{p}, m_{0}^{p}$ e até o min-termo $m_{c}^{p}\left(\neg p_{i} \wedge p_{j}\right)$. Entretanto, para avaliar eficientemente os min-termos compostos por dois predicados básicos $\left(m_{c}^{p}\right)$, outros algoritmos

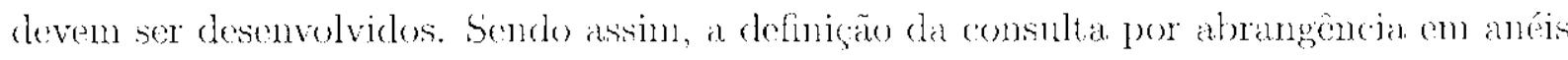
(RingRange Query) é apresentada a seguir.

Definição 1: Consulta RingRange - Dado um elemento $s_{\varphi} \in \mathbb{S}$ o dois raios $r_{i}, r_{e} \in \mathbb{R}^{+}, r_{i} \leq r_{e}$, uma consulta RingRange recilpera calda elemento $s_{i} \in S \mid r_{i} \leq d\left(s_{q}, s_{i}\right) \leq r_{c}$, onde $r_{i}$ é chamado do raio interno o $r_{e}$ de raio ex terno.

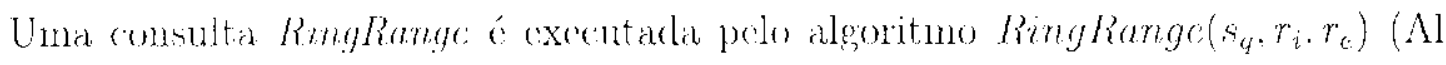
goritmo 4.3.1). Cada chamada a algoritmo RingRunge() corresponde à execuçäo de um min-terno $m_{i}^{p}$ sobre predicados range, onde $r_{i}$ ć o linute do predicado complemen- 


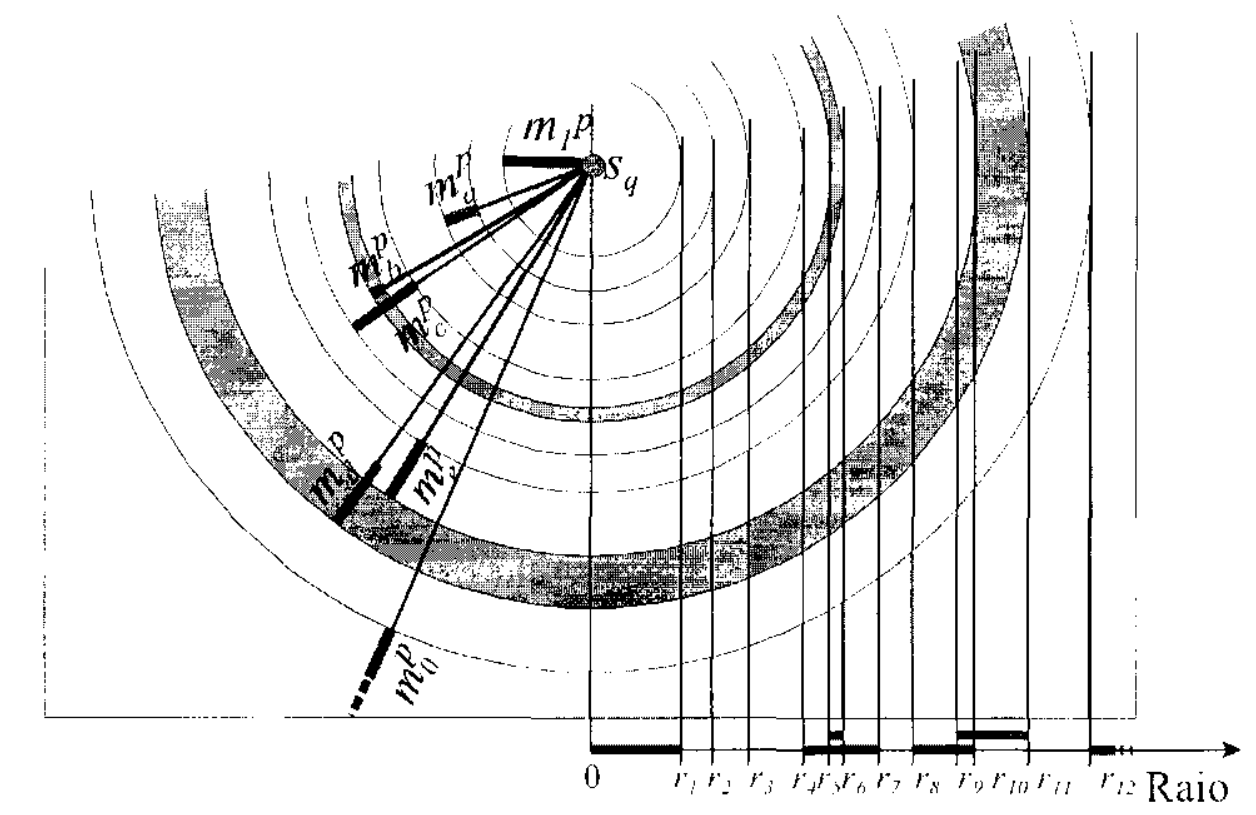

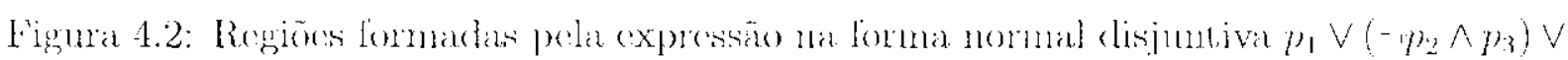
$\left(\neg p_{5} \wedge p_{6}\right) \vee\left(\neg p_{4} \wedge p_{i}\right) \vee\left(\neg p_{8} \wedge p_{10}\right) \vee\left(\neg p_{9} \wedge p_{11}\right) \vee \neg p_{12}$, consiclerando predicados range e a função de distancia Euclidiana em um espaço bidimensional.

tado e r. ó o limite do predicado náo complementado. O processo de simplificasào (Proriedades 1 a 9) garante que cada região coberta por um min-termo não se sobreponha a nenhuma outra regiāo representada por ontro min-termo. Portanto, a expres. são SCSP completa pode ser avaliada chamando o algoritmo Ring Range() uma vez para cada min-1.crmo da expressäo e $\mathrm{cm}$ seguida concatenando os resultades parciatis para produzir o resultado final. Note-se que RingRange $\left(s_{q}, 0, r_{1}\right)=\operatorname{Range}\left({ }^{\prime} \leq, s_{q}, r_{1}\right)$ e RingRange $\left(s_{4}: r_{0}, \infty\right)=$ Range $\left.\left(">, s_{4}, r_{0}\right)\right)$. Quando uma estrunura de inclexação é usada, o passo 2 do Algoritno 4.3.1 é mudado para buscar por dementos si apenas em páginas cue näo puderam ser podadas pela desigualdade triangular, nesse caso, conside-

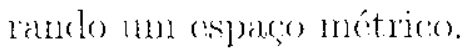

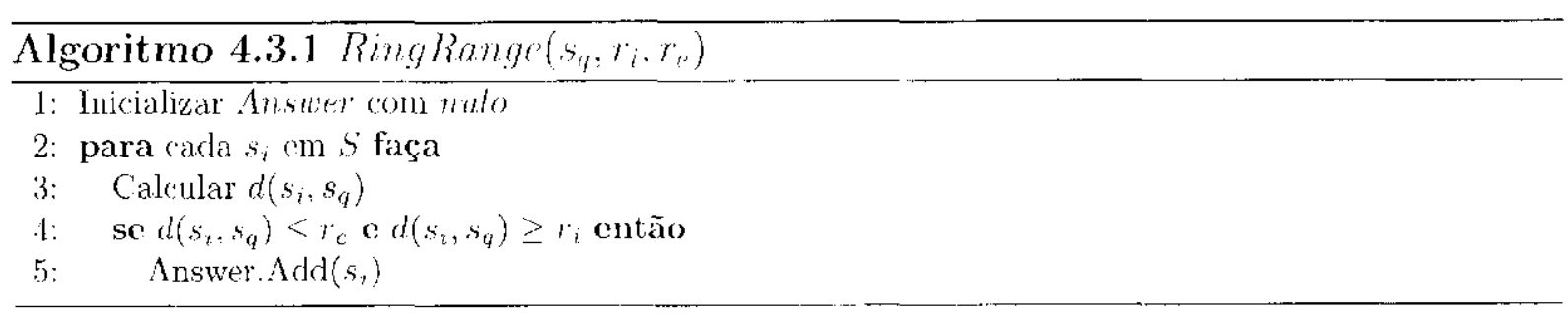

Quando a busca seciürencial é usada, os algoritmos Range() e Ring Range() pesssuem o mesmo custo computacional, considerando tanto o número do acessos a disco 
(quanto o núrnero de cálculos de funçäo distáncia. Portanto, o algoritmo RingRange () é

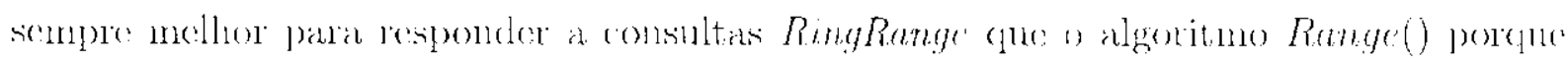
é nocessálio executar o algoritmo RingRange() apenas uma ves contra duas execucós (do algoritmo Range() e ainda a operaçăo de interseção sobre os resultados. Em estruturas de indexação, o algoritmo Ranglo (em um custo ligeiramente superior ao algoritmo RingRange(), considerando que o raio externo $r_{e}$ da consulta RingRange ó igual ao raio $r$ da consulta Rq. Portanto. una consulta RingRange sempre porde ser recpondicla por 1 m algoritmo RingRangr() (om um (usto ligeiramente inferior a uma única cxecução do algoritmo Range() (ver experimentos no Capítulo 6).

$\Lambda$ segunda abordagem para executar expressoes SCSP consiste em definir algoritmo mais geral que avalia todia a expressão de uma só ve\%. Piara predicados range

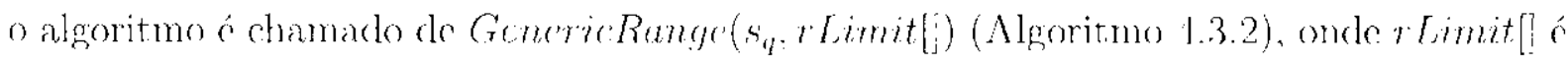
um vetor de pares $\left\langle r_{i}, r_{c}\right\rangle$ com raios em ordem crescente, carla par correspondendo a um min-temo. Esse algoritmo fi similar ao algoritmo RingRange(), mas mudando o passo 4

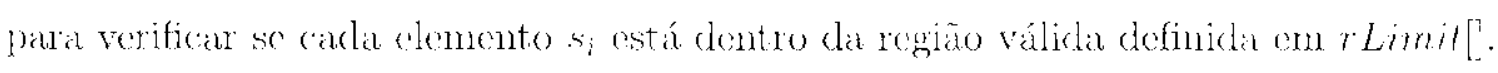

Um algoritmo equivalente, chamado de CenericNearest (s, $s_{q}$, Limit [] ) (Algoritmo 4.3.3). ¿ definido para predicados k-nearest. () votor do pares $<k_{i}, k_{e}>$ an kimitl? está em ordem crescente de valores. Assim, esse algoritmo primeiro executa o algoritmo Nearesto usanclo o maximo valor ke presente em kimitl]. Carla clemento presente no

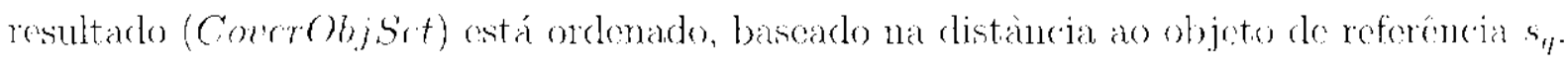
Em seguida, são incluídos na resposta apenas aqueles elementos cuja posignăo está dontro da cxtensão definida pelos min-termos segundo os pares $<k_{i}, k_{\text {e. }}>$ em kLimitl].

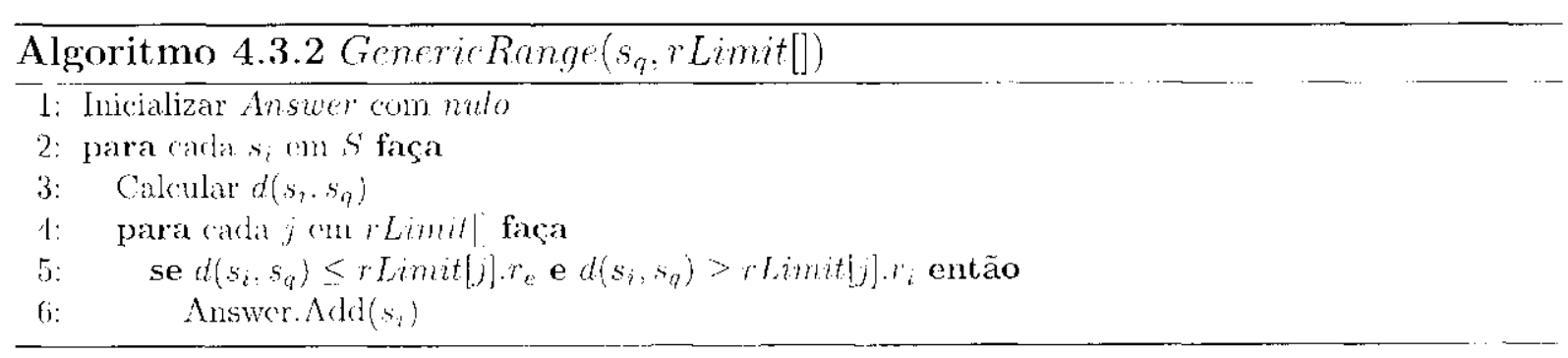

A princira abordagem não pode ser usada em expressoes envolvendo predicados fi-nearest, porque a ordem che caldi elemento, considerando a sua proximidade an objeto de referencia $s_{q}$ não pode ser determinada sem conhecer us outros clementos no ronjunte. Expressones de consulta envolvendo apenas os mintermos $m_{1}^{\psi} \mathrm{e} / \mathrm{ou} \mathrm{m}_{0}^{p}$ sobre predicados

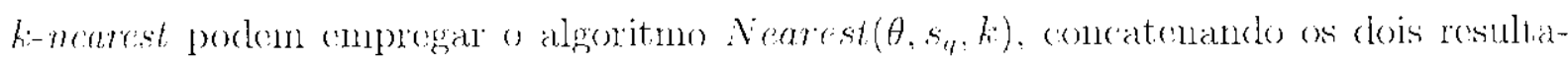
dos parciais. Entretanto, quando un min-terno composto de dois predicados ocorre na expressão de consulta, un conjunto ordenado contínuo deve ser computado, impedindo o uso de $u m$ algoritmo que compute regiöes em ancís para prodicarlos k-nearest. Portanto, responder a comsultas SCSP sobre predicados h-nearest scmpre exige a segunda

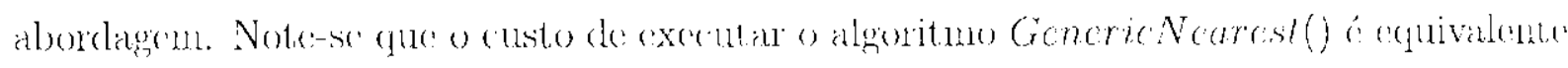
ao custo de uma única execugào do algoritmo Nearest() nando o maior valor de $k$ (am i.timiti] 


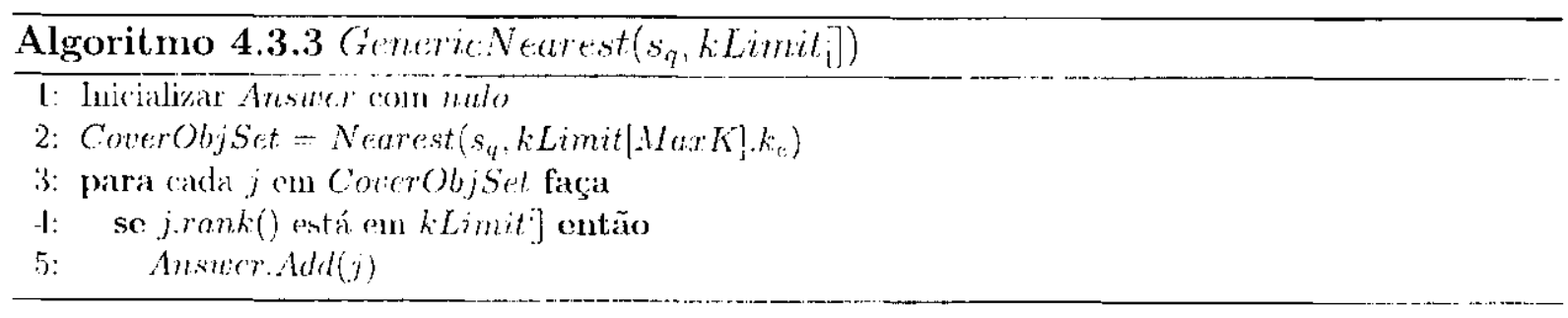

Consultals com anjenas $11 m$ min-termo $m_{1}^{p}$ säo as mais comms e, por isso, ć interessiunte manter o algoritmo básico Range $\left(0, s_{q}, r\right)$ para execut á-las, cmbora os algorit mo

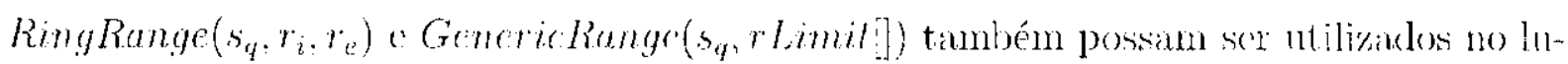
gar do algorituno bíticien.

Dado o conjunto de regras para expressoes SCSP om DNF vale salientar que

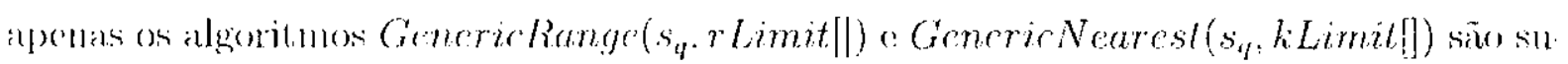
ficientes para responder a consultas por similaridade complexas SCSP em DNF.

\subsubsection{Expressões SCMP}

Consultas por similaridade complexas envolvondo ambos os predicados por similaridado básicos centrados om um mesmo objeto. são chamadas de expressóes SCMP. Para analisar uma expressão SCMP, ó necessário estender a notaçäo $p_{i} / u_{i}$ do expressóns SCSP parta representar expressóes SCMP da seguinte maneira. Se o predicaclo $p_{i}$ ć um

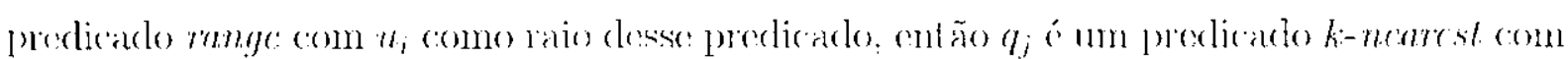
valor limite $k=r_{i}$. Análogo a $m_{a}^{p} \cdot m_{b}^{u}$ representa o min-termo conjuntiro de predicados do tipo q. Os símbolos $p_{i}$ e $q_{j}$ pockem ser atribuídos ao predicado range on k-nearest. levando crn consideração que cles são sempre elistintos mu do ontro. Un predicardo conjuntivo $p_{t} \wedge q_{j}$ com um mesmo objeto de referencia $s_{i f}$ deve recuperat calda colemento

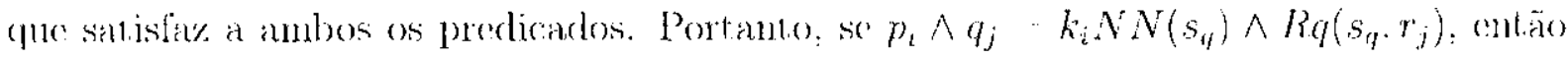

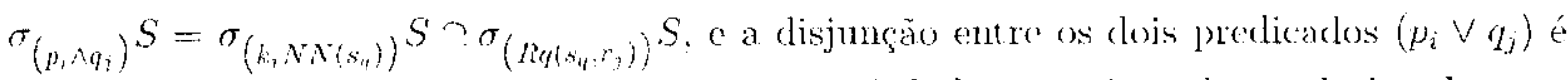

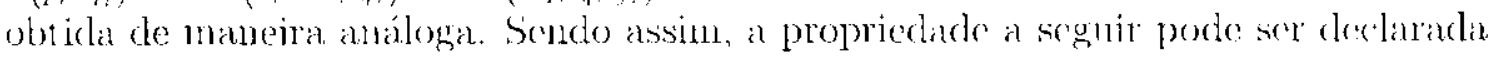

Propriedade 10: O conjunto de predicudos ronge e k-nearcst com mesmo centro forma uma álgebra Booleana - A conjungão on disjunção de um predicado k-ncarcst com um predicado range satisfar os postulados $B_{1}$ a $B_{6}$ da álgolora Booleania por isso as

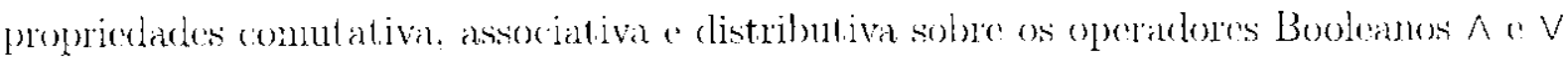
se mantém. Assim tem se: 


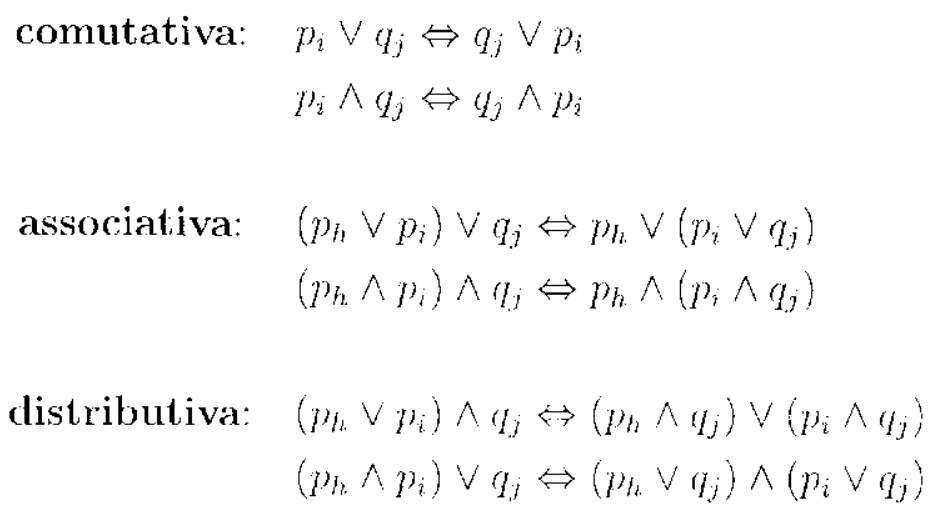

Alóm dos axiomas listados ( $B_{1}$ a $\left.B_{3}\right)$, os axiomas $B_{4}, B_{5}$ o $B_{6}$ trumbóm são satisfoitos de maneira semelhante ao já apresentado para expressós SCSP. Por exomplo, dado que $O$ e $I$ são os linites inferior e superior dessa álgehra, o axiona $B_{4}$ (Identidade) pode ser mostrado dia seguinte maneira.

$$
\begin{aligned}
& \left(p_{i} \vee q_{j}\right) \vee O \Leftrightarrow\left(p_{i} \vee O\right) \vee\left(q_{j} \vee O\right) \Leftrightarrow\left(p_{i} \vee q_{j}\right) \\
& \left(p_{i} \vee q_{j}\right) \wedge I \Leftrightarrow\left(p_{i} \wedge I\right) \vee\left(q_{j} \wedge I\right) \Leftrightarrow\left(p_{i} \vee q_{j}\right) \\
& \left(p_{i} \wedge q_{j}\right) \vee O \Leftrightarrow\left(p_{i} \vee O\right) \wedge\left(q_{j} \vee O\right) \Leftrightarrow\left(p_{i} \wedge q_{j}\right) \\
& \left(p_{i} \wedge q_{j}\right) \wedge I \Leftrightarrow\left(p_{i} \wedge I\right) \wedge\left(q_{j} \wedge I\right) \Leftrightarrow\left(p_{i} \wedge q_{j}\right)
\end{aligned}
$$

Os demais axiomas poden ser mostrados de maneira análoga. Portanto, o conjunto de predicados range o k-nearest constituem uma álgebra Booleana sobre os operadores binários $\wedge$ : $\vee$ : o operador unário $\neg$, o os operadores zero-írios $O$ o $I$, onde $O$ $\therefore O\left(s_{q}\right)$ eI $\operatorname{Rq}\left(s_{4}, \infty\right) \propto 1 \nu N N\left(s_{4}\right)$.

Uma consequiència importante desta propriedado ó que ela possibilita representar (ada expressão SCMP em DNF (ou CNF), onde cada min-termo conjuntivo (disjuntivo) b uma conjungão (disjungão) dos prodicados range e kinearest, complementados ou não. Isto quer dizer que, qualquer consulta por similariclade, oncle carla predicado tem um mesmo objeto de referência sq, pode ser simplificada a uma disjunçăo (on conjunção) de min-termos, onde cada min-termo é nma conjunção (disjunçio) de um predicaklo reversed. range, um predicado $k$-farthest, un predicado range o un k-nearest. Consiclerando a

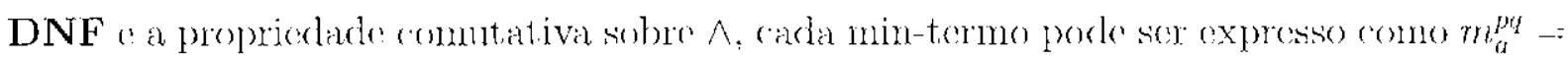
$\left(m_{b}^{p} \wedge m_{c}^{q}\right)=\left(\neg p_{3} \wedge \neg q_{h}\right) \wedge\left(p_{i} \wedge q_{j}\right)$, e qualquer expressäo pode ser representada como: $\left(\left(\neg p_{1} \wedge \neg q_{1}\right) \wedge\left(p_{2} \wedge q_{2}\right)\right) \vee\left(\left(\neg p_{3} \wedge \neg q_{3}\right) \wedge\left(p_{4} \wedge q_{1}\right)\right) \vee \ldots=m m_{a}^{p_{q}} \vee m_{b}^{p_{l}} \vee \ldots$

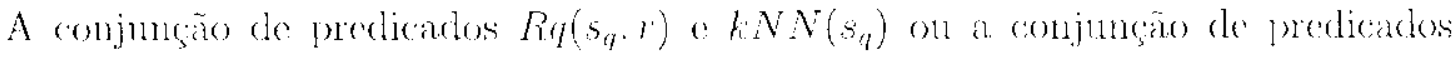
$R q$ ' $\left(s_{q}, r\right)$ e $k F N\left(s_{q}\right)$ com um mosmo objeto de referencia $s_{q}$ recupera todo elemento no

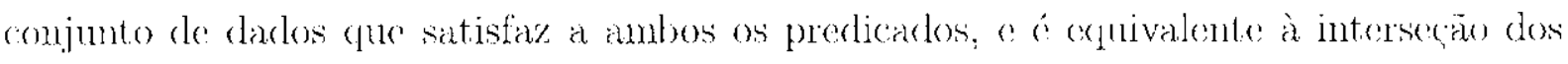
resultados intermediários obtidos pelos algoritmos básicos correspondentes. Portanto, un novo algoritmo chamalo de $h$ AndRange $\left(0, s_{q}, k, r\right)$ porle ser criado para considerar os linites de ambos os predicados: range o k-nearest. Isto fay com que esse algoritmo insira um elemento no conjunto resposta da consulta por similaridade complexa apenas quando

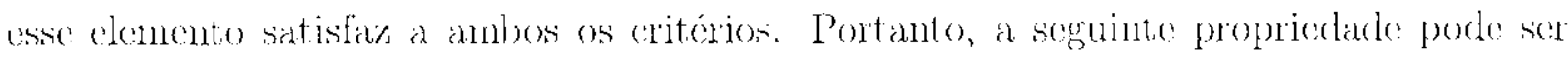
slefinicliı. 
Propriedade 11: Conjunça de predicados range e k-nearest com mesmo

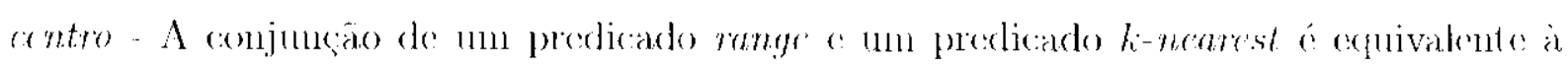
intersecão dos resultados obtidos dos operadores básicos. é rquivalente tambóm à execucão de um algoritmo $k$ AndRange $\left(\theta, s_{q}, k, r\right)$. Considerando o conjunto de dados S. tem-se:

$$
\begin{aligned}
& \sigma_{\left(k q i, i_{q}, r\right)} S \cap \sigma_{\left(k N N\left(n_{\eta}\right)\right.} S \Leftrightarrow \\
& \sigma_{\left(R q\left(\omega_{q}, r\right) \wedge k N\left(s_{q}\right)\right)} S \Leftrightarrow k \text { AndRange }\left(\theta, s_{q}, k, r\right)
\end{aligned}
$$

Usar a propricdade conntativa para representar un min-termo $m_{a}^{p q}=m_{b}^{p} \wedge m_{c}^{q}=$ $\left(\neg p_{g} \wedge p_{i}\right) \wedge\left(\neg q_{h} \wedge q_{j}\right)$, lik com (1ue a expressão se torne uma conjunçäo contre predicados range juntamente com nma conjuncäo cntre predicados $k$-nearest. Assim cada uma dessas conjunçoes pode ser simplificada usando as Propriedades 7, 8 e 9. Após a simplificação, os min-termos restantes podem ser rearranjados como $m_{a i}^{m_{i}}=\left(\neg p_{g} \wedge \neg q_{h}\right) \wedge\left(p_{i} \wedge q_{j}\right)$ c consegüentemente respondidos, chamando o algoritno kAndRange $\left(\theta, s_{q}, k, r\right)$ duas veres: primeiro para processar $\left(\neg p_{q} \wedge \neg q_{h}\right)$ e, cm seguida, para procossar $\left(p_{i} \wedge q_{l}\right)$.

Observe-se que a intersegão de clementos recuperados por dois min-termos distintos em uma expressão ou subexpressäo SCMP en DNF pode näo ser vazia. () algoritmo para processar tal expressão pode ser melhorado so os nin-temos gerurem resultarlos parciais disjuntos. Assim. a propriedacle declarada a segnir torna-se útil.

Propriedade 12: Min-termos disjuntos em uma expressäo SCMP em DNF - Considere-se uma expressão SCMP cm DNF com pelo menos dois min-termos $m_{a}^{p_{q}} \ldots\left(\left(\neg p_{1} \wedge \neg q_{2}\right) \wedge\left(p_{5} \wedge q_{i}\right)\right)$ e $m_{b}^{m_{t}}=\left(\left(q_{3} \wedge q_{q_{1}}\right) \wedge\left(p_{7} \wedge q_{s}\right)\right)$. So os valores linites

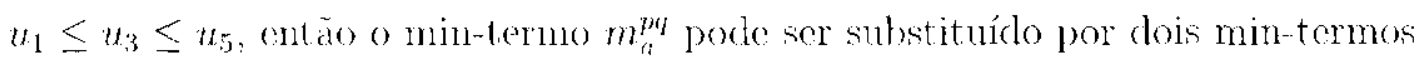

$$
m_{{ }_{i}}^{p_{i}}=\left(\left(\neg p_{1} \wedge \neg q_{2}\right) \wedge\left(p_{3} \wedge q_{6}\right)\right) \vee\left(\left(\neg p_{3} \wedge \cdots q_{2}\right) \wedge\left(p_{5} \wedge q_{(j}\right)\right)
$$

o so os valores limites $u_{3} \leq u_{5} \leq u_{7}$, então o ninin-terno $m_{b}^{\mu_{7}}$ pode ser substituído por dois minterentos

$$
m_{b}^{p q_{t}}=\left(\left(\neg p_{3} \wedge \neg q_{4}\right) \wedge\left(p_{5} \wedge q_{8}\right)\right) \vee\left(\left(\neg p_{5} \wedge \neg q_{1}\right) \wedge\left(p_{7} \wedge q_{8}\right)\right)
$$

Quando unla expressão näo tem un par de min-termos que permita qualquer

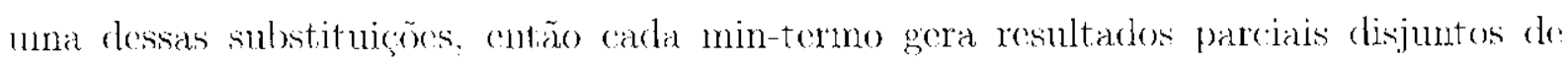
qualquer ontro min-termo. Essa cxpressão é chamada nesta tese de expressão livre de sobreposiçāo. on uma expressão $O_{j}$. Note-se que mana expressão ou é $O_{f}$ ou existe pelo menos um par de mintemos que permite a simplificagão definida pera Propriedade 12. Assim. 1ma expressia SCMP em DNF sempre pode som processada pelo algoritmo kAndRange $\left(\theta, s_{q}, k, r\right)$ o on resultades comeralenarlos sem a necessidade de verificar a ocorrencia de repeticão. 
(a)

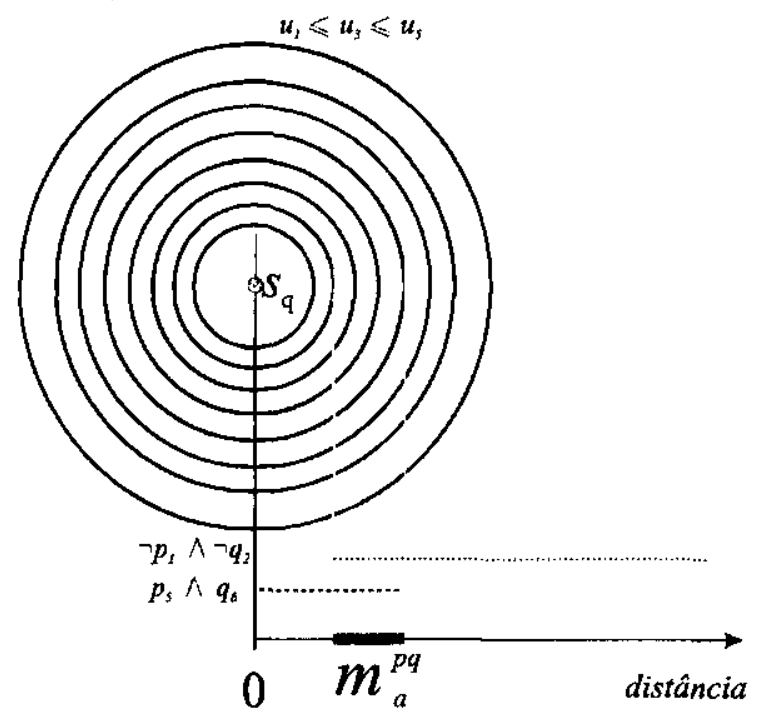

(b)

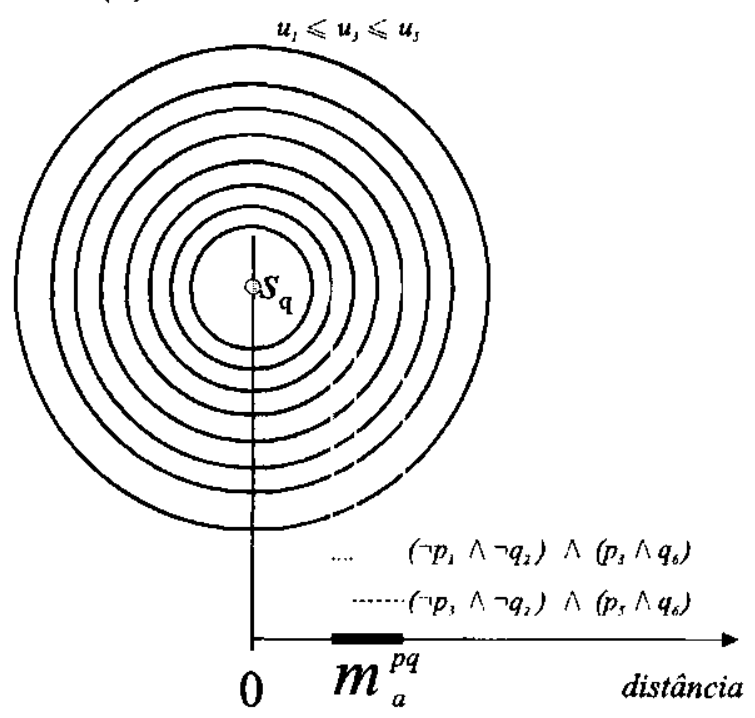

Fignar 4.3: O min-bermo $m_{a}^{p e q}$ en un espaco bi-dimensional com a métrica Euclidiana pertencente a uma expressão SCMP om DNF com pelo monos dois mintermos. (a) o

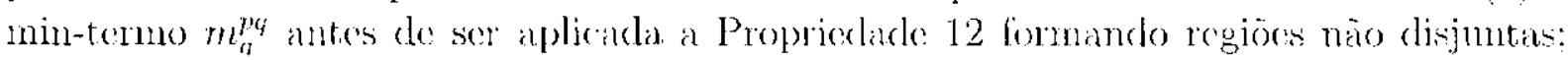

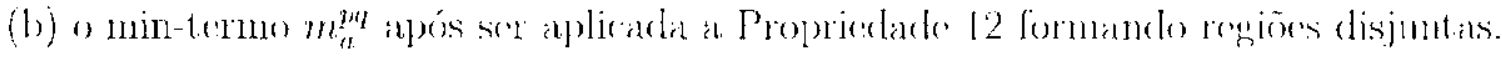

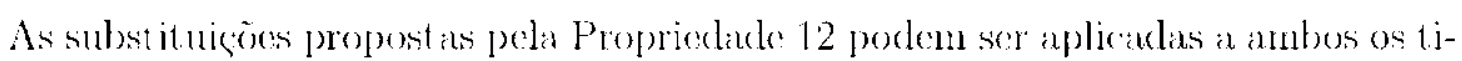
pos de predicado. poróm applicrítas a apenas um tipo já é suficiente para tomar a expressäo

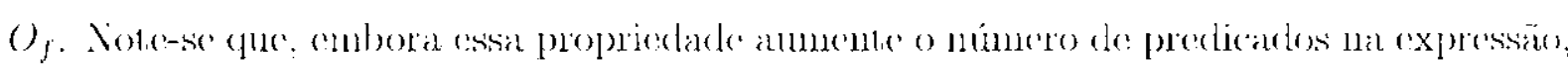

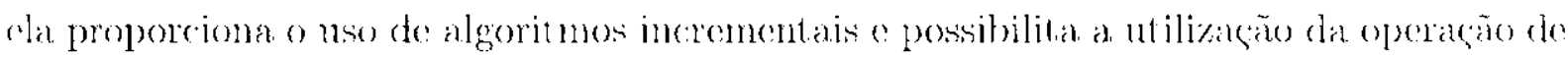
concat chação ao invós da operação de união, que $1 \mathrm{em}$ um custo computacional maior. A Figura 4.3 ilustra a utilizaçăo da Propricdade 12 para o nnin-termo $m_{a l}^{p i q}$.

Considerando expressoos SCMP representadlas em CNF. a disjunção de predicados $R_{q}\left(s_{q}, r\right)$ o $k N N\left(s_{q}\right)$ ou de predicados $R q^{-1}\left(s_{q}, r\right)$ e $k F N\left(s_{q}\right)$ com um mosmo objeto

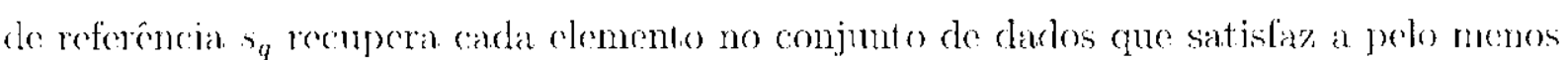
Iurn dos predicades. Isto á ecpuivalente à união dos resultados intermediários obtidos pelos algoritmos básicos correspondentes. Portanto, expressoes SCMP em CNF podem ser

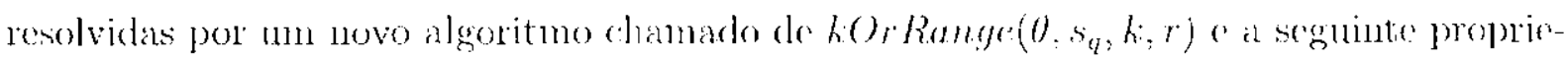
clade porle ser clefinicla.

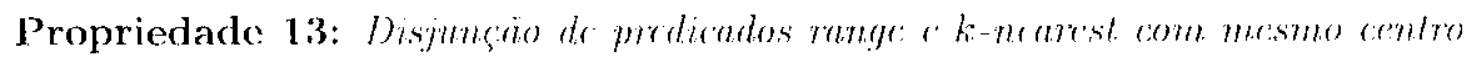
- $A$ disjunção do um predicado runge e un predicado k-nearest é equivalente à união posterior dos resultados intermediários obticlos dos oporadores básicos, e também equivalente à execugăo do algoritmo korkange $\left(0, s_{f}, k . r\right)$. Considerando o conjunto do rados $S$, isto ce definido como:

$$
\begin{aligned}
& \sigma_{\left(h i\left(s_{q}, r\right)\right)} S \cup \sigma_{\left(k N N\left(s_{q}\right)\right)} S \Leftrightarrow
\end{aligned}
$$

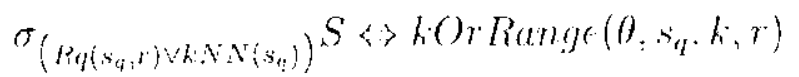




\section{Algoritmos para Executar Expressões SCMP}

$\Lambda$ s cxpressões SCMP em DNF: após sofrerem as devidas simplificações, podem ser executadas por meio de algoritmos de recuperaçăo específicos. Cm algoritmo inportante para ser implementado é o relacionado à consulta por similaridade complexa chvolvendo os predicados básicos por sinilaridade: range o k-nearest. Fsssa consultat. que corresponde a uma subexpressão SCMP (m DNF. é definida a segunir.

Definição 2: Consulta por Abrangência e a.os k-Vizinhos Mais Próximos kiAndRange Query - Dado um elemento $s_{q} \in \mathbb{S}$ o valor $k$ definiclo no predicado kincurest. a distancia $r \in \mathbb{R}^{*}$ definida no predicado range o operador relacional $\theta \in\{\leq>\}$, mma consulta kAndRunge lecupera cada elomento $s_{i} \in S \mid d\left(s_{q}, s_{i}\right)$ Ore $s_{i} \in$ Nearest $\left(0, s_{q}, k\right)$.

Uma consulta kAndRange pode ser executada pelo algoritmo

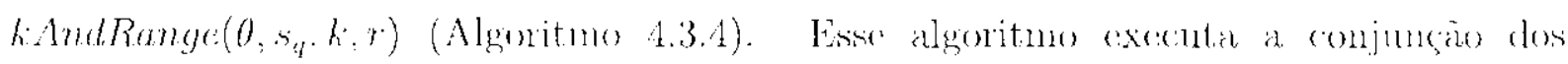
predicados range $\mathrm{r}$ k-nearest, complementados on näo, com um momo objeto de: referência $s_{q}$. A conjunção exige que ambos os predicados satisfaçam a mesma conclição $\theta$. Esste algoritmo ó baseado no algoritmo Nearest $\left(\theta, s_{q}, k\right)$. A distáncia máxima, a qual culalifica um ob jeto pertencer à resposta, é representakla por $r_{c}$. Devido à conjungão entre os predicados, r pode iniciar com $r$ an invés do x o é reduzido (aumontado) conforme elementos mais próximos (mais distantes) sâo encontrados. A resposta ć ordenada pela distância en relagăo a objeto de referencia da consulta. () algoritno utiliza os métodos: Add() insere un novo elemento mantendo a lista ordenada; Lengtho retoma o numero

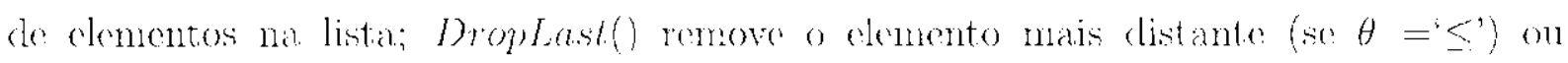
mais próximo (se $\left.\theta=>^{\prime}\right)$ na lista: e MaxDist() retorua a distancia an cemento mais próximo ou mais distante (consiclerando $\theta$ ) na lista. A Figura 4.4 ilustra as possibilidades cxistentes de una conjunção entro os predicados básicos, considerando o operador $\theta$ como

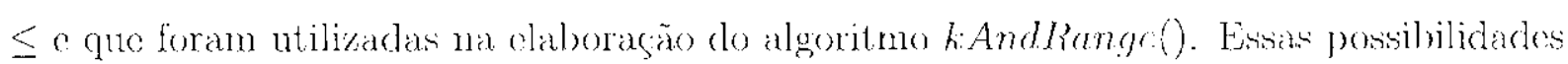
são tratadas por esse algoritmo nas linhas 5 a 9 que verificam se um oljeto está dentro da rogião definida pelo raio $r_{r}$ e também se csse ele é um dos $k$ objetos mais próximos $(\nu-h$

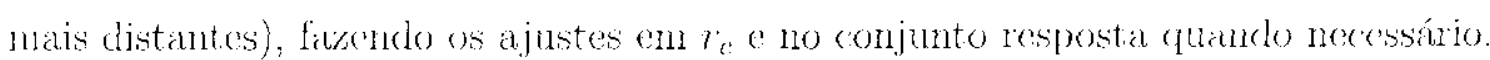

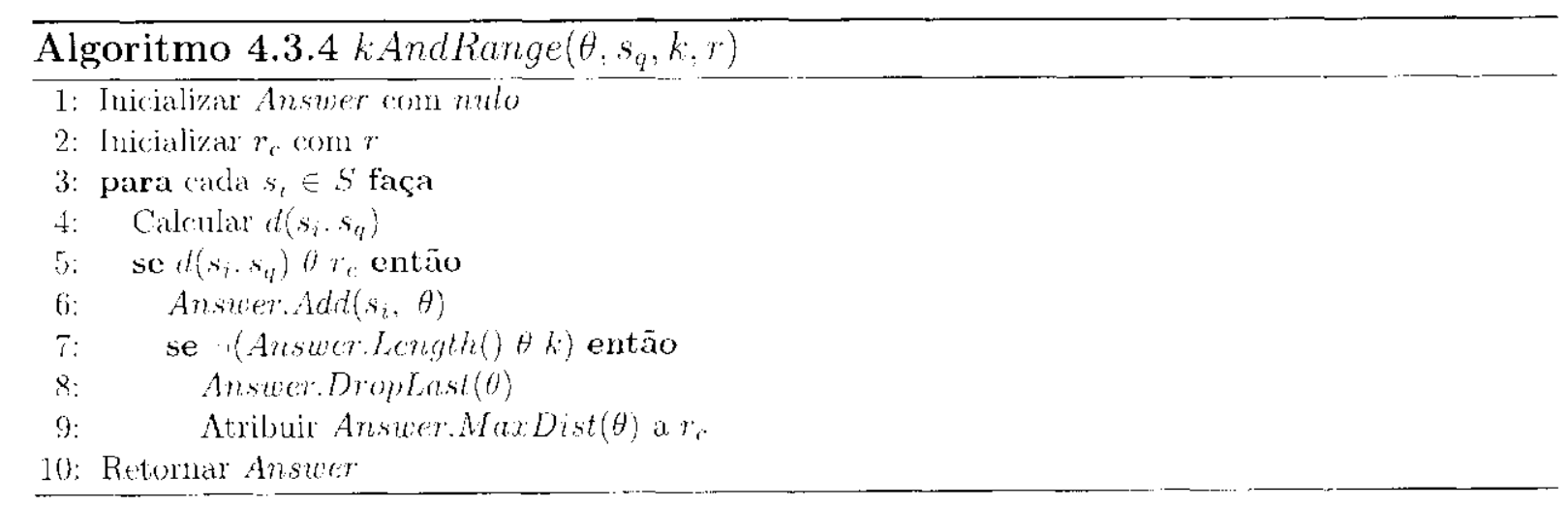

O algoritmo UniSimDNF(minterms[]. $s_{4}$ ) (Algoritmo 4.3.5) responde a uma ex.

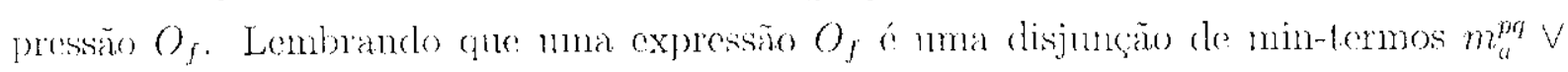




\section{$u_{i}$ - range}

$\cdots \cdot v_{i}-k$-nearest

(a)

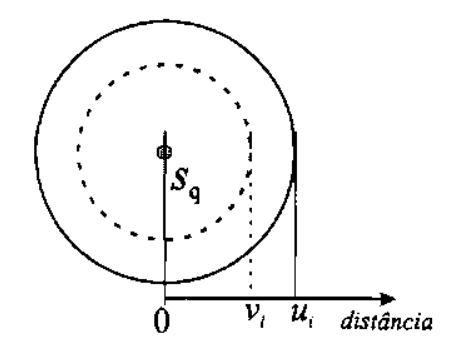

$u_{i}>v_{i}$ (b)

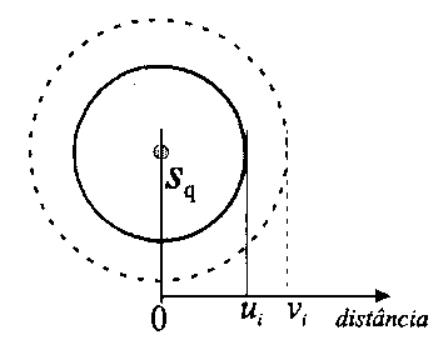

$u_{i}<v_{i}$ (c)

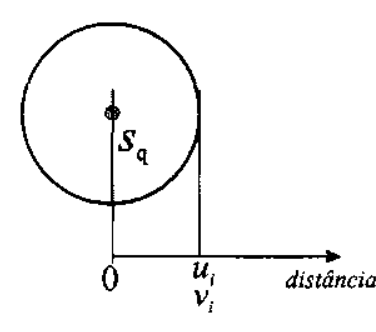

$\boldsymbol{u}_{i}=\boldsymbol{v}_{i}$

Figura 4.4: Casos possíveis entre os valores limites dos predicados range e k-nearest, dada

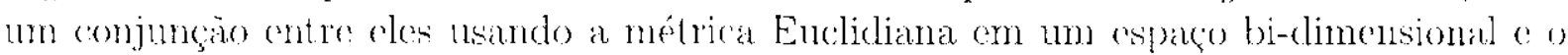
operador $\theta-{ }^{-} \leq$. A área cinza representa o conjunto resposta para a consulta connjexa, considerando os valores limites dos predicados. (a) Valor limite do predicado range maior que o do predicado k-ncorest $\left(u_{i}>v_{i}\right)$ : (b) Valor limite do predicado range menor clue o do predicado k-nearest $\left(u_{i}<v_{i}\right)$; (c) Valor limite do predicado range ignal ao do predicado Linenerest $\left(u_{i}=v_{i}\right)$.

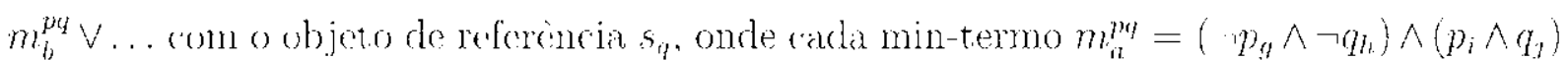

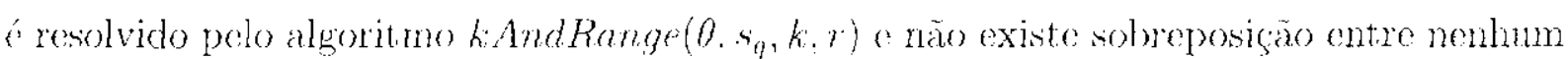

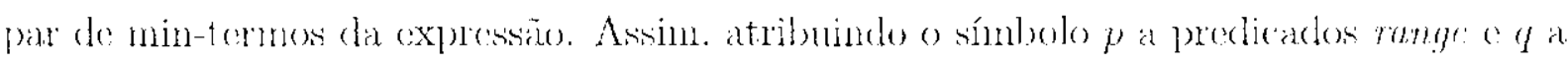
prodicados ki-nearest, tem-so:

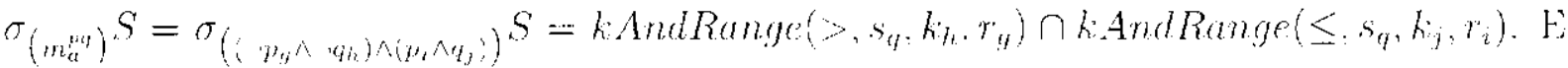

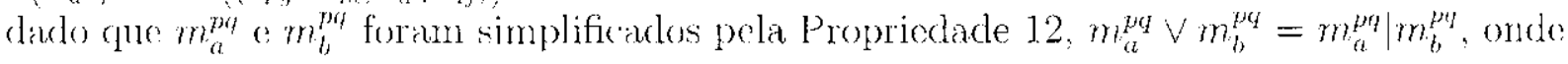

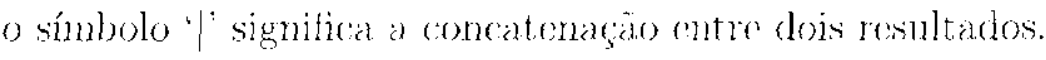

Os resultados intermediários de (ada (hatmada no algoritmo handRange() é um conjunto de olementos ordenados pela distancia en relação ao objeto de referencia da consulta $s_{q}$. A resposta final de todo o min-tomo é a intersegão de ambos os resultados intermediários, mas como as respostas săo orderadas pela distância de cada clemento a

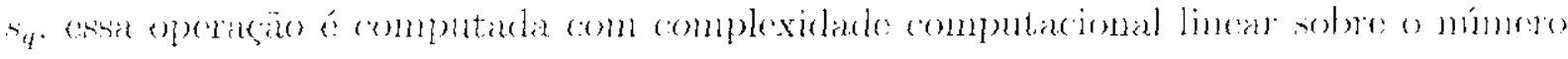
de elementos envolvidos.

Uma expressãu SCMP en DNF é enviada ao algoritmo UniSimDNF() com o parânetro minterms|f. Após o cálculo de cadin min-termo, o resultado é náantido eru

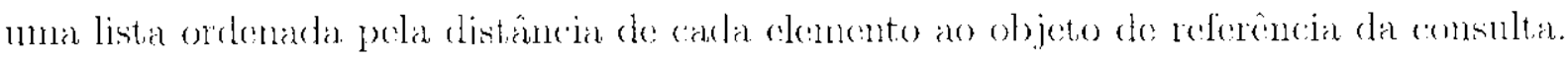
Portasto, a uniano de cada min-termo com o resultake do min-termo antorior, para forma o resultado de toda a expressão, também poele ser excoutadia com complexidade computiaciomal linear em relação ao número de elomontos envolvidos. A Figura 4.5 mostra os casos possíveis para o min-teno $m_{a}^{p q}$ os quais näo cobertos pelo algoritmo UniSimDNF().

Note-se cue algoritmos mais esperéficos que es propostos aqui para expressoúch SCMP om DNF aincla poderiann sere descunolvides. Para o caso especifico do min- 


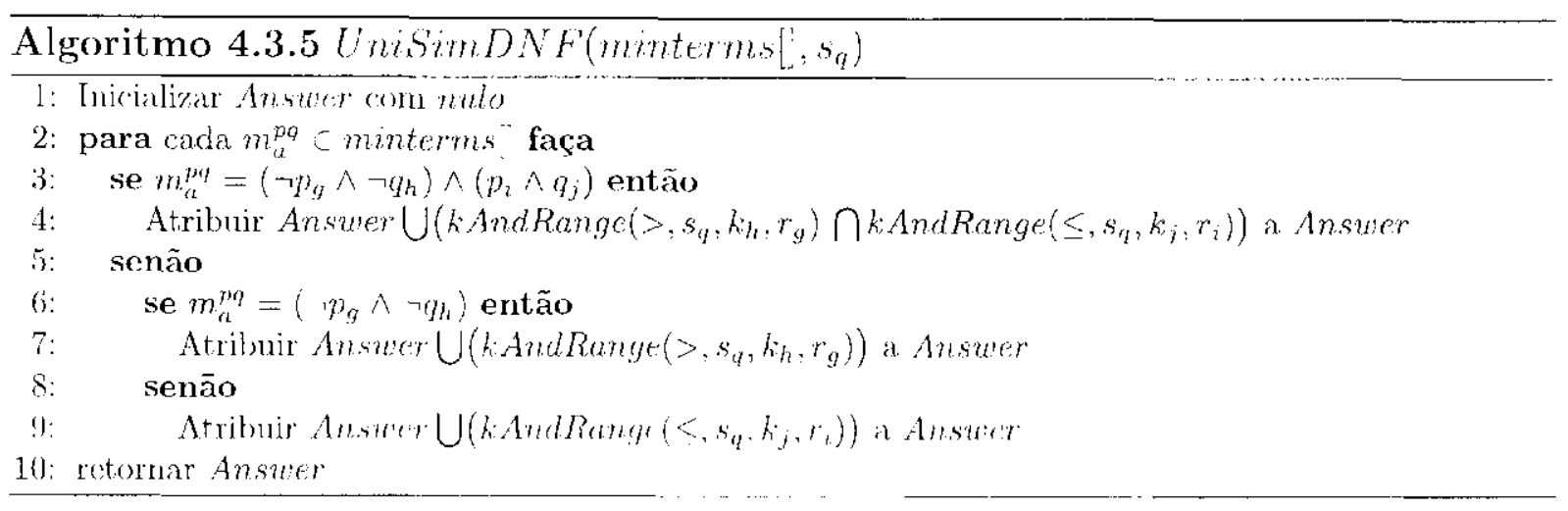

\section{$\cdots p_{i} \wedge q_{j}$ \\ $m^{p q}$}

(a)

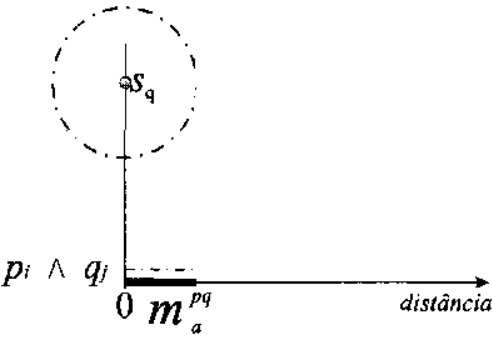

(b)

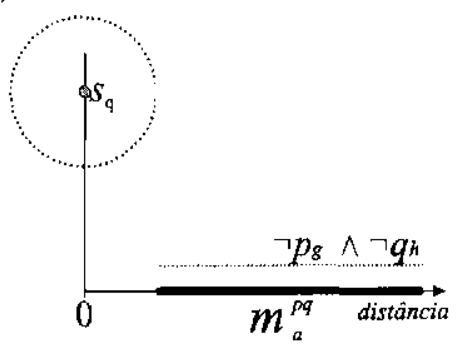

(c)

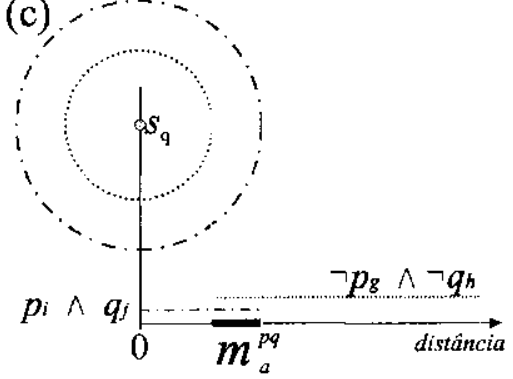

Figura 4.5: As tres possibilidades que o min-temo $m_{n}^{p q}$ pode assumir em una expressão SCMP om DNF sendo ilustradas por regioes an mo espaco mótrico bi-dincusional com função de distáncia Euclidiana. (a) $m_{a}^{p q}=-\left(p_{i} \wedge q_{j}\right)$; (b) $m_{a}^{p q}=\left(\neg p_{g} \wedge \neg q_{h}\right) ;(c)$ $m u_{a}^{p_{q}}-\left(\neg p_{g} \wedge \neg q_{h}\right) \wedge\left(p_{i} \wedge q_{j}\right)$.

tormo $m_{a}^{p q}=\left(\neg p_{l} \wedge \neg q_{h}\right) \wedge\left(p_{i} \wedge q_{j}\right)$, por exemplo, um algoritmo de custo equivalente a uma única excuçäo do algoritmo $k$ AndRange() pode ser implementado. Algoritmos

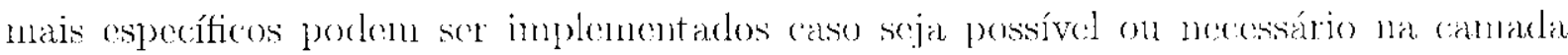
Executor dos gereneiadores. Entretanto, como um dos objetives destat tese ć apresentar un pequeno número de algoritmos que sejam gerais o suficiente para responder a qualquer consulta por similaridade complexa. algoritmos mais específicos, como o discutido neste parágrafo, não foram desenvolvidos.

Considere-se agora una expressão SCMP em CNF. Essats expressoon tamborm podem se beneficiar com a construgăn de algoritmos especificos paru responder a consultas

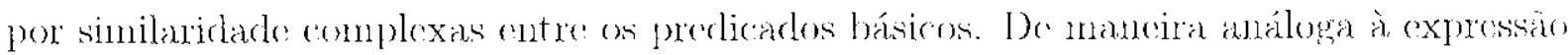

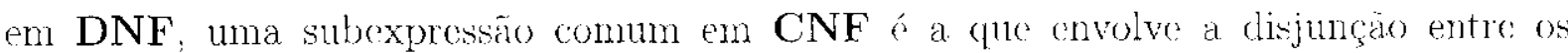
predicados básicos por similaridade, definida a seguir.

Definição 3: Consulta por Abrangência ou aos k-Vizinhos Muis Prómimos kOrRange Query - Dado um clemento $s_{\eta} \in S$, o valor $k$ definido no predicado k-nearest, a distancia $r \in \mathbb{R}^{1}$ definida no predicado range, o operador relacional $\theta \in\{\leq,>\}$, uma consulta kOr Range recupera calda clemento $s_{i} \in S \mid d\left(s_{q}, s_{i}\right) \theta$ rou $s_{i} \in \operatorname{Nearest}\left(\theta, s_{q}: k\right)$.

() algoritmo k.Or Range $\left(0, s_{q}, k, r\right)$ (Algoritmo 4.3.6) pode ser utilizado para res- 
ponder a consultas hor Range. Fsse algoritmo exeruta a disjungäo dos predicalos range

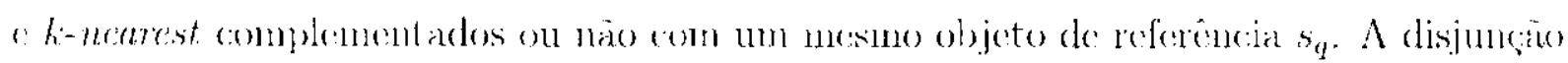
permite que un alencenuo, para ser inclúrlo no conjunto resposta, satistaça a qualquer $111 n$ dos predicados básicos segundo a rondicano $\theta$. Fote-se fue osse algorituno liambém á bascado no algoritruo Nearest $\left(0 . s_{q} . k\right)$. Entretanto, diferente do (pue ocorre no Nlgoritmo)

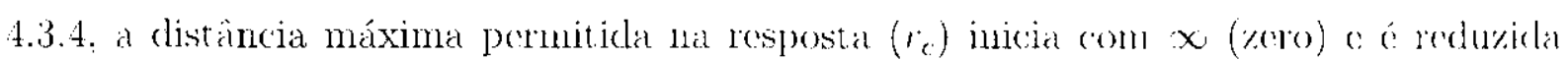

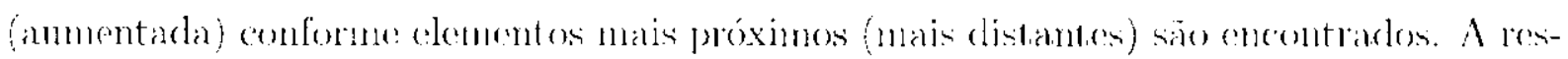

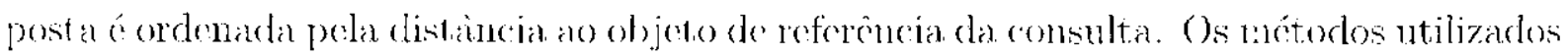
sào os mesmos descritos para o $\Lambda$ lgoritmo 4.3 .4 e a Figura 4.6 ilustra as posibilidades existentes para a disjuncão entre os predicados básicos. considerando gure o operaclor $\theta$ scja $\leq$. Essa tigura foi utilizada na elaboraça do algoritmo kOr Range(). onde as linhats

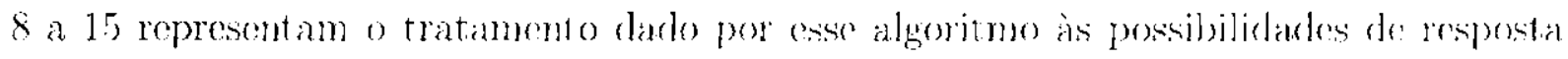
ilustradas nos itens (a), (b) e (c) da Figura 4.6, incluindo no conjunto resposta os objetos que estão dentro da regiào definda polo raio $r_{c}$ on ontre os $k$ objotos mais próxinos ( $/-k$ mais distantes).

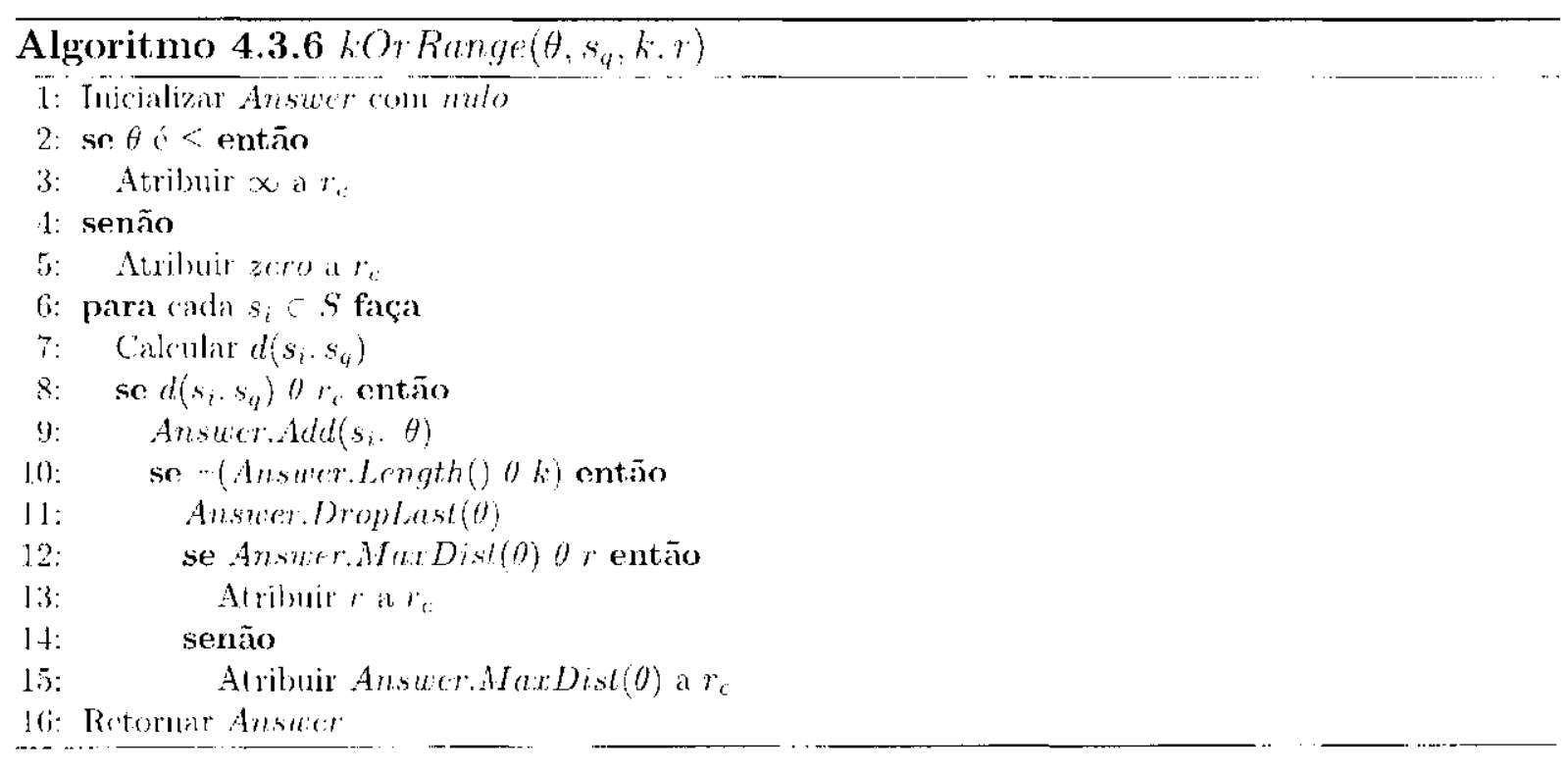

Ainda se torna necessário desemvolver un algoritmo correpondente ao Algoritmo 4.3.5 para responder a expressoes SCMP on CNF mais romplexas. Como cste trabalho

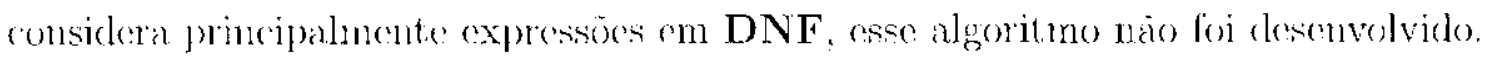

Vale salientar (pue o algoritmo handRange() tem um custo equivalente alo algo-

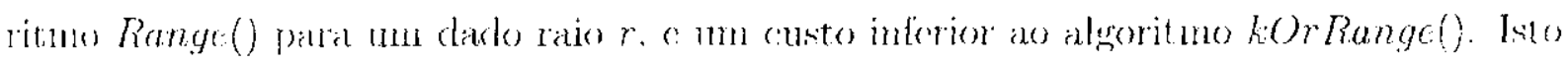
se deve à condição conjuntiva para a consulta por similaridade complexa implementada

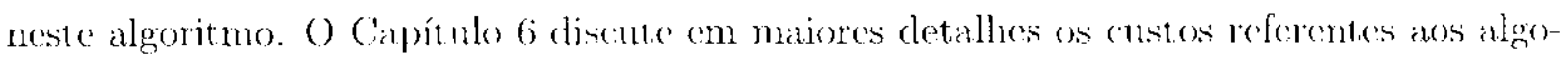

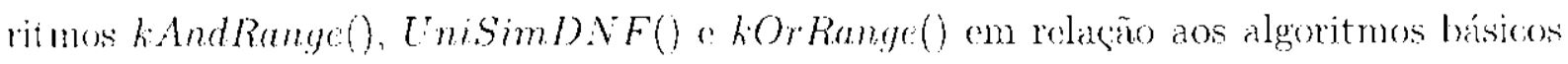
para responder a uma consulta por similaridade complexa.

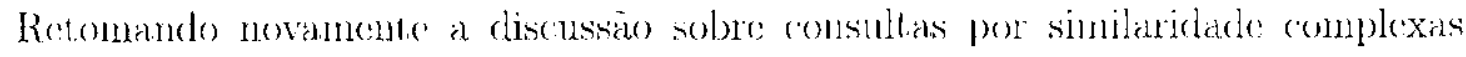
em DNF, o caso mais geral para esse tipo de consulta, cmolvendo diferentes objotos o diferentes prodicartos, é tratado a sconir 


\section{$-u_{i}$-range \\ $\cdots \cdot v_{i}-k$-nearest}

(a)

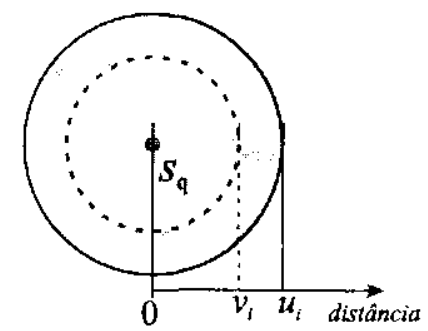

$u_{i}>v_{i}$ (b)

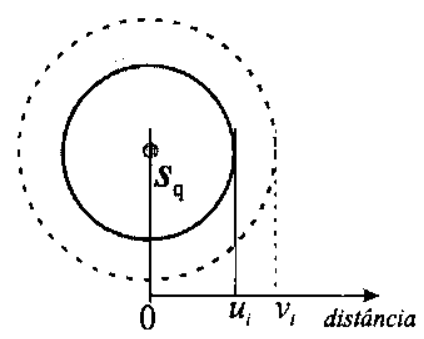

$u_{i}<v_{i}$ (c)

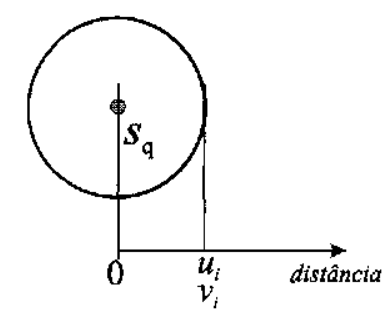

$\boldsymbol{u}_{i}=\boldsymbol{v}_{i}$

Figura 4.6: Casos possíveis cutre os valores linites dos predicados range ou k-nearest. dada um disjunçäo entre eles usando a métrica buclidianta con um expago bi-dimensional e o operador $\theta={ }^{\prime} \leq$. A área cinza representa o conjunto resposta para a consulta complexa: considerando os valores limites dos predicados. (a) Valor limite do predicado mange maior que o do predicarlo ki-nearest $\left(u_{i}>v_{i}\right)$ : (b) Valor limite clo predicado range menor que o do predicado k-nearest $\left(u_{i}<v_{i}\right)$ : (c) Valor limite do predicado range igual as do predicado ki-neares $\left(u_{i} \cdot v_{i}\right)$

\subsection{Consultas por Similaridade Complexas com Múl- tiplos Centros}

A forma mais genérica de expressôes envolvendo os predicados básicos por similaridado pode incluir predicantos gue possuem objetos centrais diferentes, chandadas neste trabalho

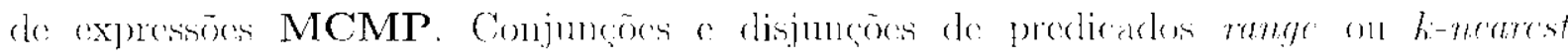
com objetos centrais diferentes não tèm quaisquer propriedades especiais. Apenas as equivalencias usuais cntre composição de predicados usando os operadores Boolcanos $\wedge c V$ com os operadores sobre conjuntos união e intersegão se mantên. Assim, tem-se que:

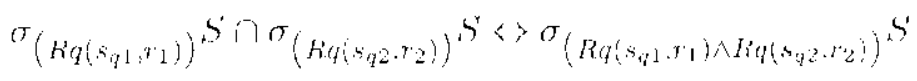

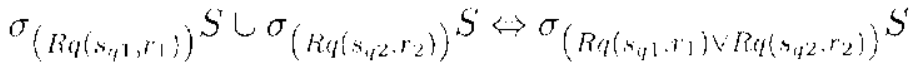

$$
\begin{aligned}
& \left.\sigma_{\left(k_{1} N N\left(s_{q_{1}}\right)\right)} S\right\urcorner \sigma_{\left(k_{2} N N\left(s_{q_{2}}\right)\right)} S \Leftrightarrow \sigma_{\left(k_{1} N N\left(s_{q_{1}}\right) \wedge k_{2} N N_{\left(s_{q_{2}}\right)}\right)} S \\
& \sigma_{\left(k_{1} N N\left(s_{q_{1}}\right)\right)} S \cup \sigma_{\left(k_{2} N N\left(s_{q_{2}}\right)\right)} S \Leftrightarrow \sigma_{\left(k_{1} N N\left(s_{q}\right) \cup\left(k_{2} N N\left(s_{q_{2}}\right)\right)\right.} S
\end{aligned}
$$

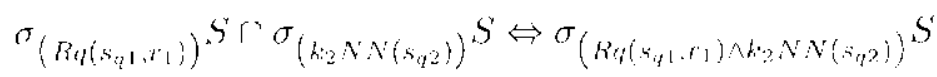

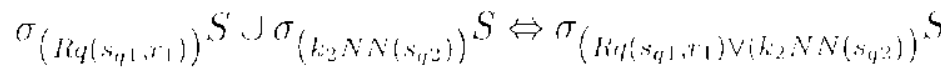

Entretanto, as propriedarles comutativa, ansociativa e distributiva sobre os

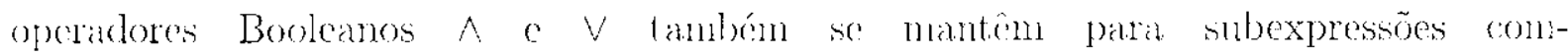




$$
\begin{aligned}
& \text { postas do predicados com objetos centrais diforentes. Assim, tem-se: }
\end{aligned}
$$

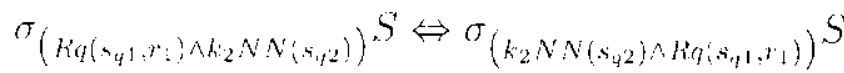

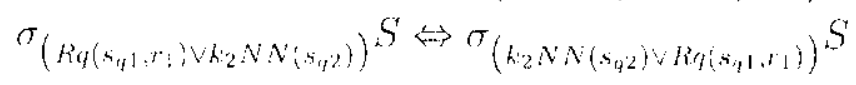

associativa:

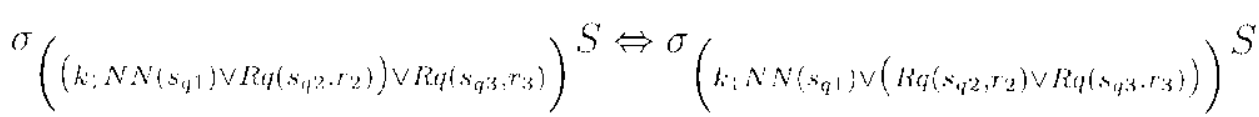

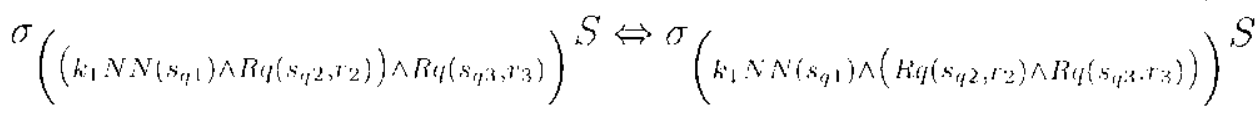

\section{distributiva:}

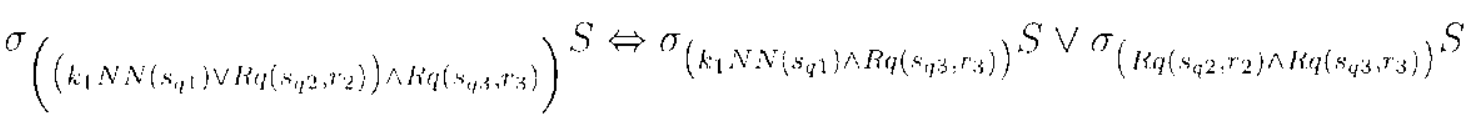

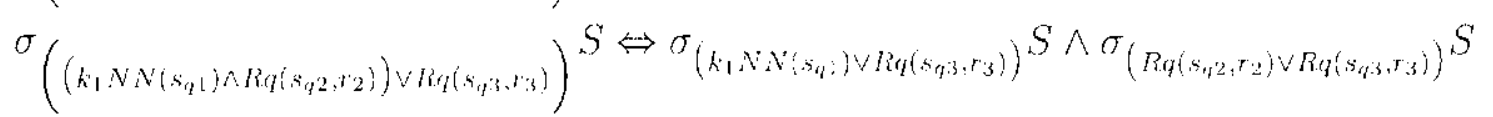

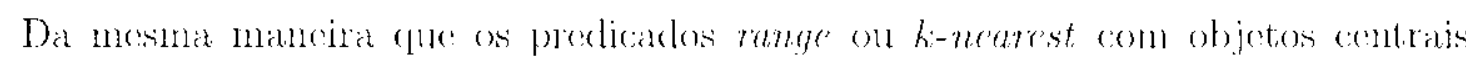
diforentes satisfazom os postularlos $B_{1}$ a $B_{3}$, eles tambóm satisfazen os postudados $B_{4}$ a $B_{6}$ que podem ser mostrados de forma análoga aos já apresentades para exprestoon SCSP a SCMP. Conseqüentemente, o conjuntu de expressöes MCMP também constiui nuna álgebra Boolenan sobre os operadores binánios $\wedge$ o $\vee$ o operador nuário $\neg$ e os operadores

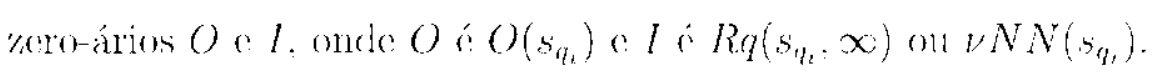

As propriedades para expressoes MCMP podem ser usadas juntamente com as propriedades apresentadas para expressós SCSP o SCMP para representar expressoos em um formato útil para melhorar algoritmos de consultat.

Fxpressios MCMP podem ser representadas en DNF (ou CNF), onde os mintormos conjuntivos (disjuntivos) säo compostos for predicados range ou k-nearest, complemcntados on não, cujos objetos de referencia são igulais on distintos. Este trabalho considera a DNF.

Suponha uma cxpressão de consulta cine onvolva prodicades com no objetos de

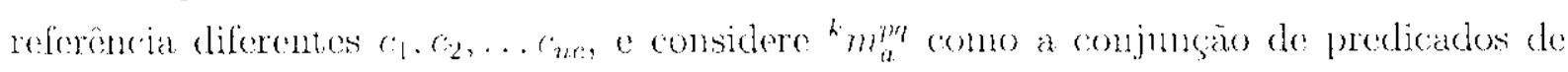

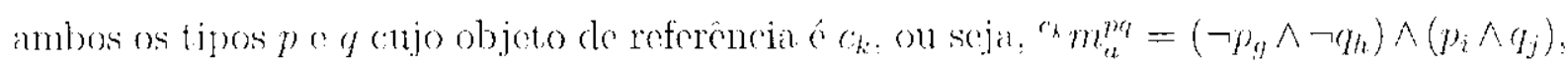
onde $p_{g}, q_{h}, p_{i}$ e $q_{j}$ săo predicados com objeto de referencia $c_{k}$. Portanto, cada min-termo de uma expressão MCMP tem a forma: ${ }^{c} m_{u}^{p q} \wedge^{c a} m_{b}^{p q} \wedge \ldots{ }^{c} m_{z}^{p u}$.

Para avaliar a consulta MCMP em DNF, esta tese propóe fatorizá-la usando um de seus objetos de referêteia por ve. $\Lambda$ ssim, sem perda do generalidade, assume-so que o conjurito de objetos de referencia é mantido om uma deterninada ordem, de mancira que ci precede s se $i<j$. Uma expressĩo fatorizada por sen centro co tem a forma

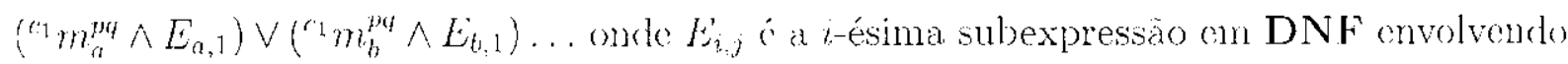

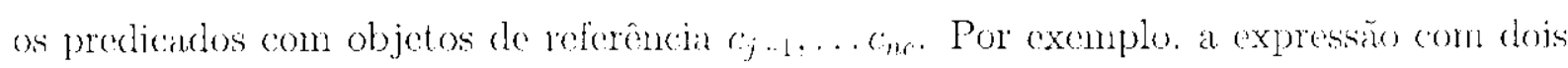
objetos centrais $c_{1}, c_{2}$ 


$$
\left({ }^{\left(c_{1}\right.} m_{a}^{p q_{1}} \wedge^{c_{2}} m_{b}^{p q_{q}}\right) \vee\left({ }^{c_{1}} m_{c}^{p / q} \wedge^{c_{2}} m_{d}^{p q}\right) \vee\left(c_{1} m_{a}^{p q_{q}} \wedge^{c_{2}} m_{e}^{p q}\right)
$$

pode ser fatorizada considerando o objeto central $c_{1}$ como

$$
\left({ }^{c_{1}} m_{a}^{p q} \wedge\left({ }^{c_{2}} m_{b}^{p q} \vee c^{c_{2}} m_{c}^{p q q}\right)\right) \vee\left({ }^{c_{1}} m_{c_{c}}^{p q} \wedge c^{c_{2}} m_{d l}^{p q}\right) \text {. }
$$

Cada expressão $E_{i, j}$ pode voltar a ser fatorizada considerando os centros restanles, ran un processo recursivo. Caula subexpressião $E_{i, j}$ e toda a expressão podo ser simplificada usando as propriedades para expressoes SCMP e SCMP cm DNF.

Em seguida é necessário executar a expressão simplificada para recuperar a resposta da consulta complexa. Un algoritmo para executar consultas por similaridade complexas MCMP em DNF, chanado de GenSimDNF(minlerms[], ccnters[]), cstá

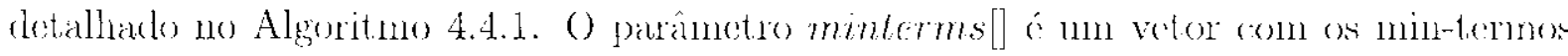
(incluindo seus respectivos objetos de referência) da expressâa simplificada a ser executada, o centers[] ó um vetor com os centros que ocorrem em pelo menos um predicado dos min-termos. A execução desse algoritmo é descrita a soguir. Se uma expressão tem apenas um centro e, ele retorna o resultado do algoritmo UniSimDNF(minterms[] c).

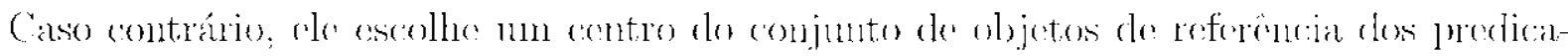
dos como c, o fatoriza a expressão procurando cada formo " $m_{i}^{p q}$ distinto gue ocorre no conjunto de min-termos. Para cada min-termo composto do termo "mpq ele calcula as subexpressoes correspondentes dos termos restantes o recursivanente execula o algoritmo GenSimDNF(). Os objetos encontrados como respostas para cada subexpressäo sofrem

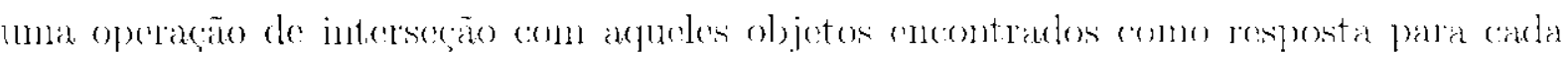
termo ${ }^{c} m_{i}^{p q}$ : gerando os resultados do cada min-tcrmo, os quais são, na volla do processo recursivo, concatenados para obter o resultado final da expressão MCMP completa.

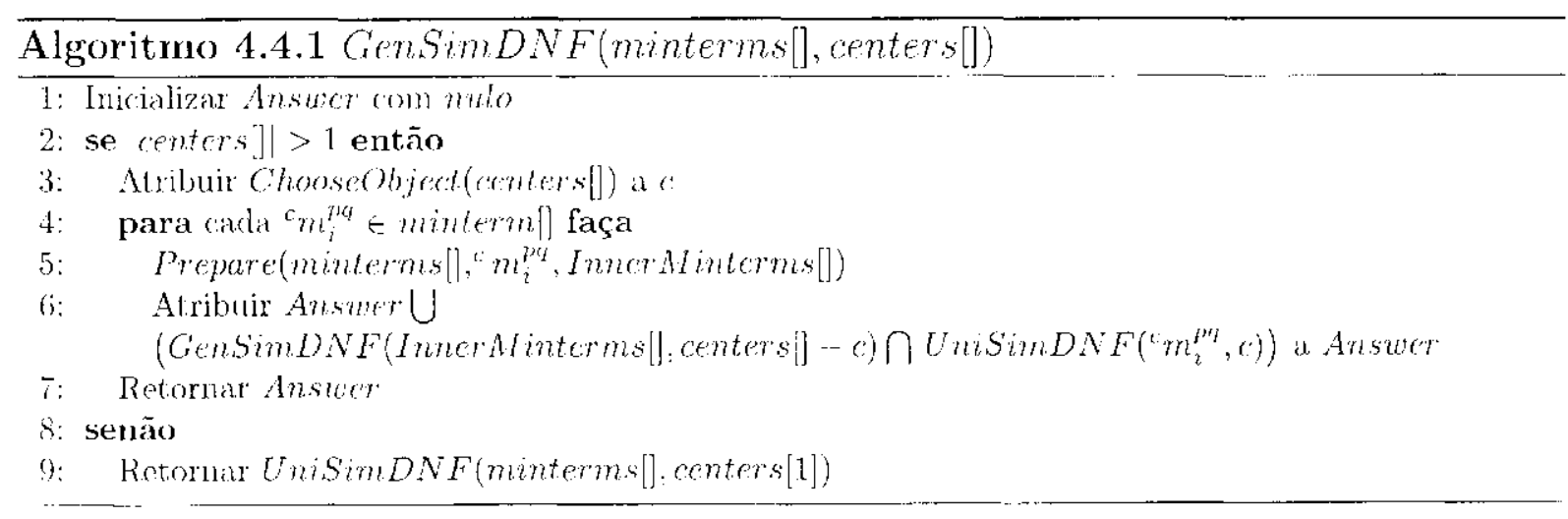

O algoritmo Chooseobject(center []) usado pelo algoritmo GenSimDNF(mintermsi], centers[]) escolhe um contro do conjunto de objetos de referencia clos predicados envolvidos e, por consequiència, define uma ordem para o conjunto de objetos de referoncia a serem avaliados. Ele pode ser implementado considerando diforentes heurísticas para definir a orden para o conjunto de objedos de referencia. Alguns exemplos de heurísticas que podem ser consideradas são: hamanho relativo dos raios de consulta e diametro do conjunto de dabos, numero b de elementos 
desejados e número de elementos no conjunto de dados. Uma heurística genérica útil em

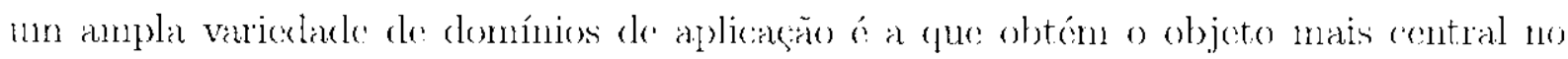
conjunto de objetos de referencia restantes, da seguinte maneira. A soma das rlistancias

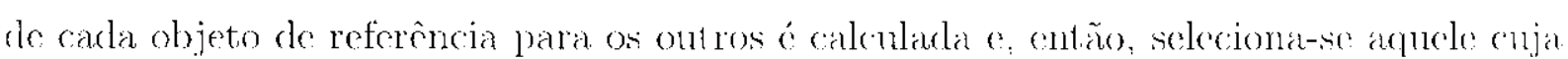
soma é a menor. () algoritmo Prepare (minterms|]. ${ }^{m p q}$, Inner Minterms[]) seleciona do conjunto minterms|] o termo $' m_{i}^{\beta q}$ retirando-o desse conjunto, o cm seguida armazena a subexpressäo resultante en Inner Minterms[: Anbos os algoritmos poelem se beneficial de otimizações devido a peculiaridades de um determinado domínio de aplicação.

Consultas por similaridade complexas envolvendo múltiplos centros, considerando o caso particular onde apenas predicados de urn sí tipo estiano prescntes na expressão,

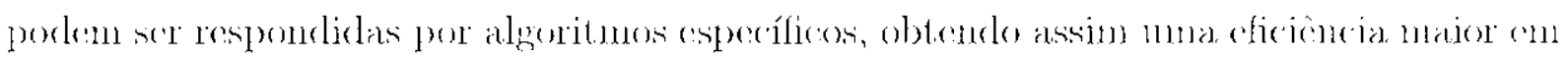
relação ao apresentado nesta sesão. Entretanto, conforme discutido em operadores parn exccutiar expressões SCMP da Seção 4.3 .2 algoritmos mais específicos não são apresentados neste trabalho. $\Lambda$ seguir 6 apresentada a conclusão deste capítulo.

\subsection{Conclusão}

Comsullas por similaridade são necessárias para recuperar dados complexos em grandes conjuntos de dados. Entrotanto, até agora não havia um estudo de como analisar uma expressão de consulta por similaridade envolvendo mais de um predicado. $\Lambda$ principal contribuição deste capítulo é dividir o problema de analisar expressöes por similaridade complexas em 3 passos: Mesmo Centro/Nesmo Tipo de Predicado (SCSP), Mesmo Contro/Tipens de Predinades Dilerentes (SCMP). Contros Distintes/Tipes de Predicados Diferentes (MCMP). Seguindo esta abordagem, regras para simplificar expressões por similaridlade complexas são obtidas diretamente.

Com o objetivo de incorporar consultas por similaridade cm un gerenciador relacional, uma extensão à álgebra relacional e una coleçao do algoritmos de recuporação baseados em similaridado são apresentados. Esses algoritnos săo simples e genéricos po-

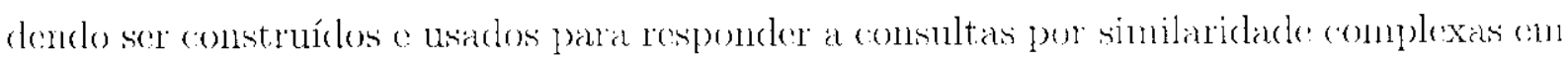
um tempo linear. Note-se que apenas (1latro algoritmos säo suficientes para responder a qualduer consulta por similaridade complexa envolvendo os predicados range c k-nearest, sendo eles: GenericRange(), GenericNearest(). UniSimDNF(), e GenSimDNF(). Os algoritmos RingRange() e $k$ AndRange() bem como o algoritmo kOr Range(), para expressöes cm CNF, também poden ser inclúdus para melhorar o desemuenho de respostias para tipos de consultas por similaridade mais simples que sĩo frecuïentementer utilizadas. A Tabela 4.3 mostra as expressón onde cada algoritmo é utilizado.

O conjunto de novos algoritmos propostos tem por finaliclade responder a expres-

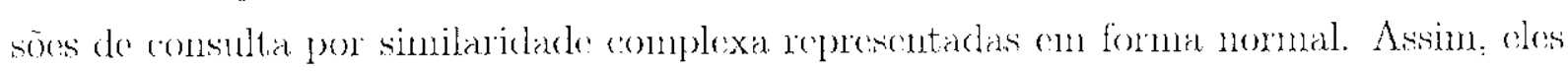
são denoninados nesta tese de algoritmos para consultas por similaridade normativos, ou simplesmente algoritmos nornativos, cun contraposiçäo ans algortmos básicos que requer- 
Tabela 4.3: Os algoritmos desenvolvidos c as expressões em que cada um deles é utilizado.

\begin{tabular}{|c|c|c|}
\hline Algoritmo normativo & Expressão & Exemplos \\
\hline Ringhange() & SCSP & $\neg p_{i} \wedge p_{j}$ \\
\hline $\begin{array}{l}\text { GenericRange()/ } \\
\text { GonerieNearest() }\end{array}$ & SCSP & $p_{i} \vee\left(\neg p_{i} \wedge p_{j}\right) \vee\left(\neg p_{g} \wedge p_{h}\right) \vee \neg p_{k}$ \\
\hline LAndRange() & SCMP & $\left(\neg p_{g} \wedge \cdots q_{h}\right) \cdots\left(p_{i} \wedge q_{j j}\right)$ \\
\hline kor Range() & SCMP & $\left(\neg p_{g} \vee \neg\left(h_{i}\right) \subset\left(p_{i} \vee q_{j}\right)\right.$ \\
\hline UnisimDNF() & SCMP & $m_{a b}^{p q} \vee m_{b}^{p q} \vee m_{c}^{p q}$ \\
\hline (ronsimDNF() & MCMP & 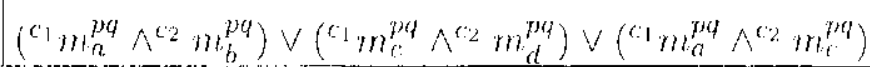 \\
\hline
\end{tabular}

rem algoritmos de uniäo o intersegão de conjuntos para gerarem as respostas solicitadas.

Os algorilmos normalivos para comsultas por similaridade apresentados neste ca-

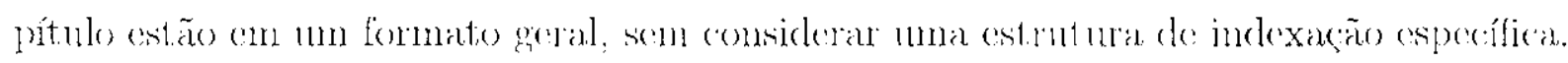
Dessa maneira, a implementaçào específica de cada algoritmo pode se favorecer das propricdades da estrutura utilizarla, contribuindo para mellowar o processo de respostia da

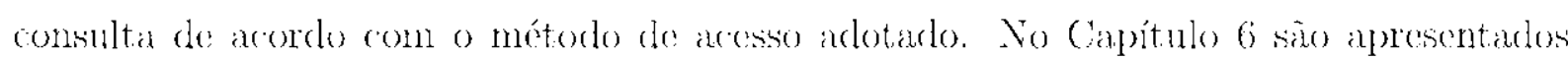
experimentes considerando o método de aresso métrico Sham-tree a uma implementacan de lista seceüencial. comparando os algoritmos momativos eom os respextivos algoritmos básicos seguidos dos operadores sobre conjuntos minão o intersegấo para responder a una consulta por similaridade complexa.

O modo proposto para analisar exprescónes por similaridarle complexas para operacoes de selecão o as regras derivalas a part ir dessa análise podom manipular expressões por

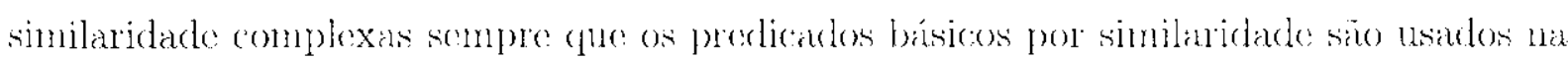

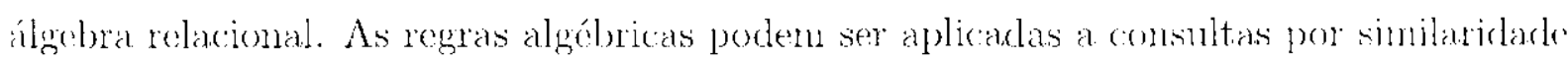
complexas, simplificando o preparando uma expressán por similariclade complexa para set submetida aos algoritmos nomativos propostos. Portanto, isto abre a possibilidade para dar suporte ao armazenanento e recuperação de darkos complexos bastados on conteúdo,

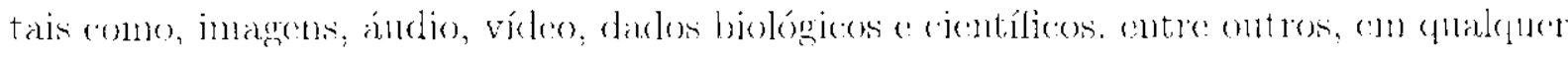
sistema basendo sobre a algetra relacional r. principalmente, nos atuais gerenciadores relaciomais bascaclos cm SQL. 
Capítulo

5

\section{Estimativa de Seletividade}

\subsection{Introdução}

$\mathrm{O}$

Otimizador de um Sistema de Gerenciamento de Bases de Dados (SGBD), tem como objetivo escolher, entre os planos gerados pelo módulo Gerador de Planos. aquele de menor custo computacional. A estimativa de custo feita pelo Otimizador utiliza a seletividade de carla predicado de uma consulta, junlamente com outras informaçōes (ver Seção 2.5), para determinar o custo de execução de urn detcrminado plano de consulta. Assim, a seletividade é utilizada pelo módulo Estimador de Planos para anxiliar o processo de estimativa de custo de um plano de consulta, e a sua precisão influencia diretamente o processo.

Para obter estimativas de seletividade cadla vez mais precisas, diversos estudos têm sido realizados, tanto para dados convencionais quanto para dados complexos. Apesar do não haver um conscnso entre os pesquisadores sobre qual modelo de estimativa do scletividade adotar para dados complexos (ver Seçăo 3.5), o modelo basearlo na teoria do fractais tem sido adotarlo para a amálise de enjuntos do dados complexos con traballos recentes, tais como [Böhm et al., 2000], [Korn et al., 2001\% mostrando uma tendência cm se utilizar esse modelo. Nesse modclo pressupōe-se que distribuição dos dados no espaço é não uniforme, caracterizando de maneira mais adequada conjuntos de dados reais [Belussi \& Faloutsos, 1995]. [Belussi \& Faloutsos, 1998], [Traina Jr. et al., 2000a] (ver Sc-

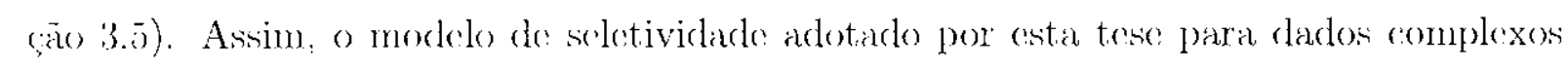
em domínios métricos é baseado na teoria de fractais.

Utilizando o modelo adotado, este capítulo apresent a um conjunte de regras para derivar fórmulas de estimativa de seletividade para consultas por similaridade complexas. Essas fómulas visan a fornecer estimativas para expressöes por similaridade complexas 
envolvendo os dois tipos de predicados básicos por similaridade, combinados pelos operadures Boolanos $\wedge(\mathbf{E}), \vee(\mathbf{O U})$ : $\neg($ Negação). As regras ut ilizadlas, pard a partir delas derivar as fórmulas de estimativas de seletividades propostas, baseiam-se nas três classes em que una expressão por similaridade complexa pode ser clivíclida (ver Capítulo 4). Assim, tên-se estimativas de seletividade para expressões SCSP (Seção j.3.1), para expressões SCMP (Seção 5.3.2) e para expressões MCMP (Seção 5.3.3).

Para que as fómulas de estimativas de seletividade para consultas por similaridade complexas possam ser obtidas, primeiro é necessário mostrar como o modelo de seletividade adotado pode ser ntilizado para estimar o número de objetos considerando um determinarlo raio $r$.

\subsection{Estimando o Número de Objetos Usando Fractais}

Estimar o número de objetos ou elementos para uma consulta por similaridade básica significa "prever" a cardinalidade de uma consulta por abrangência $(R q)$, conforme discutido na Seção 3.5, uma vez que para a consulta aos $k$-vizinhos mais próximos $(k N N)$ csisa cardinalidade já ostá definida. $\Lambda$ estimativa usindo a teroria de fractais pode ser feita utilizando a Dimnensão de Correlação Fractal (DCF) D (ver Seção 3.5.1) de 1um conjunto de dados.

É interessante notar que uma vez determinada a DCF de um conjunto de dados, a inserção ou climinaçăo de novos objetos no conjunto não afeta a dimensão $\mathcal{D}$, se as caracteristicas gerais do conjunto forem preservadas. Por isso, se o distance plot for refeito, ele irá gerar uma nova reta com a mosma inclinação (ângulo) da anterior. Ou seja, a reta que define o distance plot de um conjunto de dados sobe ou desce conforme esse conjunto tenha mais ou nonos clenentos, porén cla sempre mantén o mesmo àngulo.

Lsando o distance plot de um conjunto de dados e uma reta adequada com ângulo $\mathcal{D}$ (lambém chamarlo de distance exponent), é possivel obter o número $k_{r}$ de elementos dentro de um raio de cobertura $r$, definido por uma consulta $R q$. Para isso, é usada a propriedade que o distance exponent $\mathcal{D}$ näo se altera quando o conjunto de dados é atoulizardo.

Mesmo conhecendo a dimensão $\mathcal{D}$ de um conjunto de dados, isso não é suficiente para determinar uma rota em particular no distance plot, pois, para traçála com a inclinação $\mathcal{D}$ correspondente, é também necessário definir um ponto por onde a reta passa.

Portanto, a hipótese formulada a a seguinte. Quando uma consulta $R_{q}$ for executada, para se estimar o múmero $h_{r}$ de objetos, deve-se utilizar o distanct exponent $\mathcal{D}$ como o ângulo da reta e as coordenadas $(R, \nu)$ para o ponto conhecido da reta, onde $R$ é o diàmetro desse conjunto de dados e $\nu$ é o número total de objotos do conjunto de dados

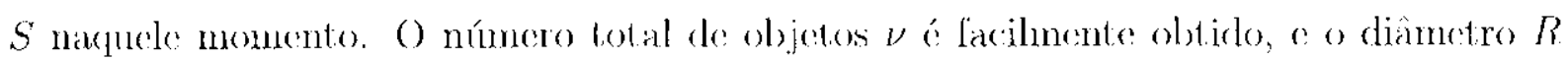
pode ser estimado a partir da estumtura de indexação utilizada, obtcndo o diâmetro do nó raiz da estrutura. 
Tabela 5.1: Principais símbolos utilizados neste capítulo.

\begin{tabular}{|c|c|}
\hline Símbolos & Definições \\
\hline $\mathcal{D}$ & Dimonsão de Correlaçäo Fractal ou distance exponent. \\
\hline$\nu$ & Número total de objetos de um conjunto de dados $S$. \\
\hline$R$ & Diàmetro do conjunto de dados $S$. \\
\hline$I^{\mathrm{S}} \mathrm{C}(r)$ & Número do pares de elementos dentro de uma distância $r$. \\
\hline$k_{r}$ & Núnero estimado de objetes a ser retornado por umat consulta $R q$ de raio $r$. \\
\hline$\overline{k_{r}}$ & $\begin{array}{l}\text { Núnero estimado de objetos a ser retomado por uma consulta } \neg R q \text { de raio } r \text {, } \\
\text { onde } \overline{k_{r}}=v-k_{r} \text {. }\end{array}$ \\
\hline$k$ & Número de objetos recuperados por uma consulta $k N N$. \\
\hline$k$ & Número de objetos retornados por uma consulta $\neg k N N$, onde $\bar{k}-\cdots-k$. \\
\hline
\end{tabular}

O processo para so obter o valor estimado $k_{r}$, dado um determinado raio $r$, é descrito a seguir. A Equação 3.9, apresentada na Seção 3.5.1, usa o número de pares PC (r) dentro de uma distáncia $r$. Porém, o que se deseja estimar co o múnero de elementos $k_{r}$ dentro de um raio $r$ e não o número de pares de elemontos dentro do um rajo conforme é definido pela equação. Assim, ć preciso converter o número de pares em número de elementos $k_{r}$ dentro de uma distância $r$. Portanto, dado um subconjunto de $k_{r}$ elementos do conjunto de dados $S$, o número de pares que esses elementos geram ó:

$$
\operatorname{Pairs}\left(k_{r}\right)=\frac{k_{r}\left(k_{r}-1\right)}{2}
$$

porque cada par deve ser contiado alpenas uma vez.

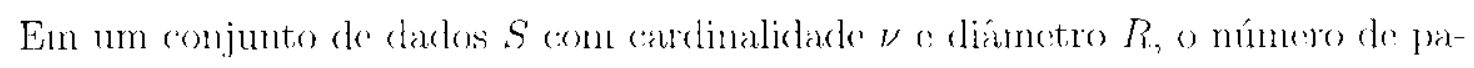
res separados por distâncias menores que o diâmetro do conjunto de dados é $P C(R)=$ Pairs $(\nu)=\nu(\nu-1) / 2$. Assim, quando a consulta por similaridade é feitá, a reta específica para o conjunto de dados $S$ é determinada pelo ponto $\langle\log (R), \log (\operatorname{Pair} s(\nu))\rangle$ no gráfico do distance plot para esse conjunto de dados. Usando essa reta, o número de elementos $k_{r}$ que formam pares a uma distância menor ou igual a $r$ pode ser estimada usando $P C(r)=\operatorname{Pairs}\left(k_{r}\right)$.

A Figura 5.1 ilustra essa idéia onde a Reta 0 é a reta usada para calcular a dimensão intrínsica $\mathcal{D}$ do domínio de dades a partir de unla anostra representativa desse domínio. Fssar reta aproxima o número médio de pontos (cm escala log-log) sobre a variação total de distâncias que ocorrem no conjunto de dados. Observe-se que conjuntos do dados reais usualmente têm poucas distâncias com valores perto do diâmetro do conjunto: entäro, a quantidade de distancias maiores aumenta en menor proporção (que a

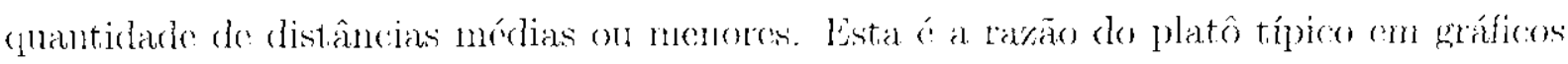
de distance plot para raios grandes em conjuntos de dados reais, tais como o conjunto de dados MGCounty nas Figuras 3.6 e 5.1 .

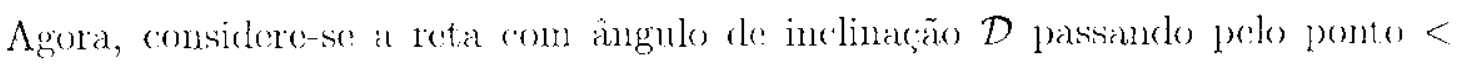
$\log (R), \log ($ Pairs $(\nu))>$, identificado como Ponto 1 na Figura 5.1. Essa reta, idlentificada como Reta 1 ra figura, representa o relaciomamento entre os raios e o número de pares 


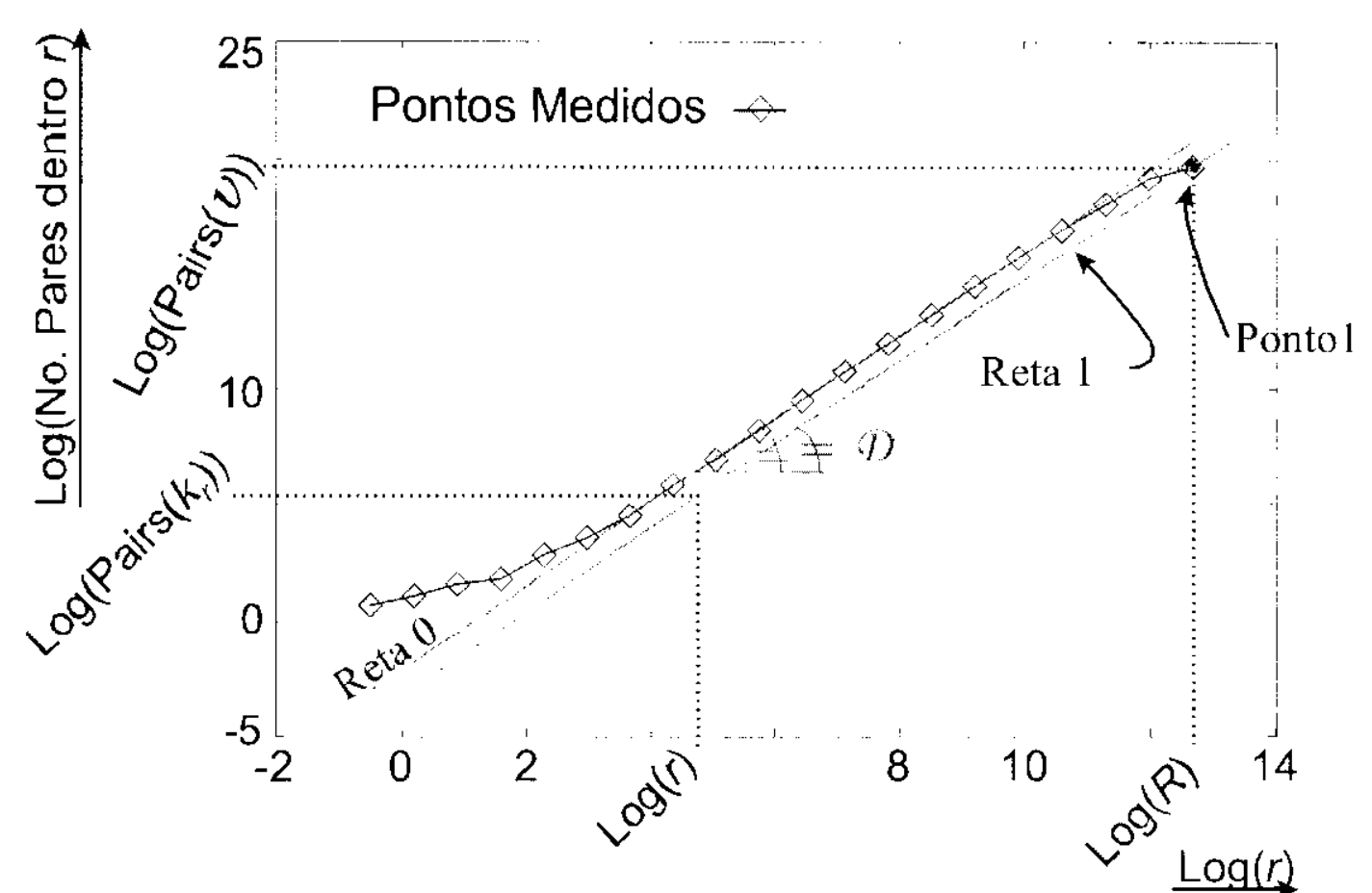

Figura 5.1: Como usar o distance plot de un conjunto de dados para cstimar o número k. do elementos.

dentro de cada raio, em um conjunto de dados $S$ específico do domínio $\mathbb{S}$. Portanto, ela ć adecluarla para estinnar o núnere de clementes $k_{r}$ nesse conjunto a partir de mon raio $r$. $A$ constante $K_{d}$ da Equação 3.9 para a Reta 1 pode ser calculada considerando-se o Ponto 1 como:

$$
\begin{aligned}
\log (P C(R)) & =\mathcal{D} \cdot \log (R)+K_{d} \\
K_{d} & =\log (\text { Pairs }(\nu))-\mathcal{D} \cdot \log (R) \\
K_{d} & =\log \left(\frac{\nu(\nu-1)}{2}\right)-\mathcal{D} \cdot \log (R)
\end{aligned}
$$

Combinando a Equação 5.2 com a Equação 3.9 que representa o número de pares de elementos dentro de um raio $r$, substituindo $P C(r)$ pela Equação 5.1 , e simplificando a expressão tem-se

$$
\begin{aligned}
\log (P C(r)) & =\mathcal{D} \cdot \log (r)+K_{d} \Rightarrow \\
\log (P C(r)) & =\mathcal{D} \cdot \log (r)+\log \left(\frac{\nu(\nu-1)}{2}\right)-\mathcal{D} \cdot \log (R) \Rightarrow \\
\log \left(\frac{k_{r}\left(k_{r}-1\right)}{2}\right) & =\mathcal{D} \cdot \log (r)+\log \left(\frac{\nu(\nu-1)}{2}\right)-\mathcal{D} \cdot \log (R) \Rightarrow \\
\log \left(k_{r}\left(k_{r}-1\right)\right) & =\mathcal{D} \cdot \log (r)+\log (\nu(\nu-1))-\mathcal{D} \cdot \log (R)
\end{aligned}
$$

Obtendo $k_{r}$ a partir da Equação 5.3 , tem-se a seguinte equação

$$
\begin{aligned}
k_{r}\left(k_{r}-1\right) & =\exp (\mathcal{D} \cdot \log (r)+\log (\nu(\nu-1))-\mathcal{D} \cdot \log (R)) \Rightarrow \\
k_{r}^{2}-k_{r}-N u m & =0, N u m=\exp (\mathcal{D} \cdot \log (r)+\log (\nu(\nu-1))-\mathcal{D} \cdot \log (R))(5.4)
\end{aligned}
$$


Dado que $k_{\tau}$ precisa ser um valor inteiro maior que zero, a equação do segundo

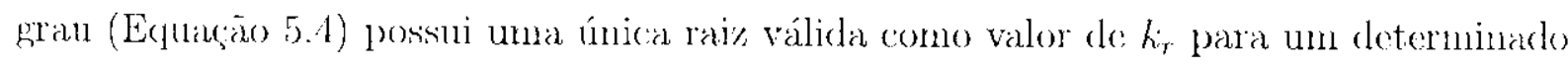
raio $r$. Assim, o valor estimado de $k_{r}$ é expresso pela Equação 5.5, arredondande o seu valor, caso esse seja um valor fracionário.

$$
k_{r}=\frac{1+\sqrt{1+4 \cdot N u m}}{2}, k_{r} \geq 1
$$

Portanto: a Equaço 5.5 o a equação final do processo que permite estimar o número de elementos que serão recuperados em uma consulta $R q$ dado $r$, podendo ser utilizarla para prever a seletividade desse tipo de consulta. A Tabela 5.1 sumariza os principais símbolos utilizados neste capitulo.

\subsection{Seletividade para Consultas por Similaridade}

Para formalizar as estimativas de seletividade para consultas por similaridade, assume-

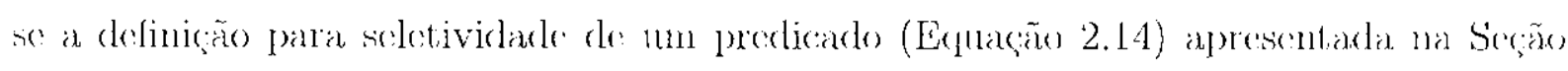
2.5 , onde nup (número do valores prováveis) representa a quantidade de elementos a ser recuperada pelo predicado por similaridade. Considerando que a existência do dois clementos exatamente iguais é rara [Faloutsos, 1996], nvd (número de valores distintos) ́́ igual a $\nu$. Além disso, uma pequena mudança na notação para soletividade é foita, pois a partir dacui a seletividade ó (expressa por sel(tipo de consulla) alo invís do sel (atributo) da Seção 2.5

Estimativas de seletividade para consultas por similaridade complexas podem ser formalizadas utilizando a mesma classificação para as expressoes apresentada no Capítulo 4. Portanto, para consultas envolvendo a composição dos dois tipos de predicados básicos por operadores Booloanos, as suas seletividades também pordern ser classificadas em expressôes SCSP, SCMP e MCMP. A seguir são apresentadlas as fóm mulas derivadas para expressós SCSP, isto é, consultas formadas apenas por predicades do tipo range ou $k$-nearest com suals respectivas variagoes c composiçós.

\subsubsection{Seletividade para Expressões SCSP}

Inicialmente, considere-se estimar a seletividade para ma consulta ans $k$-virinhos matis próximos expressa pelo predicado $k N N\left(s_{y}\right)$. A seletividade para esse tipo de consulta é obtida diretamente, uma vez que a quantidade $k$ de elementos expressa pelo predicado, corresponde ao número do elementos a ser recuperado na consulta. Assin, a seletividade para esse predicado pode ser definida conforme descrito a seguir.

Seletividade 1: Consulta $k N N$ - Sendo $\nu$ o número total de elementos em um conjunto de dados $S$, o $k$ a quantidade do elementos definida no predicado $k N N\left(s_{q}\right)$, a 
seletividade desse predicado é expressa por

$$
\operatorname{sel}(k N N)=\frac{k}{\nu}
$$

De mancira semelhante e também direta, a seletividade correspondendo ao complemento de uma consulta aos $k$-vizinhos mais próximos expressa polo predicado $\neg k N N\left(s_{q}\right)$ pode ser calculada da seguinte mancixa.

Seletividade 2: Complemento de $k N N(\neg k N N)$ - Sendo $\nu$ o número total de elementos em um conjunto de dados $S, k$ a cuantidade de elementos rlefinida no predicarlo $\neg k N N\left(s_{q}\right)$, e $k$ o múmero de clementos recuperades por esse predicado, onde $\bar{k}$ ć igual a b menos $k$ a a seletivilade desse predicado é expressa por

$$
\operatorname{sel}(-, k N N)=\frac{\bar{k}}{\nu} \Rightarrow \frac{\nu-k}{\nu} \Rightarrow 1-\frac{k}{\nu}
$$

Em uma consulta $R$ q expressa pelo predicado $R_{q}\left(s_{q}, r\right)$ näo é possivel saber antecipardamente qual ó o número de objetos a ser recuperado. Sendo assim, a seletividade para esse tipo de predicado não porle ser obtida de modo direto como as scletividarles referentes à consulta aos $k$-vizinhos mais próximos o seu complemento, formalizadas em Seletividade 1 e 2 anteriormente. Portanto, cste trabalho usa a teoria de fractais pari est $\mathrm{j}$ -

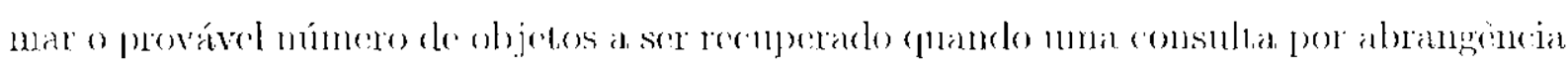
in executarda.

Esse valor, ostimado pela Equação j.j, é chamado nesta tese de $k_{r}$. Assim, a selchividade para a consulta por abrangência e seu complemento pode ser definida de mancira análoga a unara consulta anos $k$-vizinhos mais próximos da seguinte mancira.

Seletividade 3: Consulta $R q$ - Sendo $\nu$ o múmero total de elementos em um conjunto de dados $S$ o $k_{r}$ a quantidade de elementos estimada a ser recuperarla pelo predicado $R q\left(s_{q}, r\right)$, a seletividade desse predicado é expressa por

$$
\operatorname{sel}(R \varphi)=\frac{k_{r}}{\nu}
$$

A seletividade para o conplemento da consulta por almrangência é descrita conforme a seguir.

Seletividade 4: Complemento de $R q(\neg R q)$ - Sendo $\nu$ o número total de elementos em um conjunto de dados $S, k_{r}$ o número de elementos estimado a partir do raio $r$ do predicado $\neg R q\left(s_{q}, r\right)$, e $\overline{k_{r}}$ a quantidade de elementos recuperados por esse predicado,

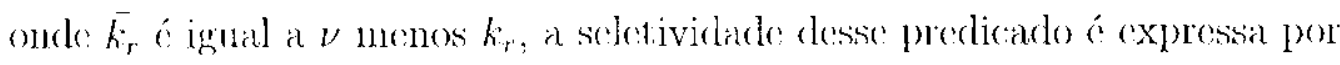

$$
\operatorname{sel}(-\neg q)=\frac{\overline{k_{r}}}{\nu} \Rightarrow \frac{\nu-k_{r}}{\nu} \Rightarrow 1-\frac{k_{r}}{\nu}
$$


As seletividades desctitas até angui representam as soletividades correspondentes aos dois tipos principais de consultas por similaridade encontradas na literatura. Entretanto, composiçoes desses operadores em uma expressão mais complexa também podem ser exigidas em um gerenciador relacional, conforme discutido no Capítulo 4. Assim, dado o) min-termo SCSP con DNF $\sim p_{i} \wedge p_{e}$ e csse min-termo forma regiós cm anéis (ver Figuma 4.1). Desse modo, é tambén necessúrio determinar a seletividade para o min-termo arima mencionado que define regióes não nulas. Portanto, considerando inicialmente que o predicado $p$ é uma consulta aos $k$-vizinhos mais próximos, a scletividade para o min-termo SCSP $\neg p_{i} \wedge p_{e}$ pode ser definicla por:

Seletividade 5: Anéis $k N N$ - Senrlo y o munero total de elementos om $\mathrm{um}$ comjunto de dados $S, k_{i}$ o $k_{c}$ as quantidades a serem recuperadas definidas respectivamente nos predicados $\neg p_{i}$ e $p_{e}$, e dado que $k_{i}<k_{f}$, a seletividade equivalente ao min-termo SCSP ó definida por

$$
\operatorname{sel}(\odot k N)=\frac{k_{i}}{\nu}-\frac{k_{i}}{\nu} \Rightarrow \frac{k_{i}-k_{i}}{\nu}
$$

De mancira análoga, a seletividade para o min-termo $\neg p_{i} \wedge p_{c}$ dado que o predicardo pó uma consulta por abrangência pode ser representada como:

Seletividade 6: Anéis $R_{q}$ - Sondo vo número total de olenentos ('m unn (onjunto de dados $S, k_{r i}$ e $k_{r e}$ respectivamente os valores estimades a partir dos raios $r_{i}$ e $r_{r}$ dos predicados $\neg p_{i}$ e $p_{e}$, e dado que $r_{i}<r_{e}$, e por consegüência $k_{r i}<k_{r e}$, a soletividade para o min-termo SCSP é definida por

$$
\operatorname{sel}(0) R q)=\frac{k_{r r}}{\nu}-\frac{k_{r i}}{\nu} \Rightarrow \frac{k_{r i}-k_{r i}}{\nu}
$$

É importante notar que as Seletividarlos 5 e 6 são soletividades que so aplicann a regiós em anel formadas por min-termos conjuntivos em DNF para os dois tipos de predicalos por similaridade búsicos que foram simplificadas pelas Propriedades 7 a 9 c náa podem ser mais simplificadas. Una expressão SCSP em DNF, conforme a expressino representada pola Figura 4.1 da Seção 4.3 .1 , pode ter sua seletividade sstimada, usando as Seletividades de 1 a 6 de maneira adequada para obter a seletividade resultante do uma consulta.

Essas expressōes têm o conjunto de elementos recuperados por cada mint-termo

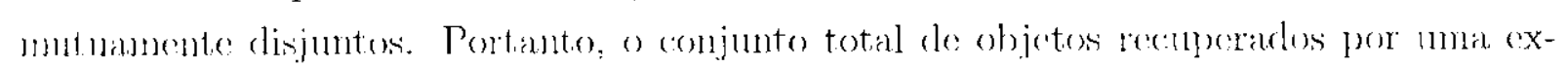
pressão SCSP em DNF tem cardinalidade igual à soma das cardinalidades obtidas de cada min-termo.

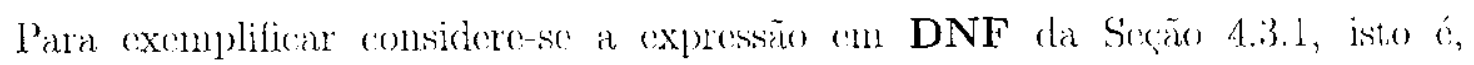
$E=p_{1} \vee\left(\neg p_{2} \wedge p_{3}\right) \vee\left(\neg p_{5} \wedge p_{6 i}\right) \vee\left(\neg p_{4} \wedge p_{7}\right) \vee\left(\neg p_{8} \wedge p_{10}\right) \vee\left(\neg p_{9} \wedge p_{11}\right) \vee \neg p_{12}$, onde o predicado $p$ correspondo apenas à consulta por albrangência ou à consulta aos $k$-vizirihos 
mais próximos. Para se obter a scletividade total para essa expressão, é necessário somar

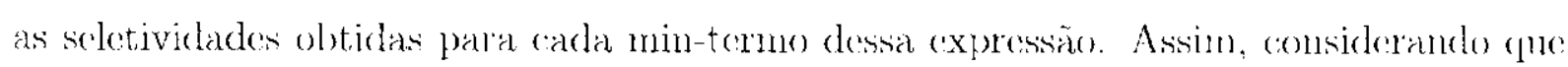
o predicado $p$ seja unda consulta por abrangência tom-se que: $\operatorname{sel}(E)=\operatorname{sel}(R q)+\operatorname{sel}(\circ R q)+\ldots+\operatorname{sel}(\odot R q)+\operatorname{sel}(\neg R q)$

Portanto, a seletividade total para a expressão $E$ comesponde à somatoria das Seletividades 3, 4 ○6, lembrando quo a Seletividade $6(\operatorname{sel}(\circ R q)$ ) é calcularla para cada um dos cinco min-termos $\neg p_{i} \wedge p_{e}$ desta expressão.

Consultas por similaridade complexas com mesmo centro podem possuir tipos do predicados diferentes em uma mesma cxpressão. Assim, estimativas de seletividade para expressões SCMP tomam-se necessárias.

\subsubsection{Seletividade para Expressões SCMP}

Cada min-termo de uma expressão SCMP em DNF é uma conjunção entre os predicados range o k-nearest, complementados on não. Conseqüientemente, o nnin-tomo SCMP $m_{a t}^{p d}$ pode possuir: aponas a parte complementara $\left(m_{a}^{p q}=-p_{g} \wedge \neg q_{h}\right)$; apemas a parte näa) complementada $\left(m_{a}^{p q}=p_{i} \wedge q_{j}\right)$ : ou ambas $\left(m_{a}^{p q}=\left(m_{b}^{p} \wedge m_{r}^{q}\right)=\left(\neg p_{q} \wedge \neg q_{h}\right) \wedge\left(p_{i} \wedge q_{j}\right)\right)$. Para simplificar a discussão nestia seção, quando o min-termo $m_{a}^{p_{1}}$ possui ambas as partes (complementada e não complementada) cle é chamado de min-termo total.

Portanto, é nocessánio dofunir mais três estimativas de seletividade envolvendo os dois tipos de predicado por similaridade. Essas tres estimativas cobrem as possibilidades de seletividade para um min-termo SCMP, scido elas: a seletividade para a parte nãu complementada $p_{i} \wedge q_{j}$ : a seletividade para a parte complementakla $\neg p_{y} \wedge \neg h_{h}$, e a soletividade para o min-1ermo total SCMP. Além dessas três seletividades, esta secão formaliza também una outra scletividade a qual se mostra útil para expressós SCMP cm CNF. Note que esta segão uliliza a notação $p_{i} / u_{i}, q_{j} / v_{j}$ apresentada na Seção 4.3.2 para expressöes do tipo SCMP.

A seletividade para conjunção entre os predicados por similaridade, isto é, $p_{i} \wedge q_{j}$, croclarada a soguir.

Seletividade 7: Conjunçăo entre $\operatorname{Rq}$ e $k N N(\operatorname{Rq} \wedge k N N)$ - Sendo $\nu$ o número total de clementos em um conjunto de dados $S, k_{r}$ a quantidade de elementos estinada a ser recuperada pelo predicado $R q\left(s_{1}, r\right)$, o $k$ a cuantidade de clomentos dofinida no predicado $k N N\left(s_{q}\right)$, a seletividade para a conjunção entre os predicados é equivalente a

$$
\begin{aligned}
\operatorname{sel}(R q \wedge k N N) & =\min (\operatorname{Sel}(R q), \operatorname{Sel}(k N N)) \rightarrow \\
& =\frac{\min (k, k)}{\nu}
\end{aligned}
$$

onde min representa o valor núnimo entre os dois valores.

A Seletividade 7 pode ser utilizada para expressõos SCMP ern basicancente duas situaços: quando o min-termo SCMP correspondente apenas à conjunção entre os pre- 
dicados $p_{i} \wedge q_{j}$, e para compor a seletividade do min-termo total SCMP. Considerando neste momento apenas a primeira situação, a Seletividade 7 co usiada de forma dircta para obter a seletividade do min-termo SCMP $m_{1}^{p q}$. A Figura 5.2 (a) ilustra essa situação, onde a linha tracejacla corresponde à região de resposta para a conjunção cintre os predicados por similaridade $p_{i} \wedge q_{j}$ (Região 1) e a linha contínua representá a região de resposta para o min-termo SCMP $m_{a}^{p q}$ (Região 3). Note-se que nesse caso a Região 1 é equivalente à Região 3, que define o conjunto resposta para o min-termo $m_{a}^{p q}$. Quando isso ocorre, a Seletividade 7 corresponde à seletividade do min-termo $m_{a}^{p q}$ conforme o item (a) dessa figura ilustra.

De maneira anćlogga à Scletividade 7 , a seletividade para a conjunção complementada entre os predicados, isto é, $\neg p_{g} \wedge \neg q_{h}$, timbém pode ser declarada.

Seletividade 8: Conjunçao complementada entre $R_{q}$ e $k N N(\neg R q \wedge \neg k N)$ Sendo y o múmero total de elementos em um conjunto de dados $S, k_{r}$ o número de elementos estinado a partir do raio $r$ do predicado $\neg R q\left(s_{q}, r\right), \overrightarrow{k_{r}}$ a quantidade de clementos recuperados por esse predicado, onde $\overline{k_{r}}$ é igual a $\nu$ menos $k_{r}$ e $k$ a quantidade de elementos definida no predicado $\neg k N N\left(s_{q}\right)$. com $\bar{k}$ elementos recuperades por esse predicude, onde $\bar{k}$ é igual a $\nu$ menos $k$; a seletividade para a conjunção complementada entre os predicados é equivalente a

$$
\begin{aligned}
\operatorname{sel}\left(\neg R_{q} \wedge \neg k N N\right) & =\min (\operatorname{Sel}(\neg R q), \operatorname{Sel}(\neg k N N)) \\
& =\frac{\min \left(k_{r}, \bar{k}\right)}{\nu} \\
& =\frac{\min \left(1-k_{r}, 1-k\right)}{\nu}
\end{aligned}
$$

É importante definir a Soletividade 8 para os casos oncle a conjuncão complementada cntre os predicados por similaridade $\neg p p_{g} \wedge \neg q_{h}$ corresponde ao min-termo $m_{a}^{p_{4}}$. Nessess casus a seletividade do min-terno $m_{a}^{p q}$ equivale a Seletividade 8 apresentada. A Figura 5.2 (b) ilustra essa situação, onde a linha pontilhada corresponde à região de resposta para a conjunção complementada entre os predicarlos $\neg p_{g} \wedge \neg q_{h}$ (Região 2) e a linba contínua representa a região de resposta para o min-termo SCMP $m_{a}^{p q}$ (Região 3).

Ainda se: fas necessário rlefinir ma outra estimativa de seletividade para a situagão cm que se tem o min-termo total em SCMP. isto é, quando se tem a parte complementada a a não complementada entre os predicados por sinilaridade. Entretanto, antes de definir esta seletividade é interessante formalizar uma outra seletividade para expressões em SCMP, a qual envolve a disjunção entre os predicados por similaridade, isto ś, $p_{i} \vee q_{j}$. Essa seletividade é importante para expressón SCMP on CNF. Portante, a selet ividade para a disjunção cutre os predicados por similaridade é formalizada a segnir. 
Seletividade 9: Disjunçäo entre Rq e $k N N$ ( $R q \vee k N N)$ - Sendo $\nu$ o número total

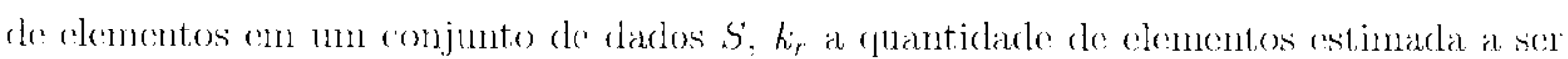
recuperada pelo predicado $R q\left(s_{q}, r\right), k$ a quanticlade de elementos definida no predicado $k N N\left(s_{q}\right)$, a seletividade para a disjunção entre os predicados é equivalente a

$$
\begin{aligned}
\operatorname{sel}(R q \vee k N N) & =\max \left(\operatorname{Sel}\left(R_{q}\right), \operatorname{Sel}(k N N)\right) \\
& =\frac{\max \left(k_{r}, k\right)}{\nu}
\end{aligned}
$$

onde max representid o valor máximo ontre dois valores.

Considere-se agora como estimar a seletividade para o mint-termo total SCMP ('m DNF. Esse min-termo, após sofrer às devidas simplificações 1sando as Propriedades 7, 8 e 9, gera uma região em forma de anel, conforme representado na Figura 5.2 (c). Assim, a mancira para se estimar a seletividade do min-terno total em expressões SCMP é a segruinte.

Seletividade 10: Anéis cntre $R q$ e kNN - Dado o min-termo $m_{a}^{p q}=\left(\neg \eta_{g} \wedge\right.$ $\neg\left(q_{h}\right) \wedge\left(p_{i} \wedge q_{j}\right)=\left(-R q\left(s_{q}, r_{i}\right) \wedge \neg k_{i} N N\left(s_{q}\right)\right) \wedge\left(R_{q}\left(s_{q}, r_{e}\right) \wedge k_{e} N N\left(s_{q}\right)\right)$, e sendo $\nu 0$ número total de clementos en $14 m$ conjunto de darlos $S, k_{r}$ a quantidade de elementos

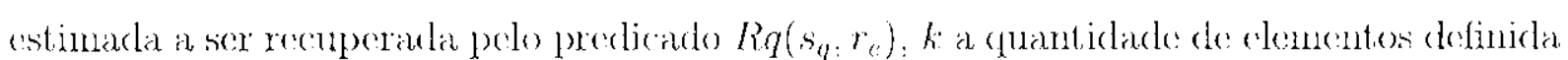
no predicado $k_{p} N N\left(s_{q}\right), k_{r} \rightarrow$ o número de elementos estimado a partir do raio $r_{i}$ do predicarlo $\neg R R_{q}\left(s_{q}, r_{i}\right), k_{\neg}$ a quantidade de elementos definida no predicado $\neg k_{i} N N\left(s_{q}\right)$; então a seletividade para o min-termo $m_{a}^{p q}$ é equivalente a

$$
\begin{aligned}
\operatorname{sel}(\circlearrowleft)(R q \wedge k N N))= & \operatorname{sel}(R q \wedge k N N)-\frac{\max \left(k_{r \rightarrow}, k_{-}\right)}{\nu} \\
& \max \left(0, \frac{\min \left(k_{r}, k\right)-\max \left(k_{r-}, k_{-}\right)}{\nu}\right)
\end{aligned}
$$

Note-se que, a Seletividade 7 pode ser usada diretamente para compor a estimativa da Seletividade 10, mas a Seletividado 8 não pode ser usada. Isso ocorre porque na Seletividade 8 , além de obter os valores a serem recuperados pelos predicades, é necestrírio efetuar o seu complemento obtendo o valor mínino entre eles. E, em se tratanto da seletividarde para méis entre os predicados range e k-nearest, ć exigido apenas obter o valor míximo entre os valores dos predicados $\neg p_{g} \wedge \neg q_{h}$ sem realizar o complemento deles. A Figura $5.2(\mathrm{c})$ ilustra a sitnação para a Seletividade 10, onde a Região 1 corresponde à

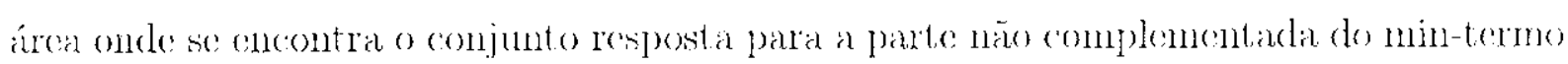
$m_{a}^{p q}$, sendo a scletividade dessa região calculada de maneira direta pela Seletividade 7. $\Lambda$ Região 2 corresponde ao conjunto resposta para a parte complementada do min-termo 


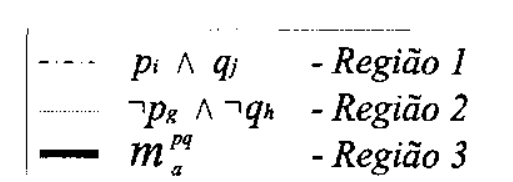

a)

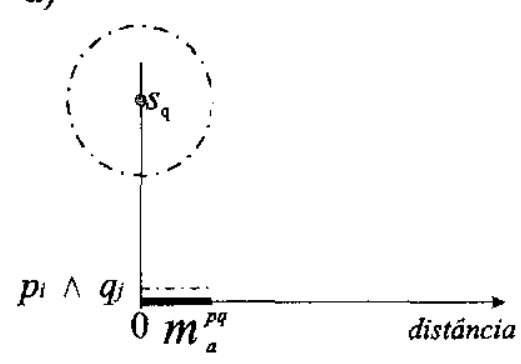

b)

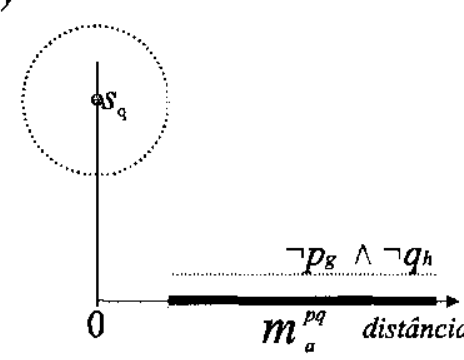

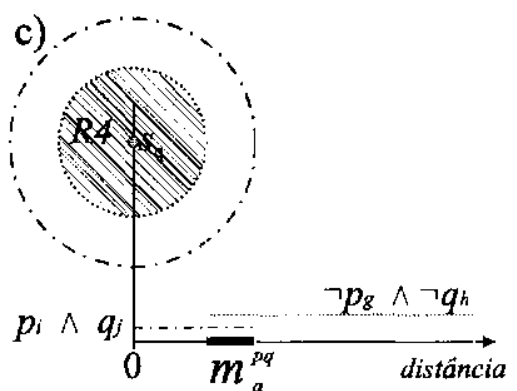

Figura 5.2: Possibilidades de estimativas de seletividade para um min-termo SCMP em DNF. (a) representação da estimativa de seletividade para o min-termo $m_{a}^{p q}$ equivalente à conjunção entre os predicados por similaridade $p_{i} \wedge q_{j}$; (b) representacão da estimativa de seletividade para o min-termo $m_{n}^{p q}$ equivalente à conjuncono complementaxia entre os predicaclos por similaridacle $\neg p_{g} \wedge \neg q_{h}$; (c) representação da estinativa do seletividado para o min-termo total $m_{a}^{p \%}$.

', como pode ser visto no item (c) da fignua, torna inviável seu uso direto para obter o conjunto resposta do min-temo que corresponde a Regiäo 3 . Nesse caso, a partir da parte complementada do min-termo $m p_{a}^{p q}$ : isto é, $\neg p_{g} \wedge \neg q_{h}$, deve-se obter apenas o valor máximo a ser recuperado pelos predicados, conforme ilustrado na figura pela parte achurada $R 4$. Sendo assim, a seletividade para anéis entre os predicados range e k-nearest podo ser obtida usando a scletividade para a Região 1 e a partir dela subtrair a seletividado obtida de R.

Definidas as Seletividades 7:8 e 10 para o mintermo $m_{a}^{p q}$ em DNF de uma expressão SCMP i possivel estimar seletividades para expressõos mais complexas desse tipo. Como os min-temos de una expressäo SCMP em DNF säo muluamente disjuntos, a estimativa de seletividade para expressoes SCMP mais complexas ó feita por meio da soma das seletividades de cada min-termo conforme definidas nesta secão. Um exomplo de expressão SCMP em DNF mais complexa é a expressão apresentada na Seção 4.3.2, sendo ela $E=m m_{a}^{p_{l}} \vee m_{b}^{p q}=\left(\left(\neg p_{1} \wedge \neg q_{2}\right) \wedge\left(p_{5} \wedge q_{6}\right)\right) \vee\left(\left(\neg p_{3} \wedge \neg q_{4}\right) \wedge\left(p_{7} \wedge q_{8}\right)\right) . A$ seletividade para essa expressão ć equivalente a $\operatorname{sel}(k)=\operatorname{sel}(O(R q \wedge k N N))+\operatorname{sel}((O)(R q \wedge k N N))$

A seletividade para a expressão $E$ corresponde a somar duas vezes a Soldividade 10: unla para o min-termo $m_{a}^{p m}$ e onlra para $m_{b}^{p q}$.

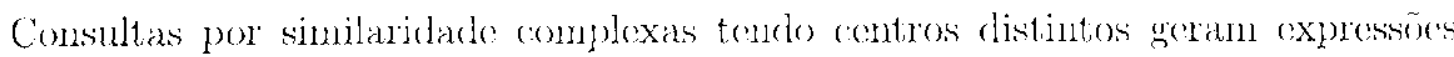
clefinidas nesta tese como expressöes MCMP. A seletividade para esse tipo de expressĩo ć discutida a seguir. 


\subsubsection{Seletividade para Expressões MCMP}

$\Lambda$ soletividade para expressões MCMP cm DNF pode ser feita de modo incremental, isto é, utilizando as soletividades para expressões SCSP o SCMP já apresentadas para compor a seletividade da expressão MCMP desejada. Além de aplicar as seletividades definidas para expressões sobre um único centro, é também nocessário realizar operações de: união/interseção para formar a seletividade resultante em expressões MCMP

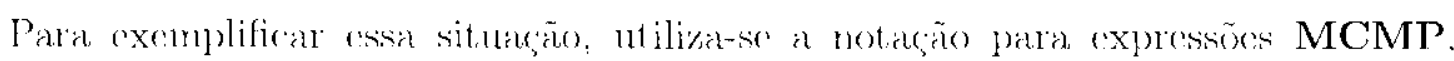
onde um min-termo é representado por ${ }^{c_{1}} m_{n}^{p q} \wedge^{c_{2}} m_{b}^{p q} \wedge \ldots{ }^{c m} m_{z}^{p q}$ sendo que ${ }^{c k} m_{a}^{p q}=$ $\left(\neg p_{g} \wedge \neg q_{h}\right) \wedge\left(p_{i} \wedge q_{j}\right)$. e $p_{g}, q_{h}, p_{i}$ e $q_{j}$ são predicados centrados no objeto $c_{k}$. E, considerese também a seguinte expressão MCMP em DNF

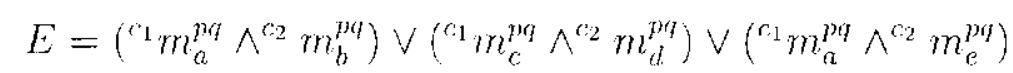

Para estimar a seletividade dessa expressão, o processo é semelhante ao descrito para exceutar essa consulta (ver Secaño 4.4). Portanto, princiro applicamr-se propriedades algébricas cntre os predicados dessa expressão para transformá-la cm uma expressão equivalente e, em seguida, estima-se a sua seletjvidade. Assim, aplicando as proprichades algébricas sobre a cxpressão $E$, ela é equivalente a

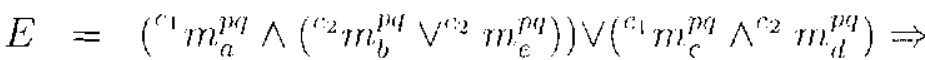

$$
\begin{aligned}
& E=\left({ }^{c_{1}} m_{a}^{p q} \wedge E_{a, 1}\right) \vee\left({ }^{c_{1}} m_{c}^{p p^{p}} \wedge^{c_{2}} m_{d}^{p q}\right)
\end{aligned}
$$

Note que, tanto o $E_{a, 1}$ quanto cadla ${ }^{k} m_{i}^{p q} \mathrm{~cm} E$ corresponde a 1 ma expressão SCMP cm DNF, e dessa maneira as suas seletividades são calculadas conforme descrito na Seçăo 5.3.2. Portanto, tendo a seletividade calculada para cada parte dia expressão E) ainda restad definir como calcular a seletividade para a intersegäo e, posteriomente. a união entre elas. Fssa interseção ó $11 \mathrm{~m}$ problema para espaços mótricos pois não há definição nem embasamento pela teoria de fractais de como calcular a sobreposição entre as regiões nesse espaço, ou seja, como calcular a interseçäo entre clas. Observe-se que csse problema se propaga tanbém para a união entre regióos não disjuntas no espaco métrico

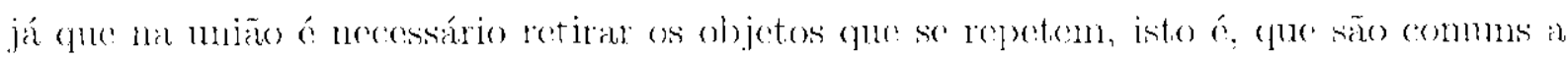
duas regióes (obtido pela interseção).

Definir manciras para se cotimar a quantislade de objetos a ser recuperada por duas regiões que se interceptan em un espaço métrico é um assunto cm abcrto e está além do escopo deste trabalho. No entanto, esta tese apresenta una proposta inicial que se bassia na adaptacão de métodos desenvolvidos com outros propósitos, mas que podem fornecer subsídios para estudos futuros mais avançados. Existem alguns trabalhos

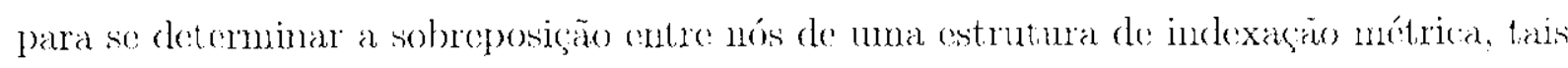
como us "Traina Jr. et al., 2002] e [Vicira et al., 2004], que poden fornecer um direção para solucionar o problema para cstimativas de seletividade. Fisses trabalhos utilizam o 
método de contagem de objetos entre os nós da estrutura (ver Apêndice $\Lambda$ ) para verificar a taxa de sobreposiegáo entre ckes. Portanto, uma possibilidade para abordar o problema é utilizar uma variação do método de contagem en estruturas de indexaçäo métricas, o qual define uma taxa de sobrejosição entre os nós, para determinar a possível sobreposição contro as respostas de uma expressão MCMP.

Assim, considere-se que o conjunto de dados esteja indexado por uma árvore mó-

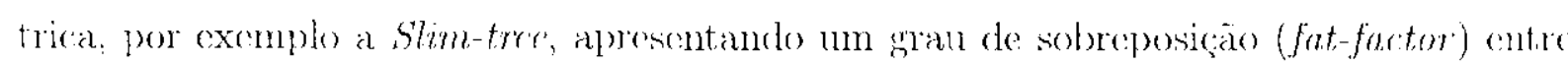
os nós igual a $f$; onde $0 \leq f \leq 1$.

O fator $f$ é, na realidarle, uma característica de sobreposição que ocorre cntro os nós de una estrutura de indexação métrica e não de una consulta. Entretanto, ele representa uma estimativa de sobreposição que ocorre, em média, quando ne regiōes de

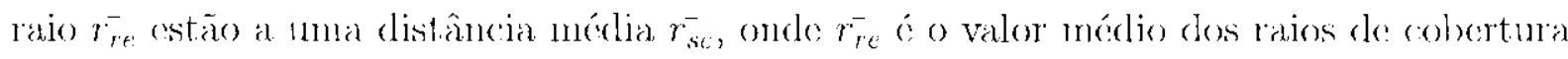
dos ne nós que formam as folhas de uma Slim-tree e. $r_{s e}^{-}$é a distância média entre todos os centros dessas folhas.

Portanto, define-se a constante $K_{d}$ como o fator de densidade da seguinte mancilat

$$
f=K_{d l} \cdot \frac{r_{r e t}^{-}}{r_{s c}} \cdot n e \Rightarrow K_{d}=f \cdot \frac{1}{n e} \cdot \frac{r_{s e}^{-}}{r_{r e}^{-}}
$$

Considerando-se que uma consulta MCMP tenha ne centros a uma distância

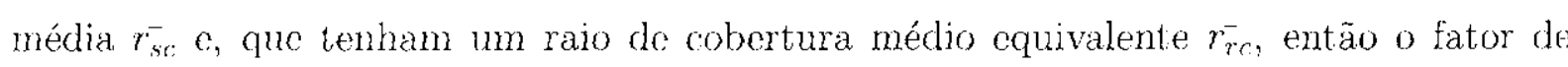
sobreposiçào correspondente à consulta MCMP com ne centros é:

$$
f_{c}=K_{d} \cdot \frac{r_{r c}^{--}}{r_{s c}^{-}} \cdot n c
$$

Portanto, o fator $f_{c}$ pode ser utilizado para calcular a sobreposiçano dos min-termos la expressão MCMP em DNF, e por consequiência: de toda a cxpressão. Poróm, por se tratar de uma proposta inicial, a qual proporciona que estudos mais avançados sojam feitos nessa direção, una fómula de estimativa para expressóes MCMP cm DNF näo a in)resentadia.

\subsection{Conclusão}

A estinativa de seletividade tom um papel importante dentro do processanento de consultas de um gerenciador relacional, una vez que ela é ntilizada no processo de estimativa de custo de um plano de consulta. Para dados complexos, trabalhos recentes apontam para o uso do modelo de seletividade baseado na teoria de fractais como o mais adequado para consultas por similaridade.

Modelos de seletividade para dados complexos, bem como estimar a cardinalidade de consultas por abrangencia tôm side propostos na literatura, porém estimativas do 
seletividade para consultas por similaridade compostas pelos dois predicados básicos por

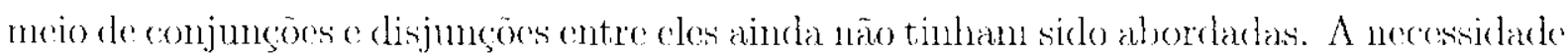
(le definir fórmulas para estimar a seletividade para essas consultas toma-se necessária a partir do momento em que se deseja incorporar consultas por similarirlade complexas em um gerenciador relacional.

Portanto, utilizando a teoria de fractais e a maneira de se analisar uma expressão por similaridade, são derivadas fórmulas para estimar a seletividade de comsultas por similaridade complexas. Resumindo os resultados deste capítulo, a Tabela 5.2 mostra as fórmulas desenvolvilas para estimar a seletividade das expressões por similaridade complexas.

A avaliação das estimativas de seletividarle desenvolvidas, bem como os algoritmos propostos no Capítulo 4, são analisados nos experimentos do próximo capítulo.

Tabela 5.2: As fómulas de astinnativa de soletividade desonvolvidas e as expressões em que cada un dolas é utilizada.

\begin{tabular}{|c|c|c|}
\hline Expressão & $\begin{array}{c}\text { Tipo/ } \\
\text { No. Selct. }\end{array}$ & Fórmula $-\operatorname{sel}(E)$ \\
\hline$\sigma_{\left(k N N\left(s_{q}\right)\right)^{S}}$ & $\mathrm{SCSP} / 1$ & $\sec (E)=\frac{k}{\nu}$ \\
\hline$\sigma_{\left(-k N N\left(s_{q}\right)\right)^{S}}$ & $\operatorname{SCSP} / 3$ & $\operatorname{sel}(E)=1-\frac{k}{\nu}$ \\
\hline$\sigma_{\left(R,\left(s_{q}, r\right)\right.} S$ & $\operatorname{SCSP} / 2$ & $\operatorname{sel}(E)=\frac{k_{r}}{\prime \prime}$ \\
\hline$\sigma_{\left(\neg R q\left(s_{q}, r\right)\right.} S$ & $\mathrm{SCSP} / 4$ & $\operatorname{sel}(E)=1-\frac{k_{r}}{\nu}$ \\
\hline$\neg p_{i} \wedge p_{e}$ & $\operatorname{SCSP} / 5+6$ & $\operatorname{sel}(E)=\frac{k_{0}-k_{i}}{\nu} \operatorname{esel}(E)=\frac{k_{r i}-k_{r i}}{\nu}$ \\
\hline$p_{i} \wedge q_{j}$ & $\operatorname{SCMP} / 7$ & $\operatorname{sel}(E)=\min \left(\frac{k_{r}}{\nu}, \frac{k}{\nu}\right)$ \\
\hline$\neg p_{i} \wedge \neg q_{j}$ & $\operatorname{SCMP} / 8$ & $\operatorname{scl}(E)=\min \left(1-\frac{k_{x}}{\nu}, 1-\frac{k}{\nu}\right)$ \\
\hline$p_{i} \vee q_{j}$ & $\mathrm{SCMP} / 9$ & $\operatorname{sel}(E)=\max \left(\frac{k_{x}}{\nu}: \begin{array}{l}k \\
\nu\end{array}\right)$ \\
\hline$m_{a}^{p q}$ & $\mathrm{SCMP} / 10$ & $\operatorname{sel}(E)=\max \left(0, \min \left(\frac{k_{r}}{\nu}, \frac{k}{\nu}\right)-\max \left(\frac{k_{r}}{\nu}, \frac{k_{r}}{\nu}\right)\right)$ \\
\hline
\end{tabular}


Capítulo

6

Experimentos

\subsection{Introdução}

$\mathcal{E}$

m domínios de dados complexos, a comparação baseada em experimentos é a abordagem mais freqüente encontrada na literatura para contrastar novos algoritmos de busca por similaridade com os já existentes. O processo envolve a coleta a a comparação de medidas de desempenho a partir de testes práticos usando Métodos de Acesso Métricos (MAMs).

Esse processo envolve a avaliação dos seguintes pontos: diferentes conjuntos de dados; a avaliação do novo algoritmo proposto com o algoritmo estado da arte correspondente; $t^{2}$ o uso de valores diferentes para os parâmetros dos algoritmos (raio $r$ e número de vizinhos $k$, por exemplo). As medidas de desempenho freqüienternente comparadas no contexto de MAMs são: número de cálculos de distância, número de acessos a disco e tempo total das consultas. É também necessário dennir os objetos que serão usados como centro das regiōes de busca. A técnica mais utilizada em MAMs para definir os objetos de consultas é a basearla na amostragem.

Como esta lise propõe algoritmos de busca por similaridade normativos para responder a consultas por similaridade complexas, torna-se necessário avaliar os pontos citados no parágrafo anterior, usando também uma lista seqüencial. Para uma consulta por similaridade complexa, a comparação é feita contrapondo os algoritmos normativos com a composição dos algoritmos básicos (consulta por abrangência e aos $k$-vizinhos mais próximos) scguidos da respectiva operaçăo sobre conjuntos para obter a resposta da consultia. Um outro ponto avaliaro para os algoritmos normativos nestes experimentos $a$ a escalabilidade.

Além dos algoritmos normativos, as fómulas de estimativa de soletividade desen- 
volvidas para consultas por similaridade complexas utilizando o modelo de seletividado achotado são analisadas. Essa análise envolve a consulta por similaridade complexa con (questão e os aspectos já discutidos para a avaliação dos algoritmos, isto é, diferentes conjuntos de dados e valores para raio e número de vizinhos mais próximos $k$. Os materiais e métodos utilizados nestes expcrimentos são apresentados a seguir.

\subsection{Materiais e Métodos}

A avaliação do desempenho dos novos algoritmos e das fórmulas para cstimativas de seletividade para consultas por similaridade complexas envolve uma grande variedade de conjuntos, tanto reais quanto sintéticos, onde as principais difcrenças são a dimensão, o tamanho dos objetos e do conjunto de dados, e a distribuicão dos dados no espaço métrico. A Tabela 6.1 apresenta os conjuntos do darlos utilizarlos nos experimentos. É indicado para cada conjunto: o nome, o número total de objetos (Nro. Objs), a dimensão de imersão $(n)$, a dimensão intrínsica $(\mathcal{D})$, o tamanho da páginas em $\mathrm{KB}(\mathrm{Pg})$, a métrica de comparação $(d())$ e a descrição de sua origem e composição.

Tabela 6.1: Descrição dos conjuntos de dados reais e sintéticos utilizados nos experimentos.

\begin{tabular}{|c|c|c|c|c|c|c|}
\hline Nome & Nro. Objs & $\vec{n}$ & $\mathcal{D}$ & $P g(\mathrm{~KB})$ & $d()$ & Descrição \\
\hline Cidades & 5.507 & 2 & 1,79 & $\overline{1}$ & $L_{\nu_{2}}$ & $\begin{array}{l}\text { Latitude, longitude e noune das cidades } \\
\text { brasileiras. Fonte: www.ibge.gov,br. }\end{array}$ \\
\hline MetricIItsto & 4.247 & $\sim$ & 3,6 & 8 & $L_{M H}$ & $\begin{array}{l}\text { Iistogramas de tons do cinza de mmathens } \\
\text { médicas. Este conjunto é adimensional o } \\
\text { foi gerarlo pelo GBDI-ICMC-USP. Madoress } \\
\text { detalhes dos dados e da métrica utilizada, } \\
\text { vide [Azevedo-Marques et al., 2002]. }\end{array}$ \\
\hline$\overline{M G C o u n l y}$ & 27.282 & 2 & 1,81 & 1 & $L_{2}$ & $\begin{array}{l}\text { Latitude e longitude descrevendo as coordenadas } \\
\text { das intersecones de ruas r estradas cm } \\
\text { Montgomery County, Maryland, EUA. } \\
\text { Fonte: www.census.gov. }\end{array}$ \\
\hline Sintélico $6 D$ & 50.000 & 6 & 5,9 & 4 & $L_{2}$ & $\begin{array}{l}\text { Vetores de dados sintéticos gerados } \\
\text { aleatoriamente em um hipercubo 6-dimensional } \\
\text { com valores entre }[0,1] \text {. }\end{array}$ \\
\hline Moedas & 2.511 & 6 & 2.6 & 4 & $L_{2}$ & $\begin{array}{l}\text { Taxas de cimbio nornalizadas de moedas de } \\
\text { scis países usando o dólar canadense como } \\
\text { referencia em um periodo de dez anos. }\end{array}$ \\
\hline Palazras & 24.893 & - & $4,7 \overline{5}$ & 1 & $L_{\text {Ledzt }}$ & $\begin{array}{l}\text { Conjunto de palavras extraídas do dicionário } \\
\text { da Lingua Inglesa. }\end{array}$ \\
\hline
\end{tabular}

Além disso, a fim de mostrar a distribuição dos objetos no espaço métrico para os conjuntos de dados utilizados nos experimentos, a visualização desses dados é ilustrada na Figura 6.1. A visualização de cada conjunto de didos foi gerada usando o algoritmo FastMap [Faloutsos \& Lin, 1995], o qual visa preservar o máximo possível as distâncias existentes entre os objetes no espaço métrico original. Essse algoritmo, dado um conjuntos de lados e uma função do distância, mapeia cada objeto no conjunto de dados em um ponto no espaço n-dimensional, gerahnente um espaço euclidiano de 2 ou 3 dimensões, ten- 


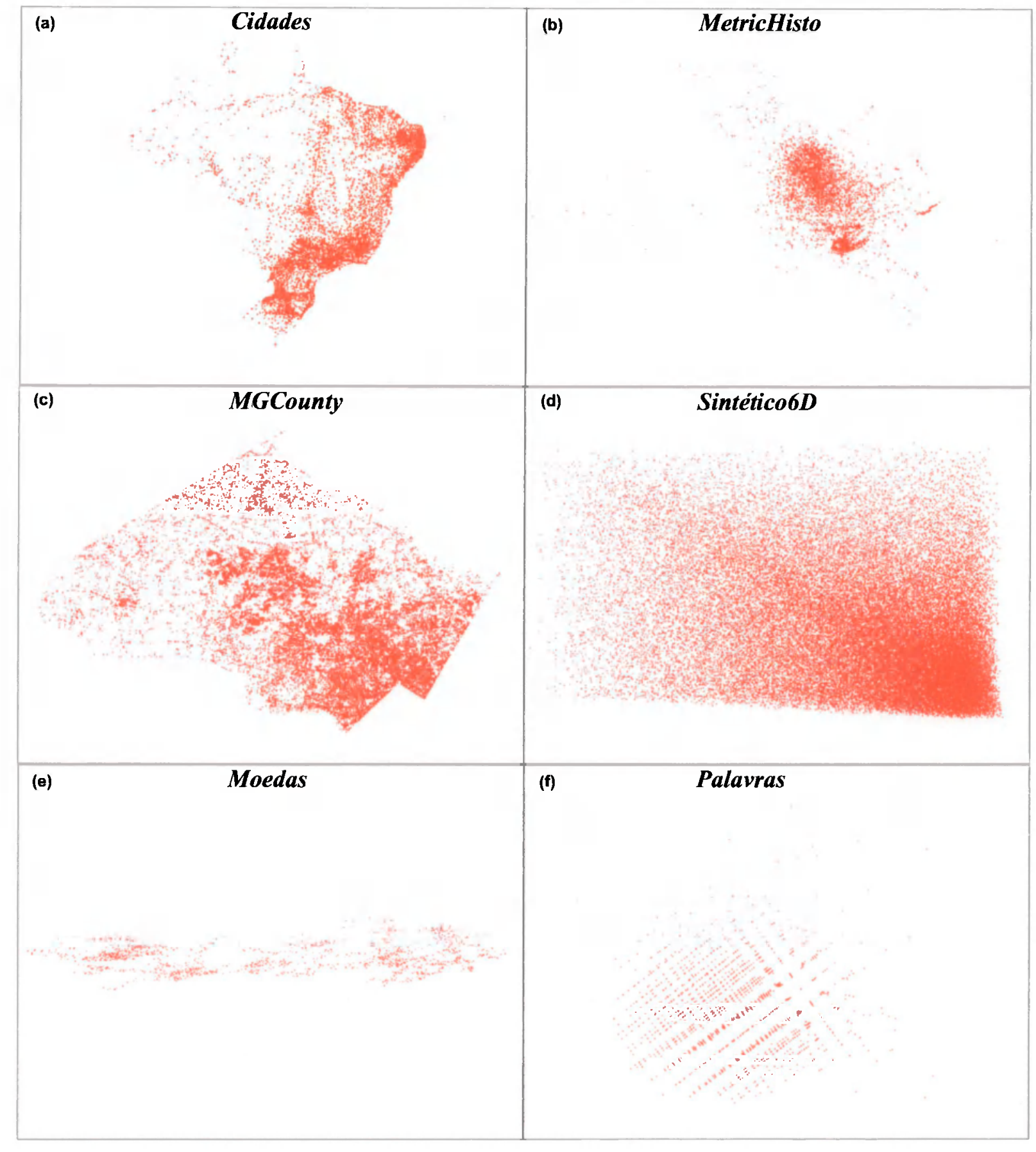

Figura 6.1: Distribuição dos conjuntos de dados utilizados nos experimentos no espaço métrico.

tando preservar as distâncias originais. Assim, aplicando o algoritmo para cada conjunto de dados foi obtida a visualização da Figura 6.1.

O computador utilizado nos testes possui a seguinte configuração: processador AMD Athlon $3 \mathrm{GHz}$, com 1 GB de memória RAM e disco rígido de $120 \mathrm{~GB}$ usando o sistema operacional Microsoft Windows 2000. As estruturas utilizadas para comparar os algoritmos foram: o MAM Slim-tree (vide Apêndice A para maiores detalhes sobre este MAM) e a busca seqüencial SeqScan. O código dos algoritmos normativos e dos algoritmos básicos estão implementados tanto na Slim-tree quanto na SeqScan pertencentes à biblioteca de MAMs Arboretum (http://gbdi.icmc.usp.br/arboretum) compartilhando da 
mesma arquitetura e otimizaçoes. Para avaliar as fórmulas de estimativa de seletividado proprostas, apenas o MA.M Slim-tre foi utilizido.

Os principais aspectos relacionados à preparação dos testes são:

- Os objetos de cada conjunto de dados foram "embaralhados", simulando a situaçăo real de insercoeces de objetos que ocomem en SGBDs (inserçốs de forma aleatória);

- Após a primeira fase, extraiu-se uma amostra de 500 objetos, o conjunto de busca, para carla conjunto de dados. Esses objetos, usados como centro da região de busca (objetos de referência), fordun cscolhidos aleatoriamente entre todos os pertencentes ao conjunto. Metade (250) desses 500 objetos foram removidos do conjunto de dados, e a outra metade foi mantida. Portanto, metade dos objetos do conjunto

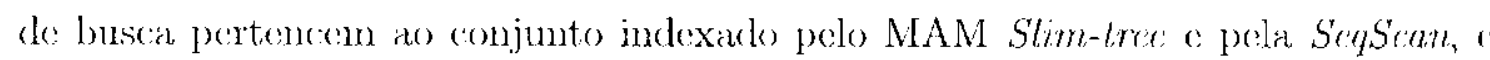
a outra metade não. A mosma amostra foi usada en todas as consultas para um mesmo conjunto de dados:

- O número de vizinhos $k$ varia de $0,1 \%$ a $10 \%$ do conjunto de dados em cuestão para as consultas por similaridado complexas que envolvem o predicado k-nearest Os valores absolutos do $k$ dependem da quantidade de objetos presentes em um conjunto de dados. A exceção é para o conjunto de darlos Palayras onde o número de vizinhos $k$ ć absoluto variando, do 1 a 6 em intervalos de uma unidade.

- O raio de abrangência $r$ varia de $0,1 \%$ a $10 \%$ do diâmetro do conjunto de dados. O diâmetro de um conjunto de dados é a maior distanncia entre un par de olonentos do conjunto. Em cada consulta por similaridade complexa, tendo o predicado range, o raio $r$ varia conforme acima mencionado. A exceção é para o conjunto de dados Pulauras, onde o raio $r$ varia de 1 a 6 cm intervalos de una unidede;

- Carda ponto medido nos gráficos apresentados para uma consulta por similaridado complexa, que cnvolve os predicados range o k-nearest, corresponde a uma coordenada $(r$, medida, $k)$. Isso equivale a expressoes do tipo SCMP ou MCMP, ondo medida é ou uma das medidas de desempenho (numero médio de acessos a disco, número médio de cálculos de distância e tempo total de processamento) ou a cardinadidade da resposta para a consulta complexa, con se tratando de avaliar as fómulas de estimativa de seletividade. O valor de $k$ nesses gráficos é fixo e, por isso, o conjunto de pontos é da forma $\{(0,1 \%$, medida, $k),(0,2 \%$, medida, $k), \ldots,(10 \%$, medida, k)\};

- Para expressões do tipo SCSP, cada ponto no gráfico correspondente equivale ao raio $r$ do predicado range ou ao númcro de vizinlıos $k$ do predicado $k$-nearest, assim, a coordenada para un ponto nesse gráfico é ( $r$ ou k, medida). Considerando consultas que formam regióes en ancéis, o ponto indicado no gráfico corresponde sempre ao arco mais externo, isto é, $r_{e}$ ou $k_{r}$. Os arcos internos $\left(r_{i}\right.$ e $\left.k_{i}\right)$ são formados tendo um 
valor $30 \%$ menor do seu arco externo correspondente. Se $r_{e}=0.5$ entäo $r_{i}=0.35$, e se $k_{e}=10$ entäe $k_{i}=7$ formando desse modo os ancíis. Pata o conjunte de dades Palauras, $r_{e}-r_{i}$ on $k_{e}-k_{i}$ ó ignal a 1 , e tanto $r$ quanto $k$, representados como abscissa nos gráficos, variam de 2 a 7 em intervalos de uma unidarle;

- A dimensão de correlação fractal dos conjuntos de dados foi obtida utilizando o processo proposto em [Traina Jr. et al., 2000c];

- Para os gráficos avaliando as fórmulas de estimativa de scletividade, assume-se um erro do $30 \%$ (barras de erro nos gráficos) para a cardinalidade estimada utilizando as fórmulas propostas para consultas por similaridade complexas ou o desvio padrão solbre a cardinalidade real;

- Os gráficos estão em escala log-log. A excegão é para os gráficos que medem a escalabilidade dos algoritmos (escala linear) e para os gráficos do conjuntos Palavras (escala mono $\log$ ).

- Estão implementados na biblioteca do MAMs Arboretum métodos para realizar a união e interseção cntre conjuntos. Esses métodos são usados após a execução dos algoritmos básicos Range() e Nearest() e suas variações para compor a resposta do uma consulta por similaridade complexa. Note-se que esses métodos são executados cm memória, sendo contabilizado apenas o sen tempo de processamento. Acessos a disco não são computados, mesmo que seja necessário usar o disco rigído para fazer as operaçồs de união e/ou interseção.

- Estão codificados métodos para contabilizar e armazenar em arquivo texto, no padrão do GNUPlot ${ }^{1}$, as seguintes medidas (considerando as 500 consultas): número médio de cálenlos de distância; número médio de acessos a disco, incluindo acessios ao nó raiz do índice; e tempo total das consultás om segundos;

- A opraza de construcão da Slim-tree para os comjuntos de dades testados é a que apresenta os melhores resultados, segundo o artigo apresentado em [Traina Jr. et al., 2000b] e [Traina Jr. et al., 2002]. 'Todas as mediclas foram feitas após a execução do algoritmo do pós-otimização Slim-Down. A ocupação mínima dos nós da Slim-tree foi de $25 \%$ da capacidade máxima dos nós, que ó o padrão desisid estruturar.

Os resultiados dos testes são apresentados e discutidos a seguir.

\subsection{Resultados e Discussão}

Os experimentos realizados consideram as consultas por similaridade complexas apresentadas na Seção 1.3, os algoritmos normativos propostos para avaliá-las no Capítulo 4,

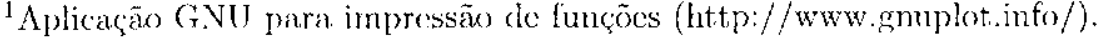


as fórmulas para estimativa de seletividade desellvolvidas no Capítulo 5 e os conjuntos do dados listados na Secäo 6.2 . Os algoritmos normativos foram avaliados con consultas para expressões SCSP, SCMP e MCMP, o as fórmulas de estimativa de seletividade em consultas para expressões SCSP o SCMP.

Para estimativas de soletividade, os gráficos contrapõem a cardinalidade estimada, utilizando as fórmulas de estimativa de seletividade desenvolvidas, com a cardinalidade obtida após a execução da consulta por similaridade complexa (cardinalidade real). Yesses gráficos assume-se on um erro em relação à cardinalidade cstimada [Belussi \& Faloutsos, 1995] on o desvio padrão em relação à cardinalidade real medido no conjunto de 500 consultas [Traina Jr, et al., 2002] (Seção 6.3.5).

Para os algoritmos nomativos, os gráficos dos experimentos comparam-os com a composição dos algoritmos básicos para responder a uma consulta por similariclade complexa usando o MAM Slim-tree e a lista seqüencial SeqScan. Para exomplicar, considerc-so a seguinte consulta por similaridade complexa do tipo SCMP: $\sigma_{\left(R_{q\left(s_{q}, r\right)}\right)} S \wedge \sigma_{\left(k N N\left(s_{q}\right)\right)} S$. O gráfico correspondente contrapõe o algoritmo normativo para responder a essa consulta, que no caso é o algoritmo kAndRange(), com a composição dos algoritmos básicos equivalente. (O processo de obtenção de resposta para essa consulta usando os algoritmos básicos implica em executar: o algoritmo Range(); o algoritmo Nearest(); e a operação cle interseçäo sobre as respostas individuais de cada algoritmo, para compor a resposta da consultac complexil.

Para facilitar a descrição dos experimentos ao longo do texto, todo o processo de obtenção da resposta para a consulta por similaridade complexa pela composição dos algoritmos básicos é resumida em algoritmos básicos ou respectivos algoritmos básicos. Portanto: para descrever os resultados obtidos para a consulta do parágrafo anterior, 1 m texto provível scria: ". . o algoritmo $k$ AndRange() faz até 2 vezes menos arcssos a diseo (que os algoritmos básicos usando uma lista seqüencial para o conjunto ...". A Tabela 6.2 mostra alguns exomplos de consultas complexas e os algoritmos usados para respondê-las em cada caso.

Tabela 6.2: Algoritmos normativos propostos e a respectiva composiça dos algoritmos básicos para responder a consultas por similaridade complexas.

\begin{tabular}{|c|c|c|}
\hline Consulta & Algoritmos Nor & $\begin{array}{l}\text { Composição do conjunto-resposta } \\
\text { usando os algoritmos básicos }\end{array}$ \\
\hline ,r) $)^{S}$ & $k:$ AndRange $\left(\leq, s_{q}, k, r\right)$ & Rangc $\left(<, s_{q}, r\right) \cap$ Nearesh $\left(\leq, s_{q}, k\right)$ \\
\hline$\sigma_{\left(\operatorname{Rr}\left(s_{,}, r\right)\right)} S \vee \sigma_{\left(k: N N\left(s_{q}\right)\right)} S$ & $k 0 \%$ & $\operatorname{Range}\left(\leq, s_{q}, r\right) \cup N \operatorname{Narest}\left(\leq, s_{q}, k\right)$ \\
\hline$\sigma_{\left(R q\left(s_{4}, r_{r}\right)\right)} S \wedge \sigma_{\left(-R_{q}\left(s_{q}, r_{1}\right)\right)} S$ & GenericRange $\left(s_{q}\right.$, rLimit []$)$ & $\operatorname{Range}\left(\leq, s_{q}, r_{e}\right) \cap \operatorname{Range}\left(>, s_{q}, r_{i}\right)$ \\
\hline$\sigma_{\left(k, N N\left(s_{q}\right)\right)^{S}} S \wedge \sigma\left(-k_{i} N N\left(s_{q}\right)\right)^{S}$ & GentricNearest $\left(s_{\varphi}\right.$, kimit []$)$ & Nearest $\left(\leq, s_{q}, k_{c}\right) \cap$ Neurest $\left(>, s_{q}, k_{i}\right)$ \\
\hline
\end{tabular}

Visando a ressaltar aspectos relevantes na comparacaio entre os algoritmos normativos e os algoritmos básicos, experimentos específicos form realizados cm algumas consultas por similaridade complexas. Para esses casos, a avaliação se restringe a apenas 


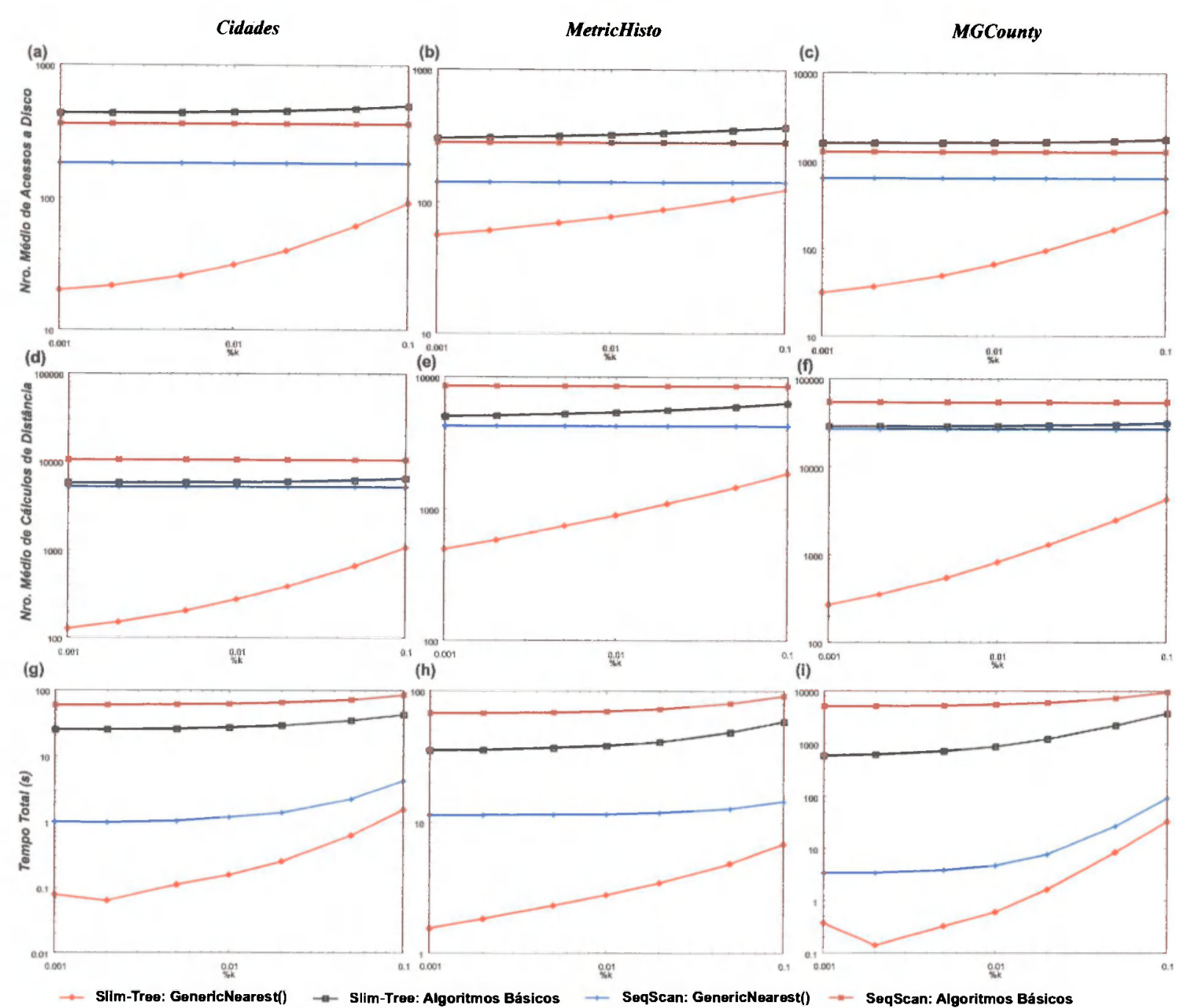

Figura 6.2: Consulta SCSP $\sigma_{\left(k_{e} N N\left(s_{q}\right)\right)} S \wedge \sigma_{\left(\neg k_{i} N N\left(s_{q}\right)\right.} S$ comparando o número médio de acessos a disco (gráficos (a), (b) e (c)), número médio de cálculos de distância (gráficos (d), (e) e (f) ) e tempo total de processamento (gráficos (g), (h) e (i) ) para 500 consultas, utilizando a Slim-tree e a SeqSan nos conjuntos Cidades, MetricHisto e MGCounty.

alguns conjuntos de dados e uma das estruturas (o MAM Slim-tree ou a lista seqüencial). Os resultados alcançados pelos algoritmos para consultas por similaridade complexas do tipo SCSP são mostrados a seguir.

\subsubsection{Algoritmos para Expressões SCSP}

As Figuras 6.2, 6.3, 6.4 e 6.5 mostram, respectivamente, os resultados obtidos ao se executar uma consulta SCSP utilizando os algoritmos normativos e os respectivos algoritmos básicos para os predicados $k$-nearest e range, onde são avaliadas três medidas de desempenho (número médio de acessos a disco, número médio de cálculos de distância e tempo total de processamento) sobre os conjuntos apresentados na Seção 6.2. As Figuras 6.4 e 6.5 apresentam os resultados experimentais do algoritmo GenericRange() e as Figuras 6.2 e 6.3 do algoritmo GenericNearest().

O algoritmo normativo GenericNearest () , para a consulta $\sigma_{\left(k_{\circ} N N_{(\circ q)}\right)} S \wedge$ 


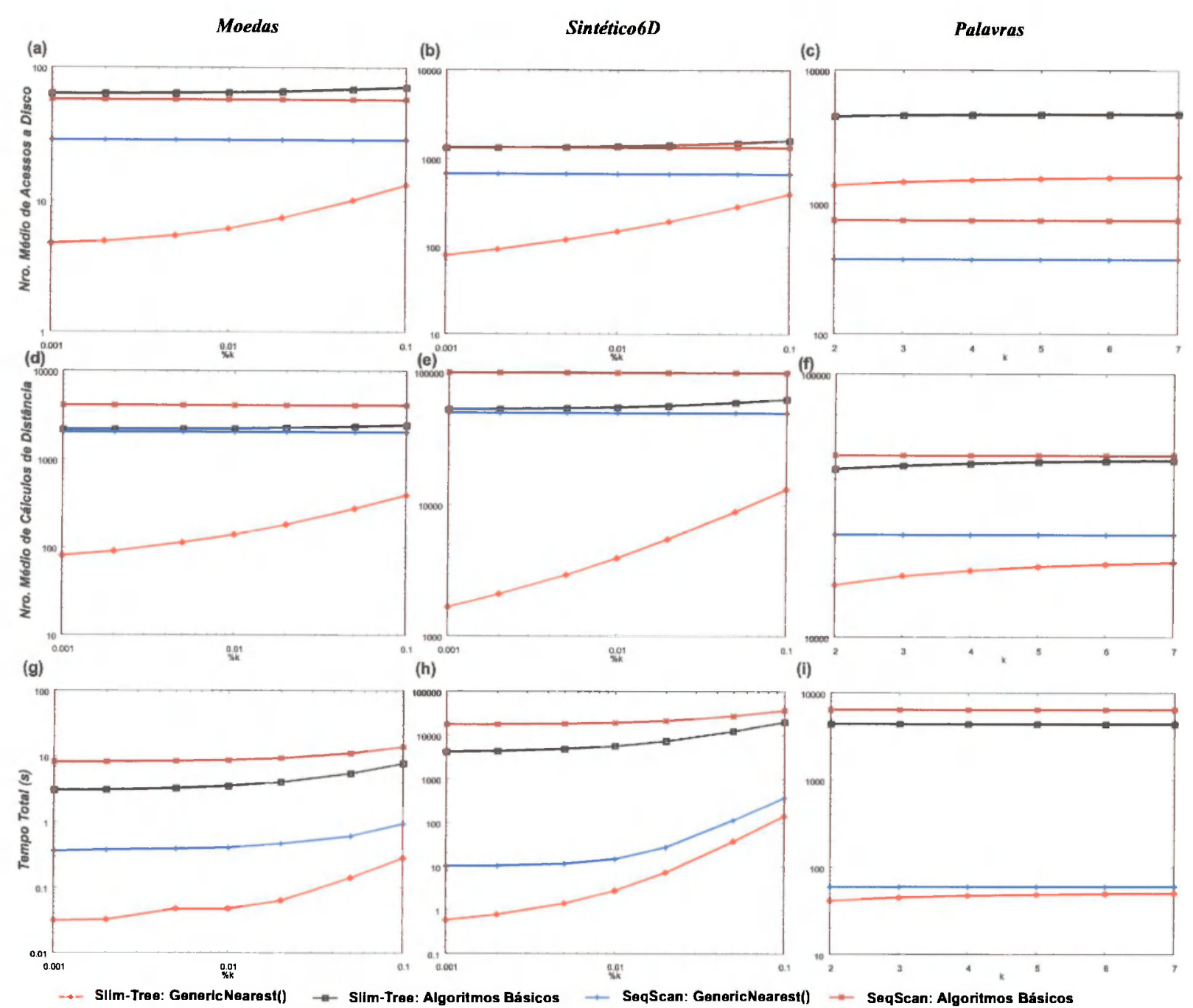

Figura 6.3: Consulta SCSP $\sigma_{\left(k_{e} N N\left(s_{q}\right)\right.} S \wedge \sigma_{\left(\neg k_{i} N N\left(s_{q}\right)\right)} S$ comparando o número médio de acessos a disco (gráficos (a), (b) e (c)), número médio de cálculos de distância (gráficos (d), (e) e (f) ) e tempo total de processamento (gráficos (g), (h) e (i) ) para 500 consultas, utilizando a Slim-tree e a SeqScan nos conjuntos Moedas, Sintético6D e Palavras.

$\sigma_{\left(\neg k_{i} N N\left(s_{n}\right)\right.} \mathcal{S}$, possui um desempenho superior em todos os conjuntos testados quando comparado com os respectivos algoritmos básicos, utilizando tanto a SeqScan quanto a Slim-tree. Para a SeqScan o algoritmo GenericNearest() faz a metade do número de acessos a disco (gráficos (a), (b) e (c) das Figuras 6.2 e 6.3) e cálculos de distância (gráfi$\cos (\mathrm{d}),(\mathrm{e})$ e (f) das Figuras 6.2 e 6.3) em relação aos algoritmos básicos. Considerando tempo total de processamento (gráficos (g), (h) e (i) das Figuras 6.2 e 6.3) os ganhos obtidos pelo algoritmo normativo são maiores, sendo pelo menos 5 vezes mais rápido que os algoritmos básicos. Para a Slim-tree o algoritmo GenericNearest() reduz de 5 a até 15 vezes o número de acessos a disco, de 3 a até 30 vezes o número de cálculos de distância e é no mínimo 15 vezes mais rápido que os algoritmos básicos.

As Figuras 6.4 e 6.5 ilustram o desempenho para se executar uma consulta SCSP semelhante a consulta Q6 da Seção 1.3, isto é $\sigma_{\left(R q\left(s_{n}, r_{e}\right)\right)} S \wedge \sigma_{\left(\neg \tilde{r} q\left(s_{q}, r_{i}\right)\right.} S^{\prime} S^{\prime}$, onde o algoritmo normativo GenericRange() e os respectivos algoritmos básicos são utilizados para respondê-la. 


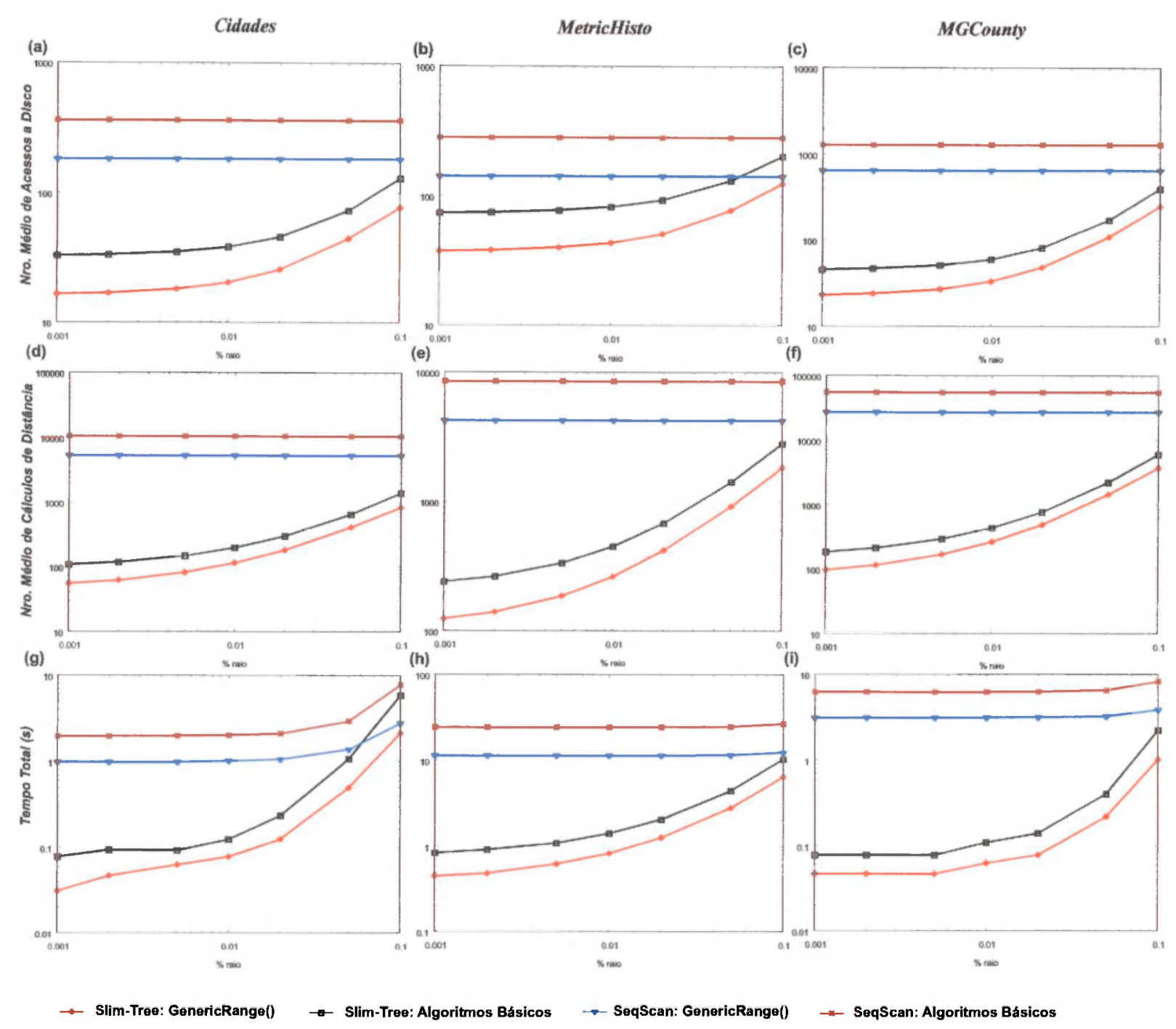

Figura 6.4: Consulta SCSP $\sigma_{\left(R q\left(s_{n}, r_{e}\right)\right)} S \wedge \sigma_{\left(\neg \bar{n} q^{\prime} s_{q}, r_{i}\right)} S^{\prime}$ comparando o número médio de acessos a disco (gráficos (a), (b) e (c)), número médio de cálculos de distância (gráficos (d), (e) e (f) ) e tempo total de processamento (gráficos (g), (h) e (i) ) para 500 consultas, utilizando a Slim-tree e a SeqScan nos conjuntos Cidades, MetricHisto e MGCounty.

O algoritmo GenericRange() também possui um melhor desempenho em relação aos respectivos algoritmos básicos. Esse desempenho superior foi verificado em todos os conjuntos de dados testados e aspectos medidos. Para a SeqScan o algoritmo GenericRange() reduz à metade tanto o número médio de acessos a disco (gráficos (a), (b) e (c) das Figuras 6.4 e 6.5) quanto o número médio de cálculos de distância (gráficos (d), (e) e (f) das Figuras 6.4 e 6.5). No tempo total de processamento (gráficos (g), (h) e (i) das Figuras 6.4 e 6.5) o algoritmo normativo é em média 8 vezes mais rápido que os algoritmos básicos. Para a Slim-tree o algoritmo GenericRange() faz até 2 vezes e meia menos acessos a disco e cálculos de distância e é em média 9 vezes mais rápido que os algoritmos básicos.

A maioria dos conjuntos de dados testados tiveram um comportamento semelhante em relação aos ganhos obtidos tanto para o algoritmo GenericNearest() quanto para o algoritmo GenericRange() em relação aos respectivos algoritmos básicos considerando 


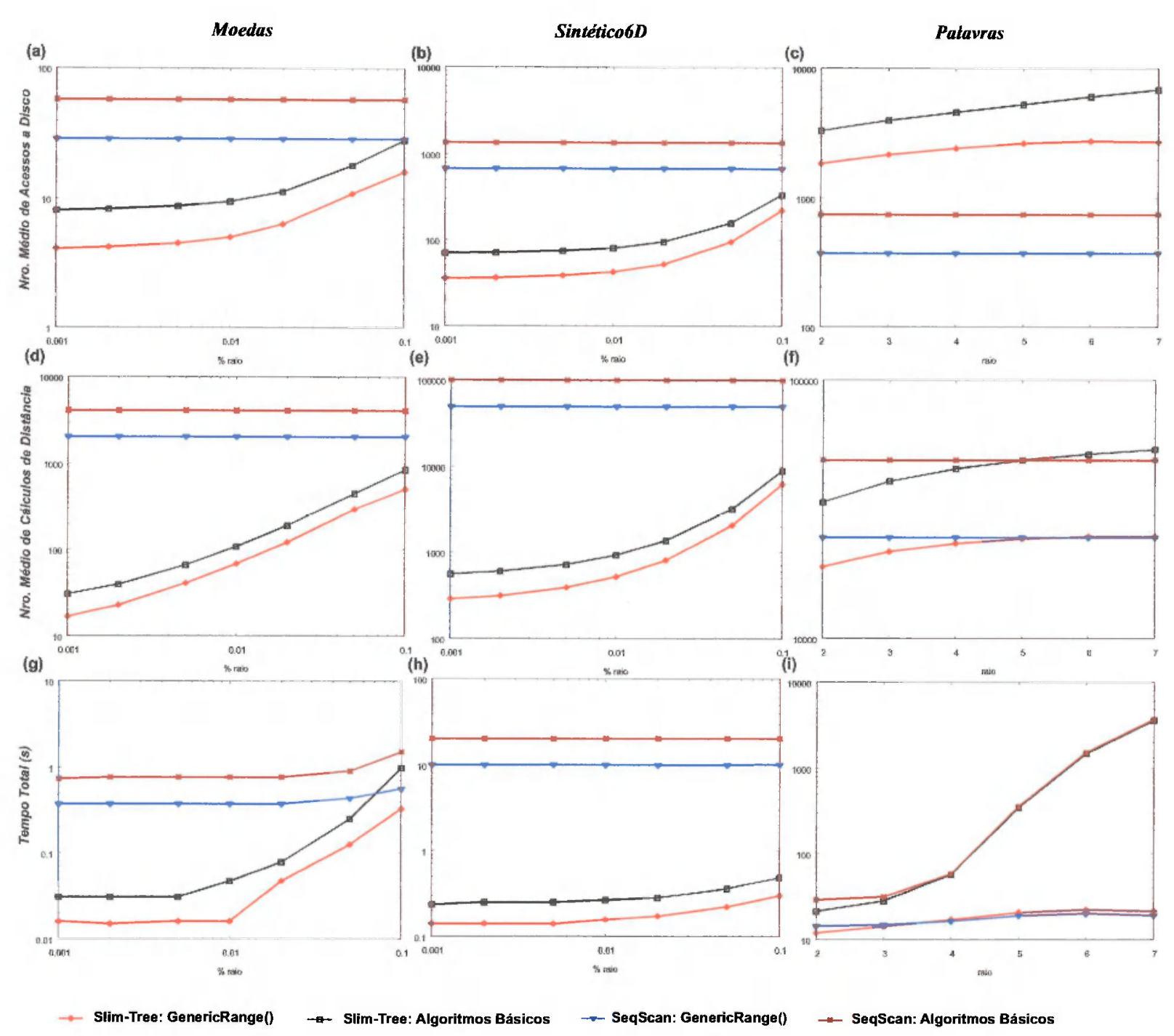

Figura 6.5: Consulta SCSP $\sigma_{\left(R q\left(s_{n} . r_{e}\right)\right)} S \wedge \sigma_{\left(\neg \tilde{R} q\left(s_{q}, r_{i}\right)\right.} S^{\prime} S^{\prime}$ comparando o número médio de acessos a disco (gráficos (a), (b) e (c)), número médio de cálculos de distância (gráficos (d), (e) e (f) ) e tempo total de processamento (gráficos (g), (h) e (i) ) para 500 consultas, utilizando a Slim-tree e a SeqSan nos conjuntos Moedas, Sintético6D e Palavras.

\section{Cidades}

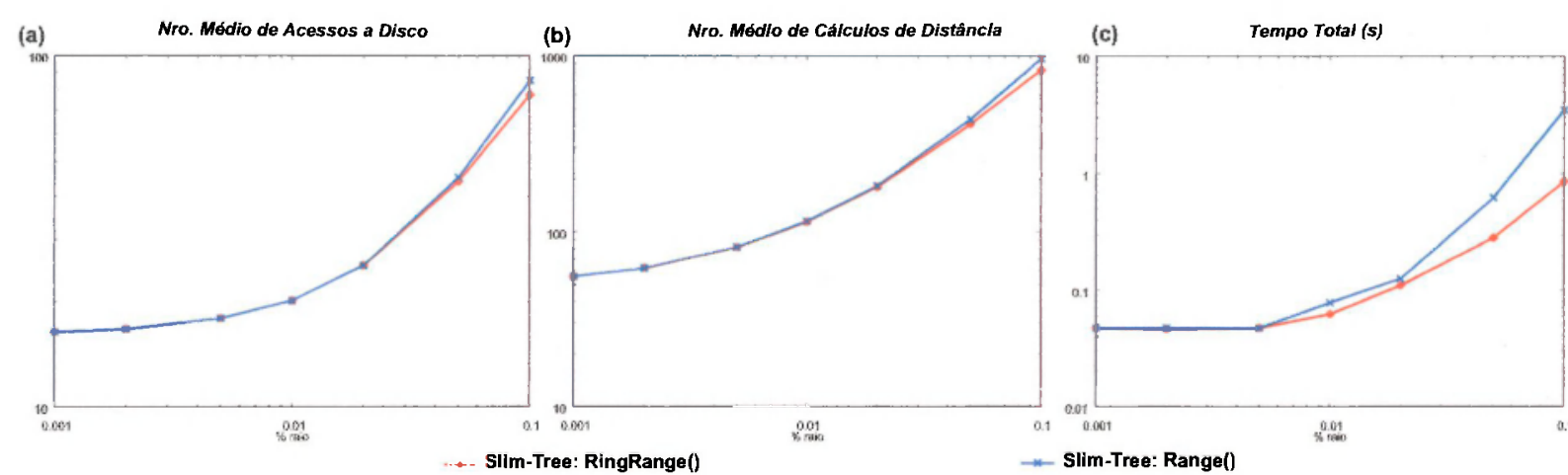

Figura 6.6: Comparação entre os algoritmos Range() e RingRange() $\operatorname{com} r=r_{e}$ medindo: o número médio de acessos a disco (gráfico (a) ); número médio de cálculos de distância (gráfico (b) ); e tempo total de processamento (gráfico (c) ) para 500 consultas, utilizando a Slim-tree no conjunto Cidades. 
os aspectos medidos. Em se tratanto de acessos a disco e cálculos de distância, ganhos mais expressivos sĩo obtidos para valores pequenos de raio o número de vizinhos. Já prara tempo total de processamento, o comportamento é semelhante, considerando o algoritmo GenericNearest(), porém para o algoritmo GenericRange(), geralmente, desempenhos melhores são obtidos para valores de raio e múmero de vizinhos maiores. Isso ocorro principalmente porque o algoritmo para a parte complementada do predicado k-nearest é mais oneroso que o do predicudo range para valores menores, fazendo com que ganhos maiores sojam obtidos nessa faixa de valores.

Um outro aspecto interessante avaliado nos experimentos foi comparar o desempenho de uma consulta por abrangência com unma consulta SCSP formando regiões em anel para o predicado range. Essa comparação é feita utilizando os algoritmos Range() : RingRange(), onde o raio externo $r_{e}$ do algoritmo RingRange() é igual ao raio $r$ do algoritmo Range(). $\Lambda$ obtenção do raio interno para o algoritmo RingRange() é feito conforme a descrigăo da Segão 6.2. Esse teste foi feito para tortos os conjuntes de dados avaliados nos experimentos, porém como eles apresentam resultados somclhantes apenas o conjuntos de dados Cidades é mostrado.

A Figura 6.6 ilustra a comparação entre os algoritmos Range() e RingRange(). O algoritmo RingRange() laz monos acessos a discos, cáleulos de distância e tempo total de processamento que o algoritmo Range(), tanto para valores menores quanto maiores de raio. Para valores menores de rajo isso não é perceptível nos gráficos, pois eles são muite próximos um do outro, tendo o algoritmo RingRange() un descrupenho ligeiramente melhor. Apenas para valores maiores de raio é possível visualizar o melhor desempenho

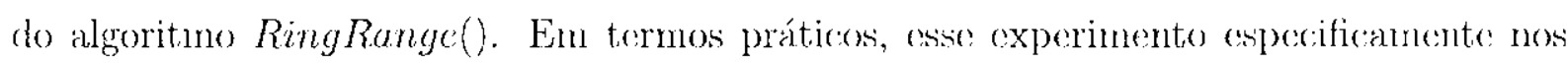
mostra que para valores pequenos de raio, onde a maioria das consultas são freqüentemente realizadasi, o custo de se exccutar um algoritmo de RingRange() é equivalente ao do se executar um algoritmo Range() $\operatorname{com} r=r_{e}$.

\subsubsection{Algoritmos para Expressões SCMP}

Os algoritmos normativos $k$ AndRange() e $k$ Or Range() e os respectivos algoritmos básicos são utilizados para avaliar expressões SCMP em DNF o CNF. As Figuras 6.7, 6.8, 6.9 e 6.10 ilustran os resultados experimentais desses dois algoritmos para os conjuntos de dados descritos na Seção 6.2, considerando o tempo total de processamento, o número médio de aressos a disco e o núnero médio de cálenlos de distância para a Slim-trex a SeqSan. Para ambos os algoritmos normativos ( $k$ AndRange() e $k$ Or Range()), quando a SeqSan é utilizada o ganho obtido para as mediclas acessos a disco e cálculos de distância é o mesmo, isto é, csses algoritmos reduzem à metade o número de acessos a disco o cálculos de distância em relação a.os respectivos algoritmos básicos. Isso ocorre porque os algoritmos normativos varem o conjunto de dados apenas una única ve\%, enquanto (que: os algoritmos básicos precisam varrer duas vezes o conjunto de dados para respondor à mesma cousulta por similaridarle complexa. 

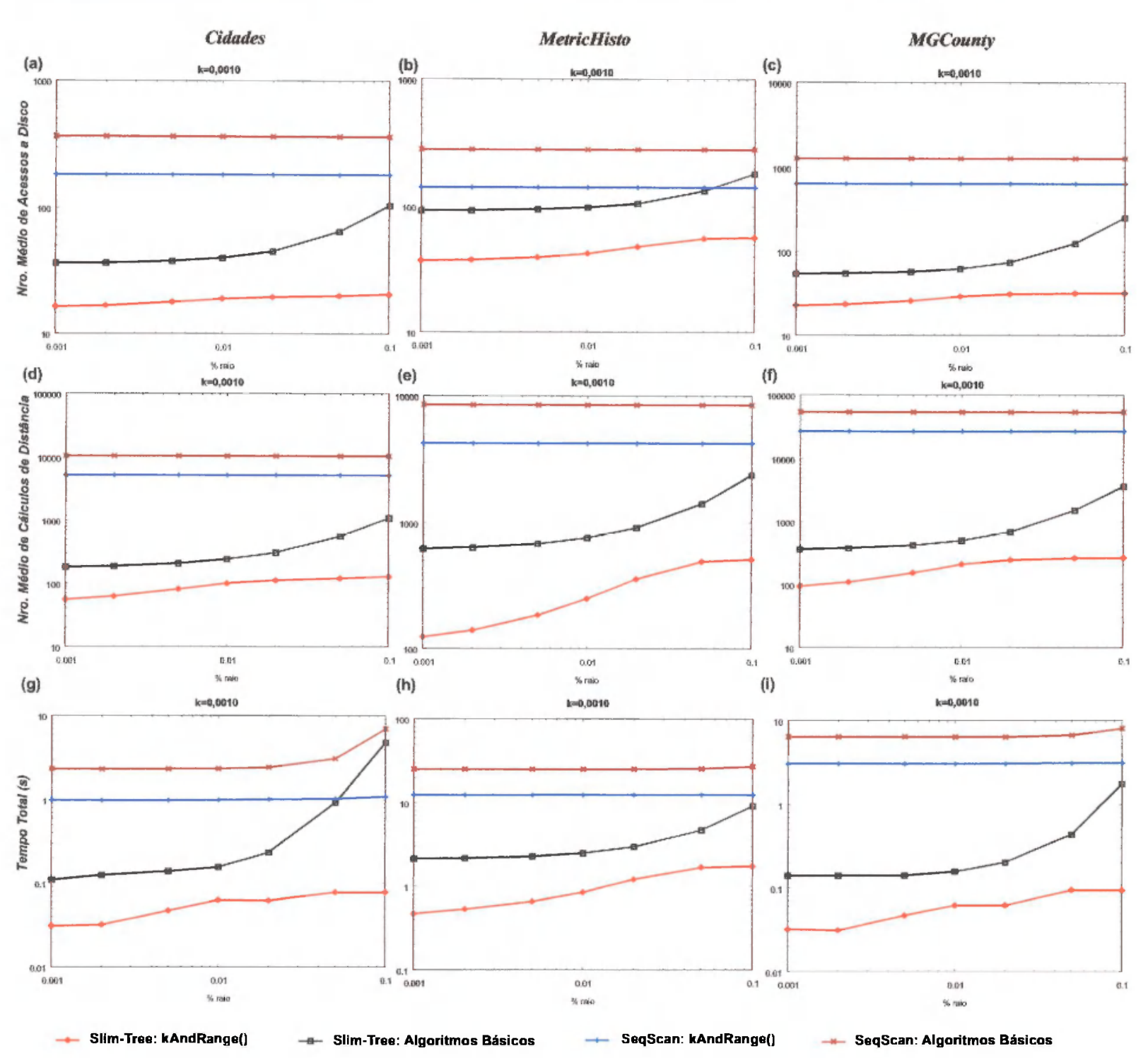

- Slim-Tres: kAndRange(]) - Slim-Tree: Algoritmos Básicos + SeqScan: kAndRange(]) \# SeqScan: Algoritmos Básicos

Figura 6.7: Consulta SCMP $\sigma_{\left(\bar{r} q\left(s_{q}, r\right)\right)} S \wedge \sigma_{\left(k N N\left(s_{q}\right)\right)} S(\theta=$ ' $\leq$ ') comparando o número médio de acessos a disco (gráficos (a), (b) e (c) ), número médio de cálculos de distância (gráficos (d), (e) e (f) ) e tempo total de processamento (gráficos (g), (h) e (i) ) para 500 consultas, utilizando a Slim-tree e a SeqScan nos conjuntos Cidades, MetricHisto e $M G$ County com $k$ igual a $0,1 \%$ ( $k=0,001$ nos gráficos).

As Figuras 6.7 e 6.8 ilustram o desempenho para se executar uma consulta SCMP em DNF semelhante às consultas Q1 e Q3 da Seção 1.3, isto é $\sigma_{\left.\left(\bar{r} q s_{q}, r\right)\right)} S \wedge \sigma_{\left(k N N\left(s_{q}\right)\right)} S$, onde o algoritmo $k$ AndRange() e os algoritmos básicos são utilizados para respondê-las.

Os gráficos das Figuras 6.7 e 6.8 mostram que o algoritmo $k$ AndRange() faz menos acessos a disco (gráficos (a), (b) e (c)), cálculos de distância (gráficos (d), (e) e (f) ) e possui um tempo de processamento (gráficos (g), (h) e (i) ) menor que os respectivos algoritmos básicos. Utilizando a estrutura de indexação Slim-tree, o algoritmo $k$ AndRange() reduz até 8 vezes o número de acessos a disco, até 14 vezes o número de cálculos de distância e é, em média, 10 vezes mais rápido que os algoritmos básicos. Para a SeqScan, o algoritmo $k A n d R a n g e()$ é, em média, 2 vezes e meia mais rápido que os algoritmos básicos.

Os gráficos das Figuras 6.9 e 6.10 ilustram o comportamento do algoritmo 

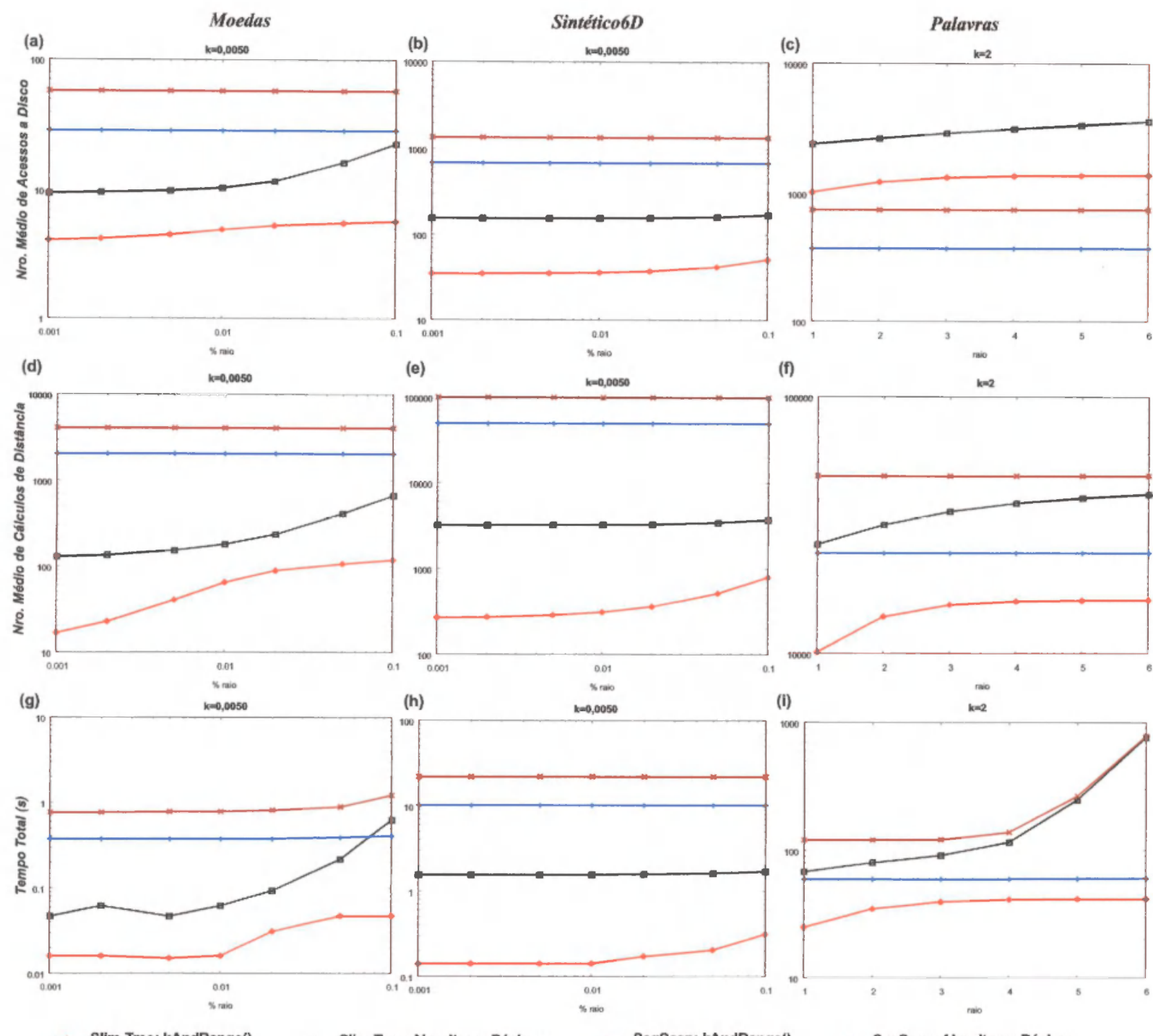

-. Slim-Tree: KAndRange()

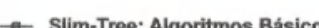

- Seqsean: kandRangen

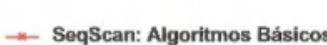

Figura 6.8: Consulta SCMP $\sigma_{\left(\tilde{r} q q^{\prime}\left(q_{q}, r\right)\right.} S \wedge \sigma_{\left(k N N\left(s_{q}\right)\right.} S(\theta=$ ' $\leq$ ') comparando o número médio de acessos a disco (gráficos (a), (b) e (c) ), número médio de cálculos de distância (gráficos (d), (e) e (f) ) e tempo total de processamento (gráficos (g), (h) e (i) ) para 500 consultas, utilizando a Slim-tree e a SeqScan nos conjuntos Moedas $(k=0,005)$, Sintético6D $(k=0,005)$ e Palavras $(k=2)$.

kOr Range() e dos respectivos algoritmos básicos para responder a uma consulta SCMP em CNF semelhante à consulta Q2 $\sigma_{\left(\bar{r} \varphi^{\prime}\left(s_{q}, r_{i)}\right)\right.} S^{\prime} \vee \sigma_{\left(k N N\left(s_{q}\right)\right)} S$ da Seção 1.3. Nesses gráficos, usando a estrutura de indexação Slim-tree o algoritmo kOrRange() faz até $90 \%$ menos acessos a disco, $81 \%$ menos cálculos de distância e é até 2 vezes e meia mais rápido que os algoritmos básicos. Para a SeqScan, o algoritmo kOrRange() é, em média, 2 vezes mais rápido que os algoritmos básicos.

Nos gráficos das Figuras $6.7,6.8,6.9$ e 6.10 os valores de $k$ para o predicado $k$ nearest das expressões SCMP são constantes, porém diferentes para cada conjunto de dados. Esses valores são de 0,1\% ( $k=0,001$ nos gráficos) para os conjuntos Cidades, MetricHisto e MGCounty, 0,5\% ( $k=0,005$ nos gráficos) para os conjuntos Moedas e Sintético6D e $k=2$ para o conjunto Palavras.

Um outro aspecto importante avaliado nos experimentos realizados para expressões 


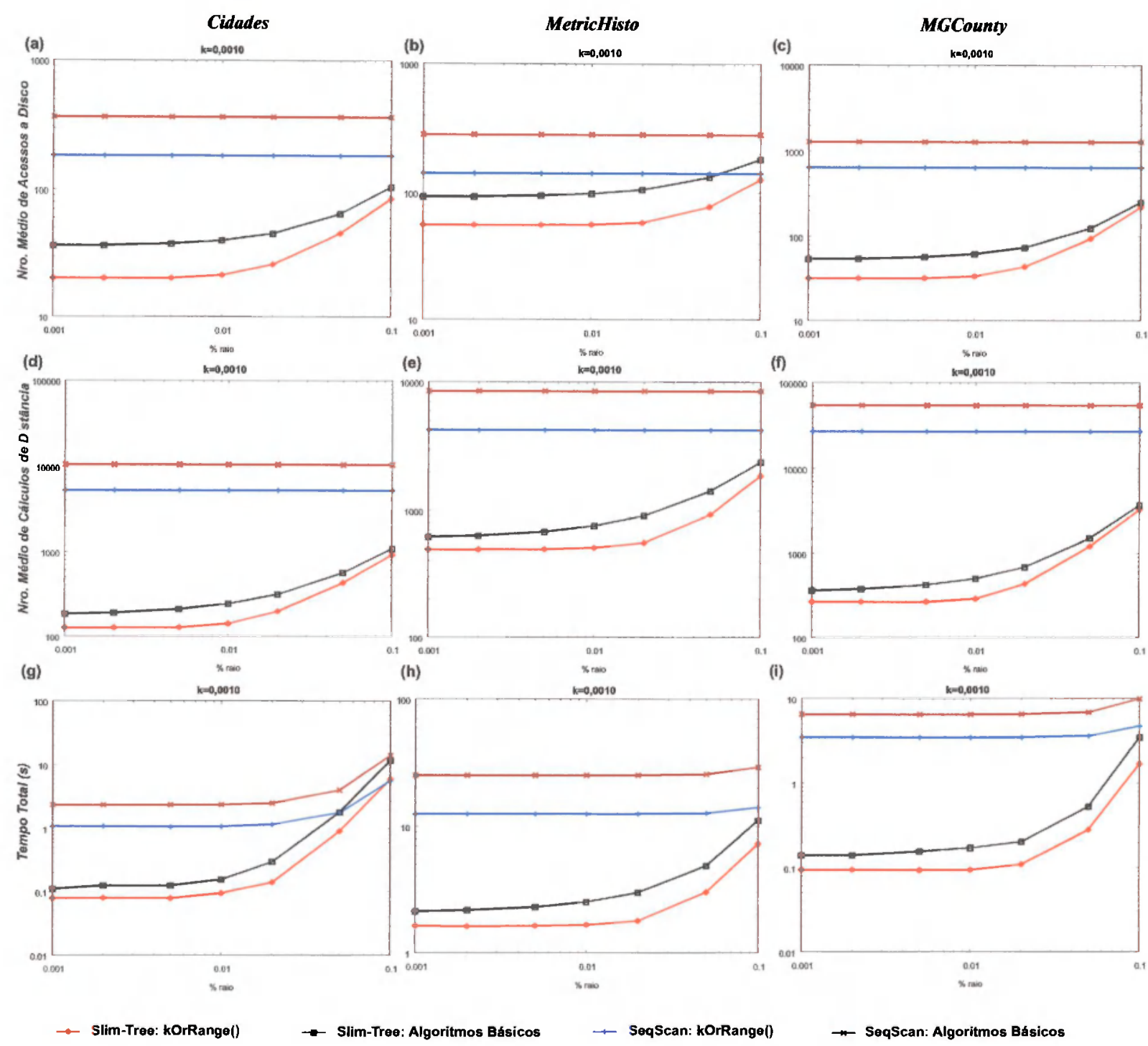

Figura 6.9: Consulta SCMP $\sigma_{\left(R q\left(s_{q}, r\right)\right)} S \vee \sigma_{\left(k N N\left(s_{n}\right)\right.} S\left(\theta-{ }^{\prime}{ }^{\prime}\right)$ ') comparando o número médio de acessos a disco (gráficos (a), (b) e (c) ), número médio de cálculos de distância (gráficos (d), (e) e (f) ) e tempo total de processamento (gráficos (g), (h) e (i)) para 500 consultas, utilizando a Slim-tree e a SeqScan nos conjuntos Cidades, MetricHisto e $M G C o u n t y$ com $k$ igual a $0,1 \%$ ( $k=0,001$ nos gráficos).

SCMP é que os valores de $k$ e do raio $r$ variam, de maneira independente, apesar dos valores de $k$ não serem mostrados variando nos gráficos até aqui. Esse aspecto permite ressaltar bem as diferenças entre os algoritmos $k$ AndRange() e kOrRange(). A Figura 6.11 ilustra essa situação. Nessa figura são apresentadas variações dos valores de $k$ e do raio $r$ para o conjunto $M G$ County, tanto para o algoritmo $k$ AndRange() (gráficos (a), (b) e (c) ) quanto para o algoritmo kOrRange() (gráficos (d), (e) e (f) ) utilizando o MAM Slim-tree para as medidas de desempenho, número médio de acessos a disco (gráficos (a) e (d) ), número médio de cálculos de distância (gráficos (b) e (e) ) e tempo total de processamento (gráficos (c) e (f)) .

A Figura 6.11 mostra que o algoritmo $k$ AndRange() obtém o menor valor entre o raio $r$ ou o número de objetos $k$, e o algoritmo $k O r R a n g e()$ o maior valor. Os gráficos (a), (b) e (c) ilustram essa afirmação para o algoritmo $k$ AndRange(). Note-se que, para 

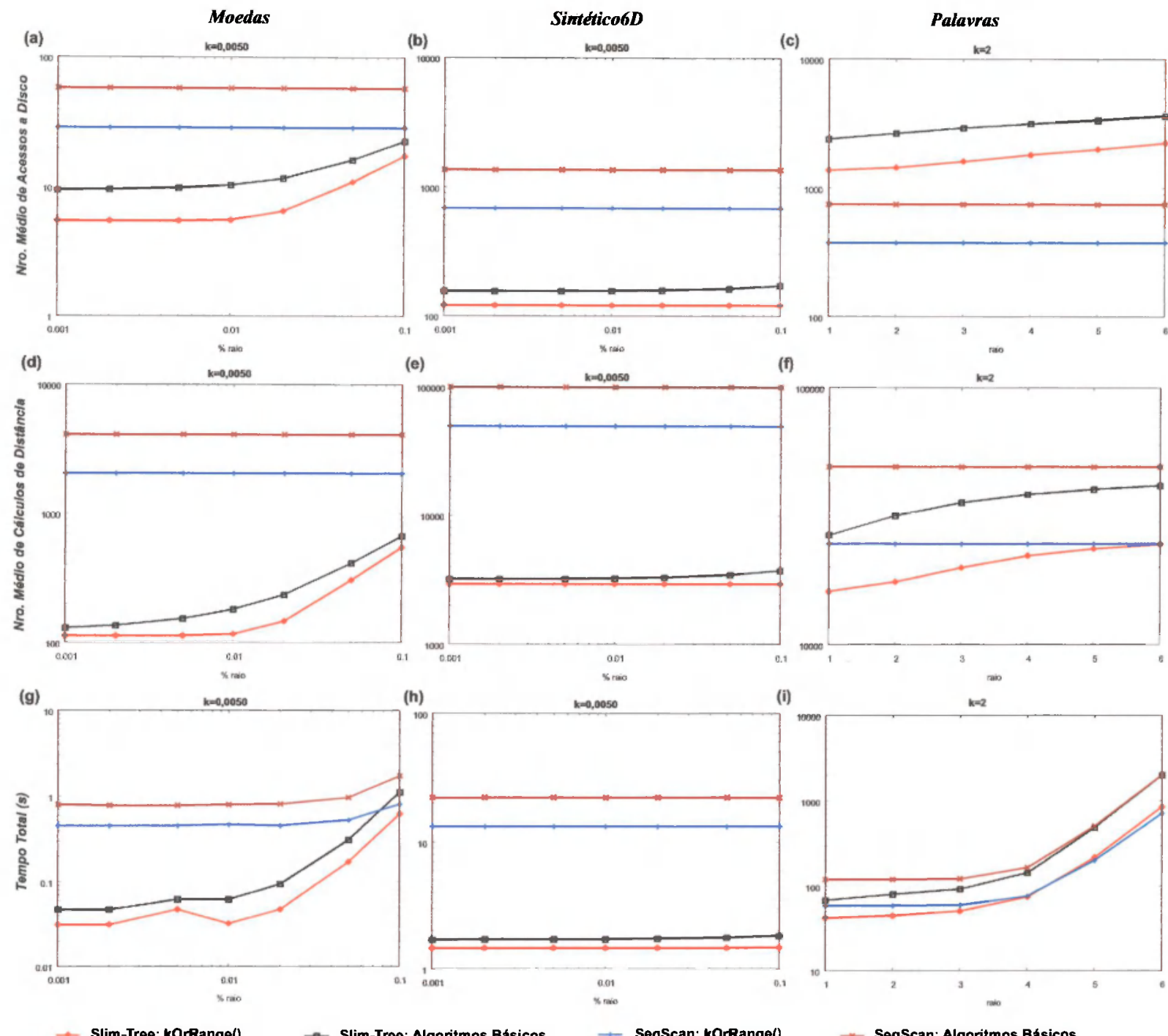

Figura 6.10: Consulta SCMP $\sigma_{\left(\bar{r} q i^{\prime} s_{q}, r\right)} S \vee \sigma_{\left(k N N\left(s_{n}\right)\right.} S(\theta=$ 's') comparando o número médio de acessos a disco (gráficos (a), (b) e (c) ), número médio de cálculos de distância (gráficos (d), (e) e (f) ) e tempo total de processamento (gráficos (g), (h) e (i) ) para 500 consultas, utilizando a Slim-tree e a SeqScan nos conjuntos Moedas $(k=0,005)$, Sintético6D $(k=0,005)$ e Palavras $(k=2)$.

valores de raio pequenos, o raio é o menor valor (até o terceiro ponto) e, por isso, as curvas representando os valores diferentes de $k$ nos gráficos estão juntas. A medida que o raio aumenta, o valor de $k$ passa a ser o menor valor entre os dois e as curvas para cada $k$ nos gráficos tendem a se estabilizar uma após a outra em ordem crescente. Para o algoritmo kOrRange() ocorre o oposto. Cada curva representando um valor diferente de $k$ é constante até um determinado ponto, pois o valor de $k$ é maior que o raio $r$. O valor medido em cada curva, isto é, acessos a disco, cálculos de distância e tempo, só é alterado quando o raio supera o valor de $k$ correspondente com uma tendência das curvas representando os valores de $k$ se unirem. 

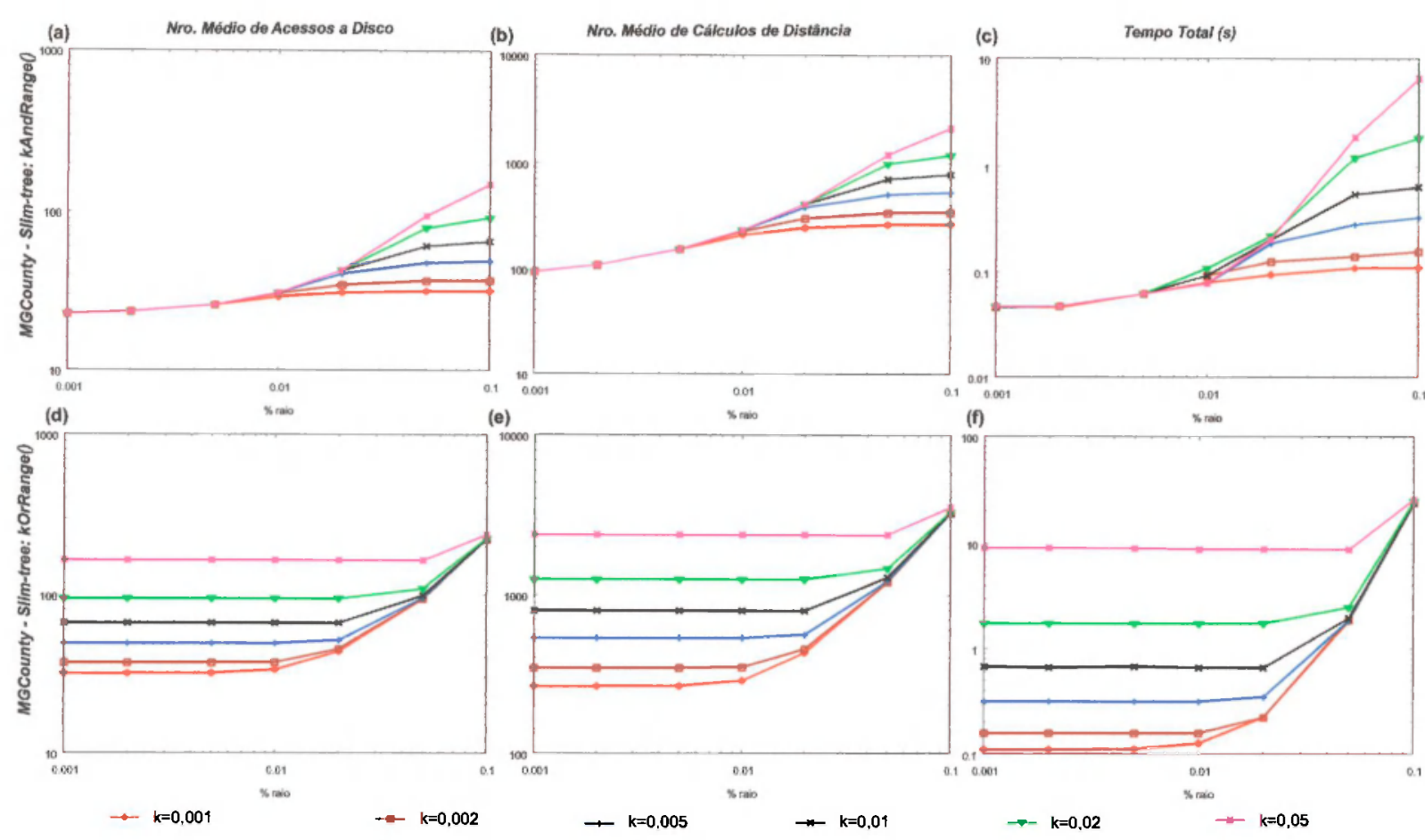

Figura 6.11: Variações dos valores de $k$ para expressões SCMP em DNF e CNF para o conjunto MGCounty. (a), (b) e (c) representam, respectivamente, o número médio de acessos a disco, número médio de cálculos de distância e tempo total de processamento para o algoritmo $k A n d R a n g e() ;(\mathrm{d})$, (e) e (f) representam, respectivamente, o número médio de acessos a disco, número médio de cálculos de distância e tempo total de processamento para o algoritmo kOrRange().

\subsubsection{Algoritmos para Expressões MCMP}

Os resultados experimentais das Figuras 6.12 e 6.13 avaliam o algoritmo normativo e os respectivos algoritmos básicos, considerando o número médio de acessos a disco (gráficos (a), (b) e (c) ), o número médio de cálculos distância (gráficos (d), (e) e (f) ) e tempo total de processamento (gráficos (g), (h) e (i) ) para a expressão de consulta MCMP correspondendo a consulta Q5 da Seção 1.3, utilizando a Slim-tree e a SeqScan. Essa expressão de consulta é composta de três min-termos, cada um deles com objetos de refe-

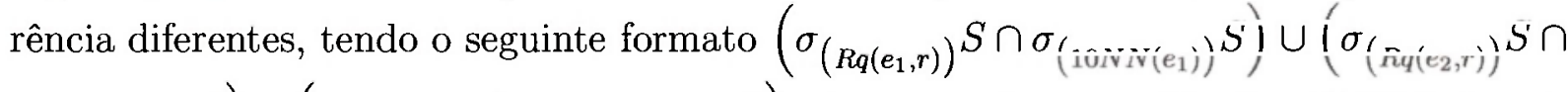
$\left.\sigma_{\left(10 N N\left(e_{2}\right)\right)} S\right) \cup\left(\sigma_{\left(R q\left(e_{3}, r\right)\right.} S \cap \sigma_{\left(10 N N\left(e_{3}\right)\right)} S\right)$. Assim, o algoritmo UniSimDNF() é equivalente a uma única chamada ao algoritmo kAndRange(). Neste experimento o número de vizinhos mais próximos é fixo em 10 e os outros 2 conjuntos de objetos de referência (objetos centrais) para essa consulta foram escolhidos de maneira semelhante ao já descrito na Seção 6.2, porém sem extrair mais objetos dos respectivos conjuntos.

Utilizando a estrutura de indexação Slim-tree, o algoritmo normativo reduz em no mínimo 3 vezes os acessos a disco e cálculos de distância e é, em média, 15 vezes mais rápido que os algoritmos básicos. Para a SeqScan o algoritmo proposto reduz em 2 vezes os acessos a disco e cálculos de distância e é, em média, 2 vezes e meia mais rápido que os algoritmos básicos.

Além da avaliação utilizando uma lista seqüencial e a estrutura de indexação Slim- 

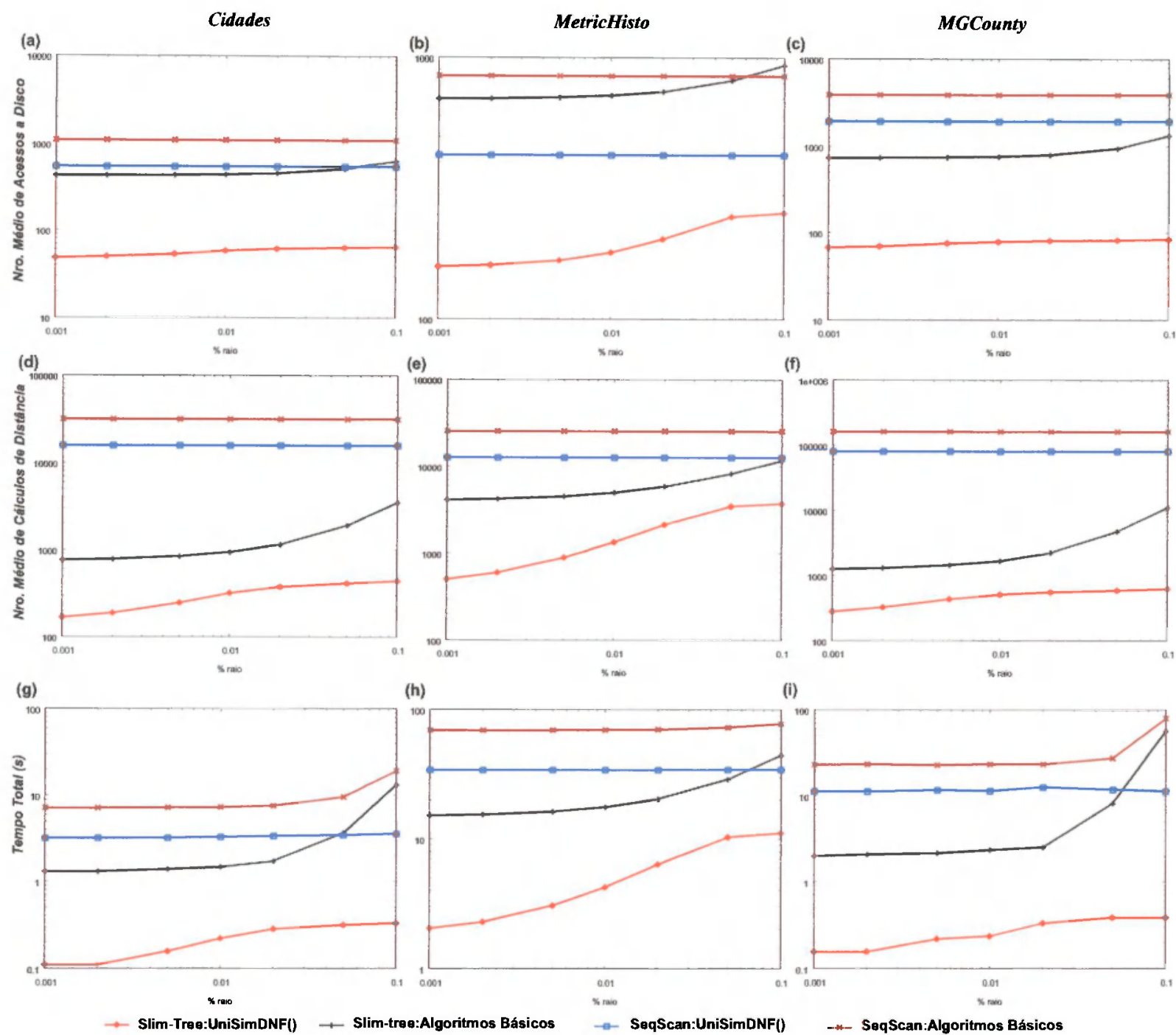

Figura 6.12: Consulta MCMP $\left(\sigma_{\left(R q\left(e_{1}, r\right)\right)} S \cap \sigma_{\left(10 N N\left(e_{1}\right)\right)} S\right) \cup\left(\sigma_{\left(R q\left(e_{2}, r\right)\right)} S \cap\right.$ $\left.\sigma_{\left(10 N N\left(e_{2}\right)\right)} S\right) \cup\left(\sigma_{\left(R q\left(e_{3}, r\right)\right)} S \cap \sigma_{\left(10 N N\left(e_{3}\right)\right.} S\right)$ equivalente à consulta Q5 da Seção 1.3 onde são comparados o número médio de acessos a disco (gráficos (a), (b) e (c)), número médio de cálculos de distância (gráficos (d), (e) e (f) ) e tempo total de processamento (gráficos (g), (h) e (i) ) para 500 consultas, utilizando a Slim-tree e a SeqScan nos conjuntos Cidades, MetricHisto e MGCounty com $k$ igual a 10.

tree para os conjuntos de dados testados, neste experimento, ilustrado na Figura 6.14, é comparado a execução da consulta MCMP completa com a execução de um min-termo e seus componentes para o conjunto de dados MetricHisto utilizando o MAM Slim-tree. Essa figura mostra as medidas de desempenho para executar apenas um min-termo por meio do algoritmo $k$ AndRange() e dos algoritmos básicos (gráficos (b), (d) e (f) ) e a execução da consulta completa (gráficos (a), (c) e (e) ). A curva do algoritmo $k$ AndRange() é utilizada como referência nos gráficos, representando a execução de apenas um min-termo, uma vez que os três min-termos possuem resultados similares.

Considerando os algoritmo básicos (ver gráficos (b), (d) e (f) ), o algoritmo Nearest() tem um valor constante, pois o valor de $k$ é fixo. Assim, as medidas de desempenho para se executar um min-termo (Range() interseção Nearest()), aumentam à 

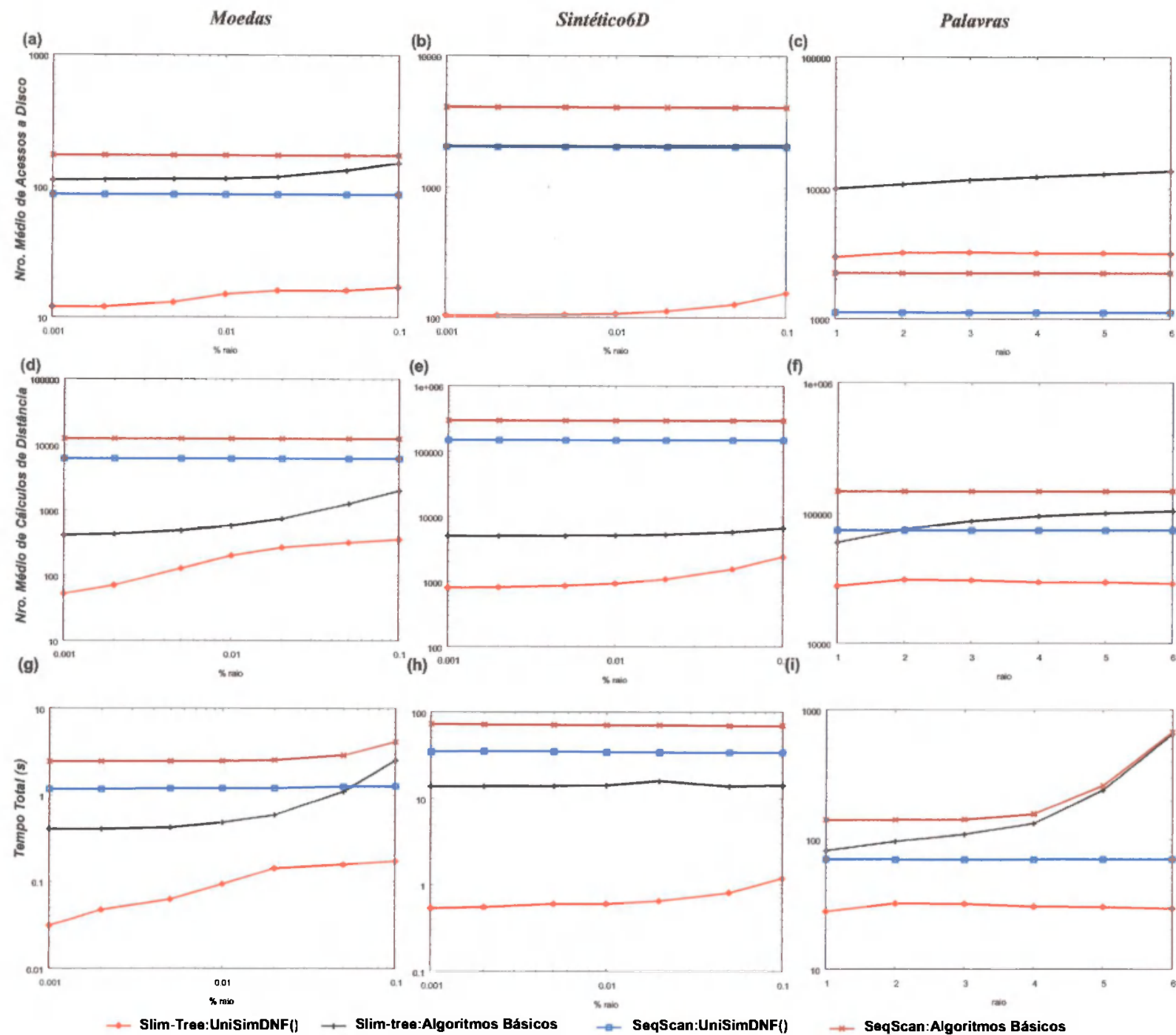

Figura 6.13: Consulta MCMP $\left(\sigma_{\left(R q\left(e_{1}, r\right)\right)} S \cap \sigma_{\left(10 N N\left(e_{1}\right)\right)} S\right) \cup\left(\sigma_{\left(R q\left(e_{2}, r\right)\right.} S \cap\right.$ $\left.\sigma_{\left(10 N N\left(e_{2}\right)\right)} S\right) \cup\left(\sigma_{\left(R q\left(e_{3}, r\right)\right)} S \cap \sigma_{\left(10 N N\left(e_{3}\right)\right)} S\right)$ equivalente à consulta Q5 da Seção 1.3 onde são comparados o número médio de acessos a disco (gráficos (a), (b) e (c)), número médio de cálculos de distância (gráficos (d), (e) e (f) ) e tempo total de processamento (gráficos (g), (h) e (i) ) para 500 consultas, utilizando a Slim-tree e a SeqScan nos conjuntos Moedas, Sintético6D e Palavras com $k$ igual a 10.

medida que o raio $r$ aumenta, porque o algoritmo Range() recupera mais elementos.

Para o algoritmo normativo, é interessante notar que ele (algoritmo $k$ AndRange() ) melhora a execução do min-termo da consulta, limitando o número de elementos a ser recuperado já que esse algoritmo se prevalece da condição mais restritiva entre os predicados range e $k$-nearest. Nos gráficos, enquanto o algoritmo Range() aumenta continuamente, até ultrapassando a curva correspondendo ao algoritmo Nearest() (gráficos (d) e (f)), o algoritmo $k A n d R a n g e()$ tende a permanecer constante à medida que o número de elementos recuperados, determinados pelo raio $r$ no início, aproxima-se de $k$. Note-se que a sua curva se mantém sempre abaixo da curva dos algoritmos básicos (Range() interseção Nearest() ). Isso se reflete nas medidas de desempenho apresentadas para a execução da consulta completa (gráficos (a), (c) e (e) ), obtendo ganhos mais expressivos a medida que 


\section{MetricHisto}

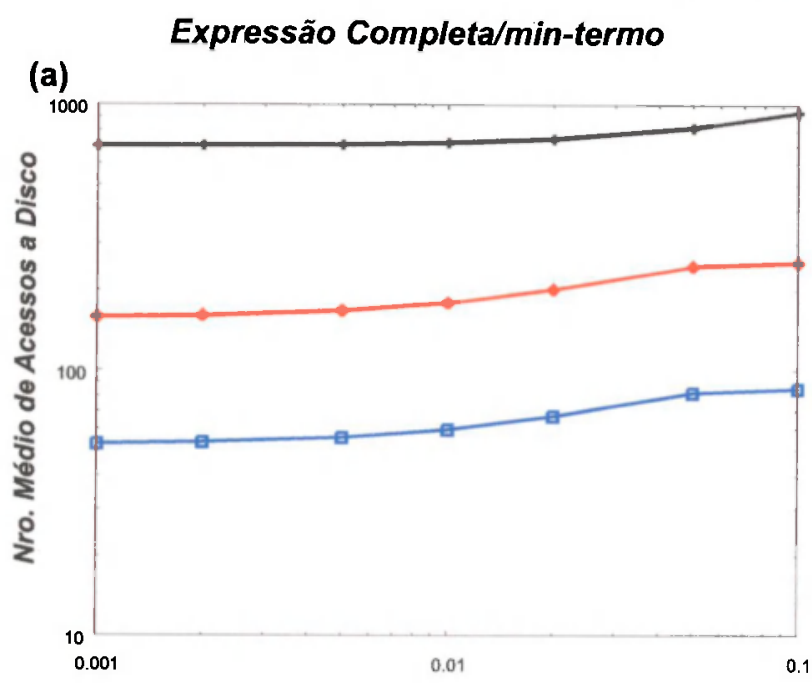

(b)

Min-termo e seus componentes
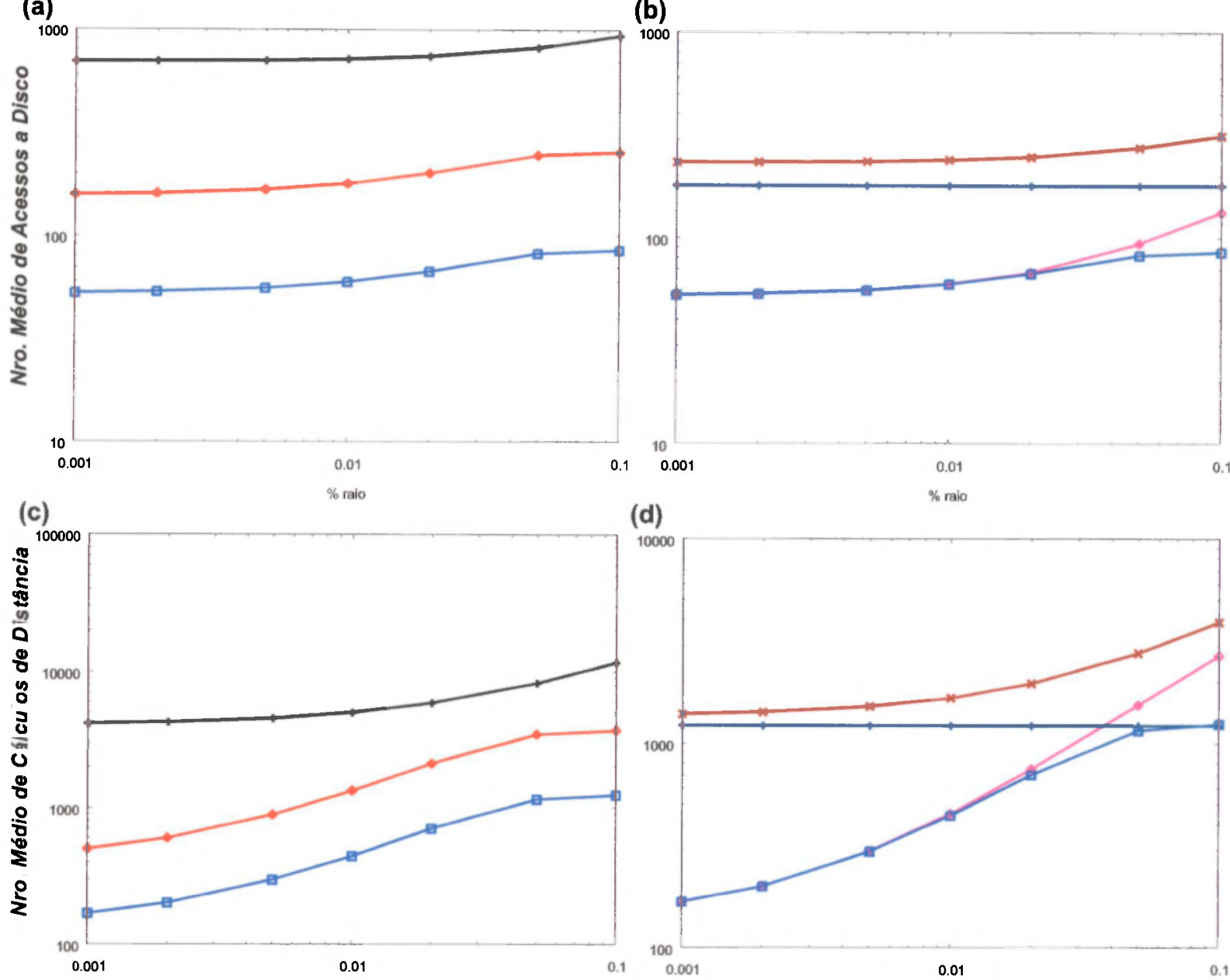

(d)

(e)

\% raio
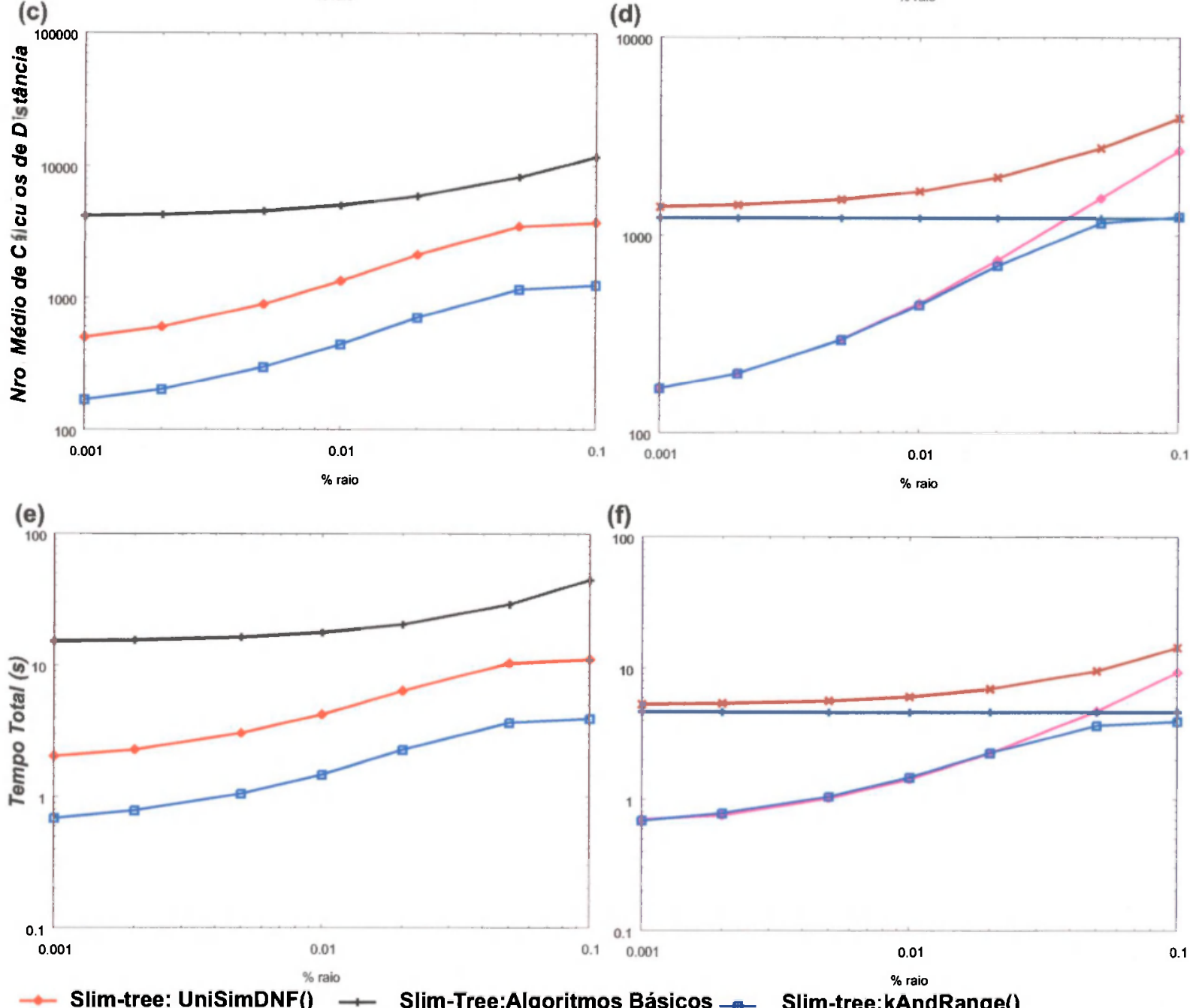

(f)

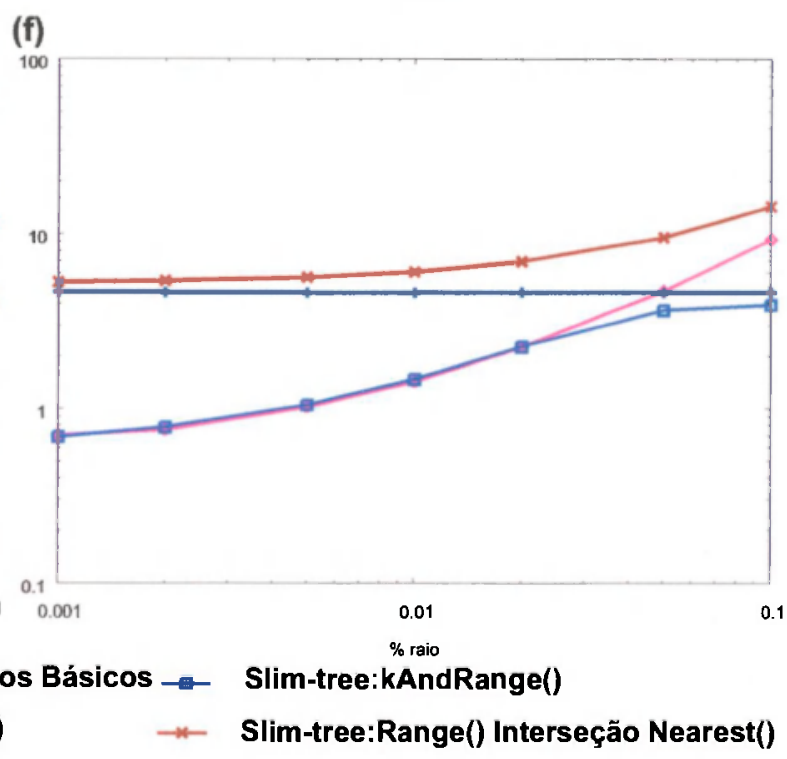

$\rightarrow$ Slim-tree: Range()

$\rightarrow$ Slim-Tree:Nearest()

\#- Slim-tree:Range() Interseção Nearest()

Figura 6.14: Avaliação da consulta MCMP $\left(\sigma_{\left(R q\left(e_{1}, r\right)\right.} S \cap \sigma_{\left(10 N N\left(e_{1}\right)\right.} S\right) \cup\left(\sigma_{\left(R q\left(e_{2}, r\right)\right.} S \cap\right.$ $\left.\sigma_{\left(10 N N\left(e_{2}\right)\right.} S\right) \cup\left(\sigma_{\left(R q\left(e_{3}, r\right)\right)} S \cap \sigma_{\left(10 N N\left(e_{3}\right)\right.} S\right)$ equivalente à consulta Q5 da Seção 1.3 onde são comparados a execução da consulta MCMP completa com apenas um min-termo considerando o número médio de acessos a disco (gráficos (a) e (b) ), número médio de cálculos de distância (gráficos (c) e (d) ) e tempo total de processamento (gráficos (e) e (f) ) para 500 consultas, utilizando a Slim-tree no conjunto de dados MetricHisto com o valor de $k$ igual a 10 . 
o raio r émaior.

\subsubsection{Escalabilidade dos Algoritmos Propostos}

Nesta últinn bateria de testes relacionados aos algoritmos propostos é avaliado o comportamento dos algoritmos para consultas por similaridarle complexas formando expresssões SCMP em relação an tamanho do conjunto. Assim, os algoritmos $k$ AndRange() e kOrRange() são avaliados utilizando a Slim-tree e a SeqScan para o conjunto de dados Sintético30D com 1.000.000 de objetos no espaço 30-dimensional comparando-os com os respectivos algoritmos básicos. () processo nuilizado para gerar esse comjunto é descrito cm [Santos Filho, 2003], onde a única diferença ć o múmoro total do objetos ${ }^{2}$.

Todos os objetos do conjunto foram considerados durante o processo de amostragem dos daclos para escolher os objetos do reforencia (500 objotos foram escolhidos aleatoriamente). () conjunto foi divido em 20 partes e, após cada $14 m$ vinte avós inserido (50.000 objetos), a amostra foi utilizada para efetuar 500 consultas com diferentes raios o valores de $k$. O comportamento das diferentes operóns se mostrou semellante para ow diferentes valores de raio $r$ e de $k$ e, portanto, é apresentado apenas um exemplo de cada tipo de consulta por similaridade complexa SCMP, com número de vizinhos igual a 15 $(k-15)$ o raio ignal a $0,02(r=-0,02)$.

As Figuras 6.15 e 6.16 ilustram, respectivamente, a escalabilidade para os algoritmos $k$ AndRange() o $k$ OrRange() em relação aos algoritmos básicos, considerando os três aspectos medidos nos experimentos desta tese.

Como pode ser observado nos gráficos das Figuras 6.15 e 6.16 , os algoritmos kAndRange() e kOrRange() apresentam um comportamento sub-linear em relação ao tamanho do conjunto de dados em todos os aspectos medidos para a Slim-iree o um comportamento lincal para a SépScan. Isso mostra que os algoritmos nomativos propostos são adequados atcé mesmo para grandes conjuntes de deados.

\subsubsection{Fórmulas de Estimativa de Seletividade Propostas}

As Figuras 6.17 e 6.18 contrapõem a cardinalidade estimada utilizando as fórmulas propostas nesta tese e a cardinalidade real obticla spós a execução da consulta por similaridade complexa para os conjuntos de dados testados. As fómmulas de estimativa de seletividade utilizadas nos testes são:

- Seletividade 6 para consultas SCSP om DNF do tipo $\sigma_{\left(R q\left(s_{q}, r_{q}\right)\right.} S \wedge \sigma_{\left(\neg R q\left(s_{q}, r_{i}\right)\right.} S$ semelhantes à consulta Q6 da Seção 1.3:

\footnotetext{
${ }^{2}$ Basicamente o vetor Sintético 300 é construido da seguinte maneira. As 5 primeiras coordenadas (de 0 a 4) correspondem a pontos uniformemente distribúdes ao longo da diagonal de um hipercubo 5-dimensional; as 1 seguintes (do 5 a 8) correspondem a coordenadas de pontos uniformemente distri buítos ao longo da diagonal de um hipercubo 4-dinetsional; os valores da coordenada seguinte (a 9) foram gerados aleatoriamente; as 20 restantes (de 10 a 29) correspondem a combinaçoes lineares de suas antecessoras.
} 

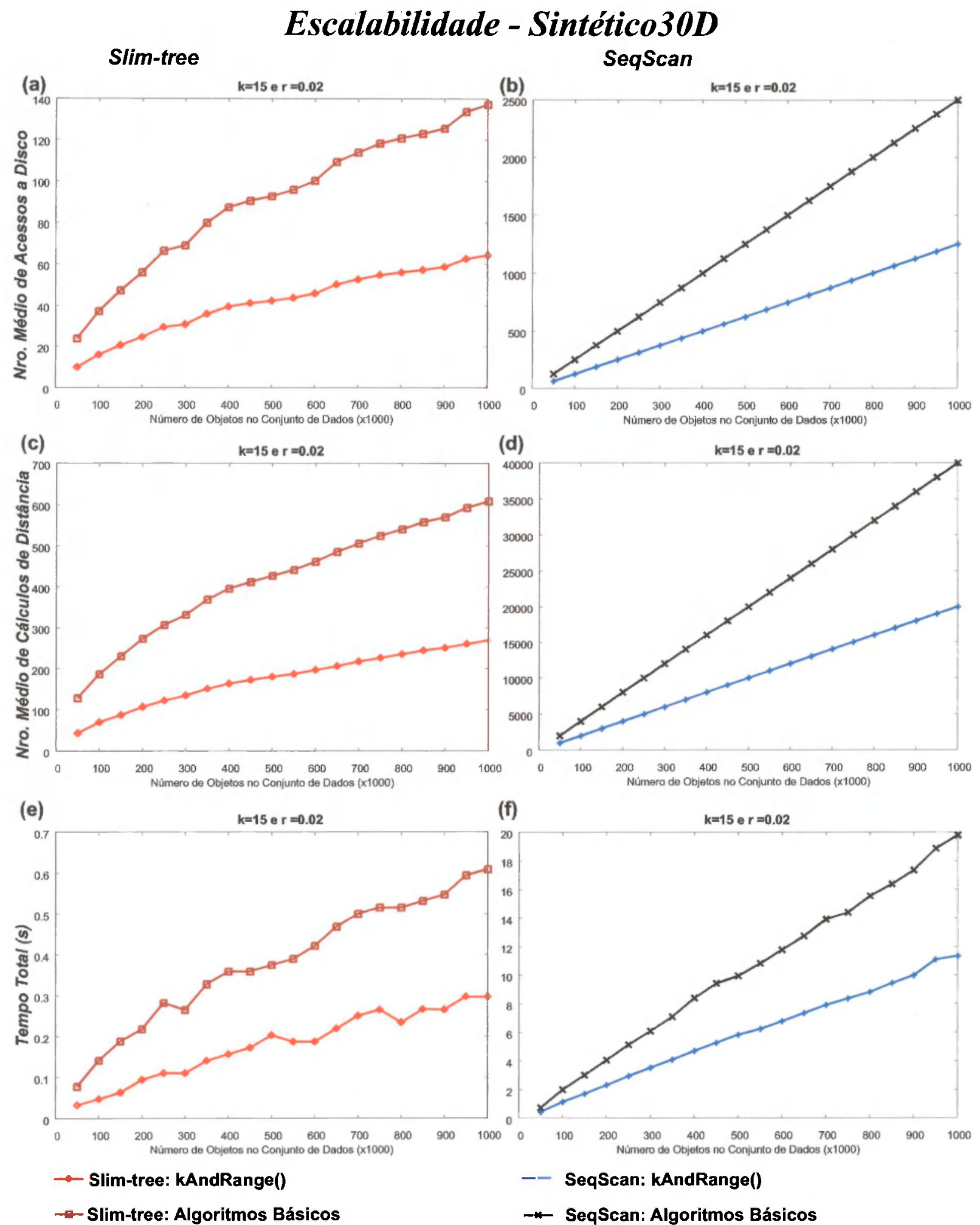

Figura 6.15: Escalabilidade do algoritmo $k$ AndRange() utilizando tanto uma lista sequencial (SeqScan) quanto a estrutura de indexação Slim-tree sobre o conjunto Sintético30D com $k=15$ e $r=0,02$. Em (a) e (b) é mostrada a escalabilidade, considerando acessos a disco; em (c) e (d) tem-se a escalabilidade para cálculos de distância; e, em (e) e (f) a escalabilidade para tempo total de processamento. 

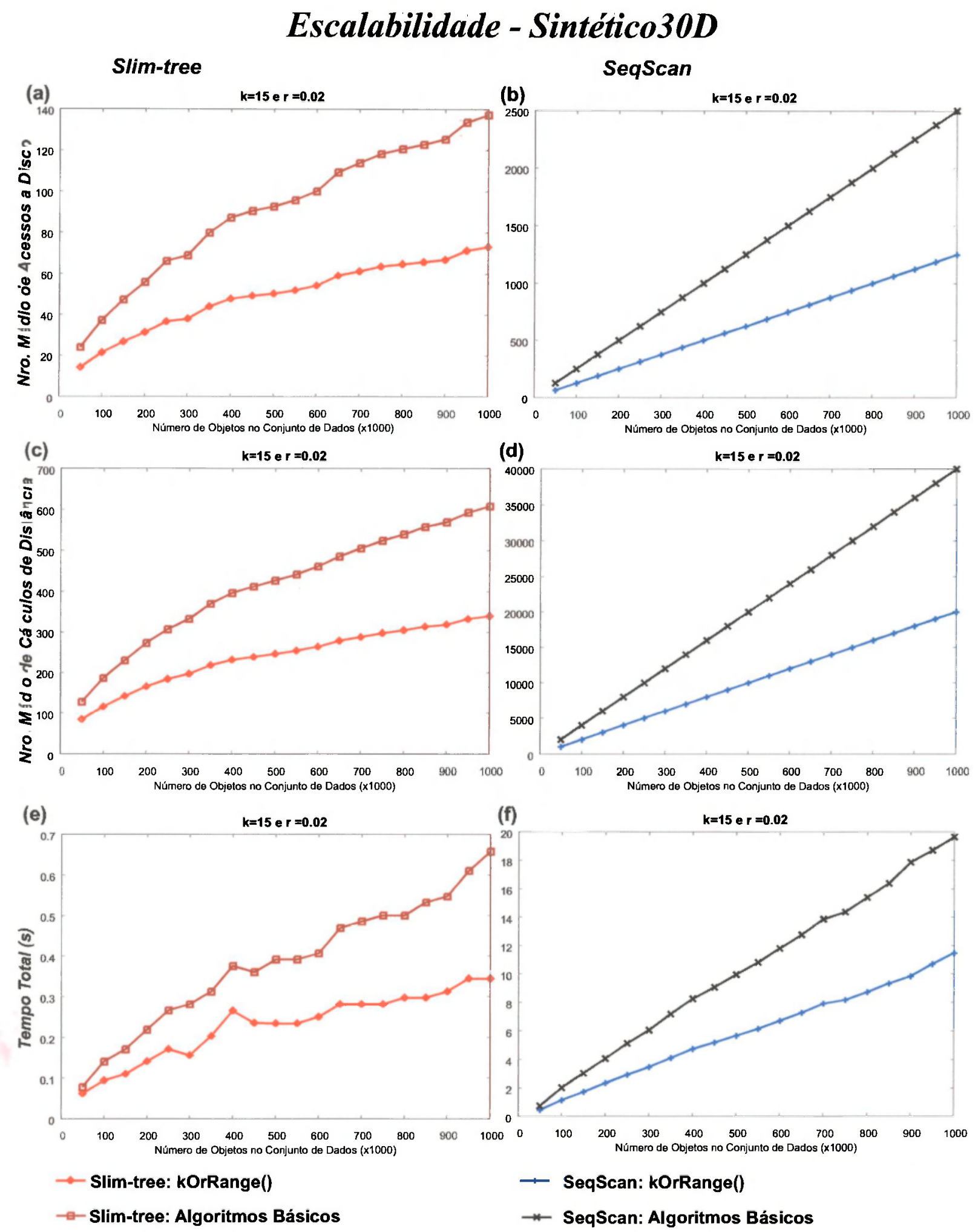

Figura 6.16: Escalabilidade do algoritmo kOrRange() utilizando tanto uma lista seqüencial (SeqScan) quanto a estrutura de indexação Slim-tree sobre o conjunto Sintético30D com $k=15$ e $r=0,02$. Em (a) e (b) é mostrada a escalabilidade, considerando acessos a disco; em (c) e (d) tem-se a escalabilidade para cálculos de distância; e, em (e) e (f) a escalabilidade para tempo total de processamento. 

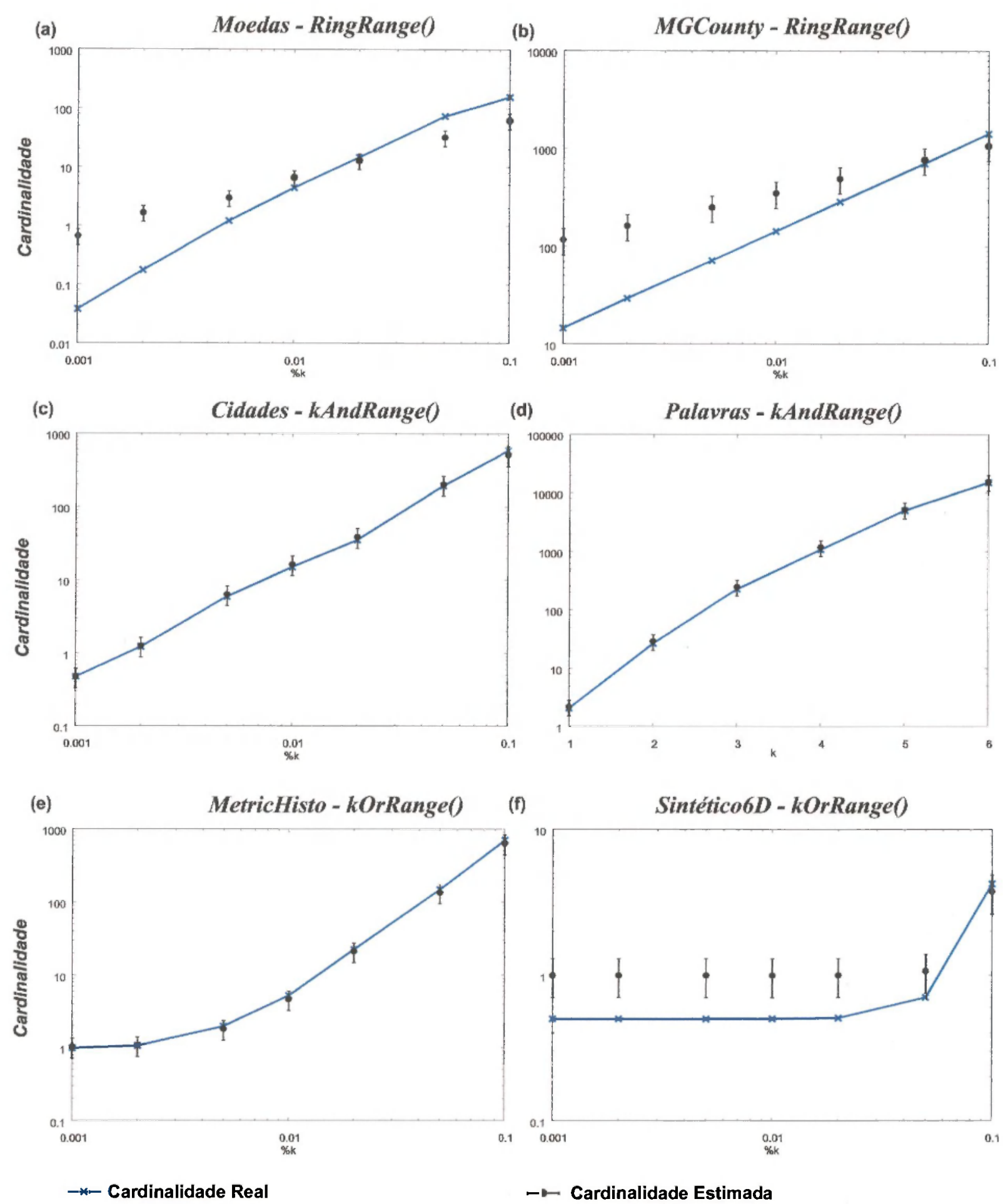

Figura 6.17: Avaliação das fórmulas de estimativa de seletividade usando o modelo baseado na teoria de fractais. Gráficos comparando a cardinalidade estimada, usando as fórmulas propostas com um erro de $30 \%$ e a cardinalidade real. Em (a) e (b) a Seletividade 6 foi utilizada para obter a cardinalidade estimada de uma consulta SCSP, respondida pelo algoritmo RingRange(); Em (c) e (d) a Seletividade 7 foi utilizada para obter a cardinalidade estimada de uma consulta SCMP em DNF, respondida pelo algoritmo $k$ AndRange(); e, em (e) e (f) a Seletividade 9 foi utilizada para obter a cardinalidade estimada de uma consulta SCMP em CNF, respondida pelo algoritmo kOrRange(). 

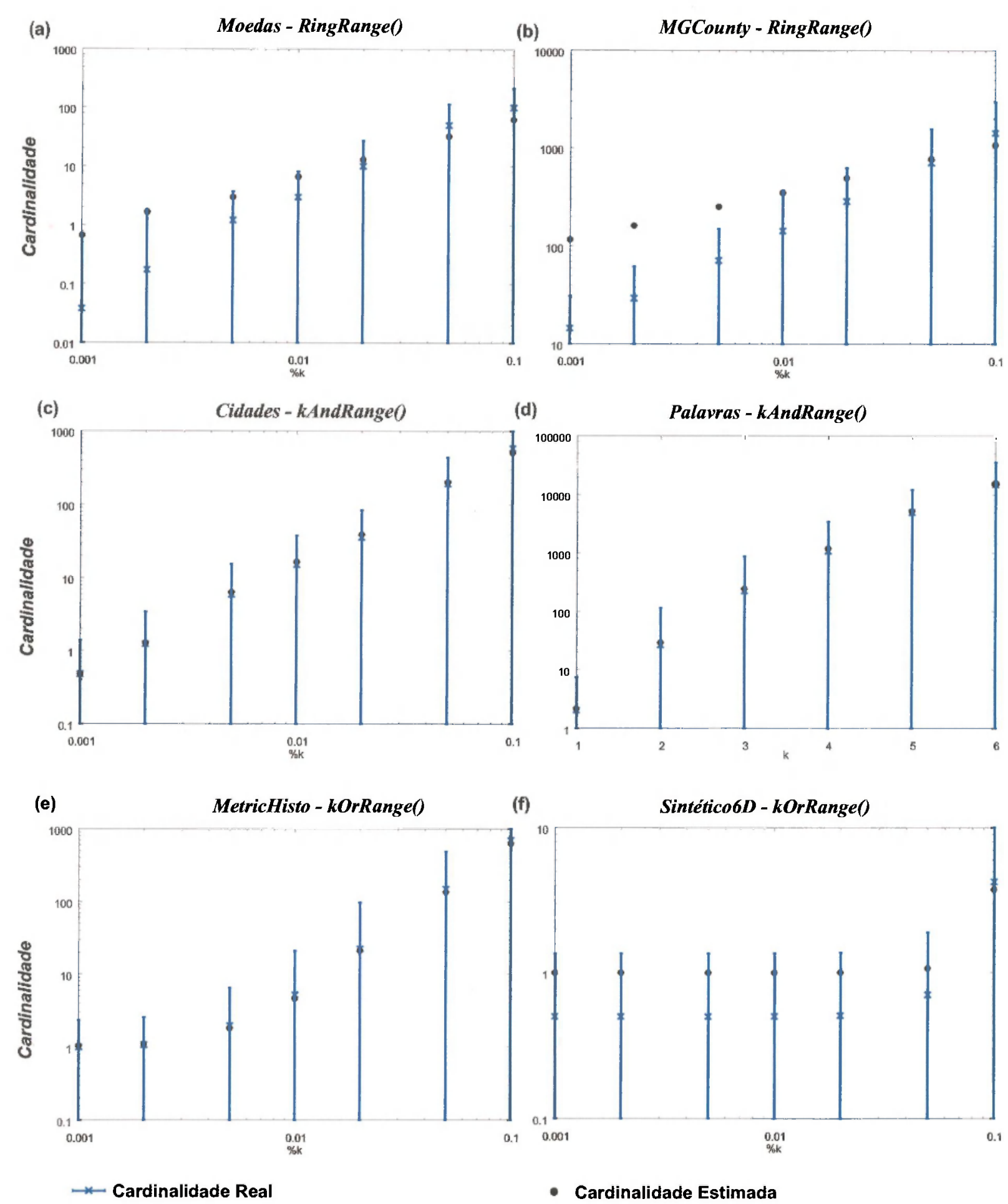

Figura 6.18: Avaliação das fórmulas de estimativa de seletividade usando o modelo baseado na teoria de fractais. Gráficos comparando a cardinalidade estimada, usando as fórmulas propostas e a cardinalidade real, considerando o desvio padrão. Em (a) e (b) a Seletividade 6 foi utilizada para obter a cardinalidade estimada de uma consulta SCSP, respondida pelo algoritmo RingRange(); Em (c) e (d) a Seletividade 7 foi utilizada para obter a cardinalidade estimada de uma consulta SCMP em DNF, respondida pelo algoritmo $k$ AndRange(); e, em (e) e (f) a Seletividade 9 foi utilizada para obter a cardinalidade estimada de uma consulta SCMP em CNF, respondida pelo algoritmo kOrRange(). 
- Seletividade 7 para consultas SCMP em DNF do tipo $\sigma_{\left(R q\left(s_{q}, r\right)\right)} S \wedge \sigma_{\left(k N N\left(s_{q}\right)\right)} S$ scmolhantés às consultas Q1 Q Q3;

- Seletividade 9 para consultias SCMP em CNF do tipo $\sigma_{\left(R_{q}\left(s_{q}, r\right)\right)} S \vee \sigma_{\left(k N N\left(s_{q}\right)\right.} S$ scmelhantes à consulta Q2.

Este conjunto do experinentos foi realizado da seguinte forma. No cixo das abscissas está o número de vizinhos $k$ que varia. Isso foi feito para que, em consultas SCMP, o conjunto de 500 consultas fosse igualmente dividido nos três casos possíveis ilustrados pelas Figuras 4.4 e 4.6. Portanto, medidas preliminares foram realizadas em todos os conjuntos para que os raios de consulta fossem definidos em função do número de objetos descijados para cada consulta. Por excuplo, para una consultia SCSP avaliada, primeiro foi determinado o valor do raio $r_{e}$ para que ela retornasse $0,1 \%$ dos objetos do conjunto de dados. Em seguida, o raio interno $r_{i}$ foi determinado em função de $r_{e}$, couforme descrito na Segão 6.2, e. após isso, a consulta foi executada. Isso foi feito para o conjunto de 500 consultas em todos os pontos medidos. Para consultas SCMP, a idéia é que, obtendo o raio do $k$-ísimo elemento descjade, pode-se ajustar o raio clo predicade range de modo a contemplar os três casos possíveis entre os valores limites dos predicados range e $k$-nearest $\left(u_{i} / v_{i}\right)$ para uma consulta SCMP, isto é, $u_{i}<v_{i}, u_{i}>v_{i}$ e $u_{i}=v_{i}$. Isso foi feito com o objetivo de tomar a comparação mais justa, uma vez que dessa maneira o conjunto de 500 consultas contempla os três casos possíveis.

A Figura 6.17 ilustra a comparação entre as cardinalidades estimada considerando um erro de $30 \%$ e a cardinalidade real, num processo de avaliação semelhante ao apresentado em [Belussi \& Faloutsos, 1995]. Os gráficos (a) e (b) mostram os resultados obtidos para as consultas executadas polo algoritmo RingRange() sobro os conjuntos do dados Moedas e MGCounty, (c) e (d) para as consultas executadas pelo algoritmo $k A$ ndRange() sobre os conjuntos de dados Cidades e Palavras, e (e) e (f) para as consultas executadas pelo algoritmo $\mathrm{kOr}$ Runge() sobre os conjuntos de dados MetricHisto o Sintético6D.

As estimativas feitas para as consultas executadas pelo algoritmo $k$ AndRange() obtiveram os melhores resultados, alcançando un erro médio de $3 \%$ para o conjunto Cidades e de 9\% para o conjunto Palavras (gráficos (c) o (d)). Para os demais conjuntos de dados, a estimativa, usando a Seletividade 7 para as consultas, obteve resultados tão bons quanto os apresentados. Para as consultas SCMP em CNF, as estimativas utilizando a Seletividade 9 também foram boas, porém nião uniformes para todos os conjuntos como a anterior. () gráficos (e) para o conjunto Metrictisto o (f) para o conjunto Sintético6D são uma amostra disso, pois para o conjunto MetricHisto o erro médio é de $5 \%$ e para o Sintético6D é de $70 \%$, com estimativas abaixo dessa média para valores maiores de $k$ ( $10 \%$ para $k=0,1$ por exemplo).

Já para consultas SCSP em DNF, em todos os conjuntos testados a curva referente à cardinalidade estimalia leve un comportanento semelhante aos wráficos (a) e (b) dos conjuntos Moedas e MGCounty das Figuras 6.17 e 6.18. Para valores menores de $k$, os resultados não são tão precisos, mqunuto que para valores maiores as estimativas en- 
tram dentro da faixa de erro, obtendo um erro de apenas $9 \%$ para o conjunto MGCounty $(k=0,05)$. Os erros médios da cardinalidarle estimada on relação à real são de $350 \%$ para o conjunto Moedas e de $200 \%$ para o conjunto MGCounty.

A Figura 6.18 apresenta as cardinalidades estimada e a cardinalidade real considerando o desvio padrão em relação à cardinalidade real, mostrando um processo de avaliação semelhante ao apresentado en [Traina Jr. et al., 2002]. Os valores de cardinalidade tanto estimada quanto roal săo os mesmos nas Figuras 6.17 e 6.18 e os conjuntos de dados também. Na Figura 6.18. ó interessante notar que os valores de cardinalidade cstimada estão dentro do desvio padrão mesmo para consultas SCSP. Isso mostra que a densidade dos objetos do conjunto de amostra é bem diversificada. pois o desvio padrão foi alto cm todos os conjuntos testados tanto que o seu valor mínimo é próximo de zero. Essa não é a melhor configuração para obter resultados com monores taxas do orro, tais como os apresentarlos em [Belussi \& Faloutsos, 1995], porém corresponden a sitnaciones reais. No trabalho de Belussi \& Faloutsos, 1995] resultados muito bons foram obtidos considerando que uma amostra do conjunto de objetos está em uma região de alta densidade e, por consequiência, com um desvio padrão bem menor do que o aprescntiado nesta tese.

Os resultados mostram que as estimativas feitas para as consultas por similaridade complexas nos conjuntos testados estão dentro de luna faixa prevista (ver Figura 6.18). mesmo aquelas que apresentaram um erro muito grancle nos testes, mostrados na Figura 6.17. Isso ilustra que as consultas apresentam muita variabilidade e, para um modelo de seletividade que considera as propriedades gerais do conjunto como um todo, como é o caso do modelo adotado nesta tese, é difícil alcançar resultados mais precisos do que o obtido. Una possível solucä́o pode vir de modelos que considerem a densidarle local. Embora estudos iniciais tenhan sido feitos nessà direção [Arantes et al., 2003b], esse atssunto está além do escopo dessa tese e não é tratado.

Portanto, como o objetivo desta tese não é medir a precisão do modelo baseado na teoria de fractais, mas sim validar os conceitos que proporcionaram derivar as fórmulas de estimativa de seletividade para consultas por similaridade complexas, apenas a amostra liversificarla apresentada nesses testes foi considerada e os resultados alcançades säo satisfatórios.

\subsection{Conclusão}

Os resultados experimentais dos algoritmos normativos para consultas por sinilaridade complexas, bem como das fórmulas de estimativa de scletividade desenvolvidas para essas (consultas estão aprescontadlas neste capítulo.

Nesses experinentos, os algoritmos normativos são comparados com os respectivos algoritmos básicos para responder a consultas por similaridade complexas do tipo SCSP, SCMP e MCMP, ntilizando uma lista següencial o a estrutura de indexação métrica 
Slim-tree para conjuntos de dados reais e sintéticos. Os resultados alcançados mostraram (1ue os algoritmos nomativos para consultas por similaridarle complexas são bem mais eficientes que os algoritmos básicos em todos os aspectos medidos para todos os conjuntos de dados testados. Alguns aspectos específicos são ressaltados nos experimentos, tais como: a comparação de desempenho entre o algoritmo Range() e RingRange() para expressões SCSP; a comparação entre os algoritmos $k$ AndRange() e kOrRange() para valores diferentes de números de vizinhos $k$ : tendo como objetivo ressaltar o aspecto da restritividade entre des (expressôes SCMP); e a comparação entre a expressão MCMP completa e apenas um min-termo dessa expressão, mostrando onde o algoritmo normativo proposto consegue obter um desempenho melhor em relação aos algoritmos básicos. Além disso, os testes confirmam que os algoritmos normativos $k$ AndRange() e kOr Range() são escaláveis em relação ao tamanho do conjunto de dados, apresentando um comportamento sub-linear, para a Slim-tree conforme mostrado.

Para as fórmulas de estimativa de seletividade desenvolvidas, os experimentos conparan a cardinalidade estimada obtida por cssas fórmulas com a cardinalidade real da consulta por similaridade complexa em expressões SCSP e SCMP, considerando um erro módio e o desvio padrão. Resultados expressivos são alcançados para expressões SCMP enquanto que resultados não tão precisos são obtidos para cxpressõos SCSP devido à variabilidade da amostra do conjunto de consultas, confonuc discuticlo na Secäo 6.3 .5

Em resumo, os experimentos mostratran fure os algoritmos normativos propostos para ronsultas por similaridade complexas são eficientes c escaláveis e, as fórmulas desenvolvidas para essas consultas usadas em estimativas de seletividade apresentam resultados aceitáveis, podendo ambos sercm utilizados em um gerenciador relacional com suporte a dados complexos. 
Capítulo

\subsection{Considerações Finais}

$4 \begin{aligned} & \text { tualmente, tipos de dados mais complexos que os convencionais, tais como } \\ & \text { dados multimídia, cadeias do DNA, entro outros, estão sendo armazcnados } \\ & \text { em gerenciadores. Para esses dados, a similaridade entre pares de elementos }\end{aligned}$ é a relação mais natural, possibilitando a realização de consultas utilizando este fator. Domínios métricos admitem consultas por similaridade que podem ser respondidas de maneira eficiente utilizando MAMs. Os tipos de consultas por similaridade mais comuns são: por abrangência e aos $k$-vizinhos mais próximos.

Consultas por similaridade têm sido consideradas como equivalentes ao operador de solecão para dados convencionais, porém para que essas consultas possan ser incorporadas em gerenciadores relacionais, alóm de algoritmos eficientes específicos para cada uma dessas consultas usando mótodos de acesso para dados complexos, é necessário fornecer suporte a consultas por similaridade no processamento de consultas de un gerenciador relacional.

Isso implica em permitir que: consultas por similaridade sejam expressas na linguagem nativa do gerenciador possibilitando a sud composicano em oxpressoes mais complexas: as expressões envolvendo os dois tipos de predicados por similaridade possam ser otimiZadas; e algoritmos respondam às consultas por similariclade complexas eficientemente.

Dentro do contexto necessário para dar suporte a consultas por similaridade complexas em gerenciadores relacionais, esta tese responde a cinco questöes principais, apresentadas na Secão 1.4. O ponto limdamental para responder às questóns da Seção 1.4 ó como analisar una consult a por similaridade envolvendo mais de um predicado básico por similaridarle. Partindo desse príncipio, as questões levantadas são resolvidas conforme se 
discute a seguir.

A terceira questrão, "Como representar uma consulta em uma forma normal, ade(quada a ser submetida aos algoritmos de busca por similaridade", é resolvida dividindo o problema de analisar expressōes por similaridade complexas em três passos: Mesmo Centro/Mesmo Tipo de Prodicado (Single Center/Single Predicate - SCSP); Mesmo Centro/Tipos de Predicados Diferentes (Single Center/Multiple Predicate types - SCMP); e Múltiplos Centros/Tipos de Predicados Diforentes (Multiple Centers/Multiple Predicate (ype's- MCMP).

Seguindo esta abordagem, regras para simplificar uma expressão por similaridade complexa são obtidas diretamente, resolvendo a segunda questão "Quais regras são necessúrias para guiar o processo de otimização de consultas na geração de estratégias alternativas de execução para consultas por similaridade:. Essas regras permitem representar qualquer expressão de consulta por similaridade complexa de tal modo que algoritmos podem ser executados com uma complexidade linear em relação ao número de elementos envolvidos.

De fato, utilizando essas regras para desenvolver algoritmos para consultas por similaridade complexas, foi possível identificar que quatro algoritmos, entre os apresentados no Capítulo 4, são suficientes para responder a qualquer consulta por similaridade complexa envolvendo os predicados range e $k$-nearest com suas respectivas variações, resolvendo assim a primcira questão, "Como escolher quais algoritmos são necessários para responder a consultas complexas, envolvendo conjunçöes e disjunçós de predicados por similaridade".

Portanto, uma extensão ì álgebra relacional para fornecer suporte a consultas por similaridade é apresontada, juntamente com um pequeno conjunto de algoritmos baseados em similaridade os quais são simples e genéricos, e podem ser construídos para responder a qualquer consulta por similaridade complexa (m un tempo linear.

As regras algébricas apresentadas para simplificar uma expressão por similaridade complexa permitem que o Otimizador, mais especificamente o Gerador de Planos, possa gerar múltiplas representações para uma consulta. O Otimizador, tendo as várias representaçóes equivalentes de uma consulta, pode estimar o custo de cada uma delas, escolhendo o de monor custo computacional. Dentro desse processo, csta tese aborda estimativas de seletividade que são utilizadas pelo módulo Estimador de Planos do Otimizador para avaliar o custo de um plano de consulia, visando a responder às últimas duas questoones levantadas na Secão 1.4 para consultas por similaridade complexas.

Entre os modelos de seletividade propostos na literatura, o baseado na teoria de fractais tem sido adotado por trabalhos recentes para a análise de conjunto de dados reais e, por isso, foi escolhido cono o modelo do seletividade desta tese, resolvendo assim a quarta questão, "Qual modelo de seletividade poderia ser adotado para consultas por similaridade complexas".

O modo proposto para analisar expressóns por similaridade complexas envolvendo 
os operadores de seleção por similaridade permite também que fórmulas de estimativa do soletividade para consultas por sinilaridado complexas sejan definidas. Essas fómulas são cutão apresentadas, segundo essa abordagem e utilizando o modelo de seletividade arlotado, para resolver a quinta e última questão, "Quais fórmulas são necessárias para. estimar a quantidade de objetos a ser recuperada pelos operadores compostos".

Finalmente, os experimentos realizados mostran a eficiencia e escalibiliclade dos novos algoritmos popostos, bem como avalian as fómmulas de estimativa de seletividade para consultas por similaridade complexas, validando os conceitos aqui apresentados.

Portanto, esta tese contribui para a incorporação de consultas por similaridade complexas em gerenciadores relacionais, pois fornece suporte às camadas Otimizador e Executor do processamento de consultas de um gerenciador relacional por meio de regras

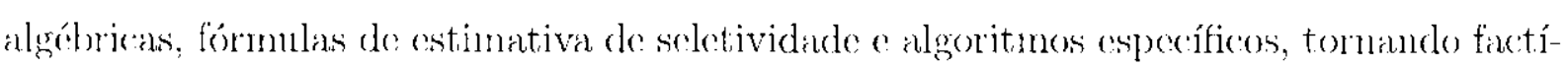
vel a inclusão dessas consultas para dados complexos no núcleo interno de un gerenciador rolarional.

\subsection{Principais Contribuições}

As principais contribuições desta tese de doutorado são:

- Classificação das expressóes por similaridade complexas para o operador cle scleção em três classes: Mesmo Centro/Mesmo Tipo de Predicado (SCSP); Mesmo Centro/Iipos de Predicados Diferentes (SCMP); e Máltiplos Centros/Tipos de Predicalos Diferentes (MCMP);

- Definição de regras algébricas para transformações de expressões compostas pelos dois tipos básicos de predicado por similaridade range e k-nearest. Essas regras podem ser utilizadas na otimização de consultas por similaridade complexas, considerando expressões SCSP, SCMP c MCMP em DNF (Forma Normal Disjuntiva), formando assim o Espaço Algébrico de um Otimizador de comsultas baseado em similaridade:

- Definição de um conjunto pequeno de algoritnos, mas abrangente o suficiente, para responder a cuadequer consult a por similaridade complexa cnvolvendo os predicados range e $k$-nearest. Esses algoritmos, que podem estar presentes no Executor de um gerenciador relacional, são: Generichange(), GenericNourest(), UniSimDNF() e GenSimDNF();

- Definicara de fómulins de estimativa de seletividade para expressocs SCSP e SCMP cm DNF utilizando o modelo de seletividade baseado na teoria de fractais.

- Implementacão dos algoritmos normativos propostos para expressós SCSP a SCMP para o MAM Slim-tree e para a lista sequiencial na bilioteca de MAMs Arboretum; 
As principais contribuições desta tese de doutorado podem ser detalhadas nos seguintes itchn:

- Definição de uma representação formal para as variações dos tipos de predicados básicos e do algoritmos correspondentes para executá-los;

- Demonstração de que os operadores de seleção por similaridado básicos formam uma álgebra Booleana ce, assinn, podem ser incluídos ná álgebra relacional;

- Proposta de uso dos principais operadores de seleção por similaridade como parte da álgetbra relaciomal;

- Definição de min-termos em DNF para consultas por sinuilaridade complexas em expressões SCSP, SCMP o MCMP:

- Definição da consulta RingRange para expressóes SCSP e desenvolvimento do algoritmo RingRange() para essia consulta:

- Desenvolvimento do algoritmo GenericRange() apto a responder uma expressão de consulta genérica SCSP em DNF para os predicados range;

- Desenvolvimento do algoritmo GenericNearest () o qual responde a uma expressão de consulta genérica SCSP em DNF para os predicados $k$-nearest;

- Definição da consulta $k$ AndRange para expressões SCMP crn DNF e desenvolvimento do algoritmo $k A n d R a n g e()$ para essa consulta;

- Desenvolvimento do algoritmo UniSimDNF() para responder a unia expressão de consulta genérica SCMP em DNF:

- Definição dir consulta kOrRange para expressóes SCMP en CNF e desenvolvimento do algoritmo kOrRange() para essa consulta;

- Uso de fatoração para simplificar uma expressão por similaridade complexa em MCMP;

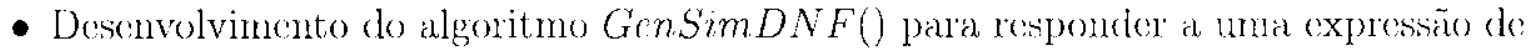
consulta genérica MCMP con DNF:

- Utilizarãa da teoria de fractais como modelo de seletividade adotado para expressócs por similaridade complexas que poderia ser incluído no nódulo Estimador EspaçoDistribuição de um gerenciador relacional; 


\subsection{Proposta para Trabalhos Futuros}

O trabalho realizado por esta tese de doutorado proporciona que novas frentes de pesquisa possam ser desenvolvidas, entre elas estão:

- Extensão do Espaço Algébrico proposto para a incorporação de operador do jun(rĩo por similaridade;

- Extcusão do Espaço Algébrico proposto para consultas, convolvendo operadores. de seleção por sirnilaridade c por rolação de ordem num mesmo comando;

- Definição de estimativas de custo para as novas consultas propostas neste trabalho: RingRange, kAndRange e KOrRange;

- Desenvolvinento de algoritmos mais específicos para consultas por similaridade complexas para expressões SCMP em DNF;

- Desenvolvimento de algoritmos específicos para consultas por similaridade complexas com múltiplos centros e mesmo tipo de predicado:

- Definição de um conjunto de heurísticas para simplificar expressões MCMP além da já proposta. Essas heurísticas seriam utilizadas na preparação da expressão a ser executada pelo algoritmo GenSimDNF();

- Desenvolvimento de algoritmos para expressócs por similaridade complexas em CNF;

- Desenvolvimento de algoritmos específicos para dar suporte à composição de opcracócs de seleção por similaridade e por relação de ordem num mesmo comando;

- Utilização do modo de análise e dos algoritmos desenvolvidos nesta tese para aplicações envolvendo realimentação por relevância (Relevance Feedback);

- Estudo mais detalhado sobre as operaçoes de união e interseção en espaços nétricos visando desenvolver fórmulas de estimativa de seletividade para expressões MCMP;

- Desenvolvimento do módulo Gerador de Planos de um gerenciador para consultas por similaridade complexas envolvendo o operador de seleção;

- Desenvolvimento de um Otimizador de consultas baseado em sinilaridade considerando os operadores de seleção e junção;

- Incorporação dos pontos abordados nesta tese en un gerenciador relacional. 


\section{Referências Bibliográficas}

[13249-3:2001, 2001] 13249-3:2001, I. (2001). Information technology -- Database Languages - SQL Multimedia and Application Packages - part 3: Spatial - ISO/IEC.

[Adali et al., 1998 ] Adali, S., Bonatti, P. A., Sapino, M. L., e Subrahmanian, V. S. (1998). A multi-similarity algebra. In Proceedings of the ACM Internalional Confercnce on Management of Data (SIGMOD), pp. 402-413, Washington, EUA. ACM Press.

Aggarwal et al., 2001] Aggarwal, C. C., Itinneburg, A., e Kcim, D. A. (2001). On the surprising belavior of distance metries in ligh dimensional spaces. In International Conference on Database Theory (ICDT), pp. 420 434, Londres, UK. Springer Verlag.

[Antoshenkov \&. Ziandelin, 1996); Antoshenkov, G. o Zianddin, M. (1996). Query processing and optimization in oracle rdb. The Intcrnational Journal on Very Large Data Bases (The VLDB Journal), 5(4):229-237.

[Arantes et al., 2003a] Arantes, A. S., Vieira, M. R., Traina, A. J. M., e Jr., C. T. (2003a). The fractal dimonsion making similarity queries more efficient. In II Workshop on Fraclals, Power Laws and Other Next Generation Data Mining Tools. In conjunction with 9th ACM International Conference on Knowledge Discovery and Data Mining $(S I C K D D)$, pp. 12--17, Washington, ECA. ACM Press.

[Arantes et al., 2003b] Aranl.es, A. S., Vicira, M. R., Traina Jr., C., e Traina, A. J. M (2003b). Operadores de sclegão por similaridade em sistemas de gerenciamento de bases de dados relacionais. In XVIII Simpósio Brasileiro de Banco de Dados (SBBD), pp. 341 355, Manaus, Brasil. UFAN.

[Arantes et al., 2004] Arantes, A. S., Vieira, M. R., Traina Jr., C.. e Traina, A. J. M. (2004). Efficient algorithns to execulc complex similarity queries in rdbms. Journal of the Brazilian Computer Socicty (JBCS), 9(1):5-24.

[Araujo et al., 2002] Araujo, .M. R. B., Traina, A. J. M., e Traina, Cactano, J. (2002), Extcnding SQL to support image content-based retricval. In Proceedings of the IASTED 
International Conference on Information Systerns and Databases (ISDB), pp. 19-24. Tóquio, Japáo. Acta Press.

[Arcf \& Samet, 1991] Aref, W. G. e Samet, H. (1991). Optimization strategies for spatial query processing. In Proceedings of the International Conference on Very Large Data Bases (VLDB), pp. 81 90, Barcelona, Espanha. Morgan Kaufmann.

[Atnafu et al., 2001] Atnafu, S., Brunie. I., e Kosch. H. (2001). Similarity-based operators and query optimization for multimedia database systems. In Proceedings of the International Database Engineering \&3 Applications Symposium (IDEAS), pp. 346-355, Grenoble, França. IEEE Computer Society.

[Azevedo-Marques et al., 2002] Azevedo-Marques, P. M., Traina, A. J. M., Jr., C. T., e Bueno, J. M. (2002). The metric histogram: A now and efficient approach for contentbased inage retrieval. In IFIP Working Conference on Visual Database Systems (VDB), pp. 297-311, Brisbane, Austrália. Kluwer.

[Belussi \& Faloutsos, 1995] Belussi, A. e Faloutsos, C. (1995). Estimating the selectivity of spatial queries using the 'corrclation' fractal dincusion. In Proceedings of the Internalional Conference on. Very Large Data Bases (VLDB), pp. 299 310, Zurich, Suíça. Morgan Kaufmann.

[Belussi \& Faloutsos, 1998] Belussi, 1. e Faloutsos, C. (1998). Self-spacial join selectivity estimation using fractal concepts. ACM Transactions on Information Systems (TOIS), $16(2): 161201$.

[Benctis et al, 2002] Benetis, R., Jensen, C. S., Karciauskas, G., o Saltenis, S. (2002). Nearest neighbor and reverse nearest noighbor queries for moving objects. In Prorerdings of the International Database Engineering 83 Applications Symposium (IDEAS), pp. 44 53, Edmonton. Canadá. IEFF Computer Society.

[Berchtold et al., 1997] Berchtolı, S., Böhm, C., Braunmüller, B., Keim, D. A., e Kriegel, H.-P. (1997). Fast parallel similarity search in multimedia databases. In Proceedings of the ACM International Conference on Management of Data (SIGMOD), pp. 1-12, Tucson, EUA. ACM Press.

[Beyer et al., 1999] Beyer, K., Godstein, J., Ramakrishnan, R., e Shaft, U. (1999). When is "nearest neighbor"meaningful? In Proceedings of the International Conference in Database Theory (ICD'T): pp. $217-235$, Jerusalém, Israel. Springer.

[Birkhoff \& Bartec, 1970] Birkhoff, G. e Bartee, T. C. (1970). Moder Applicd Algetrra. McGraw-Hill Book Company, Now York.

[Bozkaya \& Özsoyoglu, 1997] Bozkaya, T. e Özsoyoglu, Z. M. (1997). Distance-based indexing for ligh-dimensional metric spaces. In Procedings of the ACM International 
Conference on Management of Data (SIGMOD), pp. 357 368, Tucson, EUA. ACM Press.

[Braunmüller et al., 2000] Braunmüller, B., Ester, M., Kricgel, II.-P., e Sander, J. (2000). Efficiently supporting multiple similarity cuueries for mining in metric databases. In Procedings of the International Conference on Data Engineering (ICDE), pp. 256267. San Diego, EUA. IEEE Computer Society.

[Burkhard \& Keller, 1973| Burkhard, W. A. e Keller, R. M. (1973). Some approaches to best-match file scarching. Communicalions of the ACM, 16(4):230 236.

Böhm et al., 2001] Böhm, C., Berchtold, S., e Keim, D. (2001). Searching in highdinensional spaces - index structures for improving the performanee of multimedia datablatses. ACM Computing Surveys (CSUR), 33(3):322 373.

Böhm et al., 2000] Böhm, C., Berchtold, S., e Keim, D. A. (2000). Cost model for query processing in high dimensional data spares. ACM Trunsactions On Database Systems (TODS), 25(2):129-178.

[Camastra \& Vinciarelli, 2001] Camastra, F. o Vinciarelli, $\Lambda$. (2001). Intrinsic dimension estimation of data: An approach based on grassberger-procaccia's algorithm. Neural Processing Letters, 14(31):27 34 .

[Chaudhuri, 1998] Chaudhuri, S. (1998). An overview of query optimization in relational systems. In Procedings of the ACM SIGACT-SIGMOD-SIGART Symposium on Principles of Database Systems (P'ODS): pp. 34 43, Scattle, EUA. ACM Presi.

[Chandhuri et al., 2003] Chaudhuri, S., Ganesan, P., e Sarawagi, S. (2003). Factorizing complex predicates in querios to exploit indexes. In Proceedings of the ACM International Conference on Management of Data (SIGMOD), pp. 361-372, San Diego, EUA. ACM Press.

[Chaudhuri \& Gravano, 1996] Chatudhuri, S. e Gravano, L. (1996). Optinizing queries over multimedia repositories. In Procedings of the ACM International Conference on Management of Data (SIGMOD), pp. 91 102. Montreal, Canadá. ACM Press.

[Chandhuri \& Shim, 1999] Chaudhuri, S. o Shim, K. (1999). Optimization of guerios with user-defined predicates. ACM Transactions on Database Systems (TODS), 24(2):177 228.

[Chávez et al., 2001] Chávez, E., Navarro, G., Bacza-Yates, R., c Marroquín, J. L. (2001). Searching in metric spaces. ACM Computing Surveys (CSUR), 33(3):273 321.

[Chen \& Roussopoulos, 1994] Chen, C. M. e Roussopoulos, N. (1994). Adaptive selectivity estimation using cuery fecdlack. In l'rocecdings of the ACM Intcrnalional Conference on Management of Datu (SIGMOD), pp. 161-172, Minneapolis, ELA. ACM Press. 
[Chino, 2004] Chino, F. J. T. (2004). Visualizando a organizaçào e o comportamento de estruturas metricas: Aplicacoes cm consultas por similaridade. Dissertacian cle mestrado, Universidade de São Paulo, Instituto de Ciências Matemáticas e de Computação, São Carlos, Brasil.

[Ciaccia et al., 1997] Ciaccia, P., Patella, M., e Zezula, P. (1997). M-trec: An efficient. access method for similarity search in metric spaces. In Proceedings of International Confterence on Very Large Data Bases (VLDB), pp. 426-435, Atenas, Grécia. Morgan Kaufrnann.

[Ciaccia et al., 1998] Ciaccia, P., Patella, M., e Zezula, P. (1998). A cost model for similarity queries in metric spaces. In Proceedings of the ACM SIGACT-SIGMOD-SIGART Symposium on Principles of Database Systems (PODS). pp. 59-68, Scattle, EUA. ACM Press.

[Cluct \& Inclobel, 1992] Cluet, S. e Delobe], C. (1992). A general framework for the optimization of object-oriented queries. In Proceedings of the ACM International Conference on Management of Data (SIGMOD), pp. 383-392, San Diego, EUA. ACM Press.

[Codd, 1970] Codd, E. F. (1970). A relational model of data for large shared data banks. Communications of the ACM, 13(6):377387.

[Comer, 1979] Comer, D. (1979). The ubiquitous b-tree. ACM Computing Surveys (CSUR), 11(2):121 137 .

[Dayal, 1987] Dayal, U. (1987). Of nests and trees: A unified approach 1.o process queries that contain nested subqueries, aggregates and quantificrs. In Procedings of the International Conference on Very Larye Dala Bases (VLDB). pp. 197 208, Brighton, Inglaterra. Morgan Kaufmanu.

[Elmasri \& Navathe, 2000, Elmasri, R. e Navathe, S. B. (2000). Fundamentals of Database Systems. Addison-Wesley, third edition.

[Fagin, 1996] Fagin, R. (1996). Combining furay information from multiple systems. In Proceedings of the ACM SIGACT-SIGMOD-SIGART Symposium on Principles of Database Systems (PODS), pp. 216-226, Montreal, Canadá. ACM Press.

[Fagin et al., 1979] Fagin, R., Nievergelt, J., Pippenger, N., e Strong, H. R. (1979), Extendible hashing - A fast access method for dynamic files. ACM Transactions on Database Systems (TOIDS), 4(3):315-344.

[Faloutsos, 1996] Faloutsos, C. (1996). Searching Multimedia Databases by Content, v. 3. Kluwor Academic: Publishers, Boston, EUA.

[Faloutsos, 1997] Faloutsos, C. (1997). Indexing of multimedia data. In Multimedia Databases in Perspectiot, p]) 219 245. Springer Verlag. 
[Faloutsos \& Kamel, 1994] Faloutsos, C. e Kamel, I. (1994). Beyond uniformity and independence: Analysis of r-trees using the concept of fractial dimension. In Procedings of the ACM SIGACT-SIGMOD-SIGART Symposium on Principles of Database Systems (PODS), pp. 4-13, Minneapolis, EUA. ACM Press.

[Faloutsos \& Lin, 1995] Faloutsos, C. e Lin, K.-I. D. (1995). Fast.Map: A fast algorithm for indexing, data-mining and visualization of traditional and multimedia datasets. In Proceedings of the ACM International Conference on Management of Data (SIGMOD), p). 163 174, San Jose, lUA ACM Press.

[Faloutsos et al., 2000] Faloutsos, C., Secger, B., Traina, A. J. M., e Traina Jr., C. (2000). Spatial join selectivity using power laws. In Proceedings of the ACM International Conference on Management of Data (SIGMOD), pp. 177-188, Dallas, EUA. ACM Press.

[Faloutsos et al., 1987] Faloutsos, C., Sellis, T., o Roussopoulos, N. (1987). Analysis of object oriented spatial access methods. ACM SIGMOD Record, 16(3):426-439.

[Flickner \& alli, 1995] Flickner, M. c alli, c. (1995). Query by image and video content: The quic system. IEEE Computer, 28(9):23-32.

[Garcia-Molina et al., 2000] Garcia-Molina, H., Uhman, J. D., o Widow, J. (2000). Database System Implementation. Prentice Hall, first edition.

[Craefe, 1993] Graefe, G. (1993). Query evaluation techniques for large databases. ACM Computing Surmys (CSUR), 25(2):98.

[Hiads et al., 1995] Hians, P., Seshadri, J. F. N. S., e Stokes, L. (1995). Sampling-based estimation of the number of distinct values of an attribute. In Proceedings of the International Conference on Very Large Data Bases (VLDB), pp. 311-322. Zurich, Suíça. Morgan Kaufmann.

Hellerstein \& Stonebraker, 1993] Hellerstein, J. M. e Stonebraker, M. (1993). Predicate migration: Optimizing queries with expensive predicates. In Proceedings of the ACM International Conference on Management of Data (SIGMOD), pp. 267 276. Washington, EUA. ACM Press.

[Hjaltason \& Samet, 1999] Hjaltason, G. R. e Samet, H. (1999). Distance browsing in spatial databases. ACM Transactions on Database Systems ('I'ODS), 24(2):265-318.

[Hjaltasson \& Samet, 20033] Hjaltason, G. R. e Samet, H. (2003). Index-driven similarity search in metric spaces. ACM Transactions Database Systems (TODS), 28(4):517-580.

[Houaiss \& Villar, 2001] Houaiss, A. c Villar, M. d. S. (2001). Dicionário Houaiss da Língua Portuguesa. Objetiva, Rio do Janciro. Brasil. 
[Ioannidis, 1996] Ioannidis, Y. E. (1996). Query optimization. ACM Computer Surveys (CSUR), 28(1):121 123.

[Ioannidis, 2003] Ioannidis, Y. E. (2003). The history of histograms (abridged). In Proceedings of the International Conference on Very Large Data Bases (VLDB). Ten-Year Best Paper Award, pp. 19-30, Berlim, Alemanha. Morgan Kaufmann.

[Jarke \& Koch, 1984] Jarke, M. e Koch, J. (1984). Query optimization in database systems. ACM Computing Surveys (CSUR), 16(2):111-152.

[Johnson \& Shasha, 1989] Johnson, T. e Shasha, D. (1989). Utilization of B-trees with inserts, deletes and modifies. In Proceedings of the ACM SIGACT'SIGMOI)-SIGART Symposium on Principles of Database Systems (PODS), pp. 235 246, Filadélfia, EUA. $\Lambda C M$ Press.

'Kemper et al., 1994] Kemper, A., Moerkotte, G., Peithner, K., e Steinbrumn, M. (1994). Optimizing disjunctive queries with expensive predicates. In Proceedings of the ACM International Conference on Management of Data (SIGMOD), pp. 336-347, Minncapolis, EUA. ACM Press.

[Komper et al., 1992] Kemper, A., Moerkot1e, G., e Stcinbrunn, M. (1992). Optimizing boolcan expressions in object-bases. In Proceedings of the International Conference on Very Large Dula Bases (VILDB), pp. 79 90, Viuncouver, Canarlá. Morgan Kaufmann

[Knuth, 1998] Knuth, D. E. (1998). The Art of Computer Programming, v. 3. AddisonWesley, third edition.

[Korn et al., 2001] Korn, F., Pagel, B., o Faloutsos, C. (2001). On the 'dimensionality curse' and the 'self-similarity blessing'. IEEE 'Transactions on Knowledge and Data Enginecring (TKDE), 13(1):96-111.

[Kom et al., 1996] Konn, F., Sidiropoulos, N., Faloutsos, C., Sirgel, E., e Protopapas, Z (1996). Fast nearest neighbor seareh in unedieal image databases. In P'rocedinges of the International Conference on Very Large Data Bases (VLDB), pp. 215 226. Mumbai (Bombay), Índia. Morgan Kaufmann.

[Kruskal, 1956] Kruskal, J. B. (1956). On the shortest spanning subtree of a graph and the traveling salesman problem. Proceedings of the American Mathematical Socicty, $7: 48-50$

[König \& Weikum, 1999] König, A. C. e Weikum, G. (1999). Combining histograms and parametric curve fitting for feedback-driven cuery result-si\%e estimation. In P'rocedings of the International Conference on Very Large Data Bases (VLDB), pp. 423-434 Erlinburgh, Escócia. Morgan Kaufmann 
[Leslie et al., 1995] Leslie, H., Jain, R., Birdsall, D., e Yaghmai, H. (1995). Efficient search of multidimensional B-tree. In Procedings of the International Conference on Very Large Data Bases (VLDB), pp). 710 -719, San Francisco, EUA. Morgan Kaufmann.

[Levenshtein, 1966] Levenshtein, V. I. (1966). Binary codes capable of correcting deletions, insertions, and reversals. Cybernetics and Control Theory, 10(8):707-710.

[Ling: 1995] Ling, Y. (1995). An evaluation of sampling-based size estimation methods for sclections in database systems. In Procedings of the International Conference on Data Engineering (ICDE), pp. 532-539, 'Taipei, Taiwan. IEEE Computer Society.

[Lipschutz, 1964] Iipschutz, S. (1964). Set Theory and Related Topics. Schaum Publishing Co.. New York

[Lipton \& Naughton, 1990a] Lipton, R. J. e Naughton, J. F. (1990a). Praticial selectivity estimation through adaptive sampling. In Proceedings of the ACM International Conference on Management of Data (STGMOD), pp. 1 11, Atlantic City, EUA. ACM Press.

[Lipton \& Naughton, 1990b] Lipton, R. J. o Naughton, J. F. (1990b). Query sizc estimat tion by aclaptive sampling. In Procecdings of the ACM SIGAC'T-SIGMOD-SIGART Symposium on Principles of Databuse Systems (PODS), pp. 40.46, Nashville, EUA. ACM Press

[Mannino et al., 1988] Mannino, M. V., Chu, P.. e Sager, T. (1988). Statistical profile estimation in database systems. ACM Computer Surveys (CSUR), 20(3):192 221.

[Melton \& Eisenberg, 2001] Melton, J. e Eisenberg, A. (2001). SQL multimedia and application packages (SQL/MM). ACM SIGMOD Record, 30(4):97-102.

[Mohan et al., 1990] Mohan, C., Haderle, I. J., Wang, Y., c Cheng, J. M. (1990). Single table access using multiple indexes: Optimization, execution, and concurroncy comtrol techniques. In Proceedings of the International Conference on Extending Database Technology on Advances in Database Technology (EDBT), pp. 29-43, Veneza, Itália. Springer-Verlag.

[Muralikrishna \& I)ewitt, 1988] Muralikrishma, M. e Dewitt, D. J. (1988). Equi-depth histograms for estimating selectivity factors for multi-dimensional queries. In Proceedings of the ACM International Conference on Management of Data (SIGMOD), I), 2836 , Chicago, EU $\Lambda$. ACM Press.

[Natsev et al., 1999] Natsev, A., Rastogi, R., e Shim, K. (1999). WALRUS: a similarity retweval algorithn for indage databases. In Procedings of the ACM Internationut Conference on Management of Data (SICMOD), pp). 395-406), Filadélfia, EUA. ACM Press. 
[Park \& Kim, 2003] Park, D.-J. e Kim, H.-J. (2003). An cnhanced technique for k-nearest neighbor queries with non-spatial selection predicates. Multimedia Tools and Applicat tions, $19(1): 79-103$.

[Penzo, 2005] Penzo, W. (2005). Rewriting rules to permeate complex similarity and fuzzy queries within a relational database system. IEEE Transactions on Knowledge and Data Engineering (TKDE), 17(2):255 - 270.

[Poosala et al., 1996] Poosala, V., Ioannidis, Y. E., Haas, P. J., e Shekita, E. J. (1996). Improved histograms for selectivity estimation of range predicates. In Proceedings of the ACM International Conference on Management of Dala (SIGMOD), pp. 294-305. Montreal, Canadá. ACM Press.

[Porkacw et al., 1999] Porkacw, K., Mehrotra, S., e Ortega, M. (1999). Query reformulalion for content based multimedia retrieval in MARS. In Proceedings of the IEEE International Conference on Multimedia Compuling and System.s (ICMCS), v. 2, pp. 747-751. IFEE Computer Socicty:

[Ramakrishnan \& Gehrke, 2003i Ramakrishnan. R. o Gehrke, J. (2003). Database Management System. MeGraw-Hill, third edition.

¿Roussopoulos et al., 1995\} Roussopoulos, X., Kolley, S., e Vincent, F. (1995). Nearest neighbor queries. In Proceedings of the ACM International Conference on Management. of Data (SIGMOD), pp. 71-79, San Jose, EUA. ACM Press.

[Santos Filho, 2003] Santos Filho, R. F. (2003). Mélodos de Acesso Métricos para Suporte a Consultas por Similaridade: Apresentação da Técnica Omni. Tese de doutorado, Universidade de São Paulo, Instituto de Concias Matemáticas e de Computaçăo.

[Scheufole \& Moerkotte, 1998] Scheufele. W. e Moerkotte, G. (1998). Efficient dynamic programming algorithuns for ordering expensive joins and selections. In Proceedings of the International Conference on Extending Database Technology on Advances in Database Technology (EDBT), pp. 201 215, Valência, Espanha. Springer-Verlag.

[Schroeder, 1991] Schrocker, M. (1991). Fractals, Chaos, Power Laus: Minutes from an. Infinite Paradise. Freeman, New York.

'Seidl \& Kriegel, 1998] Scidl, T. e Kriegel, H.-P. (1998). Optimal multi-step k-nearest neighbor scarch. In Proceedings of the ACM International Conference on Management of Data (SIGMOD), pp. 154 165, Scatile, EUA. ACM Press.

[Selinger et al., 1979] Selinger, P. G., Astrahan, M. M., Chamberlin, D. D., Lorie, R. A. c Price, T. G. (1979). Acess path selection in a relational clatabase management system. In Proceedings of the ACM International Conference on Management of Data (SICMOD), pp. 23 34. Boston, EUA. ACM Press. 
[Shapiro \& Connell, 1984] Shapiro, G. P. e Comell, C. (1984). Accurate estimation of the number of tuples salisfying a condition. In Procedings of the ACM International

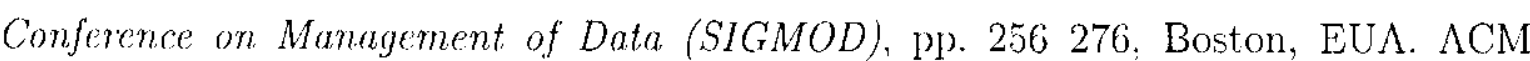
Press.

Smith \& Chang, 1975] Smith, J. M. e Chang, P. Y.-T. (1975). Optimizing the performance of a relational algebra database interface. Communications of the ACM $18(10): 568-579$

iStanoi et al., 2000] Stanoi. I., Agrawal, D., e Abbadi, A. E. (2000). Reversc nearest neiglibor queries for dynamic databases. In ACM SIGMOD Workstiop on Rescarch Issues in Data Mining and Knowledge. Discovery; p1. 44 53, Dallas, EUA. ACM Press.

[Sun et al., 1993] Sun, W., Ling, Y., Rishe, N., e I)eng, Y. (1993). An instant and accurate size estimation method for joins and selections in a retrieval-intensive enviromment. In Procesdings of the ACM Intermational Conference on Management of Data (SICMOD), pp. 79 88, Washington, EUA. ACM Press.

[T'aylor \& Frank, 1976] Taylor, IR. W. e Frank, R. L. (1976). Codasyl data-base management systems. ACM Compututing Surveys (CSUR), 8(1):67*103.

[T'raina Jr. et al., 1999] Traina Jr., C., Traina, A. J. M., e Faloutsos, C. (1999). Distanco exponent: a new concept for selectivity estimation in metric trecs. Research Paper CMU-CS-99-110, Carnegie Mellon Jniversity - Sehool of Computer Science

[Traina Jr. of al., 2000a] Traina Jr., C., Traina, A. J. M., e Faloutsos, C. (2000a). Distance exponent: a new concept for selectivity estimation in metric trecs. In Frocedings of the International Conference on Data Engineering (ICDE), pp. 195 195. San Diego, EUA. IFEE CS Press.

[Traina Jr. et al., 2002] Traina Jr., C., Traina, A. J. M., Faloutsos, C., e Seeger, B. (2002). Fast indexing and visualization of metric datasets using Slim-trees. IEEE Transactions on Knowledge and Data Engineering (TKDE), 14(2):244-260.

¿Traina Jr. et al., 2000b] 'Traina Jr., C., Traina, A. J. M., Seeger, B., e Faloutsos, C. (200)b). Slim-trees: High performance metric troes minimizing overlap botwen nocles. In Procedings of the International Conference on Extending Database Technology on Advances in Database Terhnology (EDBT), pp. 51 65, Konstan\%, Alemanha. Springer.

[Traina Jr. et al., 2000c] Traina Jr., C., Traina, A. J. M., Wu, L., c Faloutsos, C. (2000c). Fast feature selection using fractal dinension. In XV Simpósio Brasileiro de Banco de: Dados (SBBD), jp. 158 171, Joño Pessod, Brisil. CEFET-PB.

[Vicira et al., 2004] Virina, M. R., Traina, C., J., Chino, F. J. T., o Traina, A. J. M. (2004). Dbm-tree: A dynamic metric access method semsitive to local density data. In XIX Simpósio Brasileiro de Banco de Dados (SBBD), pp. 1633 177, Brasília - DF. 
[Weber ot al., 1998] Weber: R., Schek, H.-J., e Blott, S. (1998). A quantitative analysis and performance study for similarity-seard methods in high-dimensional spaces. In Procedings of the International Conference on Very Large Dala Bases (VLDB), pp. 194. 205, Nova Yorque, EUA. Morgan Kanfinamn.

[Wilson \& Martinez, 1997] Wilson, D. R. e Martinez, T. R. (1997). Improved heterogeneous distance functions. Journal of Artificial Intelligence Research. 6:1-34.

[Wong \& Yonssefi, 1976] Wong, E. e Youssefi. K. (1976). Deconnosition - a stralugy for query processing. ACM Transactions on Database Systems (TODS), 1(3):223-211.

[Yoshitaku \& Ichikawa, 1999] Yoshitaka, A. e Iclikawa, T. (1999). A survey on content-based retrieval for multimedia databases. IEEE Transactions on Knowledge and Data Engineering (TKDE), 11(1):81-93. 
Apêndice

A

O MAM Slim-tree

$\mathrm{O}$

MAM Slim-tree [Traina Jr. ct al., 2000b] é uma árvore multivias balanceada pela altura, dinâmica, e que tem todos os objetos armazenados nas folhas. A interseção das regiôes definidas pelos nós de um mesmo nível desso MAM pode não ser vazia. Ou seja, a divisão do espaço métrico não gora regiôes disjuntas, admitindo sobreposiş̃̃o.

A estrutura tem ainda recursos para a avaliação do grau de sobreposição entre seus nós (Fat-Factor) o un algoritno de pós-otimizacãõo da árvore (Slim-Down()).

\section{A.1 Organização da Slim-tree}

A Slim-tree agrupa os objetos do conjunto em páginas de tamanho fixo que representam os nós da árvore. Os agrupamentos são construídos em torno de objetos especialmente selecionados, chamados de objetos representantes, que definem os contros de regiöes delimitadas por um raio de cobertura. Os objetos podem ser asso(iados ao nó do objot(s) representante se eles forem cobertos pelo raio de cobertura associado ao objeto represenlante em questão. Dessa forma, esta organização permite ninimizar tanto o número de acessos a disco (leituras de páginas) quanto o númoro de cálculos de distância necessários para responder a consultas.

Os nós da Slim-lree podem ser do dois tipos: nó índice (indexNode); e nó folha (leafNode), que possuem cardinalidade igual ao seu grau. Todos os nós da estrutura, cxceto o nó raik, possuem um objeto representante o um raio de cobertura (ue engloba todas as suas subárvores. A Figura A.1 ilıstra a cstrutura lógica do nó índice e folha da Slim-tree.

Cada entrada no nó folla ć composta pelos atributos que compõem o objeto $\left(s_{i}\right)$; 
(a) indexNode

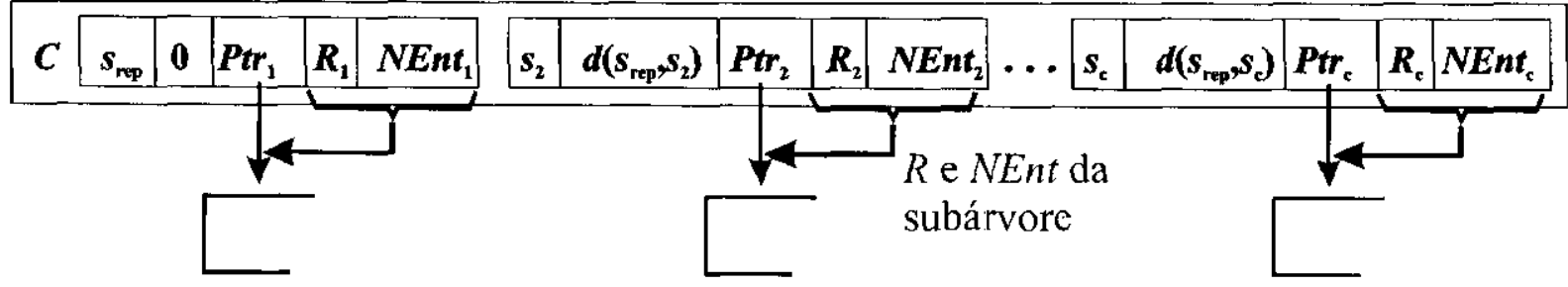

(b) leafNode

\begin{tabular}{|l|l|l|l|l|l|l|l|l|l|l|l|l|l|}
\hline$C$ & $s_{\text {rep }}$ & OId & 0 \\
\hline
\end{tabular}

Figura A.1: Estrutura lógica dos nós (a) índice (indexNode) o (b) follha (leafNode) da Slim-tree [Traina Jr. et al., 2002].

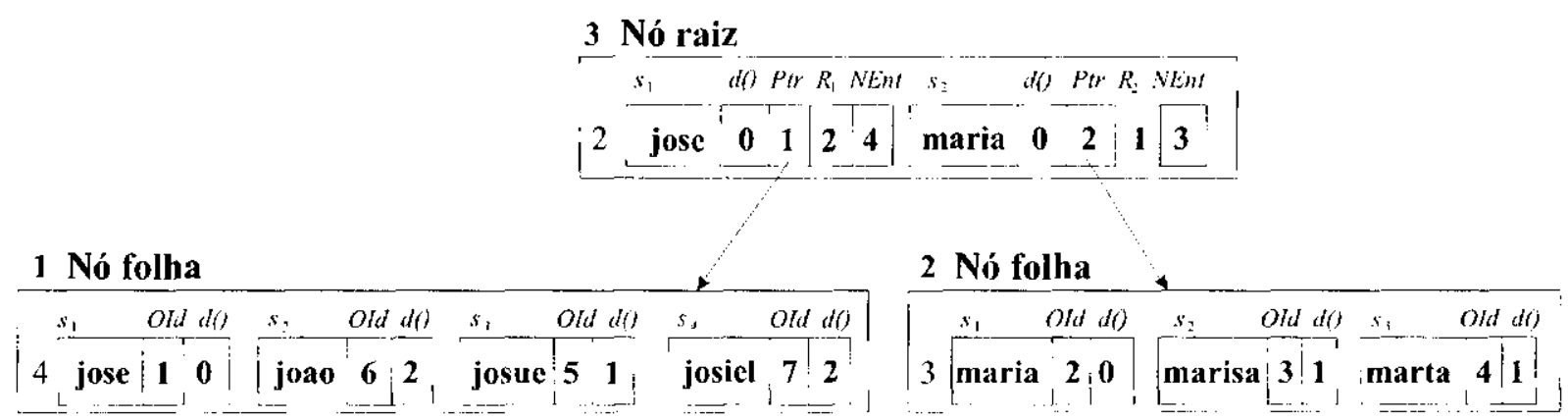

Figura A.2: Excmplo da estrutura lógica de uma Slim-tree contendo 7 cadeias de caracteres com a função de distância $L_{\text {Edit }}$.

pelo identificador do objeto $\left(O I d_{i}\right)$; e pelo valor da distância entre sste objeto e o representante do nó $\left(d\left(s_{r e p}, s_{i}\right)\right)$. Essa estrutura pode ser representada como:

$$
\text { leafNode [vetor }[1 . . C] \text { de }<s_{i}, O I d_{i}, d\left(s_{\text {rep }}, s_{i}\right)>\text { ] }
$$

Cada entrada em um nó índice é composta pelo objeto $\left(s_{i}\right)$ que é o representante

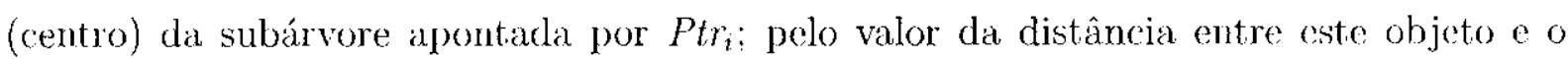
representante do nó $\left(d\left(s_{\text {rep }}, s_{i}\right)\right)$; por uma ligacão para sua subárvore $\left(P t r_{i}\right)$; um raio de cobertura abrangende todia a sua subárvore $\left(R_{i}\right)$; e pelo número de cntradas ( $N E t_{i}$ ) presentes na subárvore apontado por Ptr. $r_{i}$. Essa estrutura pode ser represcntada como:

$$
\text { indexNode [vetor } 1 . . C] \text { de }<s_{i} \text { : d }\left(s_{\text {rep }}, s_{i}\right), P t r_{i}, R_{i}, N E n t_{i}>\text { ] }
$$

A Figura A.2 ilustra a estrutura lógica de uma Slim-tree contendo 7 cadeias de caractcres, cuja função de distância é a $L_{E d i t}$.

\section{A.2 Construindo uma Slim-tree}

A Slim-tree é construída do nívol folha em direção ao nível raiz (bottom-up), igual à B-tree. Como a Slim-tree ó um MAM dinâmico, não é necessário que todos os objetos 
cstejam presentes para a construção da árvore. Novos objetos podem ser inseridos depois da cestrutura já construída.

O algoritmo de inserção comeģa a partir do nó raiz, percorrendo a estrutura até encontrar um nó folha, onde a inserção do novo objeto realmonte ocorre. () algoritmo tenta localizar um nó que possa reccbor o novo objeto sem a necessidade de aumento do raio de cobertura. Se mais de um nó pode receber o novo objeto, o algoritmo ChooseSubtree() é executado para selecionar em qual deles scrá inserido o novo objeto. Se não existir nenhum nó que possa receber o novo objeto nestas condiçoesé é solecionado um cujo centro está mais próximo do novo objeto. Esse processo é aplicado recursivamente para todos os níveis da árvore até chegar om un nó folha.

A Slim-trec possui três opcós para o algoritmo ChooseSublree():

- Aleatório (random): seleciona aleatoriamente um dos nós que podem recebero novo objeto sem aumento do raio de cobertura;

- Distância Mínima (minDist): seleciona, chtre os nós (que podem receber o novo objeto, aquele cuja distância entre seu representante (centro) e o novo objeto for mínima;

- Ocupação Mínima (minOccup): scleciona, entre os nós que podem receber o novo objeto, aquele cujo número de objetos armazenados seja mínimo. Isso é verificado através de atributo NEnt. Esta opção ó a padrão para a Slim-tree.

A escolha da opção para o algoritmo Choose SubTree() influencia bastaute as caracteristicas da árvoro resultante. A opção minOccup do algoritmo Choosesubtrece) tonde a gerar árvores com maior taxa de ocupação dos nós, como explicitado cm [Traina Jr. et al, 2000b], resultando en árvores mais baixas, porém ao custo de um maior grau de sobreposição. A opção minDist tende a criar árvores com uma taxa de ocupaçăo menor dos nós o com un grum monor de sobreposição, conseciientemente as árvores resultantes são mais altas. Surprendentennente, a opcăo random consegue gerar árvores quass. tão boas quanto as outras duas, porém sua eficiência c resultados não são detcrminísticos. Este fenômeno pode indicar que o verdadeiro responsável pelas características da árvore seja mesmo o algoritmo de redistribuição dos objetos entre os nós.

A Figura A.3(a) apresenta a disposição de 17 objetos $\left\{s_{1}, \ldots, s_{17}\right\}$ de uma Slim-tree com capacidade máxima de 3 objetos por nó. Os objetos $\left\{s_{1}, s_{4}, s_{10}\right\}$ estão em um mesmo nó follha e o objeto representante deste nó á o $s_{1}$, por isto cle aparece no nó índice do nível superior. Os círculos brancos da Figura A.3(a) representam nós follat, e o de cor cinza os nós ínclice, oncle o lamanho é proporcional ao raio de cobertura e as regióes do sobreposição são indicadas pela interseção do dois ou mais círculos. Os pontos pretos da Figura A.3(b) indicam os objetos representantes do respectivo nó. Note que o nó raiz não possui nenhum objeto representante.

Durante o processo de insergão de um novo objeto, pode ocorrer que o nó escollido para inserção já esteja com a sula taxa do ocupação máxima preenchida. Neste caso, deve 


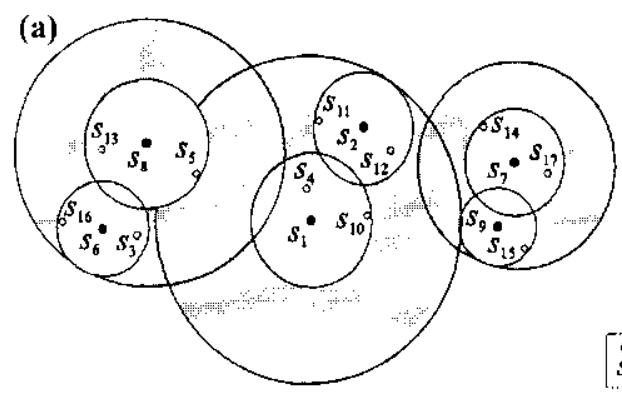

(b)

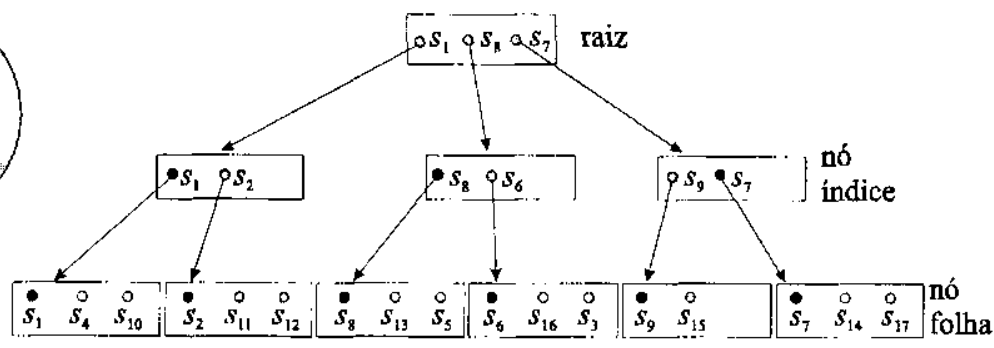

Figura A.3: Representação de uma Slim-tree contendo 17 objetos em (a), e sua correspondente cstrutura lógica em (b). Os círculos brancos em (a) representam os nós follha, enquanto os de cor cinza representan os nós índice. Os pontos pequenos dos objetos, preenchidos de cor preta, representam os objetos representantes do nó.

ser alocado um novo nó e as entradas que estavan no nó anterior (com a taxa rle oruparão preenchida) devem ser redistribuídos entre os dois nós, respeitando a taxa de ocupação mínima dos nós. Os dois objetos escolhidos como representantes dos dois nós (novo e antigo) a seus respectivos raios de cobertura deven ser insericles no nó pai. () atributo NEnt também deve ser atualizado nos nós dos níveis superiores. Este processo de divisão, se necessário, pode ser repetido árvore acima. To pior caso, o processo de divisão propaga até o nó raiz c a árvore aumenta a sua altura em una unidade.

A Slim-tree possui tres políticas para efetuar a redistribuiçào dos objetos entre os doss nós, sendo elas:

- Aleatório (random): selecionia aleatorianente dois objetos representantes, unn para cada nó (novo e antigo), e os demais objetos são distribuídos entre os dois nós pela menor distância entre o objeto e o representante do nó. É o mais rápido, porém seus resultardos são os monos satisfatórios:

- Mínimo dos Maiores Raios (minMax): cada possível par de objetos sĩo considerados candidatos a representantes dos dois nós. Para cada par possível, os demais objotos são inssoridos no nó cuja distância ao respectivo representante for a menor. Serão escolhidos como representiantes o par de objotos que minimizar o raio de cobertura, ou seja, o menor dos maiores raios do cobertua. A complexidade deste algoritmo é $\boldsymbol{O}\left(C^{3}\right)$, onde $C$ é a cardinalidade do nó, pois para cada objeto escolle--se dentre os clemais cuem será seu par, o para cada par possível, verifica-se em qual dos nós centrados em um dos elementos do par cada objeto restante será armazenado. Apesar dele ser extremamente custoso, ele é apontado em [Ciaccia et al., 1998 ] como o que conseguc obter arvores que possibilitam consultas mais eficientes;

- Minimal Spanning Tree (MST): bascado na Minimal Spanning Tree de [Kruskal, 1956]. A árvore de caminho mínimo é construída e um dos arcos mais longos da árvore á removido. Dessa forma, dois agrupamentos sáo obtidos o carta um ć associado a um nó. O objeto representante ć o objeto central de cada agrupamentor. Este algoritno possibilita a construção de árvores praticamente equivalentes 


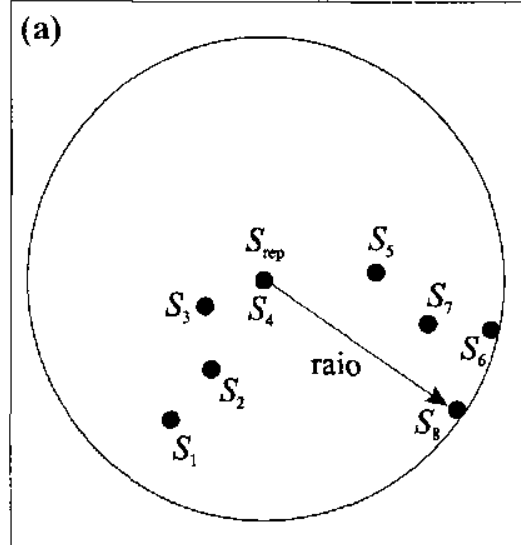

(b)

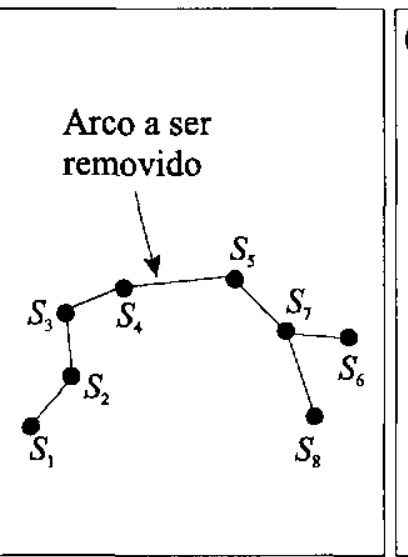

(c)

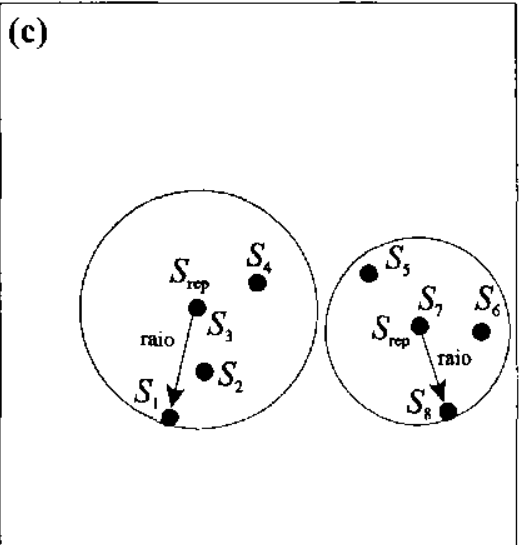

Figura A.4: Exemplificação do mecanismo de quebra de nós segundo a política MST (Minimal Spanning Tree) em um conjunto de objetos: (a) estrutura do nó antes da divisão: (b) MST constrúlda sobre os objetos do nó; (c) organização dos objetos depois da divisão do nó.

às construídas utilizando o algoritmo de quebra de nós minMax, porém com custo de processamento bem menor, resultando em um menor tempo total de construção. Isso ocorre devido à complexidado do algoritmo ser $O\left(C^{2} \log C\right)$. Esta opção é a padräo para a Slim-tree redistribuir os objetos. A Figura A.4 ilustra o mecanismo de quebra de nós utilizando o algoritmo MST. Em (a) ć representada a disposição dos objetos antes da divisão; en (b) ć ilustrada a árvore de caminho mínimo para os objetos do nó corrente; já em (c) é ilustrada a nova distribuição para os dois novos nós.

Na opção MST não existe garantia que os nós resultantes da divisão tenham ocupação mínima de entradas, podendo até existir nós com apenas uma única entrada (apenas o objeto representante com raio nulo para os nós folha). Nestes casos, a probabilidade de inserção de novos objetos, fara a opção minDist do algoritmo Choose Subtreet), é baixa devido ao raio do objeto representante ser nulo.

Embora ainda não exista a implomentação da remoção de objetos na Slim-tree, ela pode ser tratada de uma maneira similar como ocorre na $B^{\times}$-tres, onde os objetos nos nós índices são "marcados" como removidos [Johnson \& Shasha, 1989]. Porém nesta abordagem, mesmo quando um grande número de objetos for removido, a altura da árvore continua a mesma. Além disso, há a possibilidade de existirem nós folha com monos entradas que a capacidade mínima dos nós.

\section{A.3 O Fat-Factor e o Slim-Down()}

A sobreposição cntre os nós das árvores métricas é um efeito indesejável, pois obriga a busca em profundidade con diversas subárvores para a localização dos objotos solicitiados pelas consultass. Isso ocorre porque mais nós da árvore scrấo consultados (todos os que têm região se sobrepondo à região de consulta), o o descarte de subárvores fica prejudicado. Sua 
(a)

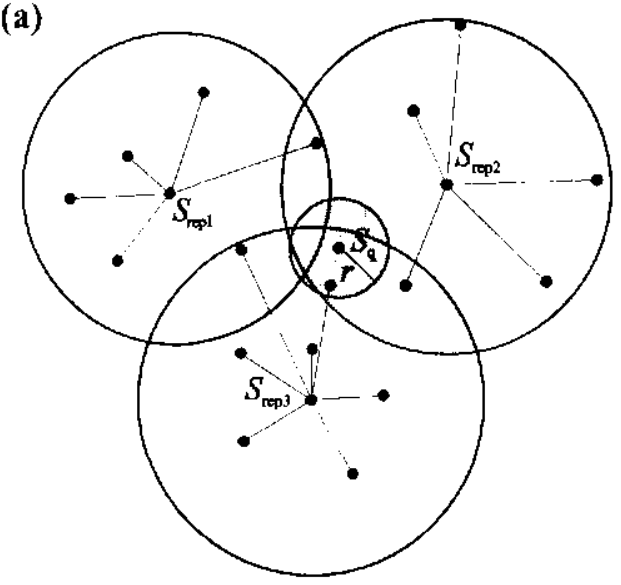

(b)

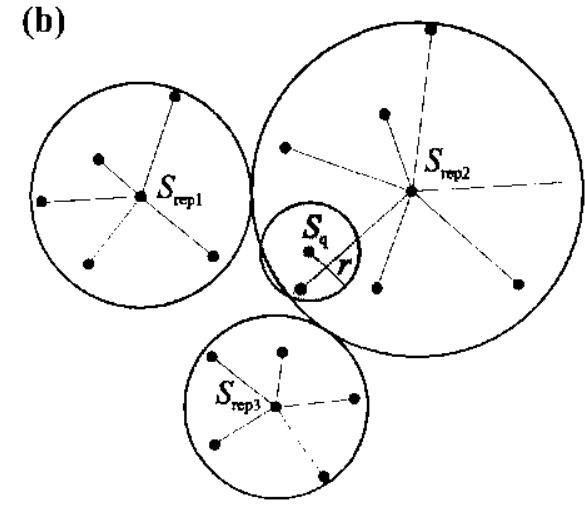

Figura A.5: Exemplo da aplicação do algoritmo Slim-Down() en très nós follha. Em (a) estão os três nós antes da otimização, e una consulta por abrangência localizada na região de sobreposição. Em (b) é ilustrado a nova configuração dos nós depois da execução do Slim-Doun(). A troca de apenas três objetos entre os nós foi suficionte para diminuir quase toda a sobreposição entre eles. As linhas intcrligando os objctos ao representante de cada nó indican a que nó cless pertencem.

influência no desempenho das buscas pode ser até maior que a altura total das árvores. Para ilustrar, considere a Figura A.5(a). Nela estão representados 3 nós com os seus respectivos representantes $\left\{s_{r \epsilon p]}, s_{r \in p 2}, s_{\text {repj3 }}\right\}$, e uma consulta na região de sobreposiçäo: no qual $s_{q}$ é o objeto de consulta e $r$ é o raio. Note que as regións escurass são as sobreposições dos nós. Nenhum dos 3 nós podem ser descartados nessa consulta por abrangência. tendo que ser percorridos, mosmo que só o nó do objeto representante $s_{\text {repis }}$ realmente tenha objetos cobertos pela consulta.

Visando evitar essa deficiência, a Slim-tree foi desenvolvida com o objetivo de diminuir a sobreposição entre os nós da árvore, bem como oferecer rmocanismos para verificação da porcentagem de sobreposição existente na árvore. Para isso, em Traina Jr. et al., 2000b], foi definido o fator de sobreposição Fat-Fractor e o algoritmo de reorganização da árvore Slim-Doun().

O Fat-Factor é uma medida para avaliar o grau de sobreposição entre os nós da árvore. Ela foi usada para desenvolver um algoritmo do reorganização dos nós, chamado Slim-Down(). Esse algoritmo visa reduzir o grau de sobreposição entre os nós através dia troca de objetos apenas cntre os nós folha. Os oljetos são transferidos de um nó origem para um destino caso o nó destino tenha espaço para o armazenamento da entrada, e ainda, a inserção da entrada não causa aumento do raio de cobertura, podendo diminuir o raio de cobcrtura do nó origen. Essse processo é rcalizado até que nāo seja mais possível realizar trocas de objetos cntre os nós envolvidos ou que passe de um certo valor limite de número de trocas. Este processo de reorganização das entradas pode dimimuir a sobreposiçãa dos nós e, conseqüentemente, diminuir o número de acesso a disco para responder a consultas.

Por ser um processo relativanente coustose, ó reconendado que o Slim-Down() seja executado apenas quando o gran de sobreposiçāo, definido atravís do Fat-Factor, ultrapasse um certo limite para toda a árvore, on que uma grande quantidade de objetos já 
tenha sido inserida na Slim-tree. Maiores detalhes sobre o Fat-Fartor e o algoritmo SlimDown() podem ser encontrades om [Traina J1. et al., 20000b] \& [Traind Jr. ct al., 2002]. A Figura A.5 representa visualmente o processo do algoritmo Slim-Doun(): em (a) ó ilustrado a distribuição dos objetos em três nós antes do processo. Os objetos pertencentes a um nó estão interligados por uma linha com o representante do nó em questão; e em (b) é ilustrada a nova configuração dos nós depois da execução do algoritmo Stim-Down(). Note que a sobreposição entre os nós dininuiu, proporcionamedo que consultas localizadas nestas regiões, como a consulta por abrangência da figura, precisem analisar monos nós que anteriormente.

Através desses conceitos, o MA.H Slim-tree permite realizar consultas por similaridade minimizando tanto o número de cálculos de distâncias quanto o de acessos a disco. 
Apêndice

B

Desigualdade Triangular

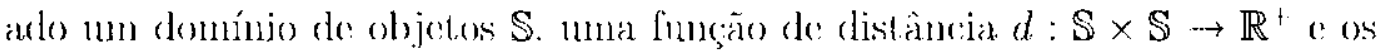
objetos $\left\{s_{1}, s_{2}, s_{3}\right\} \in \mathbb{S}$, temos a inequação da desigualdade triangular:

$$
d\left(s_{1}, s_{2}\right) \leq d\left(s_{1}, s_{3}\right)+d\left(s_{3}, s_{2}\right)
$$

Esta inequação permite inferir os limites superior e inforior de uma das três distâncias envolvidas conhecendo apenas os valores das outras duas distanncias.

Suponha que as distanncias $d\left(s_{1}, s_{3}\right)$ o $d\left(s_{2}, s_{3}\right)$ são conhecidas e deseja-se inferir o valor da distância $d\left(s_{1}, s_{2}\right)$, que será denotada por $x$ para facilitar a comprennião. Usando a Equação B.1 temos:

$$
x \leq d\left(s_{1}, s_{3}\right)+d\left(s_{3}, s_{2}\right)
$$

mas tambím:

$$
d\left(s_{1}, s_{3}\right) \leq x+d\left(s_{3}, s_{2}\right) \Rightarrow x \geq d\left(s_{3}, s_{2}\right)-d\left(s_{1}, s_{3}\right)
$$

$$
d\left(s_{3}: s_{2}\right) \leq d\left(s_{1}, s_{3}\right)+x \Rightarrow x \geq d\left(s_{1}, s_{3}\right)-d\left(s_{3}, s_{2}\right)
$$

Sabendo que $x \geq 0$, as Equaçes B.3 e B.4 podem ser combinadas, formando:

$$
x \geq\left|d\left(s_{1}, s_{3}\right)-d\left(s_{3}, s_{2}\right)\right|
$$

pois se $d\left(s_{1}: s_{3}\right)>d\left(s_{3}, s_{2}\right)$, o limite inferior será a Equação B.4, caso contrário, scrá a Equação B.3. 
Combinando as Equaçoes B.2 e B.5, temos:

$$
\left|d\left(s_{1}, s_{3}\right)-d\left(s_{3}, s_{2}\right)\right| \leq x \leq d\left(s_{1}, s_{3}\right)+d\left(s_{3}, s_{2}\right)
$$

oul seja:

$$
\left|d\left(s_{1}, s_{3}\right)-d\left(s_{3}, s_{2}\right)\right| \leq d\left(s_{1}, s_{2}\right) \leq d\left(s_{1}, s_{3}\right)+d\left(s_{3}, s_{2}\right)
$$

A Equação B.7 pode ser utilizada para descartar objetos pertencentes a consultas realizadas em MAMs. Considerando uma consulta por abrangência com raio $r$, objeto central da consulta $s_{1}$, objeto candidato $s_{2}$ e o representante de uma regiăo c, temos:

$$
\begin{aligned}
& d\left(s_{1}, s_{2}\right) \leq r . s_{2} \in \text { resposta } \\
& d\left(s_{1}, s_{2}\right)>r, s_{2} \notin \text { resposta }
\end{aligned}
$$

Sabendo apenas $d\left(s_{1}, s_{3}\right)$ e $d\left(s_{3}, s_{2}\right)$ é possível afirmar que $s_{2}$ só porle ser candidato a resposta desta consulta se, e somente se:

$$
\left|d\left(s_{1}, s_{3}\right)-r\right| \leq d\left(s_{3}, s_{2}\right) \leq d\left(s_{1}, s_{3}\right)+r
$$

partindo disto, sabe-se que $d\left(s_{3}, s_{2}\right)$ não se encontrar dentro deste intervalo, $d\left(s_{1}, s_{2}\right)$ certamente será maior que $r$ e portanto pode ser descartado sem a necessidade de calcular sen valor. Caso contrário, o linite superior do $d\left(s_{1}, s_{2}\right)$ será $2 d\left(s_{1}, s_{3}\right)+r$. Neste caso, $d\left(s_{1}, s_{2}\right)$ deve ser calculado para que possa ser comparado com $r$, descartando ou não o objeto da resposta depondendo de seu valor. 